Cristiane Fernandes da Silva

\title{
Análise geomecânica dos carbonatos do pré-sal da Bacia de Santos
}

Dissertação apresentada como requisito para a obtenção do grau de Mestre pelo Programa de Pós-Graduação em Engenharia Civil do Departamento de Engenharia Civil

Orientador: Prof. Sérgio Augusto Barreto da Fontoura

Rio de Janeiro

Novembro de 2016 


\title{
Cristiane Fernandes da Silva
}

\section{Análise Geomecânica dos Carbonatos do Pré-Sal da Bacia de Santos}

\begin{abstract}
Dissertação apresentada como requisito parcial para obtenção do grau de Mestre pelo Programa de Pós-Graduação em Engenharia Civil do Departamento de Engenharia Civil e Ambiental do Centro Técnico Científico da PUC-Rio. Aprovada pela Comissão Examinadora abaixo assinada.
\end{abstract}

\section{Prof. Sergio Augusto Barreto da Fontoura}

Orientador

Departamento de Engenharia Civil e Ambiental - PUC-Rio

Prof. Alberto de Sampaio Ferraz Jardim Sayão Departamento de Engenharia Civil e Ambiental - PUC-Rio

Prof. Claudio Rabe

Universidade Federal Fluminense

Prof. Márcio da Silveira Carvalho

Coordenador Setorial do

Centro Técnico Científico - PUC-Rio

Rio de Janeiro, 17 de novembro de 2016 
Todos os direitos reservados. É proibida a reprodução total ou parcial do trabalho sem autorização da universidade, da autora e do orientador.

\section{Cristiane Fernandes da Silva}

Graduou-se em Engenharia Química e de Produção Química pela Pontifícia Universidade Católica do Rio de Janeiro (PUC-Rio) em 2005. Conclui o curso de Pós-graduação em Engenharia de Petróleo pela PUC-Rio em 2008 e atua na área de Geomecância do Petróleo desde então. Em 2016, concluiu o mestrado em Geotecnia apresentando a dissertação na área de geomecânica do petróleo, analisando os carbonatos do pré-sal da Bacia de Santos pela PUCRio.

Ficha catalográfica

Silva, Cristiane Fernandes da

Análise geomecânica dos carbonatos do pré-sal da Bacia de Santos/ Cristiane Fernandes da Silva; orientador: Sérgio Augusto Barreto da Fontoura - 2016.

139 f.: il. color. ; $30 \mathrm{~cm}$

Dissertação (mestrado) - Pontifícia Universidade Católica do Rio de Janeiro, Departamento de Engenharia Civil e Ambiental, 2016.

Inclui bibliografia

1. Engenharia civil - Teses. 2. Carbonatos. 3. Pré-sal. 4. Modelo geomecânico. 5. Estabilidade de poço. I. Fontoura, Sergio Augusto Barreto da. II. Pontifícia Universidade Católica do Rio de Janeiro. Departamento de Engenharia Civil. III. Título. 


\section{Agradecimentos}

Palavras não são suficientes para agradecer a todos que estiveram envolvidos e me apoiaram direta e indiretamente na elaboração deste trabalho. Gostaria de agradecer a Deus por ter me dado força, paciência e me guiado nos momentos difíceis que por vezes passaram pelo meu caminho. Agradeço a Ele também por ter me dado a oportunidade de conviver com pessoas incríveis, que fizeram a diferença nessa trajetória.

À minha família que sempre me apoia e me dá o suporte necessário para atingir os meus objetivos. Obrigada à minha mãe Denise, ao meu Pai Carlos, meu irmão Danilo e meu tio Alberto, sem vocês não seria possível. Obrigada ao meu esposo, Filipe, pelo apoio, incentivo e compreensão de sempre e peço desculpas por minhas ausências. Obrigada também ao meu pequeno Tomás que chegou no meio desse furacão de ideias e estudos, mas que me deu ainda mais força para continuar.

Ao meu orientador, Sérgio Fontoura, pelo apoio, orientação e compreensão não só no período da dissertação, como durante todo o curso. Muito obrigada ao Claudio Rabe pelas palavras de otimismo e incentivo.

À Baker Hughes pela oportunidade de fazer o curso e a todos os meus amigos de trabalho que me apoiaram e incentivaram no dia a dia. Obrigada à Jaqueline Xavier e ao Thiago Pessoa e um agradecimento especial à Flavia Villaroel e Viviana Valverde que fizeram a diferença com o incentivo e o ombro amigo.

Agradecimento mais que especial às minhas amigas Bianca Hacon, Maria Mariano, Andreia dos Santos e Simone Ribeiro que viveram cada dificuldade e também venceram cada etapa do curso comigo. Obrigada pelos dias e noites de estudos, pelas palavras de motivação e força, sem vocês tudo seria muito mais difícil.

Aos meus amigos que direta ou indiretamente me apoiaram, em especial, aos meus amigos-irmãos que compreenderam a minha ausência, à Vivian Marchesi pela ajuda e orientação, Talita Miranda e Carla Carrapatoso.

À PUC-Rio e à CAPES pelo suporte financeiro concedido. 
Muito obrigada à Agência Nacional de Petróleo/ Banco de Dados de Exploração e Produção (ANP/BDEP) pela disponibilização dos dados para análise. A realização do trabalho só foi possível em função disso. 


\section{Resumo}

Silva, Cristiane Fernandes da; Fontoura, Sergio Augusto Barreto (orientador). Análise geomecânica dos carbonatos do pré-sal da Bacia de Santos. Rio de Janeiro, 2016. 139p. Dissertação de Mestrado - Departamento de Engenharia Civil e Ambiental, Pontifícia Universidade Católica do Rio de Janeiro.

As descobertas no pré-sal estão entre as mais importantes no setor de óleo e gás em todo o mundo na última década. As operações de perfuração na área do présal brasileiro são complexas e desafiadoras em função de fatores como águas ultra profundas, efeito do creep na seção evaporítica (fluência do sal), geologia estrutural complexa, presença de cavernas e poros de diferentes tamanhos geradores de perda de circulação. Estima-se que os custos associados à instabilidade de poços representem cerca de 5 a $10 \%$ dos custos de perfuração nas fases de exploração e produção, implicando, a nível mundial, custos de centenas de milhões de dólares por ano. No presente estudo, foi desenvolvido um modelo de estabilidade de poços na área do pré-sal brasileiro utilizando-se correlações analíticas para a obtenção da janela operacional de perfuração. A janela operacional auxilia na otimização do peso de fluido que deverá ser utilizado na perfuração e é definida por um limite inferior (pressão de poros ou de colapso) e por um limite superior (gradiente de fratura). Para a construção do modelo geomecânico, foram considerados perfis de oito poços de correlação, medições diretas de pressão, provas de integridade de formação, temperatura das formações e dados públicos do world stress map. Foram realizadas análises de sensibilidade de três parâmetros para lidar com as suas respectivas incertezas e estimar suas variações: resistência uniaxial não confinada (UCS), do coeficiente de Biot e magnitude da tensão horizontal máxima ( $\left.\mathrm{S}_{\mathrm{Hmax}}\right)$. Os resultados do estudo indicam que o gradiente de sobrecarga na profundidade dos carbonatos da área estudada (5000 até $6140 \mathrm{~m}$ - profundidade vertical (TVD)) variaram de 13,6 a 14,3ppg (lb/gal). A análise de pressão de poros (PP) indicou que na região existem dois cenários envolvendo esse parâmetro: uma área com pressão de poros levemente alta $(9,2 \mathrm{ppg})$ e em outra que apresenta pressão de poros anormalmente pressurizada (13,0ppg). A análise dos resultados das provas de integridade de formação (Leak-offs tests - LOTs) possibilitou a estimativa da Razão 
de Tensão Horizontal Efetiva mínima (ESR $\mathrm{min}_{\text {in }}$ ) como sendo uma constante de 0,65 no trecho dos carbonatos e, com isso, estimou-se a tensão horizontal mínima em 12,4 ppg para a região com pressão de poros levemente alta e 13,8ppg para a região de alta pressão. Os valores médios de resistência de rocha foram de 43MPa e foram comparados resultados de ensaios de resistência de uma rocha análoga ao pré-sal. A direção das tensões horizontais máximas foi estimada em cerca de $95^{\circ} \mathrm{NE}$ e a magnitude foi estimada através do polígono de tensões, onde considerou-se diferentes cenários nos quais envolveram a variação de UCS, coeficiente de Biot e abertura de breakout. Os resultados de $\mathrm{S}_{\mathrm{Hmax}}$ encontrados foram utilizados para a estimativa da Razão de Tensão Horizontal Efetiva máxima $\left(\mathrm{ESR}_{\max }\right)$ que variou entre 0,95 e 1,8 em função dos cenários avaliados e, com isso, concluiu-se que o campo de falhamento na área estudada estaria entre o normal e o transcorrente. Estimou-se que a janela operacional nos carbonatos na região com PP levemente pressurizada apresenta como limite inferior valores entre 10,5 e $11,1 \mathrm{ppg}$ e como limite superior 12,3 a 12,6ppg. Já na região com PP anormalmente pressurizada a janela operacional para a fase dos carbonatos compreende valores entre 13,3 a 13,8ppg. A presente pesquisa apresenta também as discussões relativas às incertezas associadas à ausência de dados e o modelo constitutivo adotado.

\section{Palavras chave}

Carbonatos; Pré-sal; Modelo geomecânico; Estabilidade de poço 


\section{Abstract}

Silva, Cristiane Fernandes da; Fontoura, Sergio Augusto Barreto (Advisor). Geomechanical analysis of pre-salt carbonates in the Santos Basin. Rio de Janeiro, 2016. 139p. MSc.Dissertation - Departamento de Engenharia Civil e Ambiental, Pontifícia Universidade Católica do Rio de Janeiro.

The discoveries in the pre-salt are one of the most important ones in the oil and gas industry around the world in the last decade. Drilling operations in the Brazilian pre-salt area are complex and challenging due to factors such as ultradeep water, effect of creep in evaporite section, complex geological structure, presence of caves and vugs generating total circulation losses etc. It is estimated that the costs associated with wellbore instability problems represent about 5 to $10 \%$ of the drilling costs in the stages of exploration and production, generating costs around hundreds of millions of dollars a year. In this study, a wellbore stability model was built of the pre-salt area using analytical correlations to obtain a mud window. The operational window assists in optimizing the fluid weight to be used in drilling and is defined by a lower limit (pore or collapse pressure) and an upper limit (fracture gradient). In order to build the geomechanical model, eight offset well with $\log$ data, direct pressure measurements, formation integrity tests, formation temperature, and data from the world stress map were used. Sensitivity analyzes were made from uniaxial unconfined strength (UCS), Biot coefficient and magnitude of the maximum horizontal stress to evaluate model's uncertainties and estimate its variations. The geomechanical model indicates that the overburden in the carbonates of the studied area (5000 until 6140m - True Vertical Depth (TVD)) ranges from 13,6 to 14,3ppg (lb/gal). Pore pressure indicates two different behavior, presenting slightly over-pressurized (around 9,2ppg) and over-pressurized in another area (13,0ppg). The results of the formation integrity test (Leak-off tests, LOTs) were used to estimate the minimum effective stress ratio $\left(\mathrm{ESR}_{\min }\right)$, a constant value around 0,65 with a minimum horizontal stress equal to $12,4 \mathrm{ppg}$ in the slightly overpressured zone and 13,8ppg in overpressure zone. The average values of uniaxial compressive strength (UCS) were 43MPa. The azimuth of maximum horizontal stress was estimated to be around $95^{\circ} \mathrm{NE}$ obtained from World Stress Map. The effective maximum horizontal stress ratio (ESR $\max$ ) is ranging between 
0,95 and 1,8 according to the presented scenarios and it can be concluded that the faulting stress regime is between normal and strike slip. It is estimated due to the slightly over pressured PP that the operational windows on the carbonates have as lower limits values from 10,5 to $11,1 \mathrm{ppg}$ and as higher limits values from 12,3 to $12,6 \mathrm{ppg}$. In the area with PP abnormally pressurized the operational window to the carbonates phase is between 13,3 to $13,8 \mathrm{ppg}$. The present research also discusses the uncertainties associated to the absence of available data and the constitutive models used.

\section{Keywords}

Carbonates; Pre-salt; Geomechanical model; Wellbore stability 


\section{Sumário}

1 Introdução 19

1.1. Motivação 19

1.2. Objetivo 22

1.3. Estrutura da dissertação 22

2 Revisão Bibliográfica $\quad 24$

2.1. O Pré-sal brasileiro 24

2.2. Geologia do pré-sal e as bacias da margem continental brasileira 26

2.2.1. Bacia de Santos $\quad 29$

2.2.1. Bacia de Campos 34

2.3. Modelo geomecânico de Estabilidade de poços 38

2.3.1. Fatores que influenciam a estabilidade de poço 39

2.3.2. Parâmetros necessários para a elaboração do modelo 42

3 Metodologia $\quad 62$

3.1. Levantamento de dados 65

3.2. Tensão vertical $\quad 70$

$\begin{array}{ll}\text { 3.3. Pressão de poros } & 71\end{array}$

3.4. Tensão horizontal mínima $\quad 72$

3.5. Resistência da rocha e propriedades elásticas 72

3.6. Tensão horizontal máxima $\quad 74$

3.7. Gradiente de Colapso 76

4 Apresentação e discussão dos resultados $\quad 79$

4.1. Tensão vertical 79

4.2. Pressão de poros 85

4.3. Temperatura 89

4.4. Tensão horizontal mínima 90

4.5. Propriedades mecânicas da rocha 92 
4.5.1. Propriedades elásticas 96

4.6. Direção da tensão horizontal máxima 99

$\begin{array}{ll}\text { 4.7. Magnitude da tensão horizontal máxima } & 101\end{array}$

4.8. Modelo Geomecânico de estabilidade de poço 106

5 Conclusões 120

6 Recomendações 124

7 Referências bibliográficas $\quad 125$

8 Anexos 134

8.1. Anexo 1: Dados gerais recebidos de cada poço 134

8.2. Anexo 2: Relação de UCS x velocidade, UCS x Porosidade e UCS $\times \mathrm{E}$ 


\section{Lista de figuras}

Figura 1.1 - Dinâmica do sistema petrolífero do pós-sal. (Fonte:

Apresentação pública da Petrobras) .....

Figura 1.2 - Dinâmica do sistema petrolífero do pré-sal. (Fonte:

Apresentação pública da Petrobras)

Figura 2.1 - Distribuição das rochas do reservatório do pré-sal em relação às bacias da margem continental brasileira (Fonte: Revista USP - modificado de Papaterra, 2010).

Figura 2.2 - Esquema paleogeográfico do estágio pós-rifte ou do golfo, durante a deposição dos evaporitos (Fonte: Revista USP, 2012) ..29 Figura 2.3 - Mapa de localização dos limites da Bacia de Santos.

(Fonte:ANP/BDEP, fev 2010)

Figura 2.4 - Carta estratigráfica da Bacia de Santos (Fonte: Moreira et $\mathrm{al}, 2007)$

Figura 2.5 - Seções Rifte, Pós-Rifte e Drifte da Bacia de Santos

(Fonte: Moreira et al.,2007)

Figura 2.6 - Seção Geológica esquemática da Bacia de Santos (Fonte: site ANP, Jul 2016)

Figura 2.7 - Mapa de localização dos limites da Bacia de Campos

(Fonte:ANP/BDEP, fev 2010)

Figura 2.8 - Carta estratigráfica da Bacia de Campos (Fonte: Winter

et al.,2007)

Figura 2.9 - Seção geológica esquemática regional da Bacia de

Campos (Fonte: site da ANP, Jul 2016)

Figura 2.10 - Parâmetros considerados em uma análise de estabilidade de poços

Figura 2.11 - Comportamento da pressão durante o teste de absorção estendido (Petrobras) (Rocha, 2007) 48

Figura 2.12 - Carta de fraturamento hidráulico em San Ado, Califórnia (Zoback e Pollard, 1978) 
Figura 2.13 - Variação da pressão ao longo do tempo em um fraturamento hidráulico, desde a pressão de propagação até a pressão de fechamento.

Figura 2.14 - Identificação do fechamento pelo método gráfico da raiz quadrada do tempo

Figura 2.15 - Comparação entre diferentes correlações empíricas utilizadas para a estimativa de resistência uniaxial de arenitos com (a) intervalo de tempo de trânsito, (b) módulo de Young e (c) porosidade. (Depois do Chang, Zoback et al. (2006))

Figura 2.16 - Comparação entre diferentes correlações empíricas utilizadas para a estimativa de resistência uniaxial de carbonatos com (a) intervalo de tempo de trânsito, (b) módulo de Young e (c) porosidade. (Depois do Chang, Zoback et al. (2006))

Figura 2.17 - Perfil de imagem com ocorrências de breakouts e fratura induzida (Fonte: Apresentação Petrobras)

Figura 2.18 - Resultado do trabalho de campo do Zoback eTownend (2001) do atrito interno da rocha de seis poços, indicando compatibilidade com a solução apresentada por Byerlee (1978)

Figura 2.19 - Polígono de tensões (Zoback e Townend, 2001) ..............60

Figura 3.1 - Indicação da área de estudo na Bacia de Santos

Figura 3.2 - Fluxo de trabalho para a obtenção da janela operacional de perfuração dos carbonatos do pré-sal

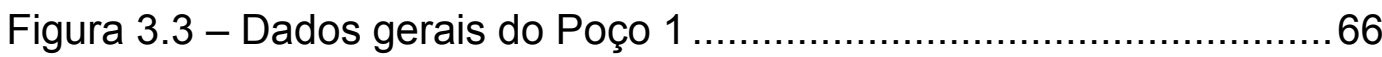

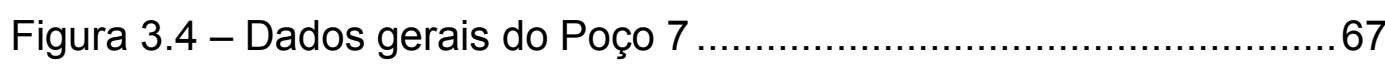

Figura 3.5 - Comparação dos topos estratigráficos e das litologias dos poços. 68

Figura 3.6 - Coeficiente de Biot em função da porosidade em amostras de carbonatos (pressão de poros de 500psi e pressão confinante de 2500psi) (Vasquez et al, 2009).

Figura 3.7 - Esquema para cálculo da estimativa do gradiente de colapso

Figura 3.8 - Relação entre tensão radial, circunferencial e envoltória de Mohr-Coulomb. 
Figura 4.1 - Comparação do perfil densidade corrida no Poço 1 e os dados de densidades sintéticas

Figura 4.2 - Comparação do perfil densidade corrido no Poço 2 e os dados de densidades sintéticas

Figura 4.3 - Comparação do perfil densidade corrido no Poço 4 e os dados de densidades sintéticas .80

Figura 4.4 - Comparação do perfil densidade corrido no Poço 5 e os dados de densidades sintéticas 80

Figura 4.5 - Comparação do perfil densidade corrido no Poço 7 e os dados de densidades sintéticas

Figura 4.6 - Comparação do perfil densidade corrido no Poço 8 e os dados de densidades sintéticas

Figura 4.7 - Resultados estatísticos da estimativa da UCS das rochas carbonáticas do pré-sal

Figura 4.8 - Direção de tensões horizontais máximas encontradas próximo à área de estudo (Imagem do Google Earth e Tensões do WSM) 100

Figura 4.9 - Direção da tensão horizontal máxima considerada para área de estudo (Imagem do Google Earth e Tensões do WSM). 100

Figura 4.10 - Resultados da simulação da profundidade de $5600 \mathrm{~m}$ TVD do Cenário 1 e com coeficiente de Biot igual a 1 (Poço 1). 103

Figura 4.11 - Resultados da simulação da profundidade de $6050 \mathrm{~m}$ TVD do Cenário 1 e com coeficiente de Biot 1 (Poço 7)

Figura 4.12 - Valores de ESRmin, ESR max e Direção de $S_{H \max }$ (Poço 1 -

Cenário 2).

Figura 4.13 - Resultado do modelo geomecânico de estabilidade

(Poço 1 - Cenário 2)

Figura 4.14 - Valores de ESR min, ESR $\max$ e Direção de $S_{H \max }$ (Poço 7 -

Cenário 2).

Figura 4.15 - Resultado do modelo geomecânico de estabilidade (Poço 7 - Cenário 2)

Figura 4.16 - Resultados da janela operacional em termos de probabilidade na profundidade de 5600m (Poço 1 - Cenário 2) 
Figura 4.17 - Resultados da janela operacional em termos de probabilidade na profundidade de 6100m (Poço 7 - Cenário 2) ....

Figura 4.18 - Resultados que ilustram a sensibilidade da previsão do peso de fluido (em ppg) associado à incerteza de cada parâmetro (Poço 1 - Cenário 2)

Figura 4.19 - Resultados que ilustram a sensibilidade da previsão do peso de fluido (em ppg) associado à incerteza de cada parâmetro (Poço 7 Cenário 2) 117

Figura 8.1 - Dados gerais do poço 2 134

Figura 8.2 - Dados gerais do poço 3 134

Figura 8.3 - Dados gerais do poço 4 ........................................... 135

Figura 8.4 - Dados gerais do poço 5 ........................................... 135

Figura 8.5 - Dados gerais do poço 6 ............................................ 136

Figura 8.6 - Dados gerais do poço 8 ............................................. 136

Figura 8.7 - Relação de UCS Militzer x Velocidade acústica 137

Figura 8.8 - Relação de UCS CPM x Velocidade acústica 137

Figura 8.9 - Relação de UCS Teikoku-VP (Rocha ígnea) x Velocidade acústica

Figura 8.10 - Relação de UCS Militzer x Porosidade 138

Figura 8.11- Relação de UCS CPM x Porosidade. 138

Figura 8.12 - Relação de UCS Teikoku-VP x Porosidade 138

Figura 8.13 - Relação de UCS Militzer x E 139

Figura 8.14 - Relação de UCS CPM x E 139

Figura 8.15 - Relação de $\vee p \times$ Vs 139 


\section{Lista de gráficos}

Gráfico 4.1 - Comparação das curvas do gradiente da tensão vertical ...85 Gráfico 4.2 - Valores dos gradientes de pressões de poros medidas nos carbonatos do pré-sal

Gráfico 4.3 - Valores de pressão de poros medidas nos carbonatos do

pré-sal

Gráfico 4.4 - Valores de temperatura medidos em perfil 89

Gráfico 4.5 - Relação dos valores de temperatura medidos

Gráfico 4.6 - Resultados da avaliação da formação de todos os testes ...90 Gráfico 4.7 - Resultados da avaliação da formação em unidades de pressão

Gráfico 4.8 - Correlação dos resultados dos testes de LOT 91

Gráfico 4.9 - Valores médios de UCS para os carbonatos do pré-sal .....93 Gráfico 4.10 - Gráfico resumido da classificação de rochas intactas para os carbonatos (Deer e Miller, 1966) 95

Gráfico 4.11 - Valores do módulo de Young dos poços em análise

Gráfico 4.12 - Valores de Poisson para os poços em análise 98

Gráfico 4.13 - Valores do coeficiente de atrito interno para os poços em análise

Gráfico 4.14 - Gráfico comparativo das curvas de gradiente de colapso resultante dos Cenários de 1 a 6 para o Poço 1

Gráfico 4.15 - Gráfico comparativo das curvas de gradiente de colapso resultante dos cenários de 7 a 10 para o Poço 1

Gráfico 4.16 - Gráfico comparativo das curvas de gradiente de colapso resultante dos Cenários 1 e 2 para o Poço 7

Gráfico 4.17 - Gráfico comparativo das curvas de gradiente de colapso resultante dos Cenários 3 e 4 para o Poço 7 


\section{Lista de tabelas}

Tabela 2.1 - Relações empíricas para estimativa de resistência de

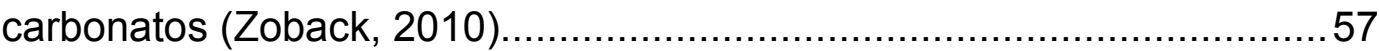

Tabela 3.1 - Informações gerais sobre os poços recebidos da ANP .......63

Tabela 3.2 - Levantamento de dados dos poços recebidos pela ANP ....65 Tabela 3.3 - Eventos ocorridos na perfuração do Poço 7 (Relatório de Perfuração - ANP), a indicação do parâmetro afetado e a litologia correspondente à profundidade indicada

Tabela 4.1 - Resultados dos índices físicos determinados no

Travertino de Itaboraí (Fonte:Domingues, 2011) ................................... 82

Tabela 4.2 - Perfis de evaporitos salinos (Mohriak et al., 2008)..............83

Tabela 4.3 - Valores estatísticos da estimativa do gradiente de sobrecarga para os carbonatos

Tabela 4.4 - Valores estatísticos da estimativa da pressão de sobrecarga para os carbonatos

Tabela 4.5 - Valores estatísticos da estimativa do gradiente de sobrecarga para as rochas ígneas

Tabela 4.6 - Valores estatísticos da estimativa da pressão de sobrecarga para as rochas ígneas

Tabela 4.7 Número de medições diretas de pressões de poros em

cada poço

Tabela 4.8 - Valores estatísticos das pressões de poros medidas nos

carbonatos do pré-sal.

Tabela 4.9 - Valores de gás registrados nos Poços

Tabela 4.10 - Valores estimados de $S_{h m i n}$ e ESR $\min$

Tabela 4.11 - Resultados dos ensaios de compressão UCS nos corpos de prova do Travertino de Itaboraí (Fonte: Domingues, 2011) 94

Tabela 4.12 - Valores médios estimados de UCS obtidos para o pré-sal e para o seu análogo de acordo com o estudo de Domingues (2011) ....95 Tabela 4.13 - Resultados estatísticos da estimativa da resistência da rocha ígnea 
Tabela 4.14 - Resultados das propriedades elásticas do carbonato Travertino de Itaboraí (Fonte: Domingues, 2011).

Tabela 4.15 - Resultados das simulações para a estimativa da magnitude da tensão horizontal máxima para a rocha carbonática do Poço 1

Tabela 4.16- Resultados das simulações para a estimativa da magnitude da tensão horizontal máxima para a rocha ígnea do Poço 1

Tabela 4.17- Resultados das simulações para a estimativa da magnitude da tensão horizontal máxima para a rocha carbonática do

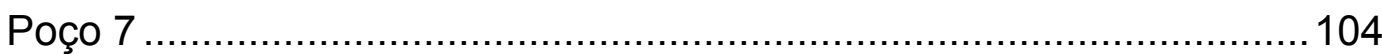

Tabela 4.18 - Resumo dos resultados da estimativa de $S_{H \max } \ldots \ldots \ldots \ldots \ldots . . . .106$ Tabela 4.19 - Resultados da janela operacional dos diferentes cenários para o carbonato do Poço 1

Tabela 4.20 - Resultados da janela operacional dos diferentes cenários para o carbonato do Poço 7 .

Tabela 4.21 - Valores estatísticos da pressão de colapso em cada cenário para o Poço 1

Tabela 4.22 - Valores estatísticos da pressão de colapso em cada cenário para o Poço 7

Tabela 4.23 - Análise de sensibilidade para a fase dos carbonatos para os Poços 1 e 7

Tabela 4.24 - Peso de fluido utilizado na perfuração de cada poço da fase dos carbonatos 


\section{1 \\ Introdução}

\section{1 \\ Motivação}

Os problemas de instabilidade são uma das situações com que a indústria petrolífera não raras vezes se depara. Estima-se que os custos associados à instabilidade de poços representem cerca de 5 a $10 \%$ dos custos de perfuração nas fases de exploração e produção, implicando, a nível mundial, custos de centenas de milhões de dólares por ano (Fjaer et al., 2008).

As operações de perfuração, produção e/ou injeção afetam o equilíbrio inicial existente nas formações rochosas, levando a uma alteração das condições mecânicas da rocha e do estado de tensão nas imediações do poço. Estas alterações podem afetar as atividades de perfuração e completação, assim como o rendimento da produção, resultando em custos imprevistos e morosidade nas operações (Gonçalves, 2015).

Com o surgimento da perfuração direcional e horizontal, bem como da exploração em ambientes de grande complexidade geológica, zonas tectonicamente ativas e em ambiente offshore de águas profundas, os problemas de estabilidade também se tornaram mais complexos, aumentando as dificuldades resolutivas, o que exigiu a crescente atenção por parte da indústria petrolífera e da comunidade técnica e científica para com esta temática (Gonçalves, 2015).

A descoberta do pré-sal representa uma grande oportunidade para o desenvolvimento industrial, tecnológico e científico do Brasil. Porém, a complexidade dos reservatórios carbonáticos do ponto de vista geológico e geomecânico indica a necessidade de estudos para o conhecimento da área visando proporcionar uma otimização da perfuração dos poços que atravessam camadas de grande espessura em águas profundas até o reservatório.

Um sistema petrolífero (Magoon e Dow, 1994) engloba uma porção de rocha geradora ativa e todas as acumulações de petróleo e gás geneticamente relacionadas (Magoon e Beaumont, 1999). A Figura 1.1 indica a dinâmica do sistema petrolífero 
do pós-sal e a Figura 1.2 indica a dinâmica do sistema petrolífero do pré-sal. Como é possível observar nas Figuras 1.1 e 1.2, os elementos essenciais do sistema petrolífero são as rochas geradoras (ricas em matéria orgânica), reservatórios e rocha selante.

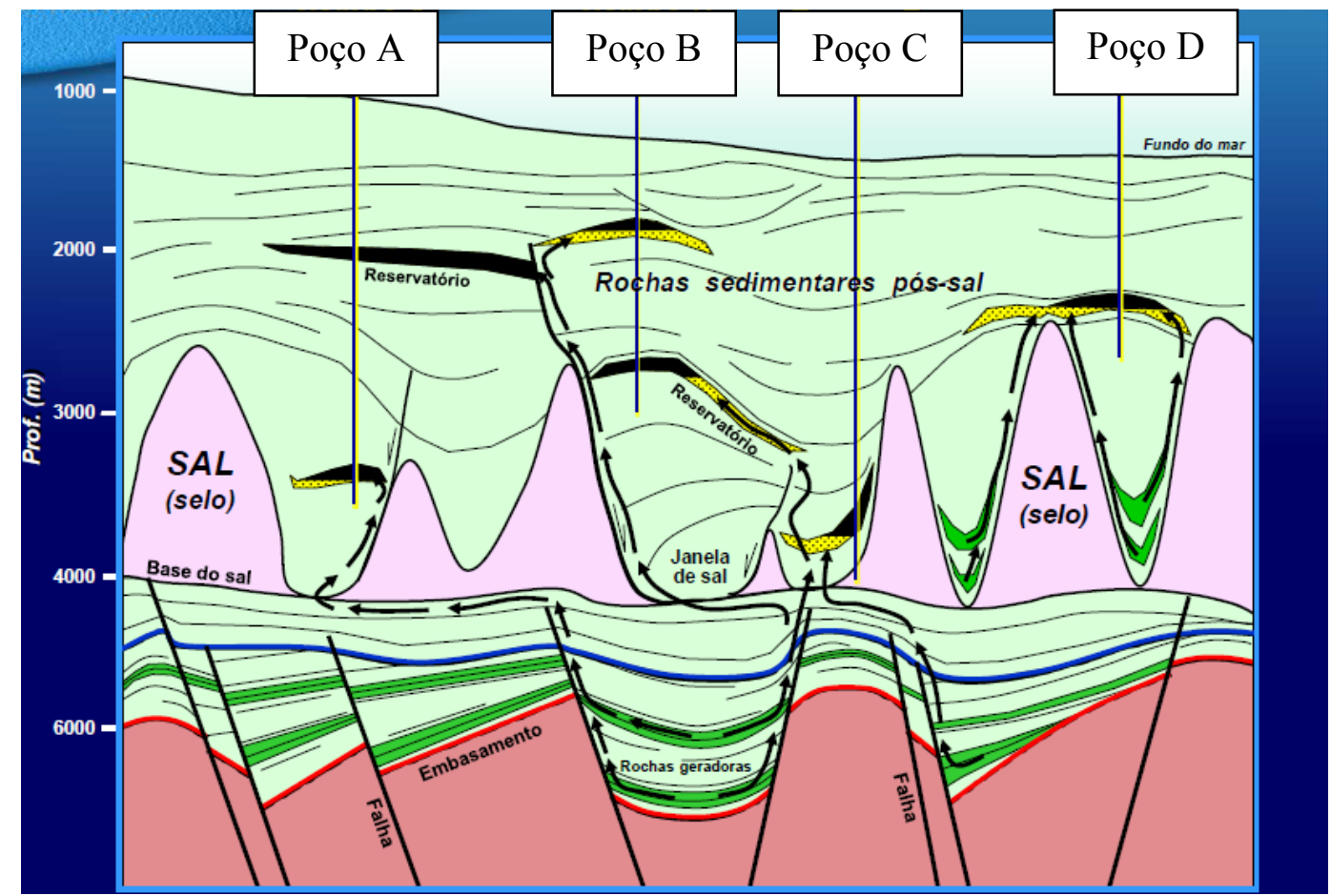

Figura 1.1 - Dinâmica do sistema petrolífero do pós-sal. (Fonte: Apresentação pública da Petrobras)

As rochas sedimentares do pós-sal são mais novas de acordo com o tempo geológico porque foram depositadas depois do sal. Uma propriedade característica do sal é a fluência que possibilita a intrusão do mesmo nas rochas sedimentares do pós-sal, como pode ser observado na Figura 1.1. Essa mobilidade do sal pode induzir um falhamento na região e uma alteração do campo de tensões com o passar do tempo. Ainda de acordo com a Figura 1.1, podem-se observar várias falhas do embasamento até a base do sal, atravessando as rochas geradoras. 


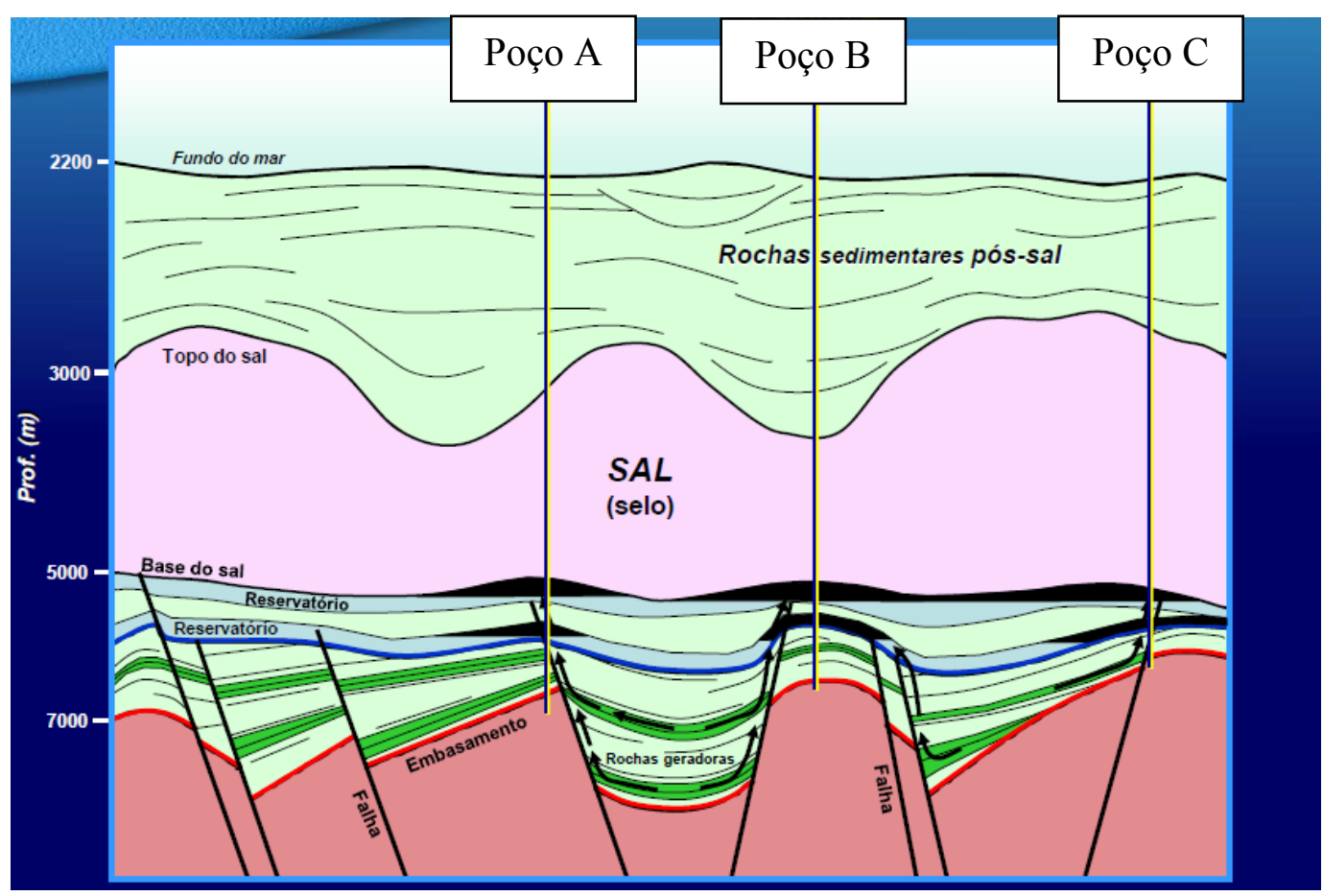

Figura 1.2 - Dinâmica do sistema petrolífero do pré-sal. (Fonte: Apresentação pública da Petrobras)

Em algumas áreas, como observado na Figura 1.2, os reservatórios do pré-sal estão localizados em profundidades em torno de 6000 e $7000 \mathrm{~m}$ abaixo de uma camada de sal de aproximadamente $2000 \mathrm{~m}$ de espessura. Essa camada de sal gera uma espécie de selo, favorecendo a acumulação de óleo e gás nos carbonatos.

A escassez de conhecimento sobre estes reservatórios dificulta sua caracterização e previsibilidade, e com isso prejudica a modelagem e a simulação. Durante a produção, a extração de hidrocarbonetos reduz a pressão nos poros, o que causa um aumento nas tensões efetivas e a compactação mecânica do reservatório. A contração volumétrica e a ruptura por compactação podem ser extensas ou localizadas apenas nas vizinhanças do poço, mas em ambos os casos as consequências podem ser severas como a subsidência da superfície, ruptura do poço, produção de areia e outros problemas na produção. A análise da estabilidade do poço e, de forma geral a deformação e a ruptura em ambientes carbonáticos, dependem de modelos constitutivos relevantes de rochas carbonáticas em uma larga faixa de porosidades (Alves et al., 2007).

A otimização da perfuração através de uma taxa de perfuração ótima, peso de fluido ideal, trajetória ótima de perfuração de poços altamente inclinados ou 
horizontais (fase de desenvolvimento do campo) para o controle da pressão de poros, pressão de colapso e da perda de circulação na interface da base do sal e do topo do reservatório, pode ser alcançada se forem desenvolvidos modelos para estudos geomecânicos de estabilidade de poços a fim de proporcionar um conhecimento da janela operacional de perfuração.

1.2

Objetivo

O presente trabalho tem como objetivo desenvolver um modelo geomecânico e aplicá-lo para obter uma estimativa da janela operacional de perfuração na área exploratória do pré-sal brasileiro na Bacia de Santos.

O modelo foi construído a partir das análises de perfis, das provas de Leak of tests (LOTs) executadas, medições de pressão de poros e dados do world stress map. Foram realizadas análises de sensibilidade dos dados a fim de estimar:

- Campo de Tensões (magnitude da tensão vertical; tensão horizontal mínima e máxima, assim como orientação das tensões horizontais);

- Pressão de poros; e

- Resistência da rocha.

Com os resultados da estimativa desses parâmetros foi possível estimar o gradiente de colapso e o gradiente da tensão horizontal mínima e, assim, estimar a janela operacional que foi considerada durante a perfuração dos poços em questão. Além disso, foram comparados os gradientes de colapso e pressão de poros para identificar o de maior magnitude, identificando o peso mínimo aceitável.

1.3

\section{Estrutura da dissertação}

A dissertação está estruturada de acordo com os capítulos descritos a seguir:

Capítulo 1 - Introdução

Neste capítulo é apresentado a motivação e o objetivo para o trabalho e a estrutura da dissertação. 


\section{Capítulo 2 - Revisão bibliográfica}

Neste capítulo de revisão bibliográfica, foram abordados a geologia do présal e o modelo geomecânico de estabilidade de poços. Foram citadas as características e geologia do pré-sal brasileiro, além das características que diferenciam as Bacias de Santos e de Campos. Com relação ao modelo, foram descritos a importância, o objetivo, fatores que influenciam a estabilidade de poços e os parâmetros necessários para a elaboração do mesmo, além de algumas metodologias disponíveis na literatura para a estimativa desses parâmetros.

\section{Capitulo 3 - Metodologia}

No Capítulo 3, foram apresentados o local da área de estudo e fluxo de trabalho para a obtenção da janela operacional de perfuração nos carbonatos. Além disso, foi indicada a metodologia utilizada para a estimativa de cada parâmetro necessário na elaboração do modelo de estabilidade de poços.

\section{Capítulo 4 - Apresentação e discussão dos resultados}

Nesse capítulo, os resultados da estimativa de cada parâmetro foram apresentados e discutidos, assim como a janela operacional obtida.

\section{Capítulo 5 e 6 - Conclusões e Recomendações}

Nesses capítulos foram apresentadas as principais conclusões deste estudo e recomendações para a redução das incertezas associadas ao modelo e para trabalhos futuros.

\section{Anexos}

As inúmeras simulações e cenários avaliados geraram um número significativo de figuras e, por isso, algumas delas foram apresentadas nos anexos. 


\section{2 \\ Revisão Bibliográfica}

\section{1 \\ O Pré-sal brasileiro}

A composição do petróleo compreende uma mistura de hidrocarbonetos, formados por moléculas de carbono e hidrogênio, predominantemente, e mínimas porcentagens de oxigênio, nitrogênio e enxofre, originados pela decomposição de matéria orgânica derivada de micro-organismos, por ação de bactérias em ambientes com baixo nível de oxigênio. No decorrer do tempo geológico, esse material se acumulou no fundo de lagos, mares e oceanos, sendo prensado pelo movimento da crosta terrestre e, assim, formando-se o petróleo, que migrou para as rochas-reservatório, ou seja, rochas sedimentares constituídas por arenitos e calcários devido ao seu caráter poroso (Zaine et al, 2012).

Atualmente, o petróleo constitui a principal fonte de energia e tem suma importância na economia, sendo responsável também por várias mudanças geopolíticas e socioeconômicas no mundo todo. De acordo com Zaine (2012), a estimativa é de que exista no planeta cerca de um trilhão de barris de petróleo, dos quais se estima que já foram extraídos e consumidos 43,4\% até 1990. A produção mundial diária chega a 24 milhões de barris, dos quais 23 milhões são consumidos e um milhão é armazenado no depósito. As reservas mundiais provadas são estimadas em torno de 137 bilhões de toneladas.

Em abril de 2006, com a inauguração da Plataforma P-50 na Bacia de Campos, o Brasil alcançou a tão desejada autossuficiência em petróleo. A partir daí o objetivo passou a ser a manutenção dessa autossuficiência, o que requeria a descoberta de novas reservas de petróleo (Riccomini et al, 2012), pois a bacia de Campos é um reservatório maduro, além de produtor de óleo pesado.

Os investimentos efetuados na Bacia de Santos na última década, inicialmente pela Petrobras e posteriormente pelas empresas a ela consorciadas, resultaram na descoberta das ocorrências do pré-sal, as quais ainda se encontram 
em avaliação pelas companhias petrolíferas. Dados divulgados pela agência Petrobras (http://www.agenciapetrobras.com.br) dão conta de que os testes preliminares em quatro áreas do pré-sal (Lula, Iara e Guará, na Bacia de Santos, e Parque das Baleias, na Bacia de Campos) permitiram prever volumes recuperáveis entre 10,6 bilhões e 16 bilhões de barris de óleo equivalente - boe (somatório de petróleo e gás natural), o que dobraria as reservas brasileiras de petróleo e gás que atualmente são de 15 bilhões de barris de óleo equivalente. Estimativas de reservas para o pré-sal brasileiro indicam potencial de 70 a 100 bilhões de barris de óleo equivalente (Riccomini et al, 2012).

De acordo com Riccomini (2012), a exploração do pré-sal encontra grandes desafios, como a profundidade da lâmina d'água, a geometria complexa dos domos salinos, a grande espessura de coluna de rochas a serem atravessadas, que alcançam cerca de 6000-7000m, as enormes pressões, tensões e alta resistência mecânica das formações, grandes desgastes das brocas, o comportamento do sal e da porosidade dos reservatórios face à perfuração e as heterogeneidades dos reservatórios carbonáticos. Além disso, creep do sal, geologia estrutural complexa, presença de cavernas, vuggs são responsáveis, respectivamente, por estreitamento do poço e perdas de circulação.

Segundo Morillos (2013), os grandes desafios à exploração do petróleo no pré-sal, são os seguintes:

- Na região dos reservatórios, há questões envolvendo a interpretação dos dados sísmicos, a caracterização dos reservatórios, a viabilidade técnica da injeção de gás e da água, e também a geomecânica das rochas adjacentes;

- Na área da engenharia de poços, as barreiras se encontram relacionadas ao desvio dos poços na região salina, à fratura hidráulica em poços horizontais, aos materiais que suportem elevada concentração de $\mathrm{CO}_{2}$, à baixa penetração no reservatório e à deposição de produtos nas tubulações extensas;

- Na logística relacionada ao gás, se apresentam como obstáculo as tubulações de alto diâmetro a profundidades maiores de 2.200 metros, as longas distâncias da costa e também as novas técnicas em alto-mar;

- Nas unidades de produção flutuantes, há o atracamento em águas profundas, o controle dos sistemas de nivelamento e o novo meio de acesso aos poços pelas plataformas. 


\section{2}

\section{Geologia do pré-sal e as bacias da margem continental brasileira}

Segundo Riccomini (2012), as perfurações demonstraram que as rochas do pré-sal são reservatórios situados sob extensa camada de sal que se estende na região costa-afora entre os estados do Espírito Santo e Santa Catarina, numa faixa com cerca de $800 \mathrm{~km}$ de comprimento por $200 \mathrm{~km}$ de largura (Figura 2.1). Nessa faixa, a lâmina d'água varia de 1.500 a $3.000 \mathrm{~m}$ de profundidade, uma camada de sedimentos clásticos de cerca de $1000 \mathrm{~m}$ e outra superior de cerca de $2000 \mathrm{~m}$ de sal. Com isto, os reservatórios carbonáticos se situam entre cerca de 6.000 a $7.000 \mathrm{~m}$. A área de abrangência dos reservatórios do pré-sal distribui-se essencialmente pelas bacias sedimentares de Santos e Campos, situada na margem continental brasileira. Originalmente interligadas, essas bacias foram formadas como um processo de rifte, no qual a crosta terrestre e a litosfera associada sofreram uma fratura acompanhada por um afastamento em direções opostas de porções vizinhas da superfície terrestre. O alargamento da crosta cria condições propícias para a subida de magma, pelo que o eixo das zonas de rifte está em geral associado a linhas de vulcanismo ativo onde as erupções geram nova crosta para compensar o afastamento.

Foi esse o caso da margem continental brasileira, na qual a formação dos extensos reservatórios do pré-sal está diretamente ligada aos processos da tectônica de placas, que promoveram a ruptura do paleocontinente Gondwana, separação dos continentes sul-americano e africano, e culminou com a abertura do Oceano Atlântico Sul.

A formação das bacias de Santos e Campos teve início no período Cretáceo, há pouco mais de 130 milhões de anos. A evolução dessas bacias tem sido relacionada a quatro estágios bem marcados pela sua conformação paleogeográfica, denominados de: estágio pré-rifte (ou do continente), estágio rifte (ou do lago), estágio proto-oceânico (ou do golfo) e estágio drifte (ou do oceano) (Ponte \& Asmus, 1978). 


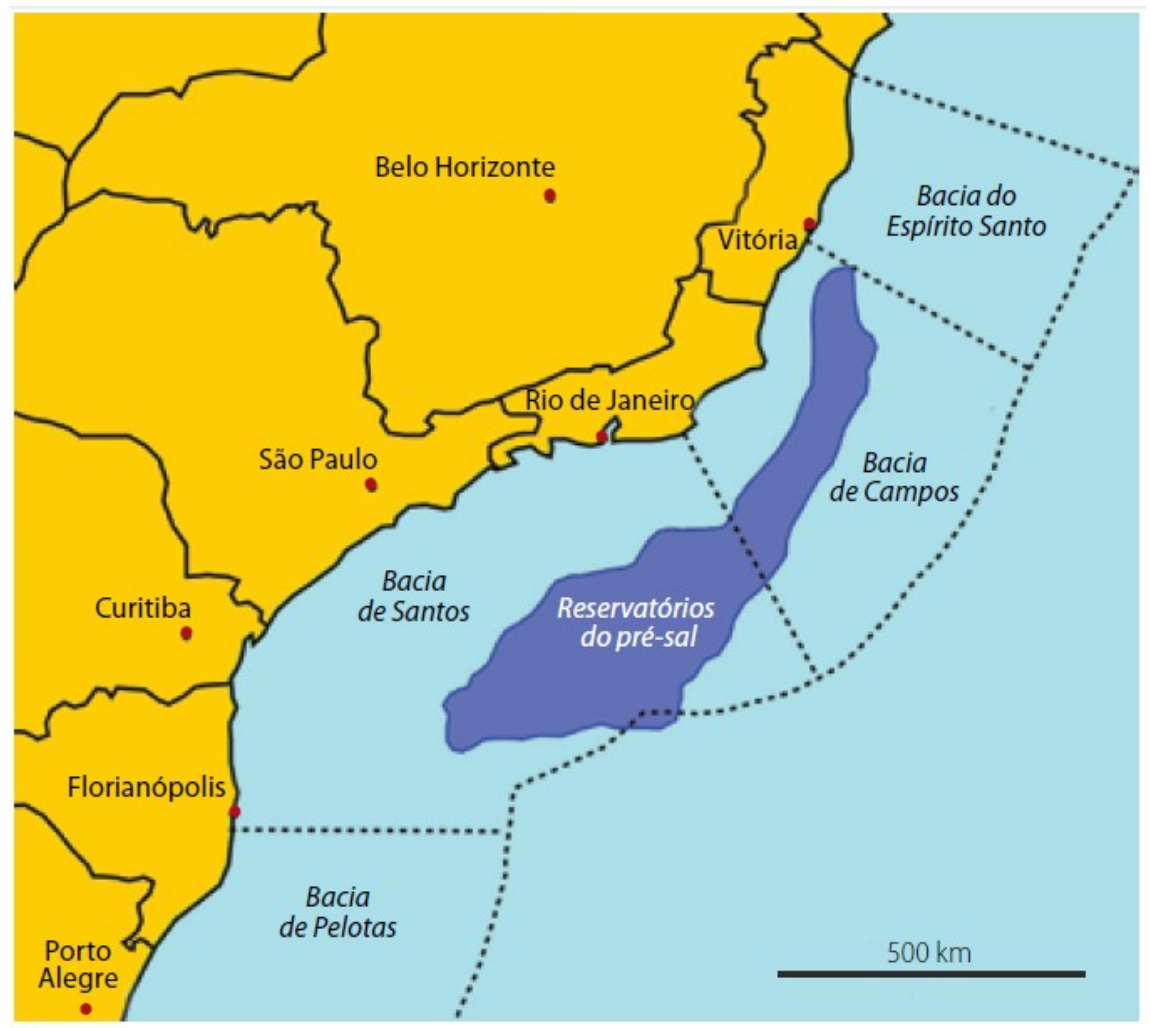

Figura 2.1 - Distribuição das rochas do reservatório do pré-sal em relação às bacias da margem continental brasileira (Fonte: Revista USP - modificado de Papaterra, 2010)

O estágio pré-rifte, ou do continente, compreendeu a deposição de sedimentos de leques aluviais, fluviais e eólicos, que teria ocorrido em uma grande depressão que envolveria a atual porção leste-nordeste do Brasil e oeste-sudoeste da África (Ponte e Asmus, 1978).

No estágio rifte, ou do lago, ocorreu inicialmente vulcanismo há aproximadamente 133 milhões de anos, sobretudo na região atualmente ocupada pelas bacias de Santos e Campos. Entre aproximadamente 131 e 120 milhões de anos atrás, a movimentação de falhas gerou bacias do tipo rifte, com uma paleotopografia em blocos altos e baixos. Nas partes baixas foram depositados sedimentos lacustres, principalmente folhelhos ricos em matéria orgânica (fitoplâncton), além de arenitos transportados por rios que formavam deltas e adentravam o lago (Pereira e Feijó, 1994). A parte superior do estágio rifte compreende rochas carbonáticas, denominadas microbialitos, cuja produção e acumulação em lagos conectados a um oceano próximo teriam sido induzidas por organismos microbianos (Estrella, 2008). Segundo Dorobek et al., (2012), a partir do estudo de rochas carbonáticas provenientes da área da atual Bacia de Campos, 
reconheceram evidências de atividade microbiana, mas consideraram que a precipitação de carbonato foi abiótica, formando uma variedade de depósitos acumulados em menos de 1 milhão de anos.

O estágio pós-rifte é marcado pela entrada periódica de um mar ao sul, controlado por um alto topográfico constituído provavelmente por rochas basálticas. O cenário paleogeográfico daquela época era o de um golfo estreito e alongado (Figura 2.2), muito semelhante ao do atual Mar Vermelho, situado entre o nordeste da África e a Península Arábica. O contínuo afundamento do assoalho da bacia, o clima quente, a salinidade da água e as altas taxas de evaporação permitiram a formação do pacote de sal, uma espessa sucessão de evaporitos com até $2.500 \mathrm{~m}$ de espessura (Chang et al., 1990), composta essencialmente de halita $(\mathrm{NaCl})$ e intercalações de anidrita, carnalita e taquidrita (Gamboa et al., 2008), depositados num prazo de 400 a 600 mil anos (Freitas, 2006), em um intervalo de tempo ainda não muito bem estabelecido entre 119 e 112 milhões de anos atrás.

No estágio drifte, ou do oceano, tem início a franca separação entre os continentes sul-americano e africano e a formação do Oceano Atlântico Sul. Esse estágio teve início há cerca de 112-111 milhões de anos e perdura até hoje. Sobre os evaporitos da fase anterior foram depositados sedimentos marinhos a transicionais, principalmente carbonáticos de plataforma e microbialitos (entre 112 a 98 e 45 a 3 milhões de anos antes do presente), folhelhos de águas profundas (a partir de 96 milhões de anos antes do presente e com franco predomínio a partir de 45 milhões de anos antes até o presente) e arenitos de águas rasas e turbiditos (a partir de 105 milhões de anos e com maior desenvolvimento entre 85 e 45 milhões de anos antes do presente) (Pereira e Feijó, 1994). 


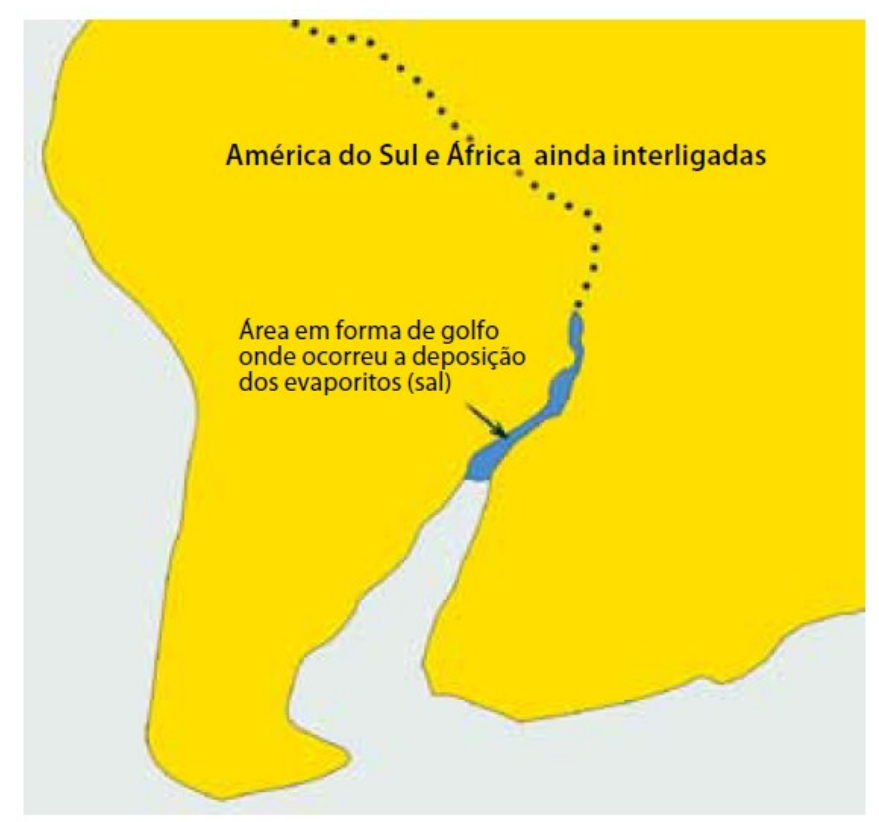

Figura 2.2 - Esquema paleogeográfico do estágio pós-rifte ou do golfo, durante a deposição dos evaporitos (Fonte: Revista USP, 2012)

\subsection{1 \\ Bacia de Santos}

A Bacia de Santos está localizada na região sudeste da margem continental brasileira, defronte aos estados do Rio de Janeiro, São Paulo, Paraná e Santa Catarina (Figura 2.3) e possui uma área total de aproximadamente $272.000 \mathrm{~km}^{2}$ até a cota batimétrica de $3000 \mathrm{~m}$. Com uma espessura sedimentar superior a 10.000 metros, a bacia representa uma das maiores depressões da margem continental brasileira.

Na Figura 2.3 é possível observar o limite sul pelo "Alto de Florianópolis", que a separa da Bacia de Pelotas, e seu limite norte que ocorre através do "Alto de Cabo Frio", que a separa da Bacia de Campos. Além disso, também são observados os campos sob concessão representados pelos polígonos coloridos. A bacia é totalmente imersa, diferentemente da Bacia de Campos que apresenta área em terra e figura entre as maiores bacias sedimentares do Brasil. 


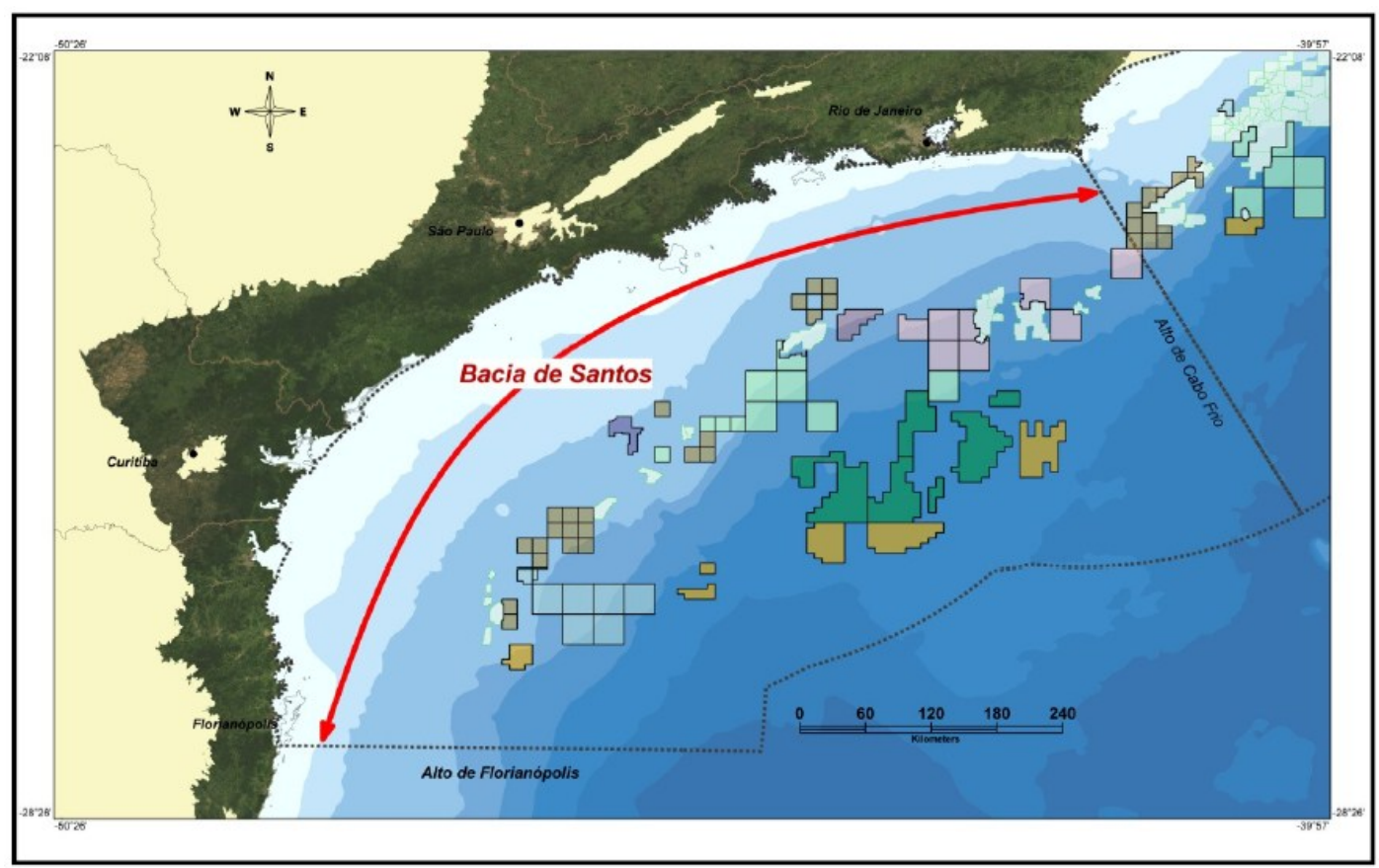

Figura 2.3 - Mapa de localização dos limites da Bacia de Santos. (Fonte:ANP/BDEP, fev 2010)

A coluna estratigráfica da Bacia de Santos (Figura 2.4) foi inicialmente definida na década de 1970 e, em seguida, Pereira e Feijó (1994), com poucos poços disponíveis, estabeleceram um arcabouço cronoestratigráfico em termos de sequências deposicionais.

De acordo com atualização feita por Moreira et al. (2007), o arcabouço estratigráfico da Bacia de Santos compreende três supersequências, correspondendo genericamente às fases Rifte, Pós-rifte (ou transicional) e Drifte (Figura 2.5). A mais antiga, corresponde à Supersequência Rifte e compreende as antigas formações Camboriú e Guaratiba (Pereira e Feijó, (1994).

Com a atualização do arcabouço estratigráfico, Moreira et al. (2007) elevam a antiga formação Guaratiba à categoria de grupo, sendo composto por cinco formações, das quais três estão inseridas na Fase Rifte (formações Camboriú, Piçarras e Itapema).

A formação Camboriú é constituída por derrames de basaltos, sobre os quais se assenta a Formação Piçarras, representada por conglomerados e arenitos constituídos de fragmentos de basalto, quartzo, feldspato, nas porções proximais, e por arenitos, siltitos e folhelhos. Já a formação Itapema caracteriza-se por apresentar intercalações de calcirruditos e folhelhos escuros. Os calcirruditos, informalmente denominados de "sequência das coquinas" na Bacia de Campos, são 
constituídos por fragmentos de conchas pelecípodes que frequentemente encontram-se dolomitizados e/ou silicificados. Nas porções mais distais ocorrem folhelhos escuros, ricos em matéria orgânica, que se constituem no potencial gerador (cf Mello et al., 1995), como acontece em outras bacias da margem leste brasileira.

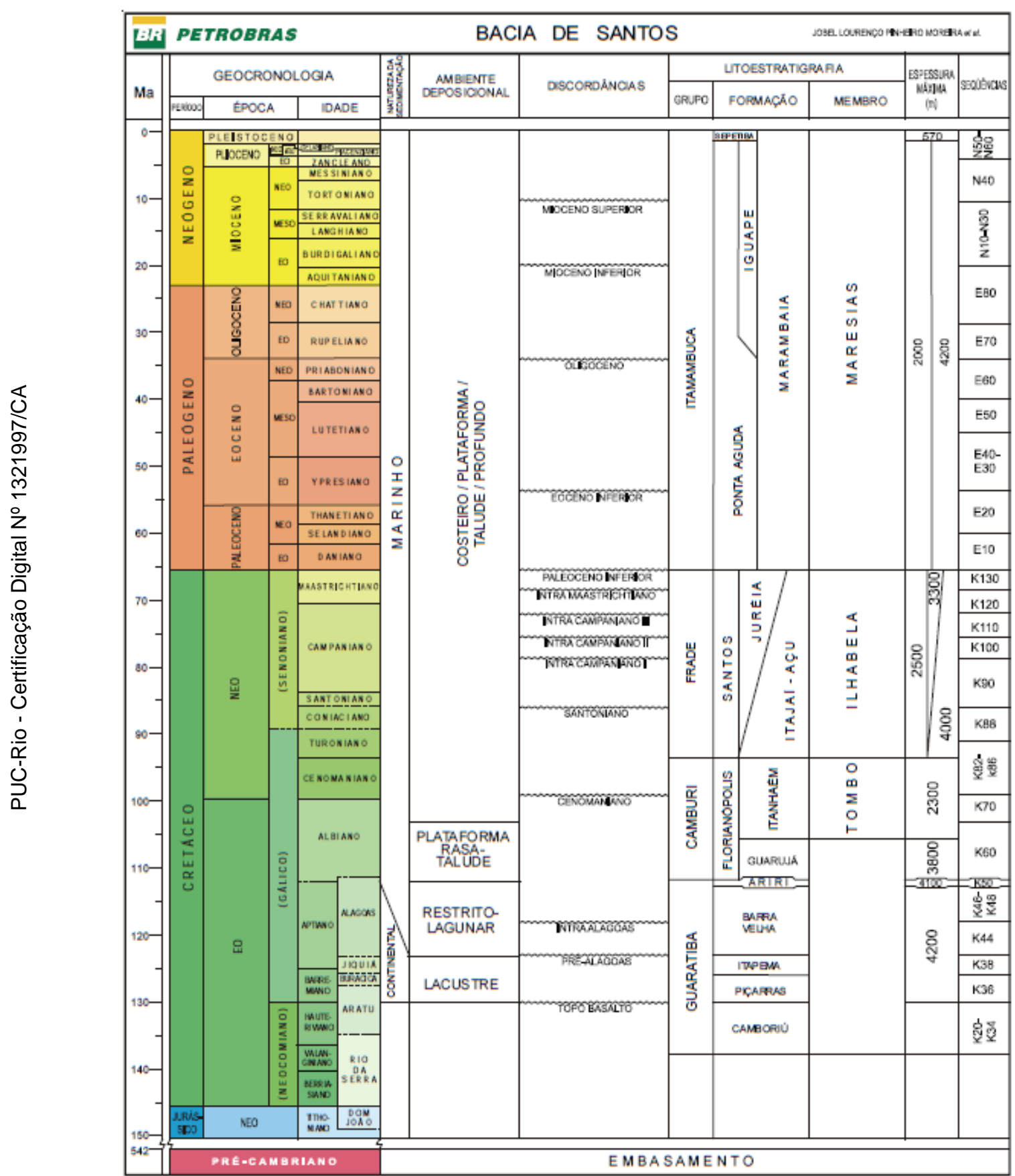

Figura 2.4 - Carta estratigráfica da Bacia de Santos (Fonte: Moreira et al,2007) 


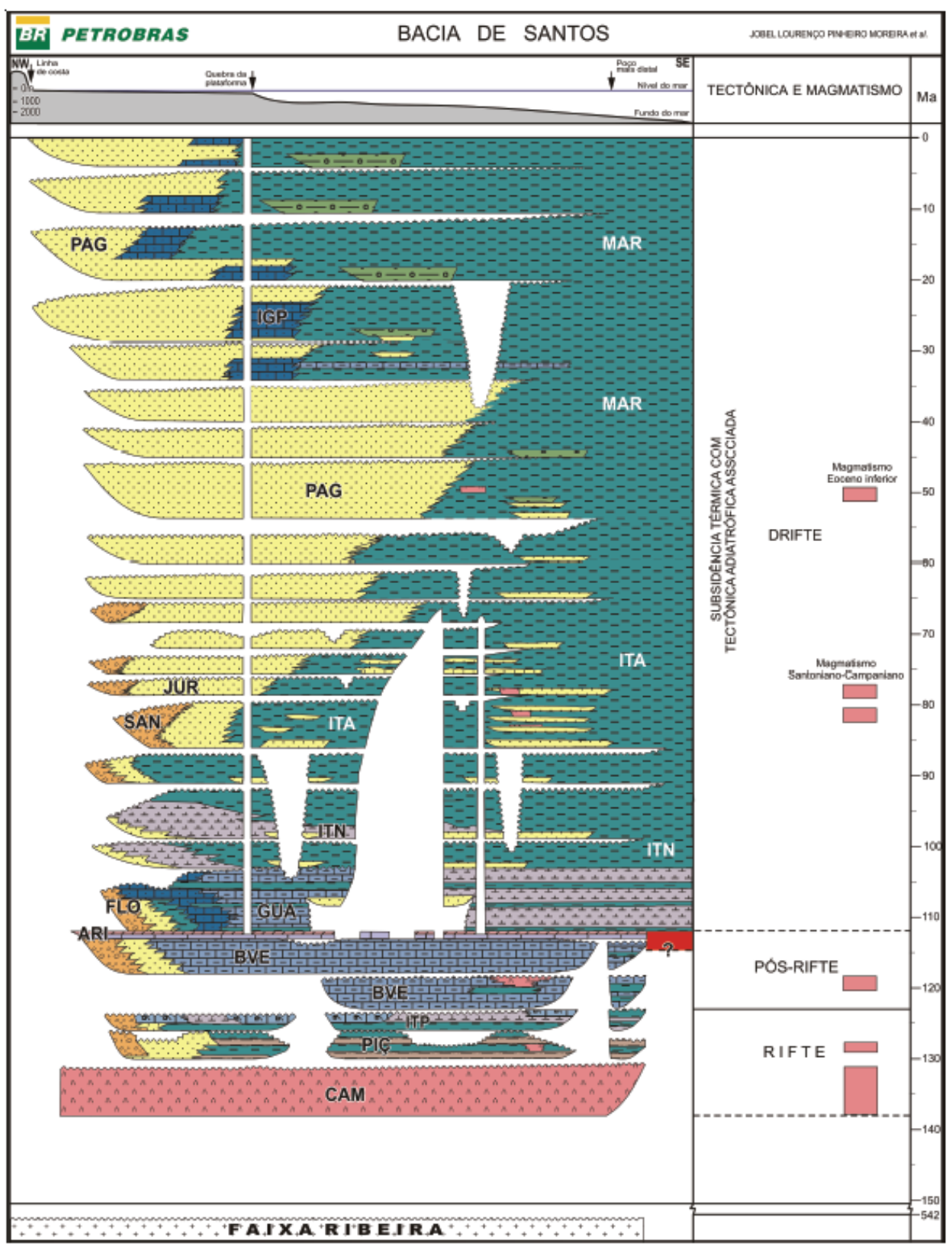

Figura 2.5 - Seções Rifte, Pós-Rifte e Drifte da Bacia de Santos (Fonte: Moreira et al.,2007)

De acordo com Moreira et al., (2007), a Supersequência Rifte é recoberta por uma Supersequência Pós-rifte (ou Transicional), depositada em paleoambiente entre continental e marinho raso bastante estressante, correspondendo às formações Barra Velha e Ariri, ambas do grupo Guaratiba.

A Formação Barra Velha, que é subdividida em duas sequências, inferior e superior, tem seu limite inferior dado pela discordância conhecida como "PréAlagoas" (cf. Moreira et al., 2007). A sequência inferior, do início do Aptiano, 
caracteriza-se pela deposição de calcários microbiais, estromatólitos e laminitos nas porções proximais e folhelhos nas porções distais. Ocorrem também granstones e packstones compostos por fragmentos dos estromatólitos e bioclástos (ostracodes) associados. Já na sequência superior, final do Aptiano, há ocorrência de calcários estromatolíticos e laminitos microbiais, localmente dolomitizados.

A Formação Ariri sobrepõe a Formação Barra Velha e é onde ocorre a deposição de evaporitos, compostos principalmente por halita e anidrita. Entretanto, já se constatou a presença de sais solúveis, tais como: taquidrita, carnalita e silvinita. O tempo de formação dos evaporitos é de 0,7 a $1 \mathrm{Ma}$, permanecendo ainda imprecisa a taxa de acumulação devido à alta mobilidade da halita (Dias, 2008).

A Supersequência Drifte está associada à subsidência térmica da bacia com tectônica adiastrófica associada, sendo constituída por sedimentos marinhos, depositados do Albiano ao Recente, conforme Moreira et al., 2007. Essa supersequência é subdividida em três sequências: Marinho Raso (plataforma carbonática), Marinho Aberto Transgressivo e Marinho Aberto Regressivo.

Em relação ao sistema petrolífero da Bacia de Santos (Papaterra, 2010), restrito à configuração subsal (intervalo do Pré-sal), tem como rochas geradoras potenciais folhelhos negros ricos em matéria orgânica, intercalados com carbonatos, depositados em paleoambiente lacustre (formações Itapema e Piçarras do Grupo Guaratiba) e, como reservatórios, carbonatos das Formações Itapema (coquinas) e Barra Velha (microbialitos), ambos do Grupo Guaratiba, podendo ainda ocorrer em rochas siliciclásticas (Formação Piçarras) e basaltos fraturados (Formação Camboriú). Já a presença e extensa camada de sal (Formação Ariri) sobreposta, provavelmente foi responsável por um selante quase perfeito para este sistema petrolífero. De acordo com Pereira e Macedo (1990), a migração de hidrocarbonetos gerados na Formação Guaratiba (Seção Rifte) deu-se através de falhas, paredes dos diáprios e discordâncias estratigráficas (Figura 2.6). 


\section{SEÇÃO GEOLÓGICA ESQUEMÁTICA DA BACIA DE SANTOS SANTOS BASIN SCHEMATIC CROSS SECTION}

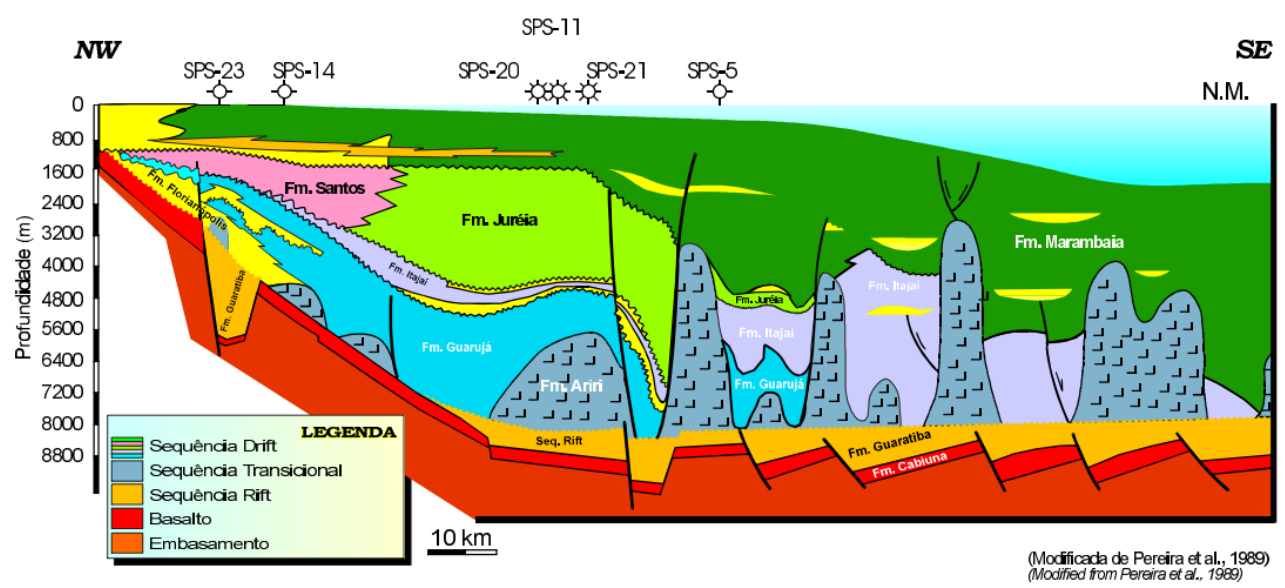

Figura 2.6 - Seção Geológica esquemática da Bacia de Santos (Fonte: site ANP, Jul 2016)

\subsection{2}

\section{Bacia de Campos}

A Bacia de Campos abrange uma área total aproximada de $102.000 \mathrm{~km}^{2}$, da qual $6500 \mathrm{~km}^{2}$ são em terra e $95.500 \mathrm{~km}^{2}$ são em mar até a cota batimétrica de 3000m. Está situada no litoral dos estados do Rio de Janeiro e do Espírito Santo e limita-se ao sul pelo "Alto de Cabo Frio", que a separa da Bacia de Santos, e ao norte pelo "Alto de Vitória", que constitui o limite com a Bacia do Espírito Santo (Figura 2.7).

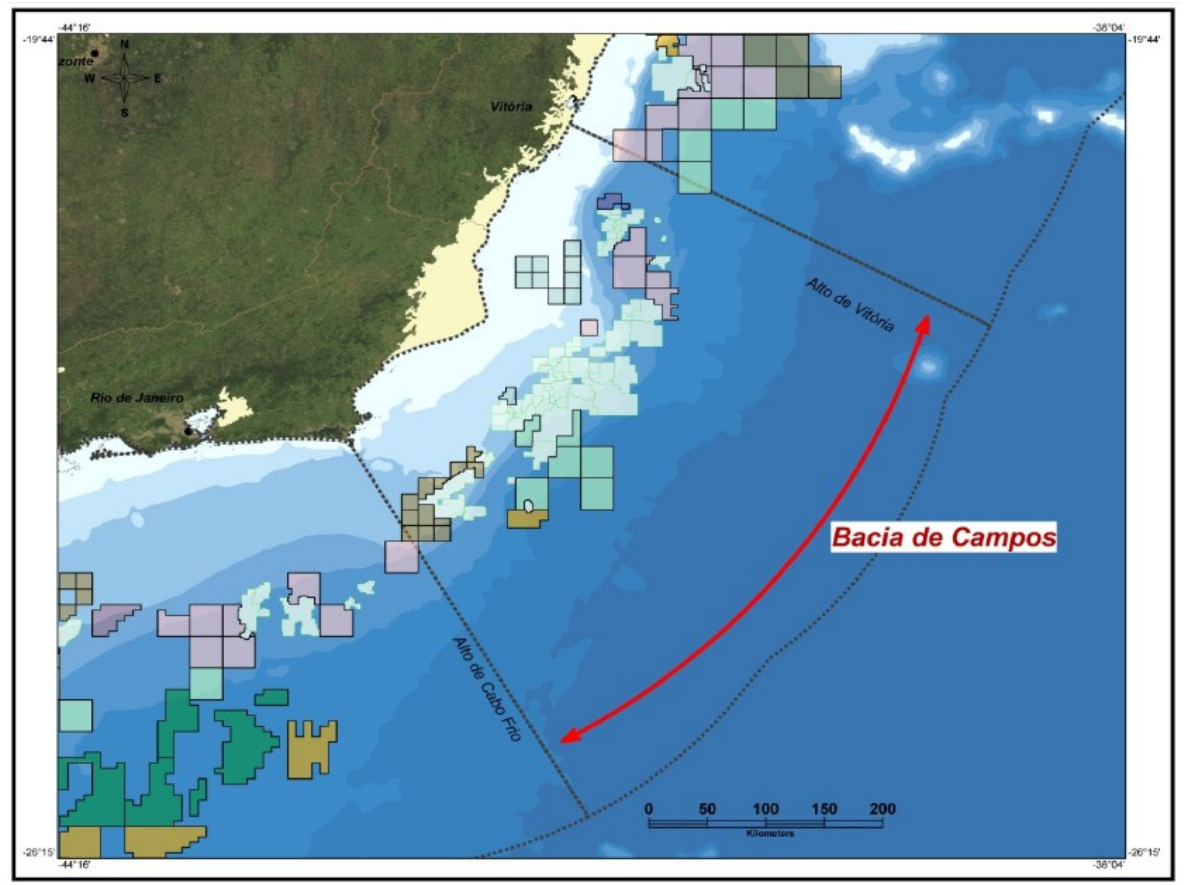

Figura 2.7 - Mapa de localização dos limites da Bacia de Campos (Fonte:ANP/BDEP, fev 2010) 
Segundo Winter et al. (2007), o arcabouço estratigráfico da Bacia de Santos (Figura 2.8), genericamente, pode ser dividido em três supersequências: rifte, pósrifte e drifte, associadas a diferentes fases de desenvolvimento da bacia.

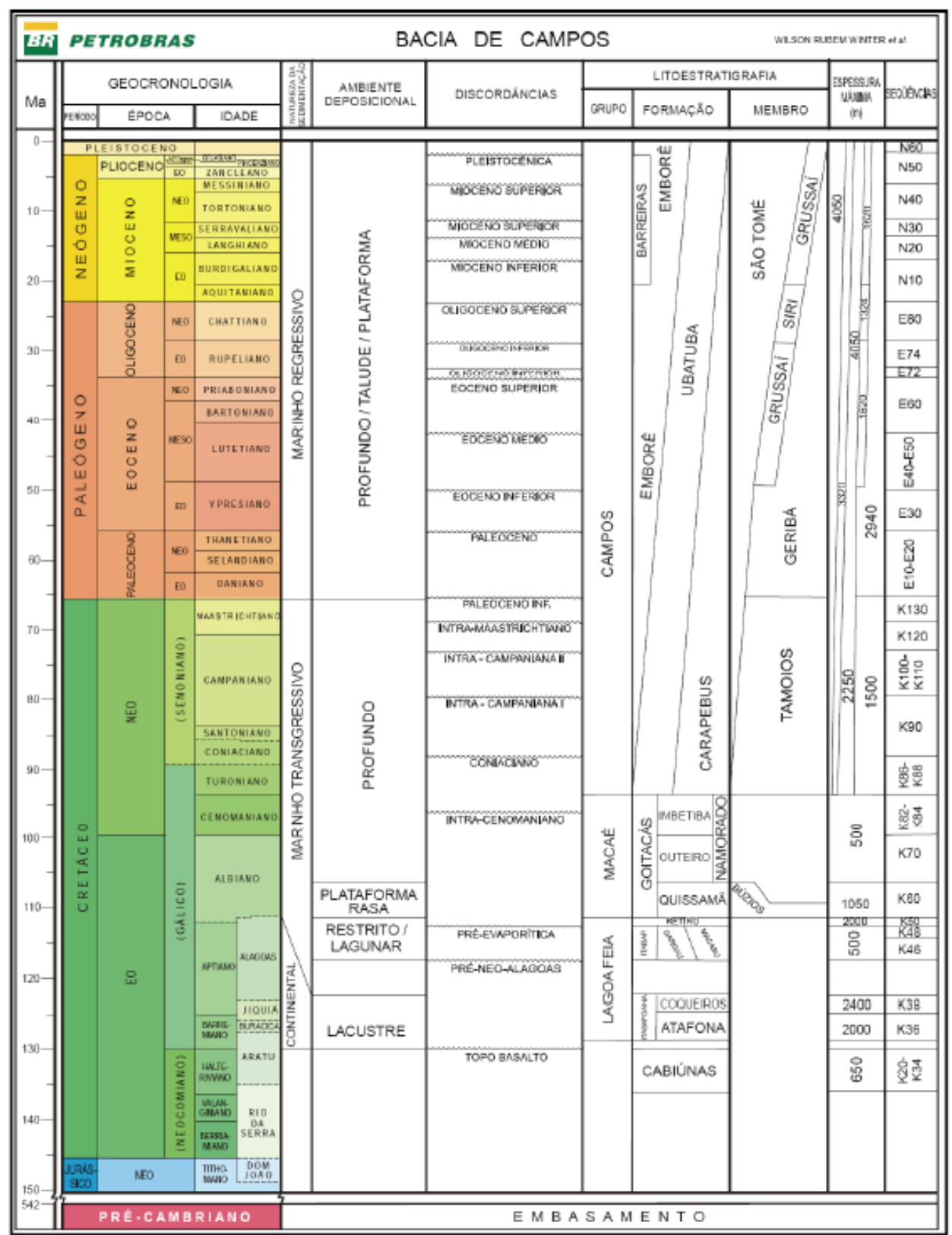

Figura 2.8 - Carta estratigráfica da Bacia de Campos (Fonte: Winter et al.,2007)

Assim como as demais bacias da margem Leste que contêm sequências de evaporitos, caracteriza-se por apresentar estilos tectônicos bem distintos: uma tectônica diastrófica, que afeta os sedimentos da Fase Rifte, e uma tectônica adiastrófica, relacionada à halocinese, que atua os sedimentos da Fase Transicional 
e Drifte. Segundo Winter et al., (2007), uma importante discordância, conhecida como "pré-neo-Alagoas", de idade aptiana, separa esses padrões tectônicos.

O padrão tectônico desta fase Pós-Rifte é caracterizado principalmente por falhas relacionadas ao fluxo de sal, de geometrias lístricas, com anticlinais e calhas associadas, domos e diáprios de sal e estruturas geneticamente relacionadas. Algumas reativações de falhas do embasamento também afetam os sedimentos das fases transicional e drifte. A Figura 2.9 mostra a seção geológica esquemática regional da Bacia de Campos.

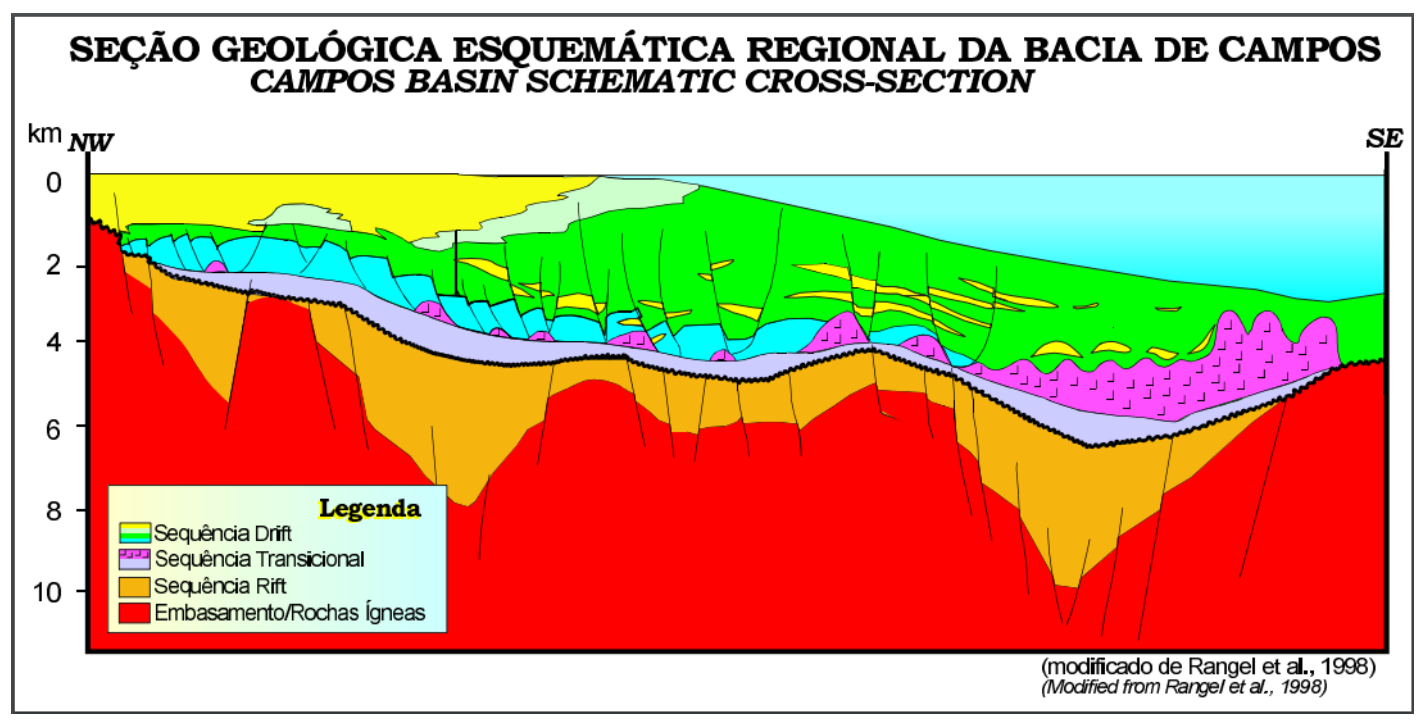

Figura 2.9 - Seção geológica esquemática regional da Bacia de Campos (Fonte: site da ANP, Jul 2016)

Winter et al. (2007) subdividiu a Supersequência Rifte, em três sequências deposicionais denominadas K30-K34 (Formação Cabiúnas), K36 (Formação Itabapoana e Formação Atafona) e K38 (Formação Itapoana e Formação Coqueiros).

A Formação Cabiúnas é composta por basaltos depositados nos andares Rio Serra e Aratu inferior, que cobrem descoordenadamente o embasamento précambriano.

A sequência K36 é constituída pelas Formações Itabapoana e Atafona, depositadas no Andar Barremiano. A Formação Itabapoana é composta por conglomerados, arenitos siltitos e folhelhos avermelhados proximais de borda de bacia e de borda de falha. A Formação Atafona é representa por arenitos, siltitos e folhelhos depositados em ambiente quimicamente alcalino (Winter et al., 2007). 
A Formação Coqueiros (K38) é composta por intercalações de camadas de folhelhos e carbonatos lacustres, compostos, predominantemente, por moluscos bivalves. Esses depósitos são denominados de coquinas e foram depositados em ambiente de alta energia (Winter et al., 2007).

Winter et al., (2007) definiu que a Supersequência Pós-Rifte é representada pelas Formações Itabapoana (conglomerados da parte superior), Gargaú, Macabi e Retiro, sendo todas pertencentes ao Grupo Lagoa Feia.

O Pós-rifte é caracterizado por um paleoambiente transicional, sendo representado por uma espessa seção de clásticos, que passam lateralmente para uma sedimentação carbonática, nas porções mais distais da bacia, sendo coberta por um pacote de depósitos evaporíticos (Formação Retiro) no final do Aptiano (Winter et al., 2007).

A Formação Guaruja é composta por folhelhos, siltitos e margas, intercalada por arenitos e calcilutitos, que gradam distalmente para os cálcarios da Formação Macabu. Ela está representada por calcários (estromatólitos e laminitos microbiais) depositados em paleoambiente subaquoso árido.

O topo desta Supersequência pós-rifte é definido pelos evaporitos da Formação Retiro, que foram depositados em paleoambiente marinho, tectonicamente calmo e com clima árido a semi-árido (Winter et al., 2007).

De acordo com Papaterra (2010), a supersequência drifte compreende os sedimentos marinhos depositados sob um regime de subsidência térmica associada a tectonismo adiastrófico.

O sistema petrolífero da Bacia de Campos (Papaterra, 2010), restrito à configuração subsal (intervalo do pré-sal), tem como rochas geradoras os folhelhos negros ricos em matéria orgânica, intercalados com as coquinas, depositados em ambiente lacustre (formações Atafona e Coqueiros) e, como rochas reservatórios, as coquinas da Formação Coqueiros e os estromatólitos da Formação Macabu. A Formação Retiro é composta por uma extensa sucessão evaporítica e funciona como um selante quase perfeito para este sistema petrolífero. 


\section{3}

\section{Modelo geomecânico de Estabilidade de poços}

A indústria do petróleo tem encontrado grandes desafios econômicos e técnicos para a exploração e extração de hidrocarbonetos, em função de cenários geológicos complexos, necessidade de perfurar em águas profundas, perfurar rochas de diferentes resistências mecânicas, heterogêneas vertical e horizontalmente, reativas quimicamente e com a presença de fraturas e falhas condutivas hidraulicamente, e, além disso, desenvolver poços direcionais e/ou horizontais para atingir os novos objetivos. Por isso, é extremamente importante dispor-se de uma estratégia para evitar ou minimizar potenciais problemas geomecânicos durante as fases de desenvolvimento e exploração de um campo petrolífero. Nesta estratégia, a análise geomecânica assume um papel significativo na prevenção de riscos associados às operações de perfuração dos poços (Gonçalves, 2015).

Os problemas de instabilidade são uma das situações com que a indústria petrolífera não raras vezes se depara. Estima-se que os custos associados à instabilidade de poços representem cerca de 5 a $10 \%$ dos custos de perfuração nas fases de exploração e produção, implicando, a nível mundial, custos de centenas de milhões de dólares por ano (Fjaer et al., 2008). Em casos severos, o aparecimento de eventos não previstos pode acarretar até mesmo na perda total do poço, com o abandono da locação e imensos prejuízos associados. De acordo com Welling (2009), cerca de $35 \%$ do tempo perdido durante a perfuração (NPT) se deve a problemas geomecânicos.

A elaboração de uma análise de estabilidade de poço de petróleo é considerada uma etapa crítica para o desenvolvimento de um projeto de sucesso, pois minimiza os riscos operacionais viabilizando a construção de poços nesses cenários cada vez mais complexos. A necessidade de projetos de poços com trajetórias e geometrias especiais e em regiões exploratórias carentes de informações básicas para o projeto de estabilidade são ingredientes que demonstram a atual complexidade do estudo. Muito são os dados requeridos para que essas análises sejam concluídas e a obtenção desses parâmetros, além de bastante onerosa, é em alguns casos, extremamente difícil (Azevedo, 2011). 
O objetivo da análise de estabilidade é o estabelecimento das condições de integridade do poço e a prevenção da perda de fluidos, tendo como resultado a definição do intervalo de densidade da lama que assegure uma perfuração estável, ou seja, a pressão mínima permitida no poço, para evitar o colapso ou influxo de fluidos, e a pressão máxima permitida, para evitar a perda de fluidos para a formação através das fraturas induzidas ou pré-existentes (Gonçalves, 2015). A geomecânica do petróleo parte da necessidade de se conhecer as pressões de colapso, que se trata de um parâmetro no qual as tensões, pressões e resistência das rochas são necessárias para a sua avaliação.

\subsection{1}

\section{Fatores que influenciam a estabilidade de poço}

As operações de perfuração, produção e injeção afetam o equilíbrio inicial existente nas formações rochosas, alterando as condições mecânicas da rocha e o estado de tensão original, com redistribuição das tensões ao redor do poço (Gonçalves, 2015). Os muitos fatores que afetam a estabilidade dos poços foram apresentados por Rocha, et al., 2007, são eles:

\section{Peso de fluido de perfuração}

O peso de fluido de perfuração é um dos fatores mais comuns que afetam a estabilidade do poço já que tem como uma das funções provocar uma tensão confinante que proporciona um aumento da resistência aparente da rocha. Quanto maior o peso do fluido, maior a tensão radial e menor a tensão tangencial compressiva. Porém, caso o aumento seja muito elevado, a tensão tangencial deixará de ser compressiva e passará a ser trativa, podendo levar à fratura da formação. Daí a necessidade de se otimizar o peso de fluido que será utilizado durante a perfuração para combater a instabilidade através de uma janela operacional bem definida.

\section{$>$ Lâmina d'água}

A lâmina d'água tem influência direta no gradiente de sobrecarga, então para o cenário de lâmina d'água profunda observa-se uma redução do gradiente de fratura. Quanto maior a lâmina d'água, menor o gradiente de sobrecarga para uma 
mesma profundidade e menor será o gradiente de fratura. Nessas condições, observa-se que à medida que a lâmina d'águia aumenta, a janela operacional, formada pela pressão de poros, gradiente de colapso e gradiente de fratura, tende a reduzir mais. Por isso, um dos maiores desafios da perfuração em lâmina d'água profunda e ultra profunda é a estreita margem operacional devido a um gradiente de fratura reduzido, dificultando a manutenção da estabilidade de poço.

\section{Resistência da Rocha}

A resistência da rocha está intimamente ligada aos seus parâmetros de resistência à compressão, coesão e coeficiente de atrito e de resistência à tração. Estes parâmetros são governados pela mineralogia, propriedades físico-químicas e pelo empacotamento dos grãos, os quais são função do intemperismo e dos processos físico-químicos envolvidos na formação da rocha. Quanto maior a resistência da rocha, maiores tensões ela suportará, porém, como são heterogêneas, as falhas ocorrerão em seus intervalos de menor resistência.

\section{Variações de temperatura}

Sabe-se que durante a perfuração a temperatura aumenta através do gradiente geotérmico normal médio em torno de 25 a $30^{\circ} \mathrm{C} / \mathrm{km}\left(1,37\right.$ a $\left.1,65^{\circ} \mathrm{F} / 100 \mathrm{ft}\right)$ conforme a profundidade aumenta, mas à medida que o fluido de perfuração circula no poço ocorre alteração na temperatura das formações expostas. As variações de temperatura podem afetar a estabilidade do poço e são mais pronunciadas quando a circulação é iniciada após um longo período sem circulação.

$\mathrm{O}$ aumento de temperatura das formações expostas influencia a estabilidade de poço de muitos modos: leva à redução na densidade do fluido de perfuração (o que reduz a tensão radial e, consequentemente, aumenta a tensão compressiva tangencial); ocasiona um aumento da pressão de poros (há uma redução das tensões efetivas radias e tangenciais e também no diferencial de pressão entre o poço e formação, o que pode acarretar em falhas da rocha); e o aumento da pressão de poros, que separa os grãos em função da força exercida sobre eles (isso provoca a redução da fricção entre os grãos e, consequentemente, a resistência da rocha).

A queda da temperatura traz efeitos opostos aos citados anteriormente. O fluido presente nos poros das rochas sofrerá contração mais rápida que a matriz da rocha, ocasionando o aumento, tanto da tensão efetiva quanto do diferencial de 
pressão, entre o poço e formação. Isso torna a rocha mais resistente, mas também leva ao aumento da densidade do fluido dentro do poço, podendo acarretar uma falha por tração.

Regime de tensão in situ e Anisotropia de tensão

O regime de tensão in situ é o resultado do soterramento e das forças tectônicas sobre a crosta terrestre e o desconhecimento desse regime durante a perfuração é preocupante, visto que os regimes de tensões são um dos responsáveis por ocasionar diferenças entre as tensões horizontais in situ $\sigma_{\mathrm{H}}$ e $\sigma_{\mathrm{h}}$. Esta diferença é chamada de anisotropia de tensão e quanto maior a diferença entre as tensões horizontais, menor será a janela operacional para a definição do peso de fluido.

Para maximizar a estabilidade do poço, deve-se minimizar o efeito da anisotropia de tensão, através de uma melhor escolha da direção e inclinação da trajetória do poço.

Inclinação e orientação da trajetória do poço

Problemas de estabilidade podem ser apresentados tanto em poços verticais quanto em poços direcionais. Considerando o estado de tensão normal, em que a tensão vertical é maior do que as horizontais, poços direcionais apresentarão maiores problemas de estabilidade, já que a distribuição de tensões tende a ser menos favorável.

Caso o regime de tensão seja transcorrente ou reverso, a situação pode ser o oposto, em que o aumento do desvio do poço é favorável à sua perfuração com menor peso de fluido.

\section{Vibração da coluna de perfuração}

A vibração da coluna de perfuração também pode contribuir mais para a instabilidade do poço. Os três tipos de esforços que aparecem devido à vibração da coluna são: axial, lateral e torsional. Eles geram uma grande variação nas tensões radial, tangencial e axial, causando fadiga da parede do poço e, em casos extremos, podem exceder o pico de resistência da rocha em apenas um ciclo. 


\subsection{2}

\section{Parâmetros necessários para a elaboração do modelo}

A análise de estabilidade de poço visa assegurar as condições de segurança e eficiência da perfuração e, consequentemente, a redução de custos operacionais não planejados e tempos não produtivos (NPT). A Figura 2.10 descreve as informações e os parâmetros necessários para a construção de um modelo geomecânico de estabilidade de poço, assim como indica os dados necessários para a obtenção da estimativa de cada parâmetro.

\section{Análise do Histórico dos Poços de Correlação}

Tensão Vertical (Sv)

Perfil densidade / acústico
Previsão de Pressão de Poros Medições de pressão

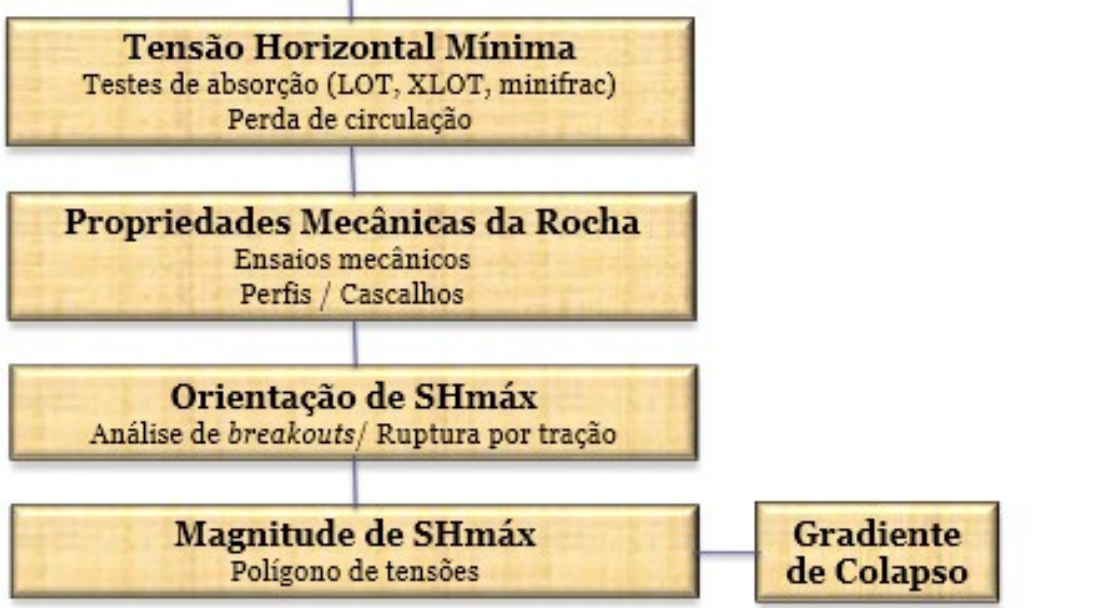

Figura 2.10 - Parâmetros considerados em uma análise de estabilidade de poços

A análise geomecânica une diversos tipos de dados a fim de que o modelo seja consistente com os eventos ocorridos, por isso a importância de se avaliar os relatórios diários de perfuração com o intuito de identificar os problemas relacionados à geomecânica que ocorreram no poço, como: perda de circulação parcial e total, prisão de coluna/ ferramentas, alto torque, excesso de cascalhos, presença de gás de conexão e kick. A análise do histórico de perfuração gera informações crucias para o entendimento do mecanismo de ruptura e para a calibração do modelo de estabilidade de poços.

Para a estimativa da tensão vertical, pressão de poros e propriedades mecânica das rochas (Figura 2.10) são necessários os dados de perfis petrofísicos 
LWD ou Wireline para a utilização de correlações referente a cada parâmetro. Já para a estimativa das tensões horizontais são considerados testes de absorção, teste de absorção estendidos, provas de minifracs, faturamento hidráulicos ou relatos de perda de circulação para a estimativa da tensão horizontal mínima e dados de imagem e caliper orientado ( 4 ou 6 braços) para a estimativa da tensão horizontal máxima (Zoback, 2007).

Abaixo serão descritos os métodos utilizados na literatura para a estimativa desses parâmetros mencionados acima.

\section{Tensão vertical $(\mathrm{Sv})$}

A tensão vertical, também chamada de tensão de sobrecarga em um ponto em particular na crosta terrestre, é aquela exercida pelo peso de todas as camadas de rocha sobrepostas acima do determinado ponto. Esta componente $\left(\mathrm{S}_{\mathrm{v}}\right)$ é calculada a partir da integração, em profundidade, do perfil de densidade e corrigida de acordo com a lâmina de água e estrutura geológica, conforme a Equação 2.1.

$$
S_{v=} \rho_{w} g d_{w}+\int_{d w}^{Z} \rho g d z
$$

Onde $\rho_{w}$ é a contribuição da coluna de água e, segundo termo refere-se às camadas sobrepostas até a profundidade de interesse (Z). Onde $\boldsymbol{g}$ é aceleração da gravidade, $\boldsymbol{\rho}_{\boldsymbol{w}}$ é a densidade da água $\left(\mathrm{g} / \mathrm{cm}^{3}\right), \boldsymbol{d}_{\boldsymbol{w}}$ lâmina d'água $(\mathrm{m}), \boldsymbol{\rho}$ é a densidade da formação $\left(\mathrm{g} / \mathrm{cm}^{3}\right)$ e $\mathrm{z}$ a profundidade $(\mathrm{m})$.

A determinação do gradiente de sobrecarga irá depender apenas do conhecimento das densidades das formações, as quais são função das densidades dos grãos que as compõem, de suas porosidades e dos fluidos contidos em seus poros (Rocha et al., 2007). Normalmente nos trechos superficiais ou acima do reservatório, pouco ou nenhum dado é conhecido e, além disso, nos trechos onde há forte arrombamento do poço, a leitura da densidade pode ser afetada. Esta insuficiência de dados de qualidade, que podem ocorrer tanto na parte superficial rochosa do poço quanto em partes mais profundas, faz com que as densidades das formações tenham que ser estimadas/ arbitradas aumentando a incerteza do cálculo da pressão de sobrecarga. 
As correlações mais utilizadas para a estimativa da densidade da formação são as de Gardner (1974) (Equação 2.2) e Belotti e Giacca (1978) (Equações 2.3 e 2.4) que são baseadas em perfis acústicos (tempo de trânsito).

$$
\rho=A *\left(\frac{10^{6}}{\Delta t}\right)^{B}
$$

$\mathrm{Na}$ equação 2.2, considera-se $\boldsymbol{\rho}$ como a densidade e A e B são parâmetros empíricos de Gardner iguais a 0.24 e 0.25 , respectivamente.

$$
\begin{gathered}
\rho_{b}=\frac{3.28-\Delta t}{88.95}(\Delta t<100 \mu s / f t) \\
\rho_{b}=2.75-2.11\left(\frac{\Delta t-\Delta t_{m a}}{\Delta t+200}\right)(\Delta t>100 \mu s / f t)
\end{gathered}
$$

Nas Equações 2.3 e 2.4, $\rho_{b}$ é a densidade total da formação $\left(\mathrm{g} / \mathrm{cm}^{3}\right), \Delta \mathrm{t}$ é o tempo de trânsito da formação ( $\mu \mathrm{s} / \mathrm{ft})$ e $\Delta \mathrm{t}_{\mathrm{ma}}$ é o tempo de trânsito da matriz ( $\mu \mathrm{s} / \mathrm{ft}$ ).

\section{Estimativa de pressão de poros}

O conhecimento da pressão de poros é essencial para a segurança da perfuração e a eficiência dos modelos de reservatório. Uma estimativa mais precisa da pressão de poros permite uma seleção mais eficiente da profundidade dos revestimentos e um programa de peso de fluido mais confiável. Os métodos mais comuns de estimativa de pressão de poros são baseados na diferença entre o "trend normal" no perfil acústico, resistividade, expoente $d$ ou densidade e o valor observado desses parâmetros em zonas com pressão anormalmente alta. A maioria dessas técnicas é baseada no comportamento dos folhelhos, no qual tipicamente exibe uma forte relação entre porosidade e pressão de poros (Atashbari e Tingay, 2012).

O princípio básico no qual fundamentam-se as metodologias de pressão de poros é a Teoria da Tensão Efetiva de Terzaghi (1943) em que ele afirmou que a compactação dos solos é controlada pela diferença entre a tensão total (pressão de sobrecarga) e a pressão de poros (Equação 2.5). Esta diferença, chamada de tensão 
efetiva, é a tensão suportada pelos grãos da rocha. Na Equação 2.5 temos que $\mathrm{P}_{\mathrm{p}}$ é a Pressão de poros; $\sigma_{v}$ é a Tensão vertical e $\sigma_{e f f}$ é a Tensão efetiva (matriz).

$$
P_{p}=\sigma_{v}-\sigma_{e f f}
$$

Abaixo, uma breve descrição das metodologias mais comuns utilizadas:

- Método da Profundidade Equivalente: Esse método parte do princípio que formações com pressão normal ou sobrepressão seguem uma mesma relação de compactação como função da tensão efetiva. Em outras palavras, assume-se que formações com sobrepressão e formações com pressão normal, que possuam porosidades idênticas, tenham tensões efetivas idênticas em profundidades distintas. Basicamente essa é a regra da tensão efetiva reescrita para uma abordagem de linha de tendência baseada em profundidade e, portanto, pode ser aplicada no cálculo de sobrepressões geradas por subcompactação em folhelhos.

- Método de Eaton: O método Resistividade de Eaton considera que a salinidade do fluido presente no folhelho seja constante e, portanto, qualquer mudança na resistividade seja oriunda de uma variação da porosidade do folhelho e por conseguinte do seu estado de compactação. Esse método utiliza a variação da resistividade que difere da leitura esperada para uma formação com compactação normal para inferir a pressão de poros fazendo uma relação com os valores de resistividades da linha de tendência de compactação normal extrapolados para as mesmas profundidades. O método Sônico de Eaton utiliza uma abordagem similar da resistividade e na fórmula é aplicado um valor de expoente definido para cada região (Eaton, 1975).

É importante levar em conta que a estimativa de pressão de poros utilizando o método de compactação normal somente pode ser aplicada em rochas sedimentares argilosas que não experimentaram nenhum levantamento ou deformação tectônica de primeira ordem. Os processos de levantamento tectônico são mecanismos típicos de geração de pressão de poros anormalmente alta. Além disso, podem gerar uma porosidade secundária dentro das rochas resultando em uma interpretação superestimada da pressão de poros da rocha. 
A maioria das estimativas de pressão de poros está baseada na hipótese de que houve compactação ou subcompacação de formações impermeáveis, como os folhelhos, e de que esta pressão de poros está relacionada com propriedades da rocha como porosidade, densidade, velocidade acústica e resistividade (Pereira, 2007; Bowers, 1995). Entretanto, as rochas carbonáticas são mais rígidas e podem apresentar pressões anormalmente altas sem nenhuma influência associada à porosidade. Na verdade, a aplicação de métodos comuns de estimativa de pressão de poros para rochas carbonáticas pode originar erros grandes e potencialmente perigosos, indicando pressão de poros normal ou subestimar a magnitude de valores de pressão de poros em zonas com pressão de poros em excesso (Atashbari e Tingay (2012)).

A complexidade dos carbonatos dificulta a estimativa de pressão de poros, por isso, os eventos de perfuração como influxos, ganhos, kicks e gás de conexão são essenciais quando a perfuração ocorre em rochas desse tipo.

\section{Tensão horizontal mínima}

Para estimativas iniciais do estado de tensão in-situ horizontal deve-se levar em conta uma relação existente entre a tensão de sobrecarga e as tensões horizontais. A sobrecarga litostática gera uma deformação axial na rocha e, a depender das condições de contorno laterais, irá fornecer também uma deformação horizontal, que é função do coeficiente de Poisson (v).

Considerando o modelo poroelástico linear e aplicando-se a lei de Hooke generalizada para o caso de deformação lateral nula, obtém-se a Equação 2.6.

$$
\sigma_{\text {hmin }}=\sigma_{\text {Hmax }}=\left(\frac{v}{1-v}\right) \sigma_{v}
$$

Da equação 2.6, temos que $\sigma_{\mathrm{h}}$ é a tensão principal efetiva horizontal menor, $\sigma_{H}$ é a tensão principal efetiva horizontal maior, $\sigma_{\mathrm{v}}$ é a tensão principal efetiva vertical e $v$ é o coeficiente de Poisson.

Também é possível utilizar o fraturamento hidráulico no processo de modelagem das tensões in situ. O modelo consiste no aumento da pressão de fluido no interior do poço por intermédio do bombeamento, cuja finalidade principal é 
abrir fraturas, conectando outras já existentes ou aumentando a porosidade efetiva da rocha, permitindo maior produção de petróleo.

Hubbert e Willis (1957) mostraram que uma fratura induzida em um poço vertical irá sempre se propagar perpendicularmente à direção da tensão horizontal mínima, mesmo em regiões com fraturas pré-existentes. Isto se deve ao fato de que esta configuração requer menos energia para o processo de propagação da fratura, razão pela qual permite o uso do fraturamento hidráulico para medições da tensão horizontal mínima.

A Figura 2.11 demonstra o ciclo do comportamento da pressão com o bombeio de fluido no processo de fraturamento hidráulico. O fraturamento ocorre com bombeamento de fluido a vazão constante e consequentemente incremento de pressão linear com o tempo (para um volume de poço fixo). No momento em que ocorre a não linearidade neste acréscimo de pressão contra o tempo, determina-se o ponto conhecido como LOT (Leak off Test). Neste ponto ocorre a inicialização do fraturamento hidráulico com pequena perda de fluido para a formação. A partir desse momento, o acréscimo de pressão devido ao incremento do volume (bombeamento de fluido) ocorre de forma menos gradual até se atingir o ponto de quebra da formação, FBP (Formation Breakdown Pressure). Esse ponto é caracterizado pela propagação instável da fratura, onde o fluido proviniente do poço flui para dentro da fratura de forma mais rápida que a bomba pode suprir, ocorrendo uma queda do nível estático e uma redução na pressão em frente à fratura. Neste nível de pressão mais baixo e com a continuidade do bombeamento de forma constante chega-se à "pressão de propagação da fratura", que é a pressão necessária para que ocorra a extensão da fratura para longe do poço. 


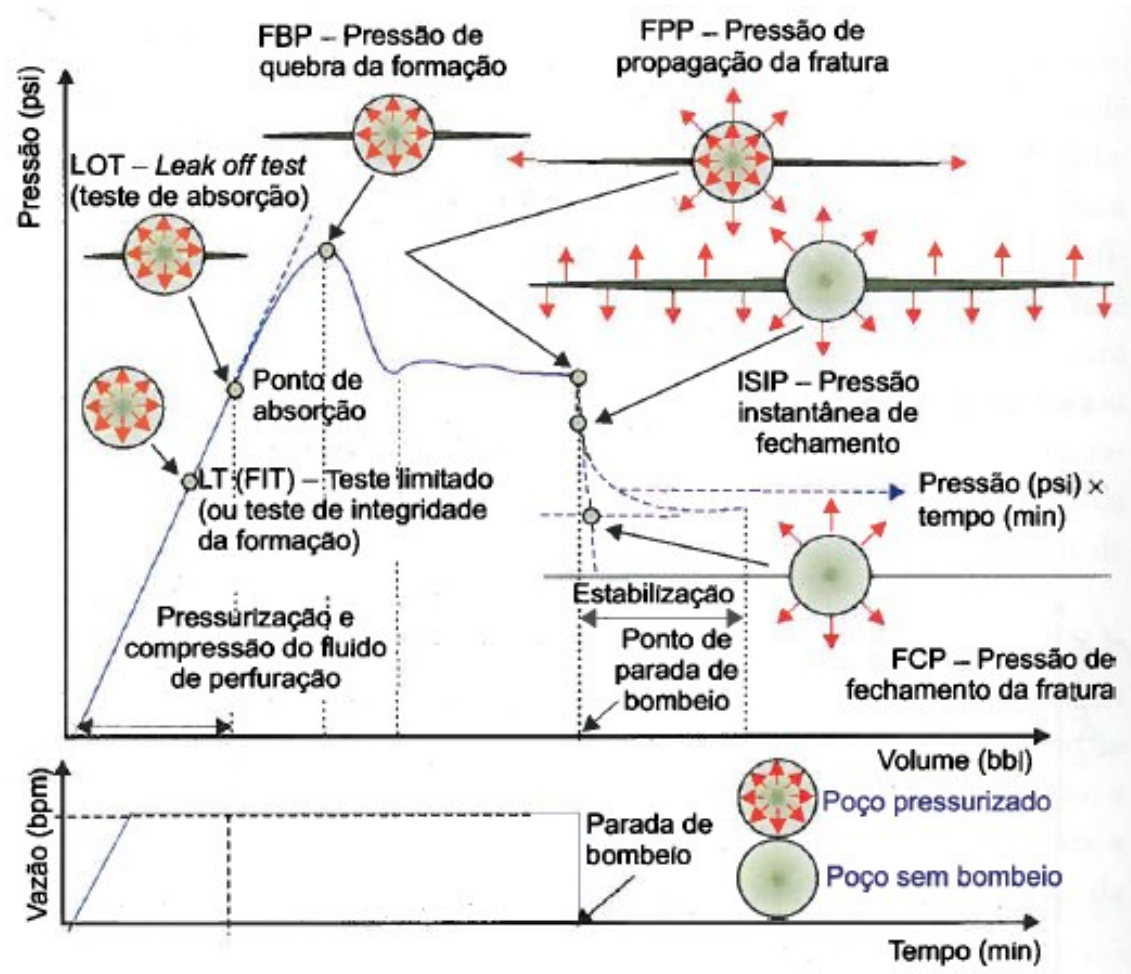

Figura 2.11 - Comportamento da pressão durante o teste de absorção estendido (Petrobras)

(Rocha, 2007)

Logo após a interrupção do bombeio, mas ainda com as válvulas fechadas, determina-se a "pressão de fechamento instantâneo", ISIP (Instantaneous Shut-In Pressure). O decaimento da pressão continua sendo medido para se observar a "pressão de fechamento da fratura", FCP (Fracture Closure Pressure).

Quando a menor tensão in situ se situa na direção vertical e as fraturas são formadas entre os Packers (borracha de vedação) ocorre a geração de fraturas vertical na parede do poço (Haimson e Fairhurst, 1970) e posteriormente, com a propagação dessa fratura, ela irá girar para um plano horizontal e se propagará perpendicular à tensão de menor magnitude, conforme pode ser observado na Figura 2.12 (Zoback e Pollard, 1978). 


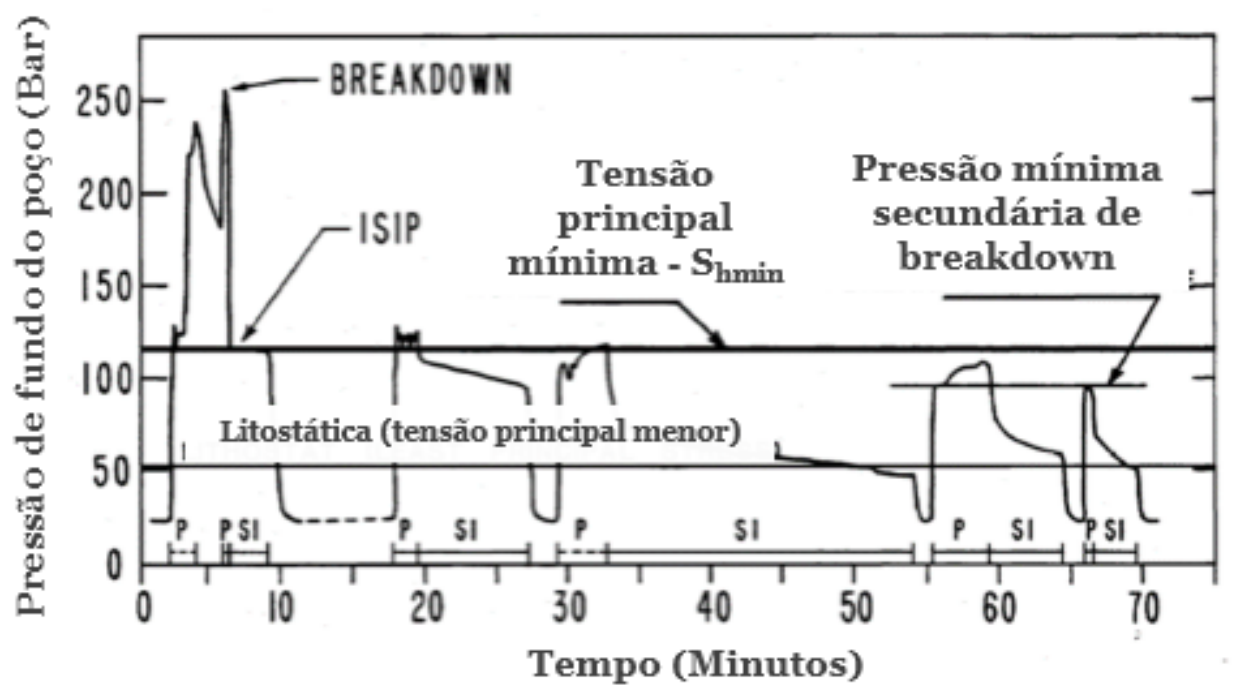

Figura 2.12 - Carta de fraturamento hidráulico em San Ado, Califórnia (Zoback e Pollard, 1978)

A pressão de propagação da fratura é uma aproximação do valor da tensão horizontal mínima (Hamimson e Faihurst, 1967), porém valores ainda mais realísticos podem ser obtidos após a pressão instantânea de fechamento (ISIP), uma vez que no momento em que se cessa a bomba, toda pressão associada à perda de carga é eliminada (Aadnoy e Chenevert, 1987). Com o desligamento da bomba, deve-se identificar a pressão na qual ocorre o fechamento total da fratura, denominado de pressão de fechamento (closure pressure). Essa é a melhor estimativa para a tensão horizontal mínima. A pressão de fechamento pode se apresentar com valores acima da tensão horizontal mínima, dependendo de fatores como: viscosidade do fluido, vazão de bombeio e extensão do leak-off para a formação. Sendo assim, seu valor representa um limite superior da tensão horizontal mínima. A Figura 2.13 ilustra as três pressões ao longo do tempo. 


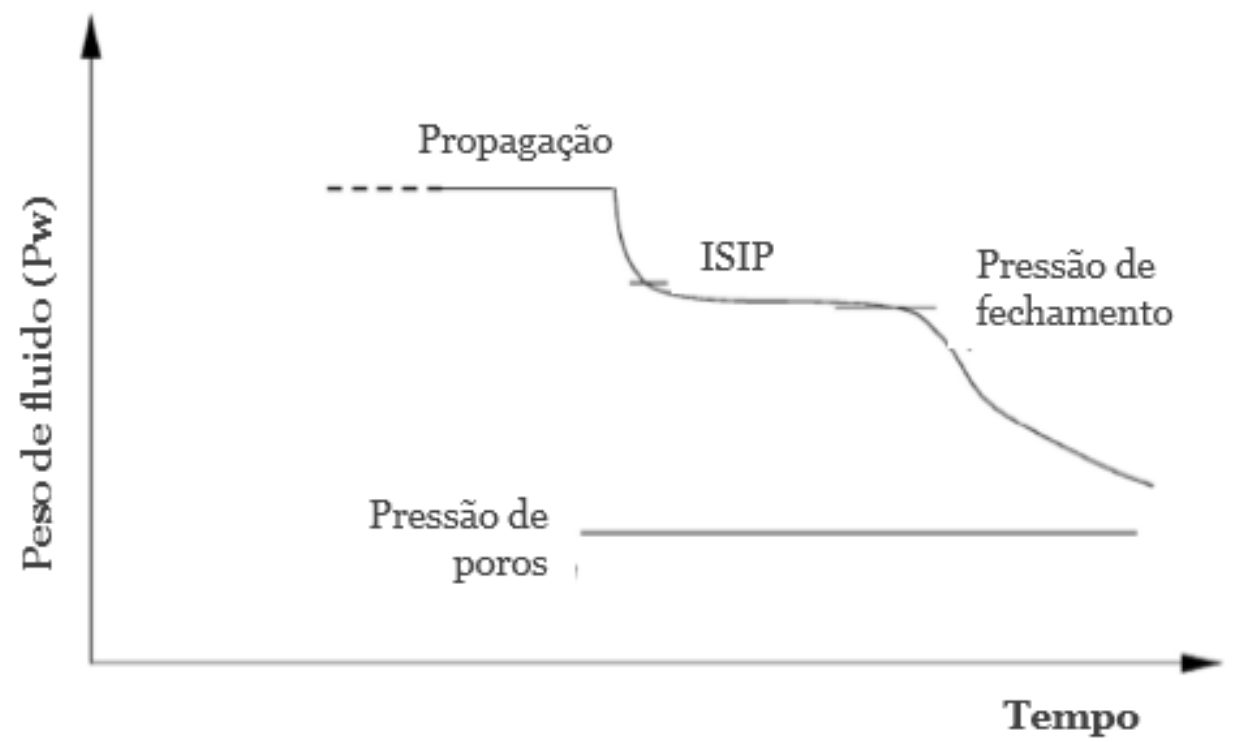

Figura 2.13 - Variação da pressão ao longo do tempo em um fraturamento hidráulico, desde a pressão de propagação até a pressão de fechamento.

A identificação acurada da pressão de fechamento pode não ser fácil uma vez que o processo ocorre de forma gradual e não instantâneo. Para auxiliar no processo de identificação dessa pressão, diversos métodos gráficos foram propostos dentre eles a raiz quadrada do tempo, pressão em log x tempo em log, etc. Um exemplo da queda de pressão plotada pela raiz quadrada do tempo é apresentado na Figura 2.14.

A curva de decaimento de pressão apresenta uma tendência, até o momento do seu fechamento, que pode ser aproximada por um trend, ocorrendo um desvio em relação a esse no momento do fechamento da fratura (pressão de fechamento).

Quando não se tem dados de fraturamento para a estimativa da tensão horizontal mínima, costuma-se considerar os dados de Leak-off Tests (LOTs). Nesse caso, deve-se procurar trabalhar com o maior número de dados possíveis de LOTs, sendo a aproximação do valor da tensão horizontal mínima representada pelo limite inferior desta população (Fjaer, 2008). 


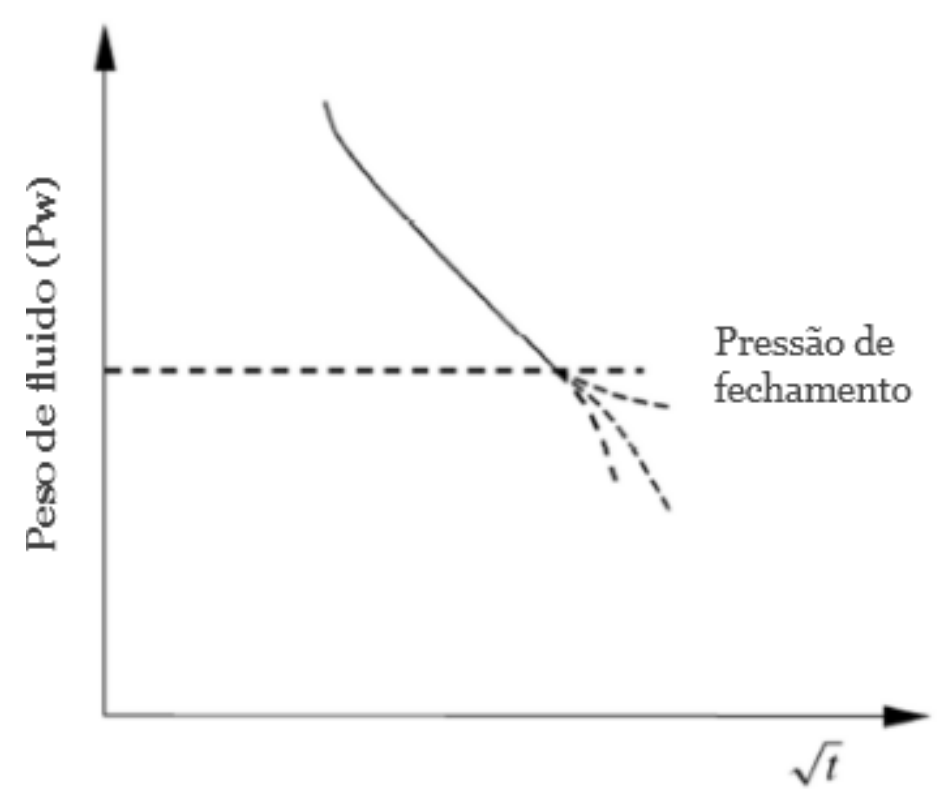

Figura 2.14 - Identificação do fechamento pelo método gráfico da raiz quadrada do tempo

O teste de leak-off é realizado durante a perfuração na formação abaixo da sapata com o objetivo de identificar a pressão máxima a qual a fase seguinte suportará, sem que ocorra o fraturamento ou perda de fluido para a formação.

Da mesma forma que no fraturamento hidráulico, o processo se dá pela injeção de certo volume de fluido a uma taxa constante (50-250 1/min) de modo a provocar o acréscimo de pressão dentro do poço (ver Figura 2.11).

O acompanhamento é realizado através de um gráfico de (pressão x volume injetado) de forma a possibilitar o monitoramento do incremento de pressão com o tempo. Essa variação se apresenta linear até o momento do início de perda do fluido para a formação. Nesse instante é verificada uma mudança no padrão do incremento de pressão e, consequentemente, a sua não linearidade, o que permite obter o ponto de Leak-off, encerrando-se o teste.

A leitura no gráfico do exato ponto onde ocorre o início da perda de pressão Leak-off está sujeito à interpretação do operador, uma vez que a perda de pressão pode ocorrer de forma sutil. Aspectos operacionais como desempenho do equipamento, taxa de bombeio, existência de canais na cimentação etc, são responsáveis por uma variação na forma do gráfico, dificultando a padronização da leitura do Leak-off.

No teste de Leak-off estendido, o bombeamento de fluido não cessa após a determinação do Leak-off point, levando-se a pressão à valores que ultrapassam o 
ponto de quebra da formação. Em um processo ideal para a determinação da tensão horizontal mínima, o bombeamento deveria continuar até a propagação estável da fratura.

Propriedades Mecânicas da rocha

A análise da mecânica das rochas é parte extremamente importante para as operações de perfuração estáveis e seguras. Como parte dessa análise, é necessário o conhecimento das tensões, pressões e a determinação dos parâmetros relacionados à resistência da rocha, para que possam ser estudadas as situações nas quais ocorrerá colapso ou fratura da formação (Zoback, 2007 e Azevedo, 2011). A estimativa equivocada da resistência da rocha pode resultar em erros do peso de fluido a ser selecionado para uma operação de perfuração segura e, consequentemente, em um aumento de custo total do poço. Portanto, a resistência da rocha é diretamente influenciada por diversos parâmetros, tais como a mineralogia, textura, porosidade, cimentação, tamanho dos grãos, entre outras.

Estudos realizados em diferentes tipos de rocha mostram correlações entre as propriedades mecânicas da rocha e suas características petrográficas com o objetivo de se desenvolver uma metodologia alternativa para substituir e/ou complementar os testes mecânicos de rocha laboratório.

Brace (1961 e 1964) mostrou pioneiramente que a resistência à compressão de carbonatos dolomitas é inversamente proporcional ao tamanho dos grãos. Hugman e Friedman (1979) descobriram uma clara correlação entre a resistência à compressão, o tamanho dos grãos e o teor de carbonato microcristalino (micrita) de uma rocha carbonática de baixa porosidade com diferentes conteúdos de dolomita. No mesmo ano, Fahy e Guccione (1979) mostraram que a resistência de arenitos calcários pode ser estimada através de propriedades petrográficas observadas em seções delgadas tais como tamanho de grãos, teor de quartzo e percentagem de contatos inter-grãos e grão a grão.

Howarth e Rowlands (1986) desenvolveram um conceito quantitativo adimensional da textura da rocha, descrevendo o formato e o grau de ligação entre os grãos, a orientação e a proporção relativa entre grãos e matriz (empacotamento de densidade). Eles correlacionaram esse índice com as propriedades mecânicas da rocha. Dois anos depois, Tokle et al. (1986) consideraram o formato, tamanho e a 
distribuição dos grãos como parâmetro de influência na resistência por atrito de arenitos, enquanto que a cimentação, superfície de contato e o fluido do poro contribuíram para a coesão.

Chang et al. (2006) mostram que as correlações entre tempo de trânsito, porosidade e módulo de Young estimadas através de perfis geofísicos de poços (velocidade compressional, cisalhante e densidade) publicadas e não publicadas podem ser muito úteis para a indústria do petróleo, principalmente quando diversos problemas geomecânicos (instabilidade de poço, produção de areia, influência do fraturamento hidráulico etc.) são analisados sem o conhecimento e a determinação direta da resistência à compressão uniaxial (UCS). As correlações empíricas podem representar adequadamente alguns tipos de rochas reservatórios, entretanto, elas precisam ser avaliadas e calibradas para o emprego em poços de reservatórios específicos.

Os mesmos autores realizaram uma análise comparativa de diferentes correlações entre UCS e intervalo de tempo de trânsito (Figura 2.11a), módulo de Young (Figura 2.11b) e porosidade (Figura 2.11c), obtidas de ensaios de laboratório em amostras de arenito, folhelho e carbonato.

A resistência à compressão uniaxial da rocha $\mathrm{e}$ as propriedades correlacionadas nas Figuras 2.15a, 2.15b e c a 2.15c foram selecionados de Lama e Vutukuri (1978), Carmichael (1982), Kwasniewski (1989), Jizba (1991), Wong et al. (1997), Bradford et al. (1998). Lama e Vutukuri (1978) e Carmichael (1982) classificaram uma lista de várias propriedades das rochas sedimentares de diferentes regiões do mundo. Kwasniewski (1989) registrou dados de UCS e porosidade de vários arenitos. Jizba (1991) apresentou as propriedades mecânicas dos arenitos com ampla variação de porosidade, recuperados de diferentes profundidades num poço no Texas, EUA. Wong et al. (1997) elaboraram tabelas de resistência e de propriedades físicas de vários arenitos porosos representativos de reservatório. Bradford et al. (1998) reportaram os resultados de ensaios mecânicos realizados em laboratório do arenito do Mar do Norte. 

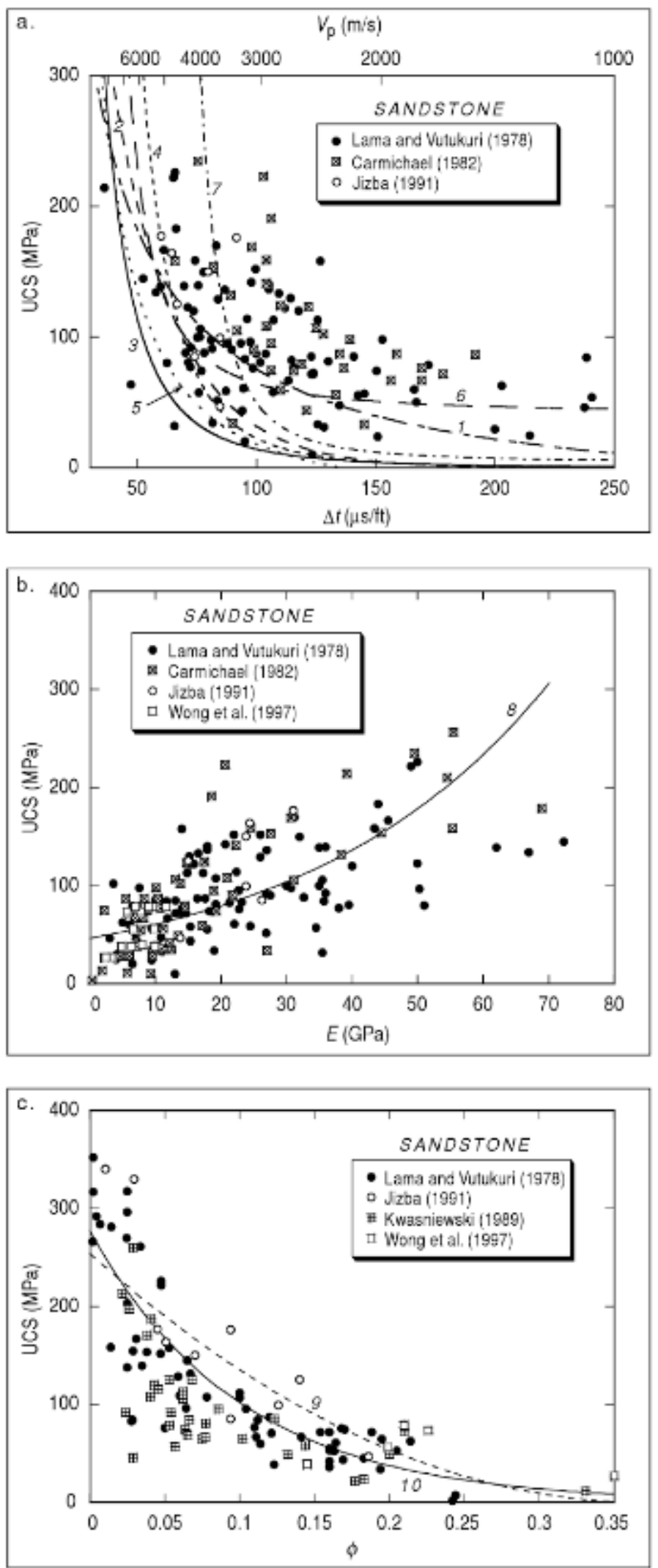

Figura 2.15 - Comparação entre diferentes correlações empíricas utilizadas para a estimativa de resistência uniaxial de arenitos com (a) intervalo de tempo de trânsito, (b) módulo de Young e (c) porosidade. (Depois do Chang, Zoback et al. (2006)) 

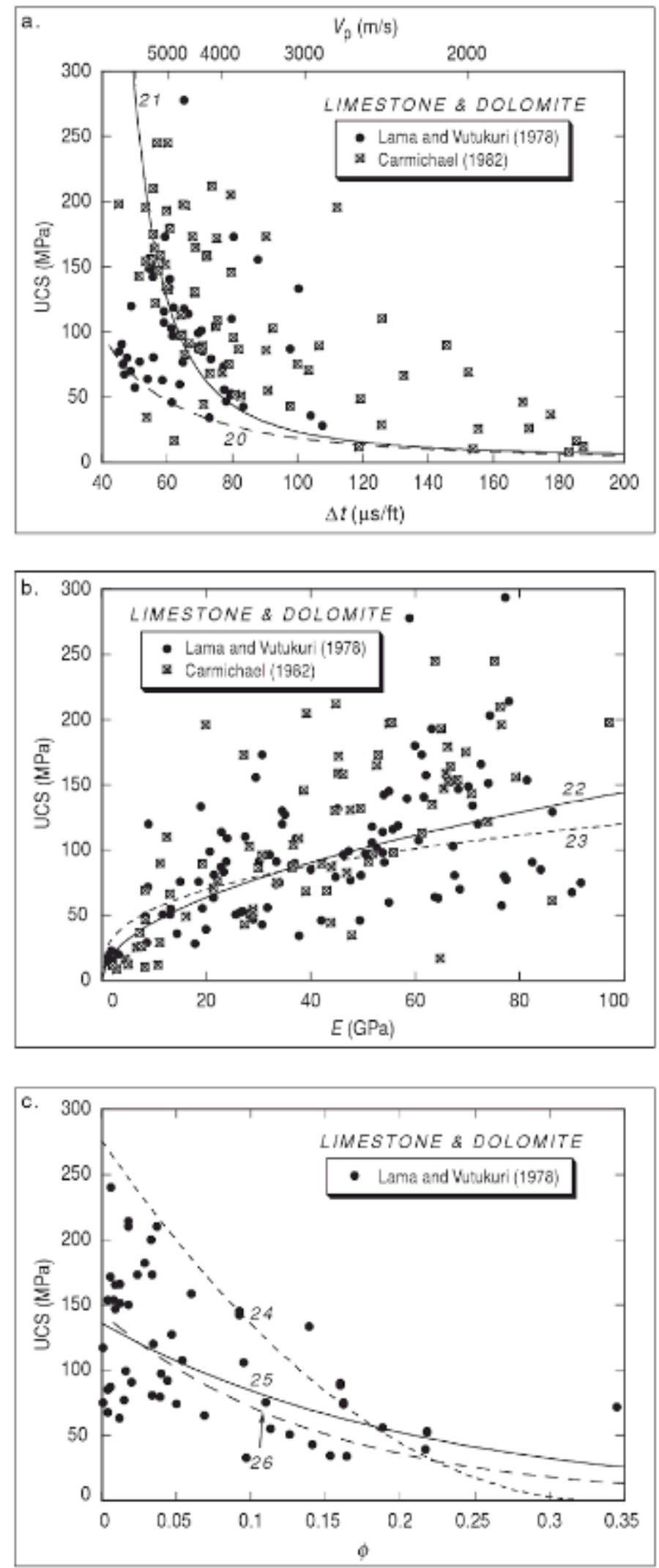

Figura 2.16 - Comparação entre diferentes correlações empíricas utilizadas para a estimativa de resistência uniaxial de carbonatos com (a) intervalo de tempo de trânsito, (b) módulo de Young e (c) porosidade. (Depois do Chang, Zoback et al. (2006)) 
Observa-se das Figuras 2.15a, 2.15b e c 2.15c (para arenitos) e 2.16a, 2.16b, 2.16c (para carbonatos e dolomita) que, apesar da considerável dispersão nos dados, há uma diminuição acentuada na resistência uniaxial com relação ao tempo de trânsito $(\Delta \mathrm{t})$ e porosidade $(\phi)$ e um aumento de resistência à compressão uniaxial em relação ao incremento do módulo de Young $(E)$.

As Figuras 2.15 e 2.16 também indicam que a resistência à compressão uniaxial é diretamente proporcional ao Módulo de Young $(E)$ e inversamente proporcional ao tempo de trânsito $(\Delta \mathrm{t})$ e porosidade $(\phi)$.

Muitos problemas geomecânicos relacionados com perfuração devem ser associados à falta de calibração de correlações acústicas em outras áreas onde as mesmas não foram desenvolvidas quando não existem testemunhos disponíveis para testes em laboratório.

Isto se deve aos altos custos e à parada na perfuração dos poços para coleta de amostras. Para resolver isso, numerosas correlações que relacionam resistência de rocha e parâmetros medidos com perfís geofísicos de poços têm sido propostas.

Quase todas as formulações propostas para a determinação da resistência da rocha através de dados de perfis geofísicos utilizam:

- Velocidade acústica da onda $\mathrm{P}\left(\mathrm{V}_{\mathrm{p}}\right)$, onda do tempo de trânsito compressional ao longo da parede do poço $\Delta \mathrm{t}\left(\Delta \mathrm{t}=\mathrm{V}_{\mathrm{p}}{ }^{-1}\right)$, expresso tipicamente como $\mu \mathrm{s} / \mathrm{ft}$;

- Módulo de Young, E (normalmente derivado de $\mathrm{V}_{\mathrm{p}}$ e dados de densidade);

- Porosidade, $\phi$ (ou dados de densidade).

Zoback (2010) mostra na Tabela 2.1 as relações empíricas relacionando resistência de rochas carbonáticas com parâmetros geofísicos. 
Tabela 2.1 - Relações empíricas para estimativa de resistência de carbonatos (Zoback, 2010)

\begin{tabular}{|c|c|c|}
\hline UCS, Mpa & Comentários gerais & Referência \\
\hline$(7682 / \Delta t)^{182 / 145}$ & - & Militzer (1973) \\
\hline $10^{(2,44+109,14 / \Delta t)} / 145$ & - & Golubev e Rabinovich (1976) \\
\hline $0,4067 \mathrm{E}^{0,51}$ & Carbonatos com $10<\mathrm{UCS}<300 \mathrm{Mpa}$ & Não publicado \\
\hline $2,4 \mathrm{E}^{0,34}$ & Dolomita com $60<\mathrm{UCS}<100 \mathrm{MPa}$ & Não publicado \\
\hline $\mathrm{C}(1-\mathrm{D} \phi)^{2}$ & $\begin{array}{l}\text { C é referência de resistência para zero de } \\
\text { porosidade }(250<\mathrm{C}<300 \mathrm{MPa}) \text {. D varia } \\
\text { entre } 2 \text { e } 5 \text { dependendo do tipo de poro }\end{array}$ & (Rzhevsky and Novick 1971) \\
\hline $143,8 \exp (-6,95 \phi)$ & $\begin{array}{l}\text { Porosidade de baixa a moderada }(0,05<\phi \\
<0,2) \text { e UCS alto }(3,0<\mathrm{UCS}< \\
150 \mathrm{MPa})\end{array}$ & Não publicado \\
\hline $135,9 \exp (-4,8 \phi)$ & $\begin{array}{l}\text { Representa porosidade baixa a moderada } \\
(0<\phi<0,2) \text { e alto UCS }(10<\mathrm{UCS}< \\
300 \mathrm{MPa})\end{array}$ & Não publicado \\
\hline
\end{tabular}

Direção das tensões horizontais

A identificação da orientação das tensões horizontais principais baseia-se na possibilidade da ocorrência de falha de compressão ou de tração na parede do poço.

Os breakouts são originados por falhas de compressão pelo uso de um fluido de perfuração insuficiente para manter as paredes do poço estáveis e ocorre na direção da tensão horizontal mínima ( $\left(\mathrm{Sh}_{\mathrm{min}}\right)$.

A fratura hidráulica (falha por tração) é originada ao se exceder o limite superior de pressão da formação. Essas são formadas na direção da tensão horizontal máxima para casos de poços verticais.

Para se determinar a direção das tensões horizontais são realizadas buscas nos perfis de imagem corridos nos poços da região, a fim de se identificar ocorrências de breakouts e fraturamentos hidráulicos (Figura 2.17). 


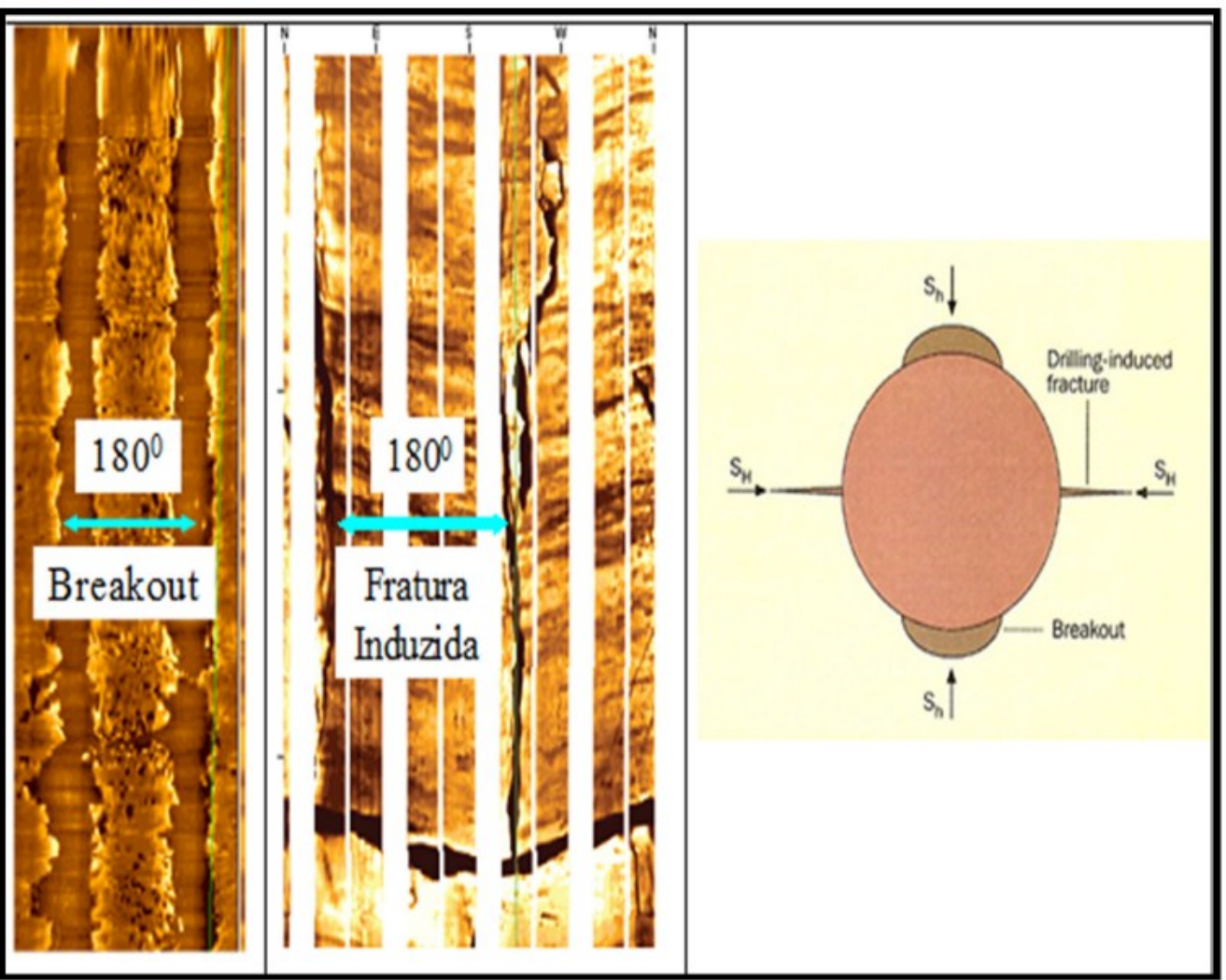

Figura 2.17 - Perfil de imagem com ocorrências de breakouts e fratura induzida (Fonte: Apresentação Petrobras)

Magnitude da tensão horizontal máxima

A magnitude da tensão horizontal máxima $\left(\mathrm{S}_{\mathrm{Hmax}}\right)$ somente pode ser obtida indiretamente, através de equação do estado de tensões do modelo escolhido. Ainda segundo (Haimson, 1978), ela pode ser avaliada para fraturas verticais no momento da realização do fraturamento $(\mathrm{Pb})$ pela Equação 2.7 .

$$
P_{b}=3 \sigma_{\text {hmin }}-\sigma_{\text {Hmax }}-P_{p}+R T
$$

Da equação 2.7 , temos que $\mathrm{P}_{\mathrm{b}}$ é a pressão de quebra, $\mathrm{RT}$ é a resistência à tração da rocha, $\mathrm{P}_{\mathrm{p}}$ é a pressão de poros, $\sigma_{\mathrm{h}}$ é a menor tensão efetiva horizontal e $\sigma_{H}$ é a maior tensão efetiva horizontal.

O valor da resistência à tração é obtido por meio de ensaio de laboratório ou do próprio fraturamento. $\mathrm{O}$ valor da menor tensão é sabido do fraturamento. 
Existe um grande debate em relação ao uso dessa metodologia para se determinar o valor da tensão horizontal máxima. A grande questão colocada no trabalho de Zoback e Pollad (1978) é a dificuldade de se detectar a inicialização da fratura durante a pressurização devido ao grande volume envolvido. Ainda segundo estes autores, o valor da pressão de quebra $\left(\mathrm{P}_{\mathrm{b}}\right)$ representa o momento de propagação instável da fratura e o início do fraturamento pode ter ocorrido a qualquer pressão abaixo desta.

A magnitude de $\mathrm{S}_{\mathrm{Hmax}}$ também pode ser estimada através do método do polígono de tensões. Segundo o estudo realizado por Zoback e Helay (1978), o estado de tensão da crosta terrestre se encontra em um equilíbrio governado pela resistência ao atrito das fraturas pré-existentes.

A resistência ao atrito das fraturas foi estimada primeiramente em experimentos de laboratório por Byerlee (1978), obtendo-se resultados variando de $0,6 \leq \mu \leq 1,0$. Posteriormente, estes mesmos valores foram encontrados em resultados de campo por Zoback e Townend (2001).

A Figura 2.18 apresenta dados de estudo de campo realizado para seis poços por Zoback e Townend (2001) que apresentam resultados do valor de coeficiente de atrito interno compatível com a solução apresentada Byerlee (1978).

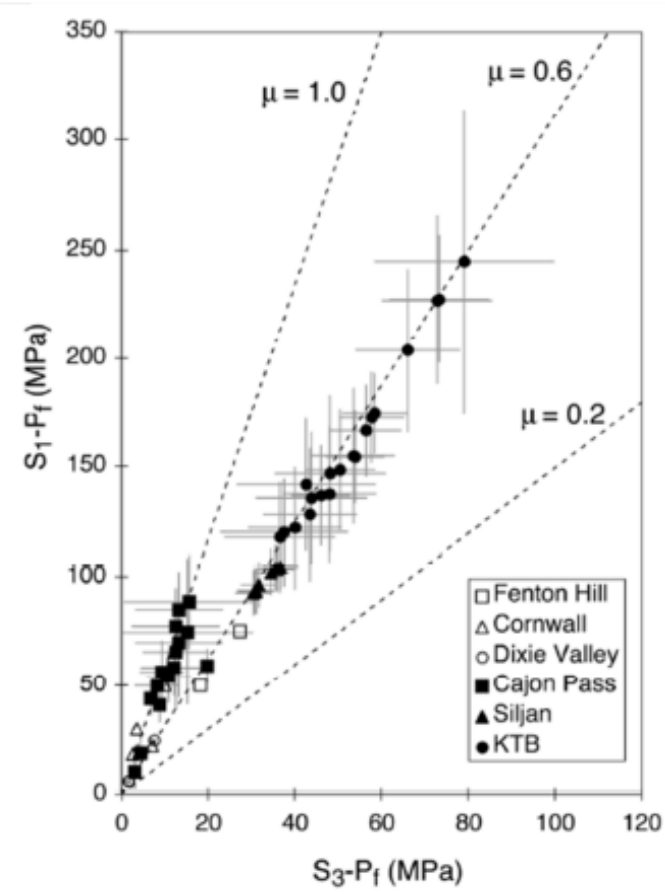

Figura 2.18 - Resultado do trabalho de campo do Zoback eTownend (2001) do atrito interno da rocha de seis poços, indicando compatibilidade com a solução apresentada por Byerlee (1978) 
As equações 2.8, 2.9, 2.10 apresentadas por Jaeger e Cook (1979) utilizam a resistência ao atrito da rocha para determinar os limites aceitáveis de tensão antes que ocorra o escorregamento da falha, assumindo a coesão nula no plano de falha e o critério de ruptura por Mohr Coulomb.

Falha Normal: $\frac{s_{v}-P_{p}}{s_{h}-P_{p}} \leq\left[\left(\mu^{2}+1\right)^{\frac{1}{2}}+\mu\right]^{2}$

Falha Transcorrente: $\frac{s_{H}-P_{p}}{s_{h}-P_{p}} \leq\left[\left(\mu^{2}+1\right)^{\frac{1}{2}}+\mu\right]^{2}$

$$
\text { Falha reversa: } \frac{s_{H}-P_{p}}{s_{v}-P_{p}} \leq\left[\left(\mu^{2}+1\right)^{\frac{1}{2}}+\mu\right]^{2}
$$

A combinação dos três regimes de falhas citados acima possibilita a construção do "polígono de tensões" que define uma relação entre as tensões principais (Figura 2.19).

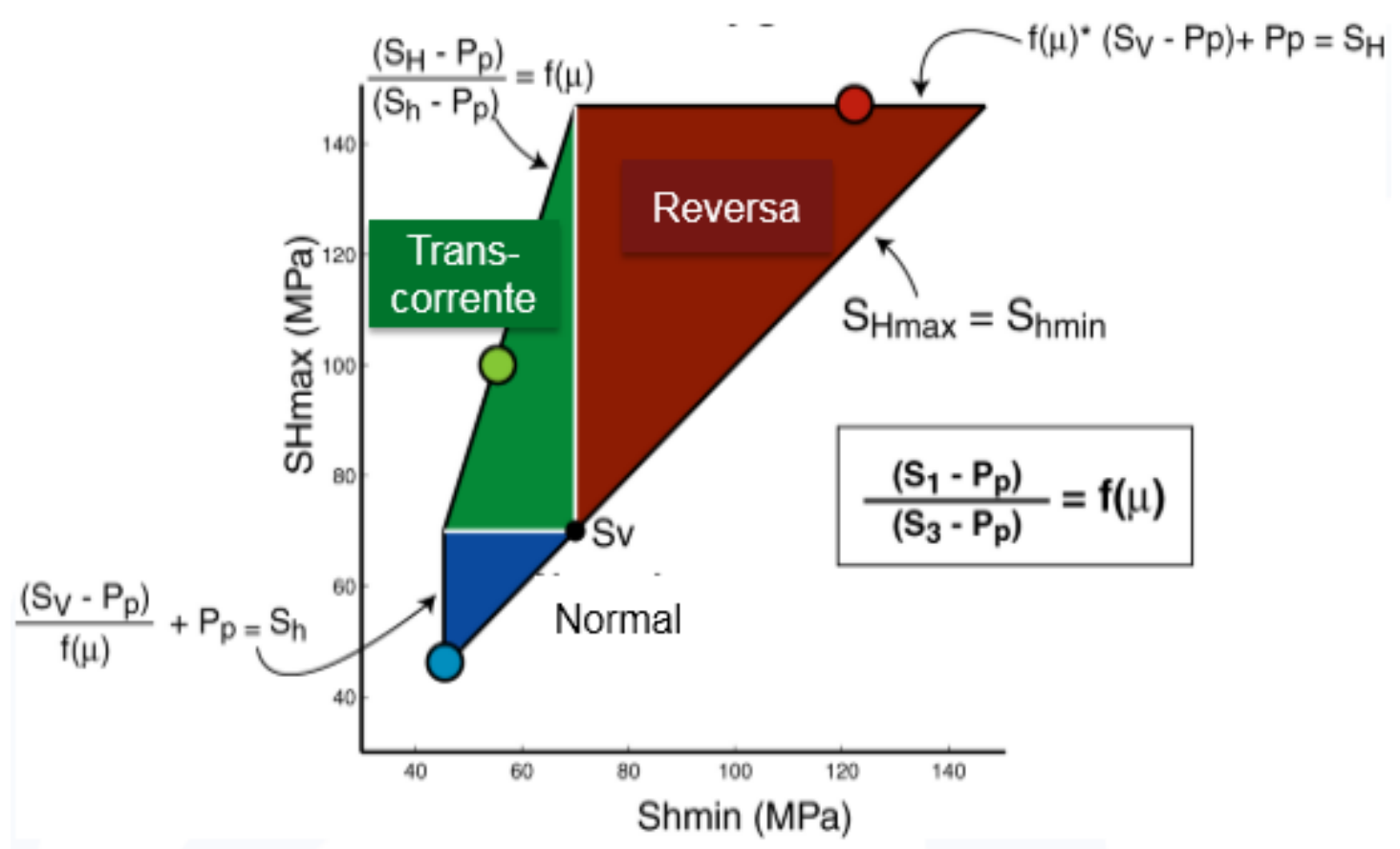

Figura 2.19 - Polígono de tensões (Zoback e Townend, 2001) 


\section{Pressão de colapso}

Diferente do gradiente de pressão de poros, o estabelecimento do gradiente de colapso exige um maior conhecimento do comportamento mecânico das rochas no subsolo. Basicamente, a rotina utilizada para a estimativa desses gradientes lida com os seguintes passos, de acordo com Rocha, 2007:

- Conhecimento das rochas a serem perfuradas e suas propriedades, de modo a estabelecer os limites de resistência ou critérios de falha;

- Estabelecimento do estado de tensões atuante ao redor do poço;

- Comparação do estado de tensão ao redor do poço com o critério de falha da rocha para a determinação da pressão dentro do poço que leve ao seu colapso. 


\section{3}

\section{Metodologia}

Para a análise geomecânica dos carbonatos do pré-sal brasileiro, um modelo de estabilidade de poço foi construído. A Figura 3.1 mostra a delimitação da área do pré-sal e em destaque a área de estudo na Bacia de Santos.

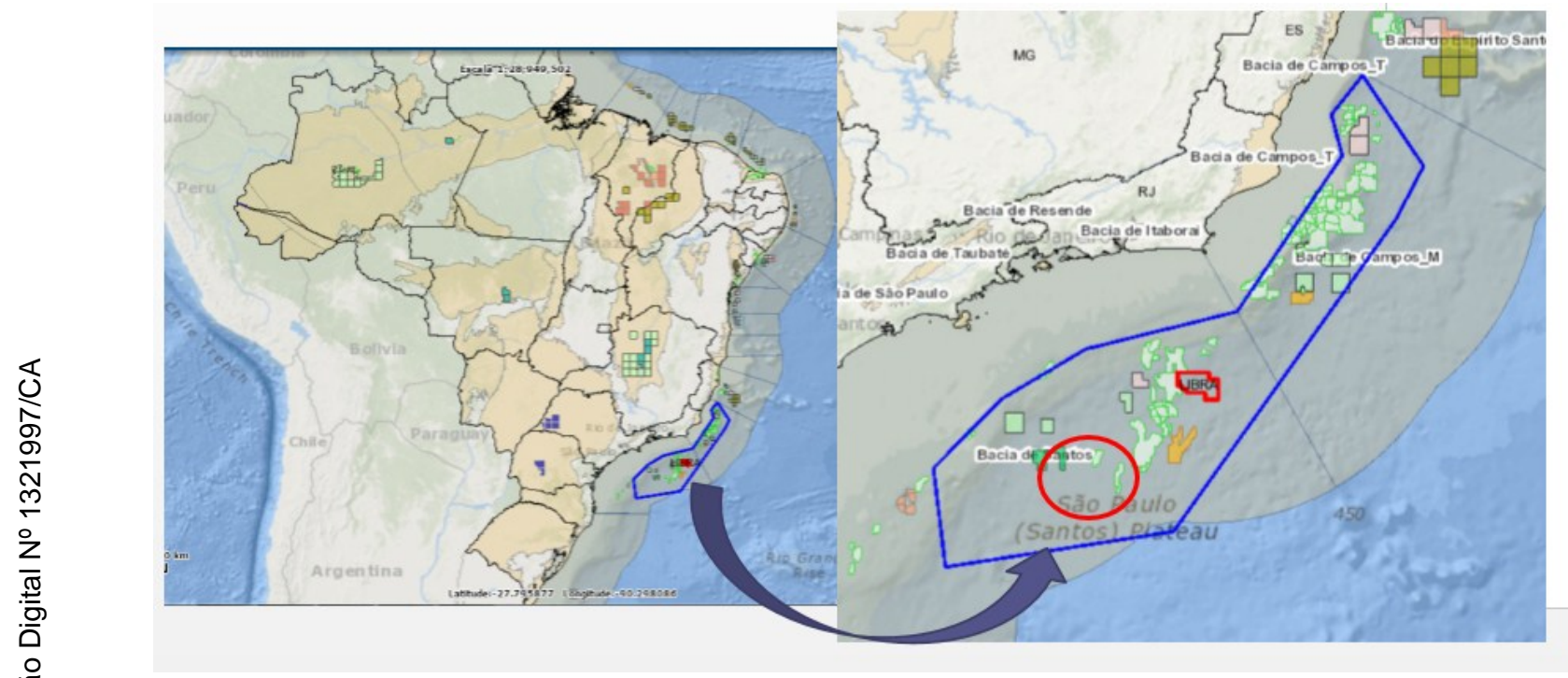

Figura 3.1 - Indicação da área de estudo na Bacia de Santos

O estudo em questão levou em conta dados de nove poços verticais de petróleo e gás localizados na Bacia de Santos e o conjunto de dados foi fornecido pela Agência Nacional de Petróleo (Banco de Dados de Exploração e Produção BDEP). De acordo com a Tabela 3.1, os poços foram perfurados entre 2011 e 2012, a lâmina d'água (LDA) varia entre 2031 e $2175 \mathrm{~m}$ e a altura da mesa rotativa (MR) variou de 18 a 33m. A distribuição da localização dos poços está apresentada na Figura 3.1 e o Poço 7 é o mais profundo, foi perfurado até $6642 \mathrm{~m}$. A distância máxima entre os poços alcança cerca de $70 \mathrm{~km}$. 
Tabela 3.1 - Informações gerais sobre os poços recebidos da ANP

\begin{tabular}{|c|c|c|c|c|c|}
\hline Poço & Ano pe rfuração & $\begin{array}{c}\text { LDA } \\
(\mathbf{m})\end{array}$ & MR (m) & $\begin{array}{c}\text { TVD final } \\
(\mathbf{m})\end{array}$ & $\begin{array}{c}\text { Distância em relação } \\
\text { ao poço 1 (km) }\end{array}$ \\
\hline \hline 1 & 2011 & 2175 & 33 & 6175 & 0,00 \\
\hline 2 & $2010 / 2011$ & 2153 & 27 & 5726 & 49,63 \\
\hline 3 & 2011 & 2118 & 24 & 5374 & 63,23 \\
\hline 4 & 2011 & 2156 & 26 & 5138 & 26,74 \\
\hline 5 & 2011 & 2156 & 26 & 5798 & 63,31 \\
\hline 6 & $2011 / 2012$ & 2150 & 26 & 5600 & 44,47 \\
\hline 7 & 2011 & 2031 & 18 & 6642 & 36,66 \\
\hline 8 & 2012 & 2120 & 24 & 6051 & 70,87 \\
\hline 9 & 2012 & 2135 & 18 & 3131 & 63,66 \\
\hline
\end{tabular}

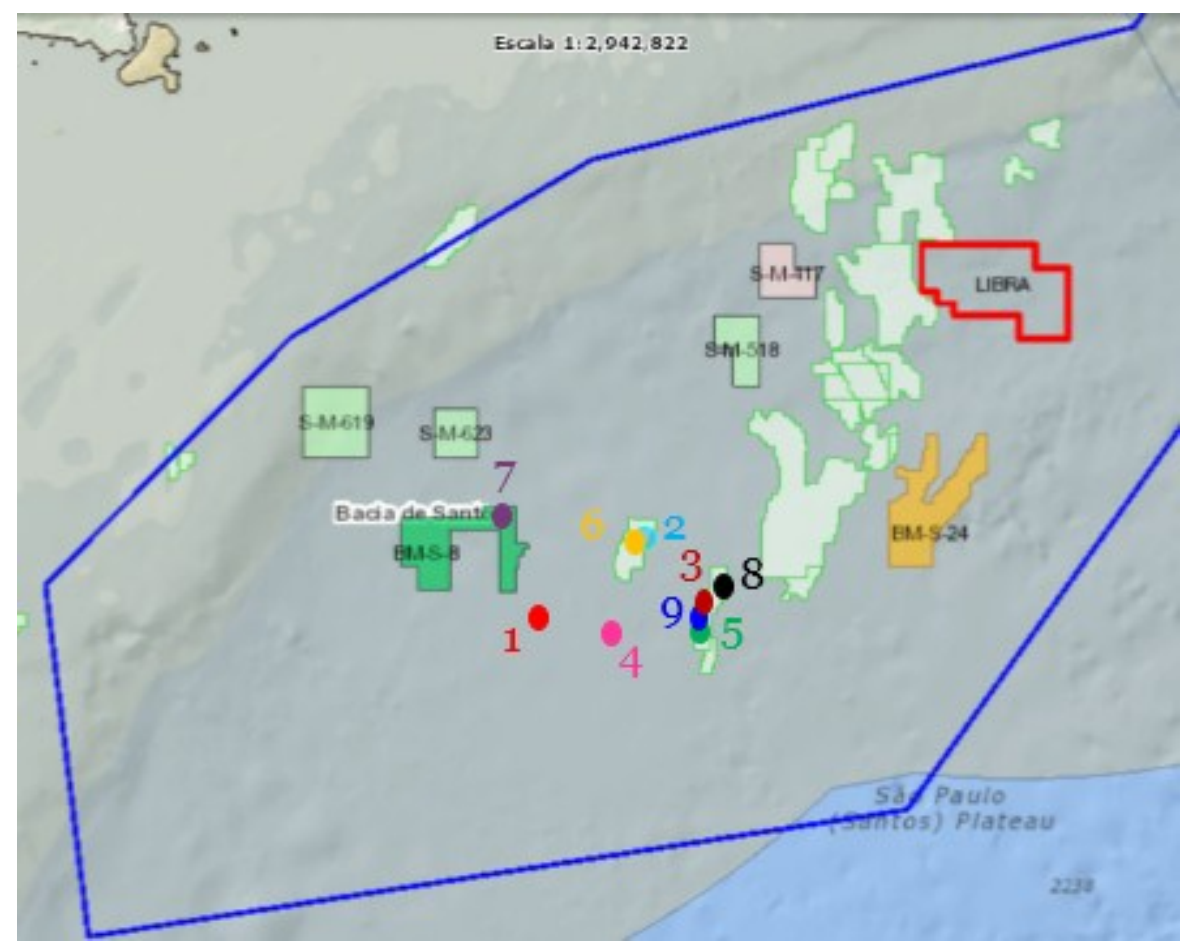

Figura 3.1 - Localização dos poços recebidos pela ANP

Para a construção do modelo geomecânico, um fluxo de trabalho foi desenvolvido e está apresentado na Figura 3.2. 


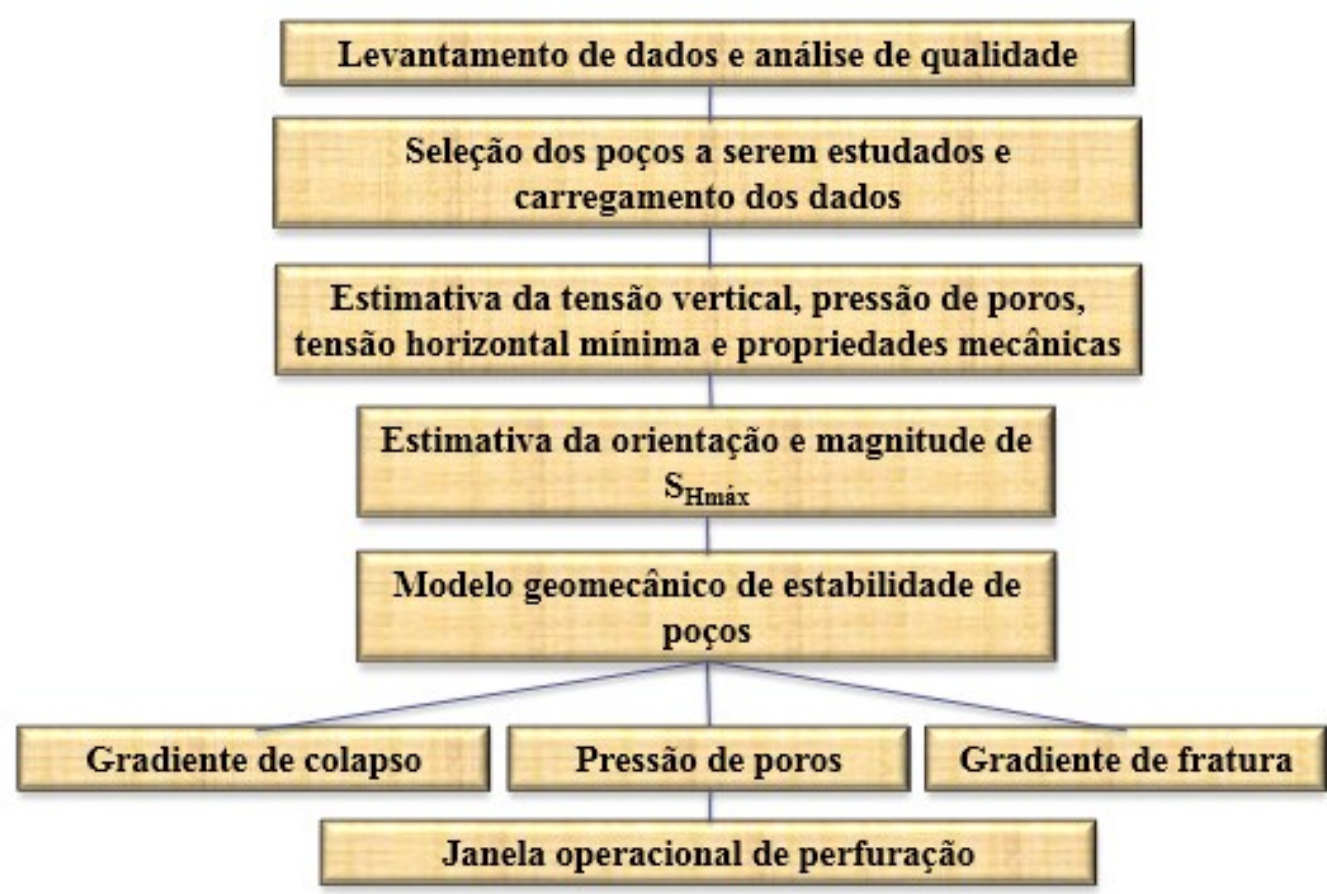

Figura 3.2 - Fluxo de trabalho para a obtenção da janela operacional de perfuração dos carbonatos do pré-sal

Como primeiro passo, foi feito um levantamento dos dados recebidos procurando verificar a existência dos dados necessários e avaliar a qualidade dos mesmos para a elaboração do modelo geomecânico. Após essa análise, verificouse que dos nove poços cujos dados foram fornecidos, apenas oito possuem dados mínimos para a utilização no estudo, então esses dados foram carregados e analisados no software Jewel Suite Geomechanics, da Baker Hughes. Na sequência, as estimativas da tensão vertical, pressão de poros, tensão horizontal mínima, resistência mecânica e propriedades elásticas da rocha foram calculadas. Com esses resultados, o software SFIB, também da Baker Hughes, foi utilizado para a estimativa da tensão horizontal máxima através do método do polígono de tensões. Para a avaliação da direção tensão horizontal máxima foi considerado o mapa global de tensões (World Stress Map) onde foi verificado a direção das tensões disponíveis na área de estudo.

A partir das estimativas dos parâmetros citados acima, o modelo geomecânico foi utilizado para estimar o gradiente de colapso, pressão de poros e gradiente de fratura que melhor representaram a estabilidade mecânica da perfuração dos poços em análise em cada intervalo de assentamento dos revestimentos. Os resultados 
desses gradientes forneceram a janela operacional para os carbonatos da área estudada utilizando os dados disponíveis e as considerações empregadas.

\section{1 \\ Levantamento de dados}

A Tabela 3.2 mostra os dados que foram disponibilizados pela ANP. Após avaliação dos dados recebidos, observou-se que os poços apresentaram os seguintes dados: informações litológicas, locação, profundidade do revestimento, profundidade dos topos estratigráficos, dados do fluido de perfuração, testes de avaliação da formação (LOT/FIT), testes de pressão da formação (MDT, RFT), temperatura, dados de permeabilidade, dados de perfil (gama ray, densidade, acústico compressional, acústico cisalhante e resistividade). Nenhum dos poços disponibilizados apresenta registros de perfis na zona de pós-sal, apenas na área do pré-sal. Além disso, nenhum deles apresentou dados de imagem, relatórios diários de perfuração e ensaios de resistência de rocha em laboratório.

Tabela 3.2 - Levantamento de dados dos poços recebidos pela ANP

\begin{tabular}{|c|c|c|c|c|c|c|c|c|}
\hline Dados / Poços & Poço 1 & Poço 2 & Poço 3 & Poço 4 & Poço 5 & Poço 6 & Poço 7 & Poço 8 \\
\hline \multicolumn{9}{|l|}{ Mapas / X-Sections } \\
\hline Informações litológicas & $\sqrt{ }$ & $\sqrt{ }$ & $\sqrt{ }$ & $\sqrt{ }$ & $\sqrt{ }$ & $\sqrt{ }$ & $\sqrt{ }$ & $\sqrt{ }$ \\
\hline Locação & $\sqrt{ }$ & $\sqrt{ }$ & $\sqrt{ }$ & $\sqrt{ }$ & $\sqrt{ }$ & $\sqrt{ }$ & $\sqrt{ }$ & $\sqrt{ }$ \\
\hline \multicolumn{9}{|l|}{ Trajetória } \\
\hline Prof. do Revestimento & $\sqrt{ }$ & $\sqrt{ }$ & $\sqrt{ }$ & $\sqrt{ }$ & $\sqrt{ }$ & $\sqrt{ }$ & $\sqrt{ }$ & $\sqrt{ }$ \\
\hline Topos estratigráficos & $\sqrt{ }$ & $\sqrt{ }$ & $\sqrt{ }$ & $\sqrt{ }$ & $\sqrt{ }$ & $\sqrt{ }$ & & $\sqrt{ }$ \\
\hline \multicolumn{9}{|l|}{ Relatório diário de perfuração } \\
\hline Dados de Fluido de perfuração & $\sqrt{ }$ & $\sqrt{ }$ & $\sqrt{ }$ & $\sqrt{ }$ & $\sqrt{ }$ & $\sqrt{ }$ & $\sqrt{ }$ & $\sqrt{ }$ \\
\hline Testes de absorção (LOT/FIT) & $\sqrt{ }$ & $\sqrt{ }$ & $\sqrt{ }$ & $\sqrt{ }$ & $\sqrt{ }$ & $\sqrt{ }$ & $\sqrt{ }$ & $\sqrt{ }$ \\
\hline $\begin{array}{l}\text { Teste de pressão de formação } \\
\text { (MDT, RFT) }\end{array}$ & $\sqrt{ }$ & $\sqrt{ }$ & $\sqrt{ }$ & $\sqrt{ }$ & $\sqrt{ }$ & $\sqrt{ }$ & $\sqrt{ }$ & $\sqrt{ }$ \\
\hline \multicolumn{9}{|l|}{\begin{tabular}{|l|} 
Dados de Imagem \\
\end{tabular}} \\
\hline \multicolumn{9}{|l|}{$\begin{array}{l}\text { Teste de laboratório de resistência } \\
\text { de rocha }\end{array}$} \\
\hline Temperatura & $\sqrt{ }$ & $\sqrt{ }$ & $\sqrt{ }$ & $\sqrt{ }$ & $\sqrt{ }$ & $\sqrt{ }$ & & $\sqrt{ }$ \\
\hline Permeabilidade & & $\sqrt{ }$ & & & $\sqrt{ }$ & & & \\
\hline \multicolumn{9}{|l|}{ Caliper } \\
\hline Gamma Ray & 3690 a 6135 & 5010 a 5730 & 4960 a 5375 & 3500 a 5130 & 5050 a 5790 & 3100 a 5585 & 5000 a 6660 & 5090 a 6040 \\
\hline Densidade & 4980 a 6135 & 5070 a 5730 & & 2740 a 4960 & 5050 a 5790 & 3200 a 5265 & 5880 a 6200 & $\begin{array}{c}5488 \text { a } 5565 \text { e } \\
5930 \text { a } 6025 \\
\end{array}$ \\
\hline Acústico Compressional & 3690 a 6135 & 5120 a 5730 & 4960 a 5375 & 4840 a 4960 & 5050 a 5790 & 5370 a 5480 & 6040 a 6660 & $\begin{array}{c}5488 \text { a } 5565 \mathrm{e} \\
5930 \text { a } 6025\end{array}$ \\
\hline Acústico Cisalhante & & 5120 a 5730 & 4960 a 5375 & 4840 a 4960 & 5050 a 5790 & 5370 a 5480 & & $\begin{array}{c}5488 \text { a } 5565 \text { e } \\
5930 \text { a } 6025 \\
\end{array}$ \\
\hline Resistividade & 4980 a 6135 & & 4960 a 5375 & 4840 a 4960 & 5050 a 5790 & & 6040 a 6180 & $\begin{array}{c}5488 \text { a } 5565 \text { e } \\
5930 \text { a } 6025\end{array}$ \\
\hline \multicolumn{9}{|l|}{ Velocidade intervalar } \\
\hline Neutrão & & & & & & & & \\
\hline
\end{tabular}

A disponibilidade de imagens de poços é importante para avaliar a presença de feições induzidas na formação, como breakouts e fraturas induzidas. Os ensaios 
de mecânica de rochas seriam utilizados para calibrar as propriedades mecânicas das rochas estimadas por perfis e o relatório diário de perfuração, que relatam detalhes da perfuração, possibilitaria o conhecimento dos problemas geomecânicos ocorridos durante a perfuração, como eventos de poços apertados, perdas de circulação total, prisão de ferramentas, influxos etc. O único dado analisado disponível trata-se de uma tabela com um resumo dos principais problemas ocorridos no Poço 7.

Abaixo estão apresentados os dados gerais dos Poços 1 e 7 que foram considerados para a elaboração do modelo geomecânico (Figuras 3.3 e 3.4) por serem os poços mais profundos e por caracterizarem regiões diferentes de pressão de poros (avaliado preliminarmente através dos valores de pressão medidas e peso de fluido utilizado). Além disso, o Poço 7 é o único que apresenta dados sobre os problemas geomecânicos ocorridos durante a perfuração. Os dados dos outros poços estão apresentados no Anexo 8.1.

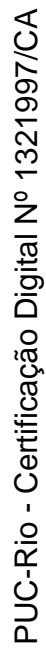

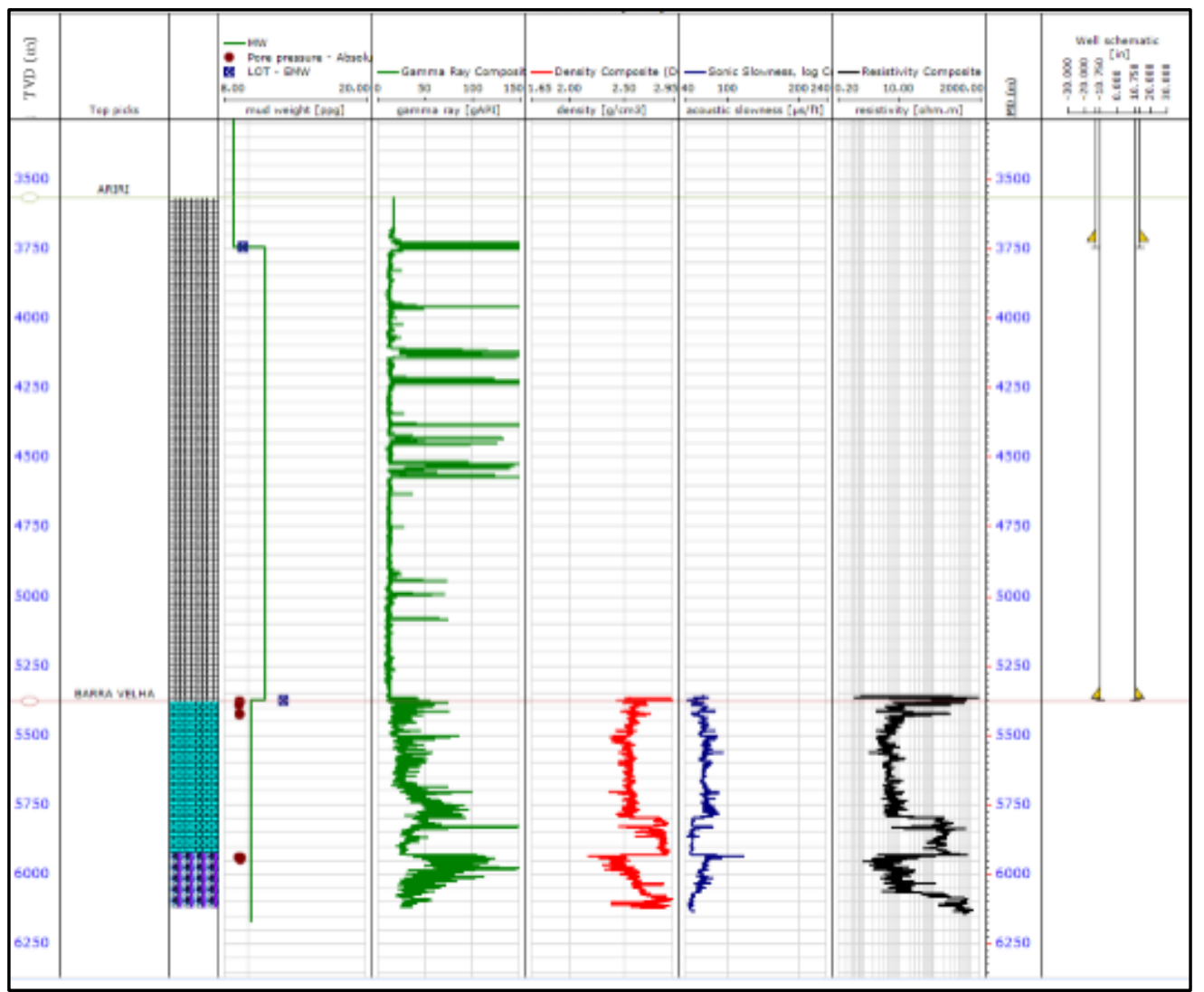

Figura 3.3 - Dados gerais do Poço 1 
De acordo com as Figuras 3.3 e 3.4, o primeiro track corresponde à profundidade vertical $(\mathrm{m})$, o segundo track apresenta a profundidade do topo das formações e ao lado deste a litologia está discriminada. Na formação Ariri foi identificado o sal, principalmente halita, e os carbonatos foram identificados na formação Barra Velha. No "Relatório final de poço exploratório" é descrito o tipo de litologia, através da análise de testemunhos. Os carbonatos, em sua maioria, foram classificados como calcário microbial.

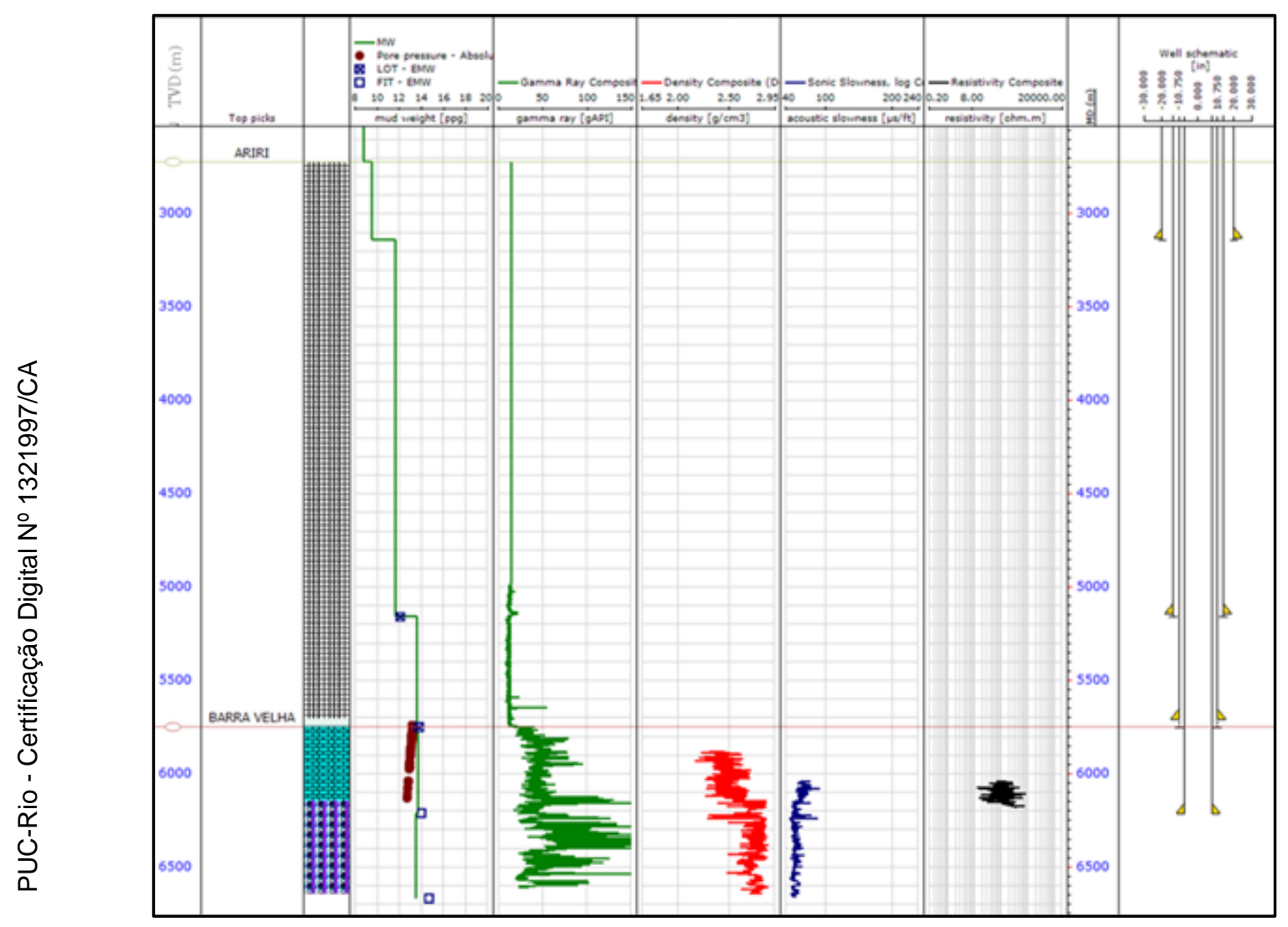

Figura 3.4 - Dados gerais do Poço 7

A Figura 3.5 mostra uma comparação entre a litologia e os topos estratigráficos das formações de cada poço em relação à profundidade vertical (m). A disposição dos poços está de acordo com a localização dos mesmos como indicado na Figura 3.1, de baixo para cima. Os poços mais profundos (1 e 7) identificaram a presença de rocha ígnea após a camada de rocha carbonática e o Poço 7 atravessou uma maior camada de sal. 
$\mathrm{Na}$ Tabela 3.3 estão apresentados os eventos de perfuração resumidos ocorridos no Poço 7. Nesta tabela pode-se concluir que os principais eventos estão relacionados à pressão de poros (prisão diferencial e o kick) e ao gradiente de fratura (perdas de circulação).

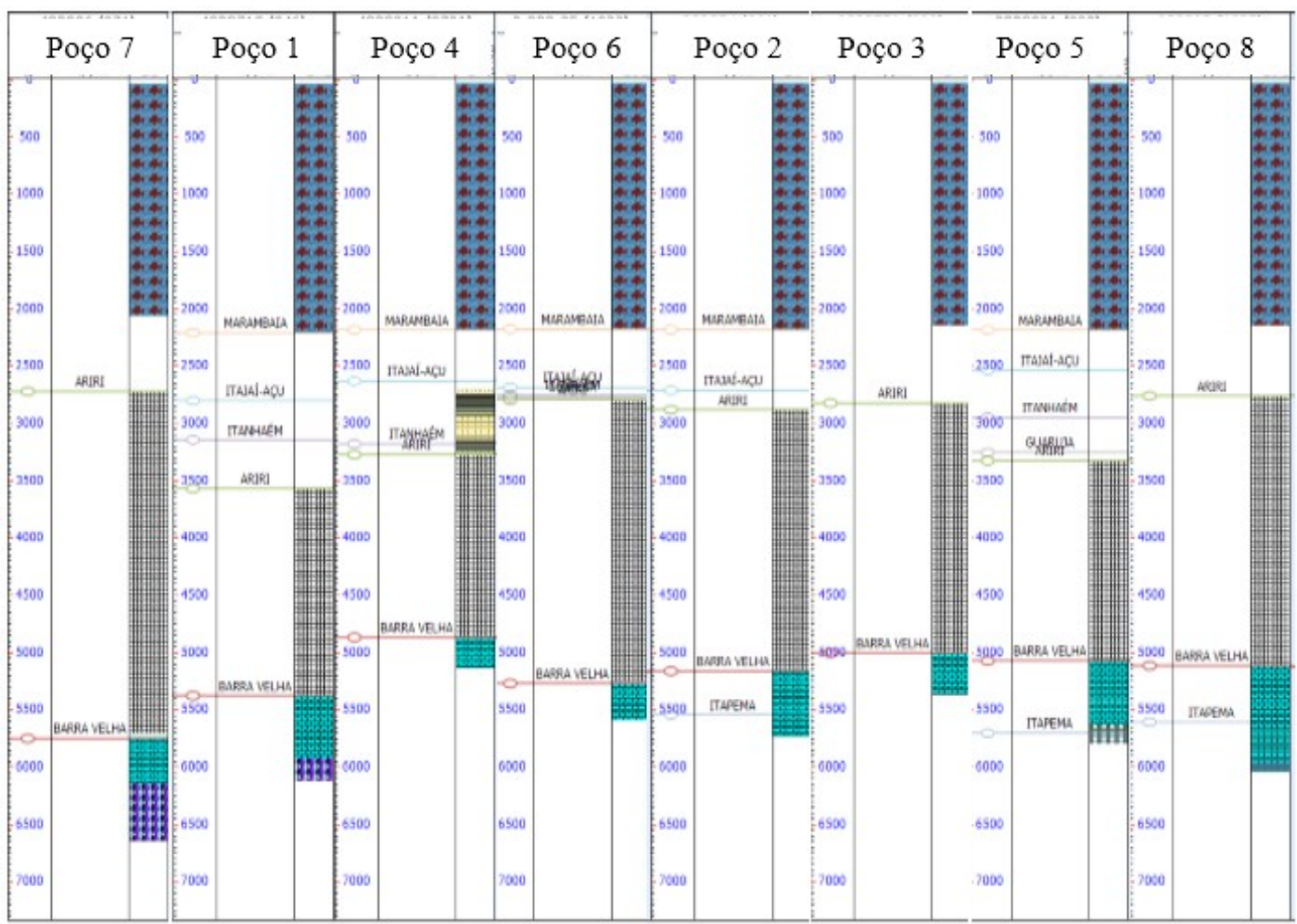

Figura 3.5 - Comparação dos topos estratigráficos e das litologias dos poços

A prisão diferencial é causada por um diferencial de pressão, ou seja, quando a coluna de fluido de perfuração exerce pressão excessiva na coluna de perfuração sobre o reboco depositado em uma formação permeável (Simon et al., 2005). Nesta categoria, a circulação do fluido é mantida, mas não é possível mover ou girar a coluna em nenhuma direção. Contribuem para este tipo de prisão o mau dimensionamento dos fluidos de perfuração e a presença de formações permeáveis (Nascimento et al., 2010).

A perda de circulação é a invasão de fluido de perfuração para a formação através de fraturas existentes ou provocadas em formações com alta permoporosidade (devido à presença de formação inconsolidada, existência de falhas, fraturas naturais, cavernas, entre outros) ou em zonas depletadas. A perda de circulação pode ser total, em que não ocorre retorno de fluido para a superfície, ou 
parcial, em que ocorre retorno parcial do fluido para a superfície (Chieza, 2011). Não existe informação se os eventos relacionados à perda de circulação foram perdas totais ou parciais e também não foram reportados os volumes.

Tabela 3.3 - Eventos ocorridos na perfuração do Poço 7 (Relatório de Perfuração - ANP), a indicação do parâmetro afetado e a litologia correspondente à profundidade indicada

\begin{tabular}{|c|c|c|c|l|}
\hline \multicolumn{2}{|c|}{ Intervalo (m) } & \multicolumn{2}{c|}{ Peso de fluido (ppg) } & \multirow{2}{*}{ Eventos } \\
\hline Início & Fim & Antes & Depois & \\
\hline \hline 3128 & 5154 & 11,5 & 11,7 & Perda de Circulação \\
\hline 5708 & 5708 & 13,4 & 13,4 & Perda de Circulação \\
\hline 5753 & 5753 & 12,1 & 13,0 & Kick \\
\hline 5527 & 5708 & 13,4 & 13,4 & Perda de Circulação \\
\hline 5896 & 6213 & 13,4 & 13,3 & Perda de Circulação \\
\hline 5978 & 6228 & 12,9 & 12,9 & Prisão diferencial \\
\hline 6220 & 6671 & 12,9 & 12,9 & Perda de Circulação \\
\hline
\end{tabular}

\begin{tabular}{|l|l|}
\hline Parâmetro afetado & \multicolumn{1}{|c|}{ Litologia } \\
\hline \hline Gradiente de fratura & Sal \\
\hline Gradiente de fratura & Entrada Carbonato \\
\hline Pressão de poros & Carbonato \\
\hline Gradiente de fratura & Sal \\
\hline Gradiente de fratura & Carbonato/ignea \\
\hline Pressão de poros & Carbonato/ignea \\
\hline Gradiente de fratura & Ignea \\
\hline
\end{tabular}

A perda de circulação total provoca instabilidade mecânica no poço devido à redução da pressão hidrostática com a queda do nível de fluido de perfuração no anular e, consequente, desmoronamento das camadas superiores ou inferiores à zona de perda, podendo inclusive, permitir a invasão indesejada dos fluidos da formação para dentro do poço (kick) pondo em risco a segurança do mesmo.

O kick é o influxo indesejado de fluidos presentes na formação (água, gás ou óleo) para dentro do poço devido à existência de uma pressão hidrostática no interior do mesmo insuficiente para conter a pressão da formação. Quando o mesmo ocorre de maneira descontrolada e atinge a superfície chama-se blowout. As causas mais prováveis de um kick são: pressão da formação anormalmente alta, pistoneio, perda de circulação, cimentação deficiente e falta de ataque do poço (falta de "preenchimento" do volume de vazio do poço, equivalente a retirada do aço da coluna, com fluido de perfuração durante as manobras).

Com relação ao influxo observado, não foi informado o valor do gradiente de pressão do kick, mas verificou-se que o peso de fluido utilizado para concluir a perfuração da fase foi de $13.7 \mathrm{ppg}$ e que houve registro de gás total de 417UGT (Tabela 4.8). A comparação dos valores de peso de fluido inicial e final $(12,1 \mathrm{e}$ 13,0UGT, respectivamente) reportados na profundidade onde ocorreu o kick pode indicar a redução do peso de fluido decorrente da presença do gás. 
A perda de circulação (caso seja uma perda de circulação total) indica que o peso de fluido estava igual ou muito próximo ao valor do gradiente de fratura (limite superior da janela operacional), enquanto que o kick indica que o peso de fluido estava abaixo do valor da pressão de poros na profundidade indicada (limite inferior da janela operacional). A prisão de coluna foi reportada como prisão diferencial, mas comparando os valores de peso de fluido e pressão de poros, não se observou um valor significativo ( $>13,8 \mathrm{MPa}$ de acordo com a Petrobras) para esse fenômeno $(7,2 \mathrm{MPa})$.

\section{2}

\section{Tensão vertical}

Para a estimativa da tensão vertical (pressão de sobrecarga), Sv, foram considerados os dados do perfil densidade e as correlações de Gardner (1974) (Equação 2.2) e Belotti (1978) (Equação 2.3 e 2.4), que são baseadas em perfis acústico (tempo de trânsito) para o cálculo do perfil densidade sintético para os trechos onde não havia dado real. Para os trechos superficiais, é feito uma extrapolação dos dados de densidade até o fundo marinho, já que normalmente não são corridos perfis nessas profundidades iniciais.

Os resultados das densidades sintéticas obtidas pelas duas correlações foram comparados em gráficos com os dados de densidade real, a fim de se definir a correlação que melhor se ajustava aos dados de densidade real do poço, de maneira que os trechos sem dados reais pudessem ser melhor representados.

A Equação 2.1 foi utilizada para o cálculo da estimativa da tensão vertical, no qual leva em conta a contribuição da lâmina d'água e o peso das camadas sobrepostas. Os resultados das tensões de sobrecarga de todos os poços foram plotados em um gráfico e valores estatísticos (média, $\mathrm{P}_{10}$ e $\mathrm{P}_{90}$ ) foram gerados através do método de Monte Carlo, que é uma metodologia estatística que se baseia em amostragens aleatórias massivas para obter resultados numéricos, isto é, utiliza uma grande quantidade de amostragens aleatórias para se chegar a um resultado próximo do real. Os resultados são expressos em termos de probabilidade de que ocorra algum parâmetro ou evento, por exemplo: $\mathrm{P}_{90}$ significa que há $90 \%$ de chance de que o valor real seja o indicado. Já no caso do $\mathrm{P}_{10}$, ocorre o contrário, havendo $10 \%$ de chance de que o valor mínimo ocorra (Lima, 2006). 


\section{3}

\section{Pressão de poros}

Com relação à pressão de poros, sabe-se que as metodologias de subcompactação (tradicionalmente empregadas no pós-sal e na Bacia de Campos, exemplificado pelo estudo de Silveira, 2009) para a estimativa desse parâmetro não se aplicam aos carbonatos em função da complexidade da sua estrutura e de seu processo de formação diagenético. Por isso, para a construção do modelo geomecânico considerou-se as pressões medidas no poço. Essas pressões podem ser medidas durante a perfuração da fase do poço (logging while drilling - LWD) ou logo após a conclusão da fase (wireline). No caso dos dados fornecidos pela ANP, o modo com que as pressões foram medidas não foi informado.

Devido às suas características de ausência de permeabilidade e porosidade, não existem poros para acumular pressão nos sais e, por isso, o conceito de pressão de poros não se aplica a eles. Por outro lado, devido à sua mobilidade, podem induzir sobrepressões nos sedimentos adjacentes e nas possíveis intercalações de arenitos, folhelhos e carbonatos que podem ter ficado confinados no sal.

A associação de diáprios de sal e pressões anormais tem sido encontrada durante a perfuração em diversas partes do mundo (Fertl et al. 1976). Há possibilidade também de ocorrência de zonas sobrepressurizadas tanto abaixo quanto acima do sal, nas profundidades superficiais (shallow hazards), sendo que a zona de transição abaixo deles é de difícil avaliação pelos processos convencionais, baseados na taxa de compactação e alteração da porosidade. Na execução de poços que atravessam grandes extensões de sal, as técnicas de aquisição de perfís durante a perfuração (LWD) associadas às técnicas já estabelecidas de sísmica de poços devem ser utilizadas para a avaliação da pressão de poros.

Em seções salinas limpas e homogêneas, o gradiente de fratura tem se mostrado, em geral, maior que a tensão vertical. Esse comportamento é explicado pela movimentação do sal dentro dos sedimentos adjacentes, que pode causar fragilização dessas interfaces. Essas zonas falhadas, causadas pela movimentação do sal, são denominadas rubble zones (Fredrich et al. 2003). O material não tem resistência devido à sua coesão ter sido destruída por essa movimentação. Tais zonas mecanicamente alteradas tendem a se localizar na interface com a base da 
seção salina, onde é possível tanto a ocorrência de perdas de circulação, quanto a de instabilidade mecânica de poço.

\section{4}

\section{Tensão horizontal mínima}

Para a estimativa da tensão horizontal mínima $\left(\mathrm{S}_{\mathrm{hmin}}\right)$ foi utilizado o método das Razões de Tensões Efetivas (Effective Stress Ratio - ESR), no qual é feito um levantamento dos leak-off tests (LOT) realizados no poço para o cálculo da tensão efetiva. Elaborou-se um perfil de tensão principal mínima utilizando uma abordagem da razão de tensão efetiva constante, descrita pela Equação 3.1. Em outras palavras, as razões de tensão efetiva são calculadas nas profundidades de execução dos testes de LOT (com os correspondentes valores de sobrecarga $\left(\mathrm{S}_{\mathrm{v}}\right)$ e pressão de poros $\left.\left(\mathrm{P}_{\mathrm{p}}\right)\right)$. Esses valores são então considerados constantes ao longo de um certo intervalo de profundidade, em determinado poço, como forma de extrapolar a estimativa de $\mathrm{S}_{\mathrm{hmin}}$ em função da profundidade, pressão de poros e pressão de sobrecarga.

$$
\boldsymbol{E S} \boldsymbol{R}_{\min }=\frac{\left(S_{h \min }-P_{p}\right)}{\left(S_{v}-P_{p}\right)}
$$

Vale ressaltar que apenas os LOTs realizados nos carbonatos foram considerados na estimativa da tensão horizontal mínima, já que em alguns poços foram encontrados resultados dos testes de LOT no sal.

\section{5}

\section{Resistência da rocha e propriedades elásticas}

A resposta geomecânica em relação à estabilidade de poço e diferenças entre as tensões é controlada pelas propriedades mecânicas de rocha. $\mathrm{O}$ entendimento das propriedades mecânicas como resistência à compressão não confinada, coeficiente de fricção, coeficiente de Poisson, módulo de Young e coeficiente de Biot fazem parte do modelo geomecânico. Por isso, as medições de laboratório são fundamentais para a calibrar esses parâmetros. 
Os valores de UCS dos carbonatos do pré-sal foram estimados considerando três correlações: Militzer (1973), Golubev (1976) e CPM (Santos and Ferreira, 2010). Já para a rocha ígnea, que foi atravessada por dois poços, utilizou-se a correlação de Teikoku-Vp (GMI, 2007). Essas correlações estão apresentadas nas Equações 3.2, 3.3, 3,4 e 3.5, respectivamente, onde $\Delta$ t é o tempo de trânsito compressional $(\mu \mathrm{s} / \mathrm{ft}), \rho_{b}$ é a densidade $\left(\mathrm{kg} / \mathrm{m}^{3}\right)$ e $v$ é o coeficiente de Poisson (adimensional). Elas foram desenvolvidas a partir de ensaios de laboratório no Brasil e em diversas partes do mundo, por isso, existe a necessidade de adequá-las regionalmente.

$$
\begin{gathered}
U C S(M P a)=(7682 / \Delta t)^{1,82} \\
U C S(M P a)=10^{(2,44+109,14 / \Delta t)} \\
U C S(M P a)=8.374 .10^{-21} \cdot \rho_{b}{ }^{2} \cdot V_{p}{ }^{4} \cdot((1+v) /(1-v))^{2} \cdot(1-2 v) \\
U C S(M P a)=167185.0,00689 . e^{(-0.037 . \Delta t)}
\end{gathered}
$$

Chang et al. (2006) estudaram as equações de Golubev (1976) e a de Militzer (1973) e concluíram que o formato da correlação de Militzer (1973) define um claro limite inferior de resistência dos dados medidos para qualquer valor de $\Delta$ t. Como uma estimativa conservadora da resistência é importante para problemas de estabilidade de poços, a correlação de Militzer (1973) fornece uma primeira estimativa satisfatória do limite inferior quando o $\Delta \mathrm{t}$ (ou a velocidade) é conhecido.

A Equação 3.3 mostra a correlação de CPM (Santos e Ferreira, 2010) que foi desenvolvida a partir de ensaios de laboratório de resistência à compressão de testemunhos do pré-sal brasileiro.

Para a estimativa do coeficiente de Poisson dinâmico ( $v_{\text {dyn }}$ - admissional), coeficiente de atrito interno ( $\phi$ - admissional) e módulo de Young dinâmico ( $\mathrm{E}_{\mathrm{dyn}}-$ em $\mathrm{Pa}$ ) foram utilizadas, respectivamente, as Equações 3.6, 3.7 e 3.8. Estas propriedades dependem da velocidade compressional $\left(\mathrm{V}_{\mathrm{p}}-\mathrm{em} \mathrm{km} / \mathrm{s}\right)$ e cisalhante $\left(\mathrm{V}_{\mathrm{s}}-\mathrm{em} \mathrm{km} / \mathrm{s}\right)$ e da densidade $\left(\rho-\mathrm{em} \mathrm{kg} / \mathrm{m}^{3}\right)$. 


$$
\begin{gathered}
v_{d y n}=\frac{V p^{2}-2 . V s^{2}}{\left.2 \cdot V p^{2}-V s^{2}\right)} \\
\phi=\tan \left(\sin ^{-1}\left(\frac{V p-1}{V p+1}\right)\right) \\
E_{d y n}=\rho * V s^{2}\left(\frac{3 V p^{2}-4 V s^{2}}{V p^{2}-V s^{2}}\right)
\end{gathered}
$$

Para análises dos resultados, foram elaborados gráficos correlacionando UCS com porosidade, com velocidade acústica e com módulo de Young dinâmico e gráficos de coeficiente de Poisson dinâmico, coeficiente de atrito interno e de módulo de Young correlacionando com a profundidade, onde os resultados de todos os poços foram plotados no mesmo gráfico.

Vale ressaltar que não foram disponibilizados dados de ensaio de laboratório para a calibração dessas propriedades mecânicas.

\section{6}

\section{Tensão horizontal máxima}

Em função da ausência dos dados de imagens dos poços, considerou-se a direção de $\mathrm{S}_{\mathrm{Hmax}}$ com base na direção das tensões encontradas no world stress map (WSM), que é uma compilação mundial de informações sobre o campo de tensões atual da crosta terrestre com registros de 21.750 dados de tensões em sua versão atual do banco de dados do WSM de 2008. É um projeto de colaboração entre a universidade, indústria e governo que tem como objetivo caracterizar o modelo de tensão e entender as suas fontes.

Em relação à estimativa da magnitude de $\mathrm{S}_{\mathrm{Hmax}}$, foram realizadas análises de sensibilidade considerando o modelo do polígono de tensões e variando três parâmetros: UCS (Militzer (1973) e CPM (2010)), abertura de breakout ( $0^{\circ}, 30^{\circ} \mathrm{e}$ $\left.60^{\circ}\right)$ e valor do Biot $(1$ e 0,9$)$.

A variação dos valores do coeficiente de Biot, se deu em função da complexidade dos reservatórios carbonáticos e sua estimativa foi feita através da revisão bibliográfica de estudos regionais de rochas análogas. Nos sólidos poroelásticos saturados com fluido, a teoria da poro-elasticidade descreve o comportamento constitutivo da rocha. De acordo com Zoback (2007), dados empíricos têm mostrado que a lei da tensão efetiva é função do coeficiente friccional das falhas geológicas. Nur e Byerlee (1971) propuseram uma lei de tensão 
efetiva na qual o coeficiente de Biot possui um efeito no cálculo das pressões de poros e sua relação com as tensões efetivas. Este modelo trabalha com o efeito da deformação volumétrica dos sistemas mecânicos da rocha e dos poros. A formulação está indicada na Equação 3.9 onde $\alpha$ é o coeficiente de Biot, expresso pela Equação 3.10 e varia entre 0 e $1(0 \leq \alpha \leq 1)$, onde $K_{b}$ é o módulo volumétrico drenando do poro (GPa) e $\mathrm{K}_{\mathrm{g}}$ é o módulo volumétrico dos grãos (GPa).

$$
\begin{gathered}
\sigma_{i j}=S_{i j}-\delta_{i j} \alpha P_{p} \\
\alpha=1-\frac{K_{b}}{K_{g}}
\end{gathered}
$$

No estudo de Vasquez et al., (2009), foram apresentados resultados de medidas em laboratório no qual se estimou os valores do coeficiente de Biot para calcários e arenitos fechados brasileiros. A Figura 3.6 mostra os resultados, que indicam valores de Biot entre 0,85 e 1,0 para valores de porosidade de $23 \%$ e $34 \%$. Devido aos resultados obtidos pelos autores, os valores de 0,9 e 1,0 foram considerados nas simulações do coeficiente de Biot para este estudo.

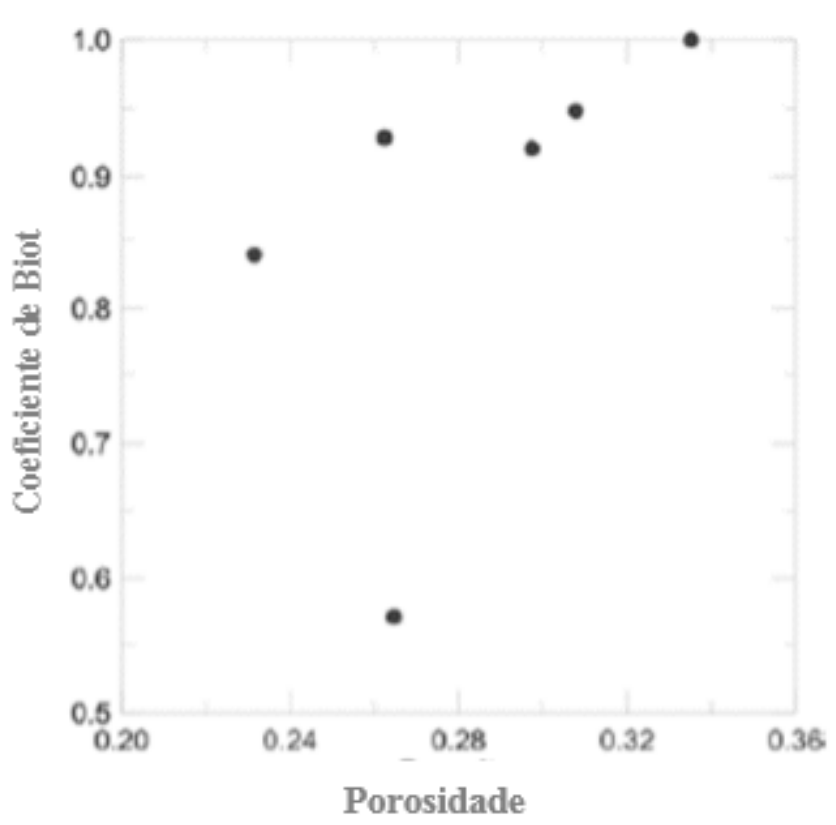

Figura 3.6 - Coeficiente de Biot em função da porosidade em amostras de carbonatos (pressão de poros de 500psi e pressão confinante de 2500psi) (Vasquez et al, 2009) 
Vale ressaltar que o critério de ruptura não foi variado em função da escassez de dados para a calibração do modelo geomecânico, que poderia auxiliar na confirmação do critério mais adequado. Em função disso, o critério de ruptura de Mohr Coulomb foi o único considerado na análise de sensibilidade.

Variando esses parâmetros como dados de entrada no polígono de tensões foi possível obter resultados que indicaram um intervalo de valores mínimos e máximos para a magnitude de $\mathrm{S}_{\mathrm{Hmax}}$. Os resultados da análise de sensibilidade da estimativa de $\mathrm{S}_{\mathrm{Hmax}}$ foram utilizados como input para o cálculo do gradiente de colapso. Além desses resultados, a estimativa da pressão de colapso também levou em conta todos os outros parâmetros que foram considerados no modelo geomecânico, como pressão de poros, tensão horizontal mínima, tensão de sobrecarga, UCS, temperatura etc.

Como nem todos os dados importantes foram disponibilizados ou não foram obtidos pelas operadoras e pela ANP, foi necessário avaliar diversos cenários no modelo geomecânico e calibrá-lo apenas com os eventos disponibilizados do Poço 7, conforme indicado na Tabela 3.3.

\section{7}

\section{Gradiente de Colapso}

O esquema apresentado na Figura 3.7 mostra o fluxo de cálculo utilizado para estimativa do gradiente de colapso.

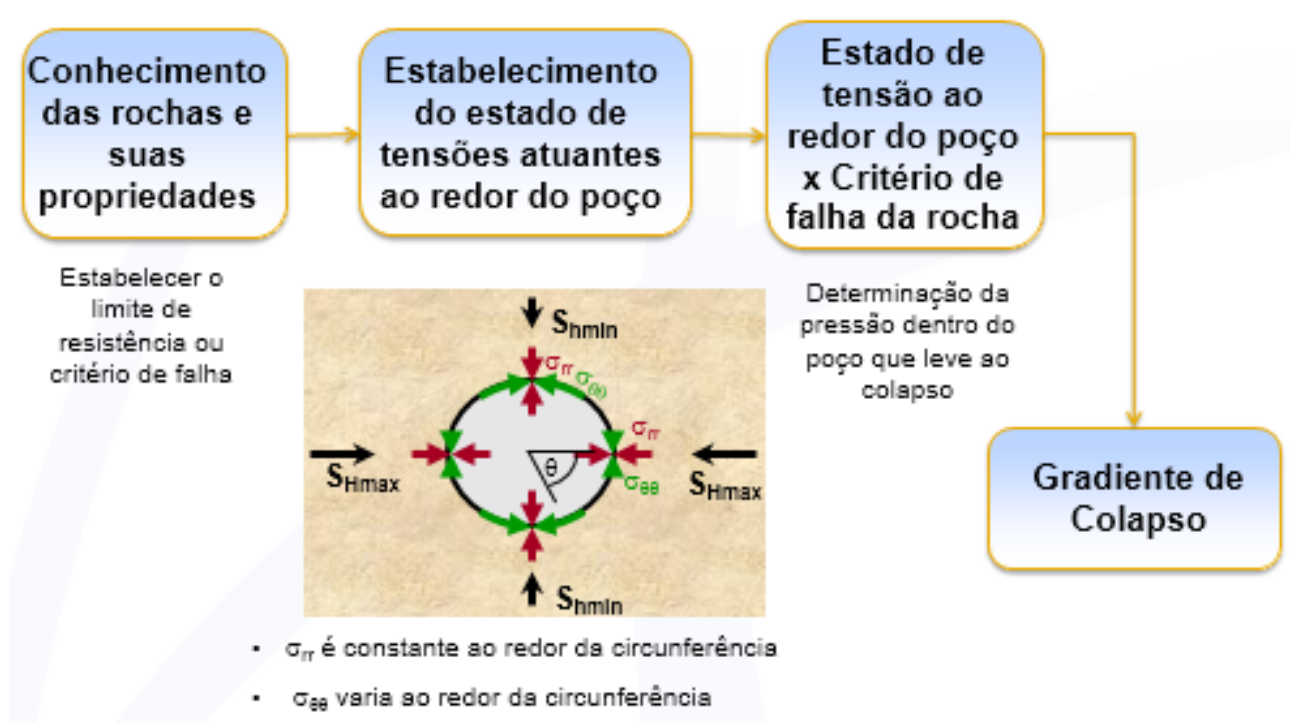

Figura 3.7 - Esquema para cálculo da estimativa do gradiente de colapso 
O estado de tensão atuante na parede do poço pode levar à deformação e ruptura de sua parede. Nesse caso, a deformação da rocha fará com que o diâmetro de poço se reduza gerando problemas, tais como: altos torques durante a perfuração e altos drags durante a retirada da coluna de perfuração. Esse comportamento é típico de rochas dúcteis.

Para outros casos, o estado de tensão poderá levar ao rompimento da rocha na parede do poço. Caso isso aconteça, pedaços da rocha cairão para dentro do poço podendo levar à prisão da coluna de perfuração. Nesse caso, este seria o comportamento de rochas frágeis. Estes modos de ruptura são chamados de falha por cisalhamento e também podem levar ao colapso do poço.

Para o estabelecimento das tensões atuantes ao redor do poço serão utilizadas as tensões em termos de tensões efetivas. Considerando o caso de um poço vertical perfurado em formações com tensões horizontais anisotrópicas $\left(\sigma_{H \max }>\sigma_{\mathrm{hmin}}\right)$, com direção $\theta=0$ fixada paralela à $\sigma_{H \max }$ e assumindo que $\sigma_{\theta}>\sigma_{\mathrm{r}}$, tem-se o conjunto de Equações 3.11. e 3.12.

$$
\begin{gathered}
\sigma_{r}^{\prime}=P_{W}-P_{p} \\
\sigma_{\theta}^{\prime}=\sigma_{H \text { max }}+\sigma_{h m i n}-2\left(\sigma_{H m a x}-\sigma_{h m i n}\right) \cos 2 \theta-P_{W}-P_{p}
\end{gathered}
$$

Como $\sigma_{\theta}$ é a tensão principal maior e $\sigma_{\mathrm{r}}$ é a tensão principal menor, o critério de falha de Mohr Coulomb, em termos de tensões efetivas, pode ser reescrito de acordo com a Equação 3.13.

$$
\sigma_{\theta}^{\prime}=C_{o}+\sigma_{r}^{\prime} \tan ^{2}\left(\frac{\pi}{4}+\frac{\emptyset}{2}\right)
$$

Observando a Equação 3.13, observa-se que enquanto $\sigma_{\theta}$ varia com o ângulo $\theta$ ao longo da parede do poço, $\sigma_{\mathrm{r}}$ permanece constante. A falha ocorrerá para o máximo valor de $\sigma_{\theta}$, já que este leva ao maior diferencial de tensão. O máximo valor de $\sigma_{\theta}$ é atingido para os ângulos $\theta=+\pi / 2$ ou $\theta=-\pi / 2$ e, nesse caso, a expressão de $\sigma^{\prime}{ }_{\theta}$ se torna a Equação 3.14 . 


$$
\sigma_{\theta}^{\prime}=3 \sigma_{H \max }-\sigma_{h \min }-P_{W}-P_{p}
$$

Introduzindo as definições de $\sigma_{\theta}{ }^{\prime}$ (Equação 3.14) e de $\sigma_{\mathrm{r}}{ }^{\prime}$ (Equação 3.11) no critério de falha de Mohr Coulomb (Equação 3.13), pode-se dizer que haverá colapso do poço caso a pressão dentro deste se torne igual ou menor que a tensão circunferencial $\left(\mathrm{P}_{\mathrm{w}}\right)$ indicada na Equação 3.14.

$$
P_{W}=\frac{3 \sigma_{H \max }-\sigma_{h \min }-C_{o}+P_{p}\left(\tan ^{2}\left(\frac{\pi}{4}+\frac{\emptyset}{2}\right)-1\right)}{\tan ^{2}\left(\frac{\pi}{4}+\frac{\emptyset}{2}\right)+1}
$$

Onde a diferença entre a tensão circunferencial e a tensão radial é maior, os breakouts serão formados se o círculo de Mohr Coulomb exceder a envoltória de ruptura para a rocha que está sendo perfurada, conforme exemplificado na Figura 3.8. Como a posição em volta do poço muda de acordo com a direção de $S_{\text {hmin, a }}$ diferença entre a tensão circunferencial e a radial é reduzida. Em algum ponto o círculo de Mohr Coulomb está em contato com a envoltória de ruptura. Esse ponto representa o limite do breakout. A abertura total do breakout pode ser verificado pela diferença angular total entre as linhas vermelhas e laranjas. Na posição em volta do poço mais próximo da tensão horizontal máxima, o círculo de Mohr tornase muito pequeno para causar qualquer falha.

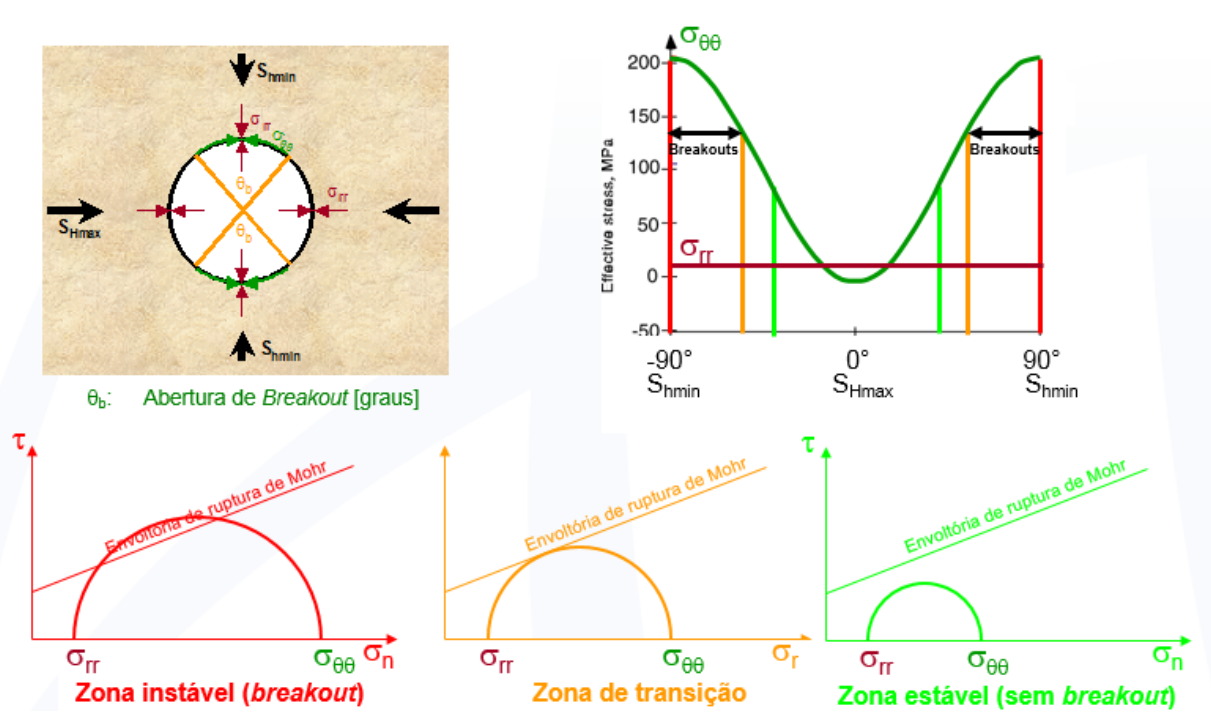

Figura 3.8 - Relação entre tensão radial, circunferencial e envoltória de Mohr-Coulomb 


\section{Apresentação e discussão dos resultados}

A seguir serão apresentados os resultados da estimativa de todos os parâmetros considerados na elaboração do modelo geomecânico de estabilidade de poço para os carbonatos do pré-sal. Vale ressaltar que os resultados serão apresentados conforme o fluxo de trabalho apresentado na Figura 3.1 e é válido apenas para a área do bloco estudado. Devido à complexidade do reservatório, não se recomenda utilizar os resultados para outros blocos do pré-sal sem aferí-los com outros dados referente ao bloco de interesse.

\section{1}

\section{Tensão vertical}

Os dados do perfil densidade e de velocidade compressional são necessários para a estimativa da tensão vertical. Como os Poços 3 e 6 não possuem esses dados de perfil e os Poços 7 e 8 não possuem dados em todo o trecho dos carbonatos, foram geradas curvas de densidade sintética com as correlações de Gardner (1976) e Bellotti e Giacca (1978) e comparadas com os dados de perfil densidade de cada poço no reservatório carbonático. Os resultados estão apresentados nas Figuras 4.1 a 4.6.
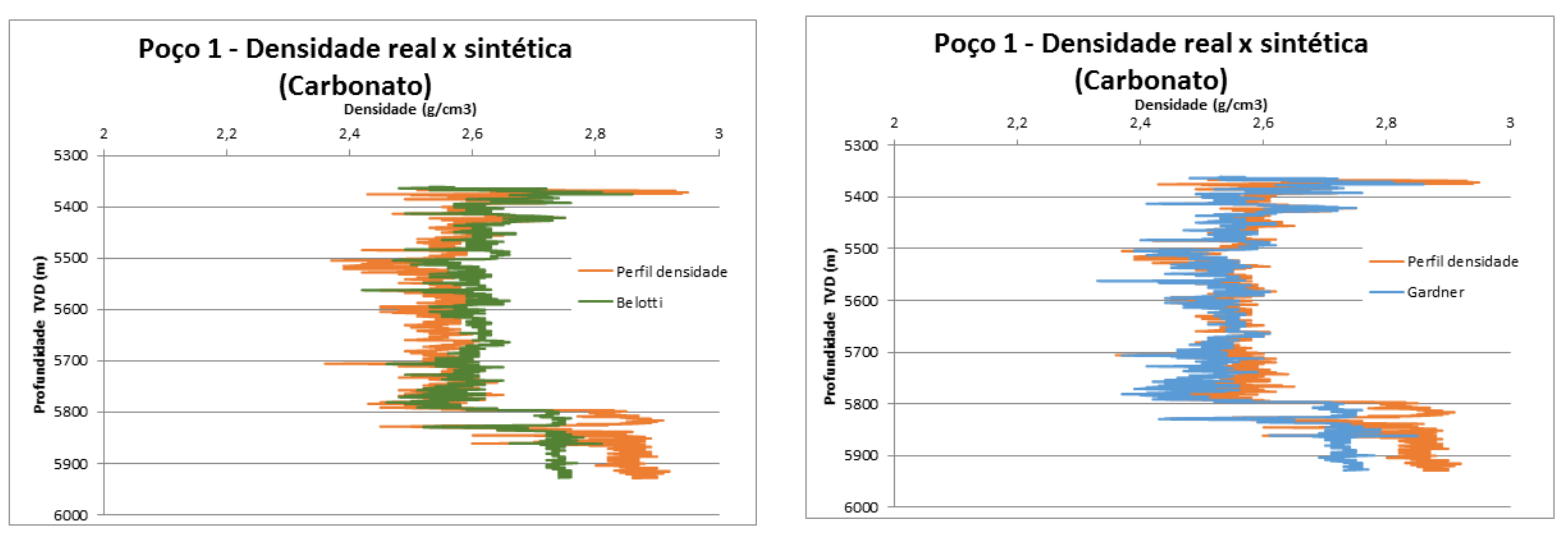

Figura 4.1 - Comparação do perfil densidade corrida no Poço 1 e os dados de densidades sintéticas 

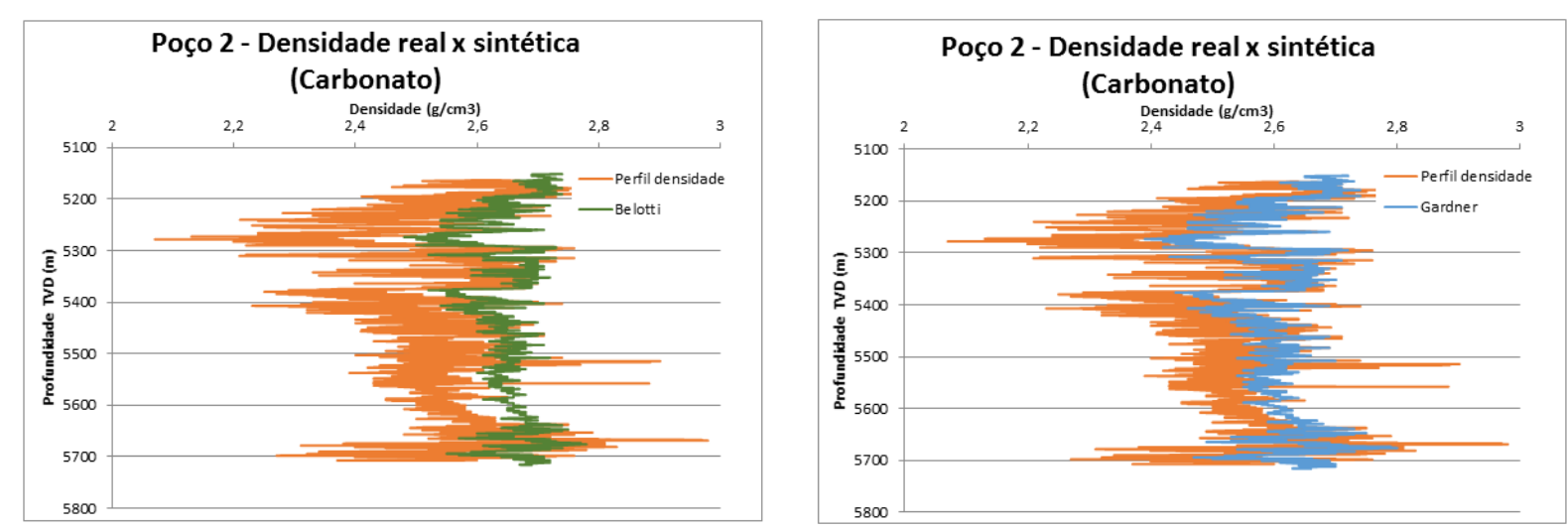

Figura 4.2 - Comparação do perfil densidade corrido no Poço 2 e os dados de densidades sintéticas
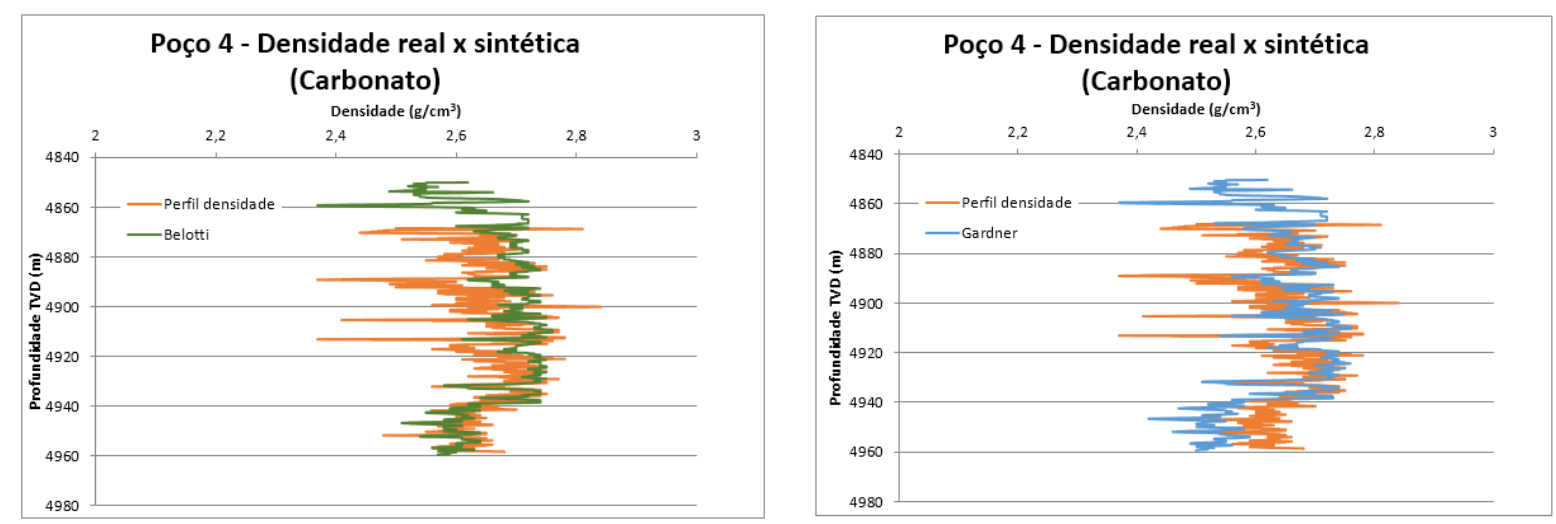

Figura 4.3 - Comparação do perfil densidade corrido no Poço 4 e os dados de densidades sintéticas
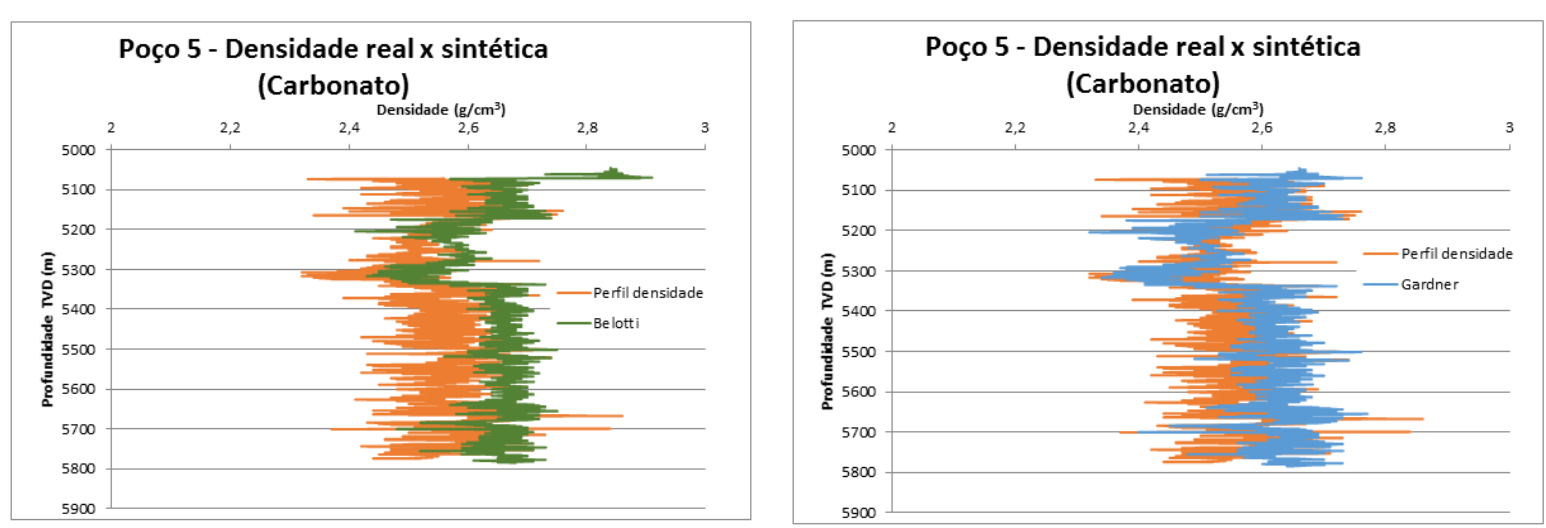

Figura 4.4 - Comparação do perfil densidade corrido no Poço 5 e os dados de densidades sintéticas 

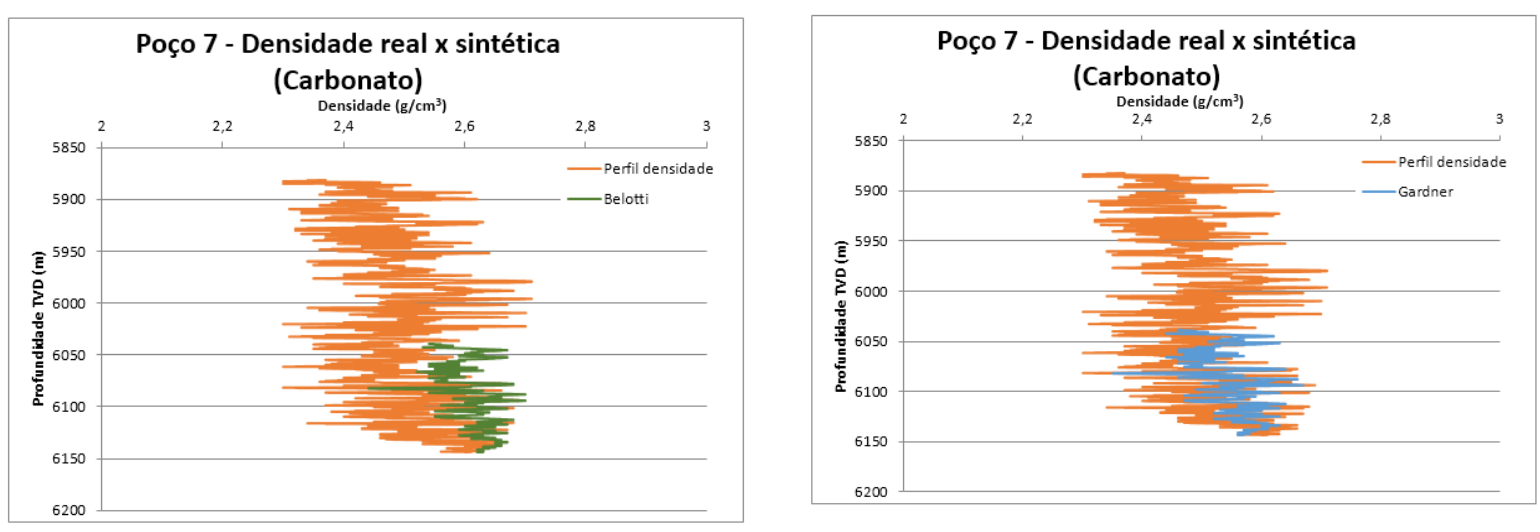

Figura 4.5 - Comparação do perfil densidade corrido no Poço 7 e os dados de densidades sintéticas
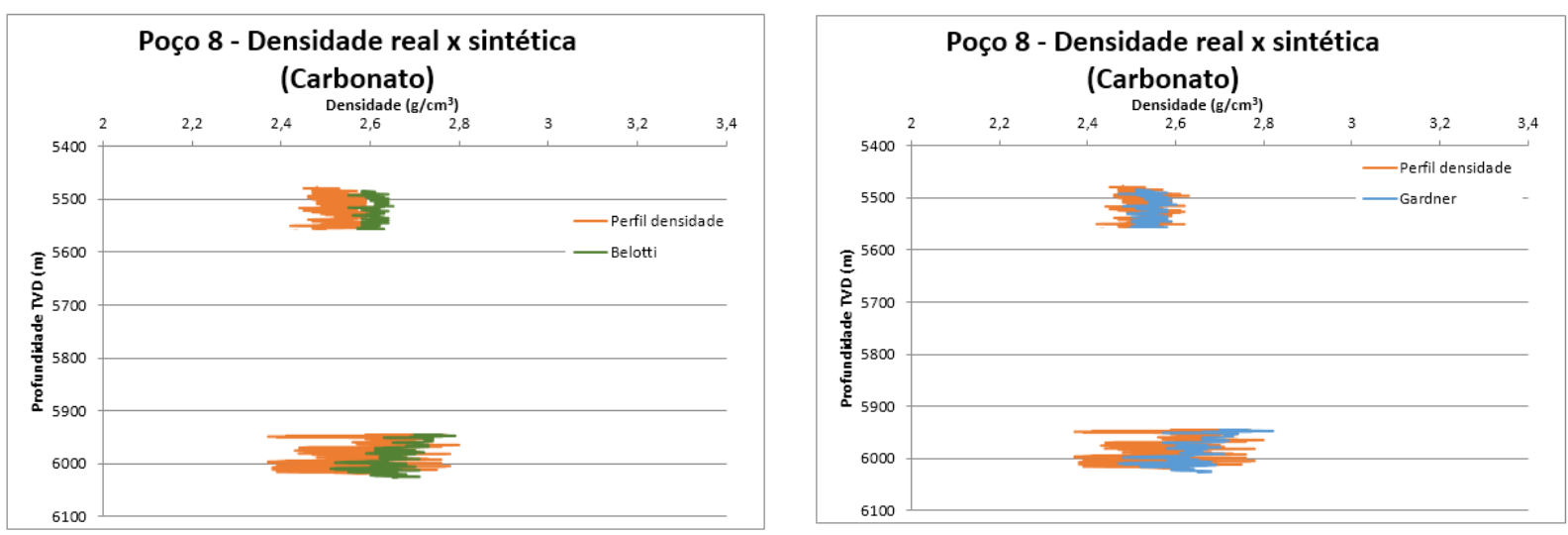

Figura 4.6 - Comparação do perfil densidade corrido no Poço 8 e os dados de densidades sintéticas

Analisando os gráficos das Figuras 4.1 a 4.6, observa-se que os perfis de densidade sintéticos obtidos pela correlação de Gardner (1974) apresentaram resultados mais próximos dos valores de densidade obtidos pelo perfil (dados medidos) e, por isso, esses resultados foram considerados nos poços onde não havia dados de densidade para o cálculo da sobrecarga.

Os valores de densidade nos carbonatos do Poço 1 estão em torno de $2,6 \mathrm{~g} / \mathrm{cm}^{3}$ enquanto que os Poços 2, 5, 7 e 8 variam de 2,4 a 2,6 g/ $\mathrm{cm}^{3}$. Já o Poço 4 apresentou valores de densidade ligeiramente maiores quando comparados com os outros poços, variando de 2,6 a $2,7 \mathrm{~g} / \mathrm{cm}^{3}$. Essa variação de densidade encontrada pode ser atribuída à presença de intercalações litológicas que foram observadas nas análises do perfil de raios gama.

Domingues (2011) fez um estudo de caracterização geológica e geomecânica de análogos do pré-sal brasileiro e, dentre as várias análises, foram determinados índices físicos nas amostras de Travertino de Itaboraí, que, segundo a autora, foram considerados como análogos devido à presença de quartzo em sua composição e de 
sua aparente resistência, o que ocorre em fáceis do reservatório do pré-sal. $\mathrm{Na}$ Tabela 4.1 estão apresentados resultados dos índices físicos avaliados. O estudo indica valores médios de densidade aparente saturada para os carbonatos análogos do pré-sal de $2,6 \mathrm{~g} / \mathrm{cm}^{3}$. Comparando com os valores obtidos no perfil densidade medido nos poços em análise, observa-se que os dados apresentam uma boa representabilidade e que, do ponto de vista de densidade, a analogia do Travertino de Itaboraí com o pré-sal da área em estudo poderia ser considerada.

Tabela 4.1 - Resultados dos índices físicos determinados no Travertino de Itaboraí (Fonte:Domingues, 2011)

\begin{tabular}{|l|l|l|l|l|l|}
\hline \multicolumn{7}{|c|}{ Indices fisicos } \\
\hline Amostra & $\begin{array}{c}\text { Massa } \\
\text { específica } \\
\text { aparente } \\
\text { seca }\left(\mathrm{Mg} / \mathrm{m}^{3}\right)\end{array}$ & $\begin{array}{c}\text { Massa } \\
\text { específica } \\
\text { aparente } \\
\text { saturada } \\
\left(\mathrm{Mg} / \mathrm{m}^{3}\right)\end{array}$ & $\begin{array}{c}\text { Densidade } \\
\text { esqueletal } \\
\text { aparente } \\
\left(\mathrm{Mg} / \mathrm{m}^{3}\right)\end{array}$ & $\begin{array}{c}\text { Porosidade } \\
\text { Aparente } \\
(\%)\end{array}$ & $\begin{array}{c}\text { Absorção } \\
\text { d'água } \\
\text { aparente }(\%)\end{array}$ \\
\hline TRI-04 & 2,56 & 2,59 & 2,62 & 2,36 & 0,92 \\
\hline TRI-05 & 2,63 & 2,65 & 2,68 & 1,74 & 0,66 \\
\hline TRI-06 & 2,42 & 2,50 & 2,63 & 7,79 & 3,22 \\
\hline TRI-07 & 2,61 & 2,63 & 2,66 & 1,97 & 0,76 \\
\hline TRI-08 & 2,61 & 2,64 & 2,68 & 2,41 & 0,92 \\
\hline TRI-09 & 2,63 & 2,64 & 2,66 & 1,12 & 0,43 \\
\hline TRI-10 & 2,54 & 2,58 & 2,65 & 4,20 & 1,65 \\
\hline
\end{tabular}

Alguns poços possuem intercalações de diferentes tipos de sais, mas em função da ausência de relatórios de caracterização geológico mais detalhado optouse por considerar apenas os sais de maior espessura, identificados como a halita $\left(2,03 \mathrm{~g} / \mathrm{cm}^{3}\right)$ e a anidrita $\left(2,98 \mathrm{~g} / \mathrm{cm}^{3}\right)$. Os valores de densidade dos sais foram considerados com base na literatura conforme Tabela 4.2 (Mohriak et al., 2008).

Os resultados estatísticos da estimativa da tensão vertical (gradiente de sobrecarga) para os carbonatos do pré-sal estão apresentados nas Tabelas 4.3 e 4.4 . 
Tabela 4.2 - Perfis de evaporitos salinos (Mohriak et al., 2008)

\begin{tabular}{|c|c|c|c|c|c|}
\hline \multicolumn{6}{|c|}{ Perfis de evaporitos salinos } \\
\hline Litologia & Fórmula & $\begin{array}{c}\text { Densidade } \\
\left(\mathrm{g} / \mathrm{cm}^{3}\right)\end{array}$ & $D t c(\mu s / \mathrm{ft})$ & Nphi (\%) & GR (API) \\
\hline Halita & $\mathrm{NaCl}$ & 2,03 & 67 & 0 & 0 \\
\hline Anidrita & $\mathrm{CaSO}_{4}$ & 2,98 & 50 & 0 & 0 \\
\hline Gipsita & $\mathrm{CaSO}_{4}\left(\mathrm{H}_{2} \mathrm{O}\right)_{2}$ & 2,35 & 52.5 & 49 & 0 \\
\hline Silvita & $\mathrm{KCl}$ & 1,86 & 74 & 0 & 500 \\
\hline Carnalita & $\mathrm{KCIMgCL}_{2}\left(\mathrm{H}_{2} \mathrm{O}\right)_{6}$ & 1,57 & 78 & 65 & 200 \\
\hline Polihalita & $\mathrm{K}_{2} \mathrm{SO}_{4} \cdot \mathrm{MgSO}_{4} \cdot 2 \mathrm{CaSO}_{4} \cdot 2 \mathrm{H}_{2} \mathrm{O}$ & 2,79 & 57,5 & 15 & 180 \\
\hline Kieserita & $\mathrm{MgSO}_{4} \cdot \mathrm{H}_{2} \mathrm{O}$ & 2,55 & & - & 0 \\
\hline Kainita & $\mathrm{KMgSO}_{4} \mathrm{Cl} \cdot 3 \mathrm{H}_{2} \mathrm{O}$ & 2,12 & & 45 & 225 \\
\hline Langbeinita & $\mathrm{K}_{2} \mathrm{SO}_{4} \cdot 2 \mathrm{H}_{2} \mathrm{O}$ & 2,82 & 52 & 0 & 275 \\
\hline
\end{tabular}

Observa-se que os valores médios estão entre de 13,6 a 14,1ppg para as rochas carbonáticas e os valores estatísticos de $\mathrm{P}_{10}$ e $\mathrm{P}_{90}$ variam respectivamente de 13,5 a 14,1 ppg e de 13,7 a 14,5 ppg.

Tabela 4.3 - Valores estatísticos da estimativa do gradiente de sobrecarga para os carbonatos

\begin{tabular}{|l|c|c|c|}
\hline \multicolumn{4}{|c|}{ Gradiente de Sobrecarga (ppg) } \\
\hline \hline Carbonato & Média & $\mathrm{P}_{10}$ & $\mathrm{P}_{90}$ \\
\hline Poço 1 & 14,1 & 13,8 & 14,4 \\
\hline Poço 2 & 13,9 & 13,6 & 14,2 \\
\hline Poço 3 & 14,1 & 13,9 & 14,3 \\
\hline Poço 4 & 13,6 & 13,6 & 13,7 \\
\hline Poço 5 & 14,1 & 13,8 & 14,4 \\
\hline Poço 6 & 13,8 & 13,6 & 14,0 \\
\hline Poço 7 & 14,3 & 14,1 & 14,5 \\
\hline Poço 8 & 13,8 & 13,5 & 14,1 \\
\hline
\end{tabular}

As Tabelas 4.5 e 4.6 apresentam os valores da estimativa do gradiente de sobrecarga para as rochas ígneas que foram encontradas nos Poços 1 e 7. 
Tabela 4.4 - Valores estatísticos da estimativa da pressão de sobrecarga para os carbonatos

\begin{tabular}{|l|c|c|c|}
\hline \multicolumn{4}{|c|}{ Pressão de Sobrecarga (MPa) } \\
\hline \hline Carbonato & Média & $\mathrm{P}_{10}$ & $\mathrm{P}_{90}$ \\
\hline Poço 1 & 93,7 & 88,2 & 99,3 \\
\hline Poço 2 & 88,5 & 83,0 & 94,1 \\
\hline Poço 3 & 85,9 & 82,4 & 89,5 \\
\hline Poço 4 & 78,7 & 77,8 & 79,7 \\
\hline Poço 5 & 88,6 & 83,0 & 94,2 \\
\hline Poço 6 & 88,2 & 85,0 & 91,4 \\
\hline Poço 7 & 99,9 & 95,9 & 103,8 \\
\hline Poço 8 & 91,4 & 82,8 & 100,2 \\
\hline
\end{tabular}

No Poço 1, a perfuração da rocha ígnea teve início a partir da profundidade de 5900m, enquanto no Poço 7 foi a partir a profundidade de $6150 \mathrm{~m}$, com espessor de $197 \mathrm{~m}$ e $157 \mathrm{~m}$, respectivamente. Apresentaram valores médios do gradiente de sobrecarga entre 14,6 e 14,8 ppg.

Tabela 4.5 - Valores estatísticos da estimativa do gradiente de sobrecarga para as rochas ígneas

\begin{tabular}{|c|c|c|c|}
\hline \multicolumn{4}{|c|}{ Gradiente de Sobrecarga (ppg) } \\
\hline \hline Ignea & Média & $\mathrm{P}_{10}$ & $\mathrm{P}_{90}$ \\
\hline Poço 1 & 14,6 & 14,5 & 14,7 \\
\hline Poço 7 & 14,8 & 14,6 & 15,1 \\
\hline
\end{tabular}

Tabela 4.6 - Valores estatísticos da estimativa da pressão de sobrecarga para as rochas ígneas

\begin{tabular}{|l|c|c|c|}
\hline \multicolumn{4}{|c|}{ Pressão de Sobrecarga (MPa) } \\
\hline \hline Ignea & Média & $\mathrm{P}_{10}$ & $\mathrm{P}_{90}$ \\
\hline Poço 1 & 100,8 & 100,8 & 100,9 \\
\hline Poço 7 & 111,6 & 106,2 & 116,9 \\
\hline
\end{tabular}

Sabe-se que o gradiente de sobrecarga é afetado pela lâmina d' água, quanto maior seu espessor, menor será o gradiente de sobrecarga. Comparando as curvas do gradiente de sobrecarga no Gráfico 4.1, observa-se que na profundidade dos carbonatos entre $5000 \mathrm{~m}$ e $6140 \mathrm{~m}$ esse gradiente varia de 13,5 a $14,5 \mathrm{ppg}$. 


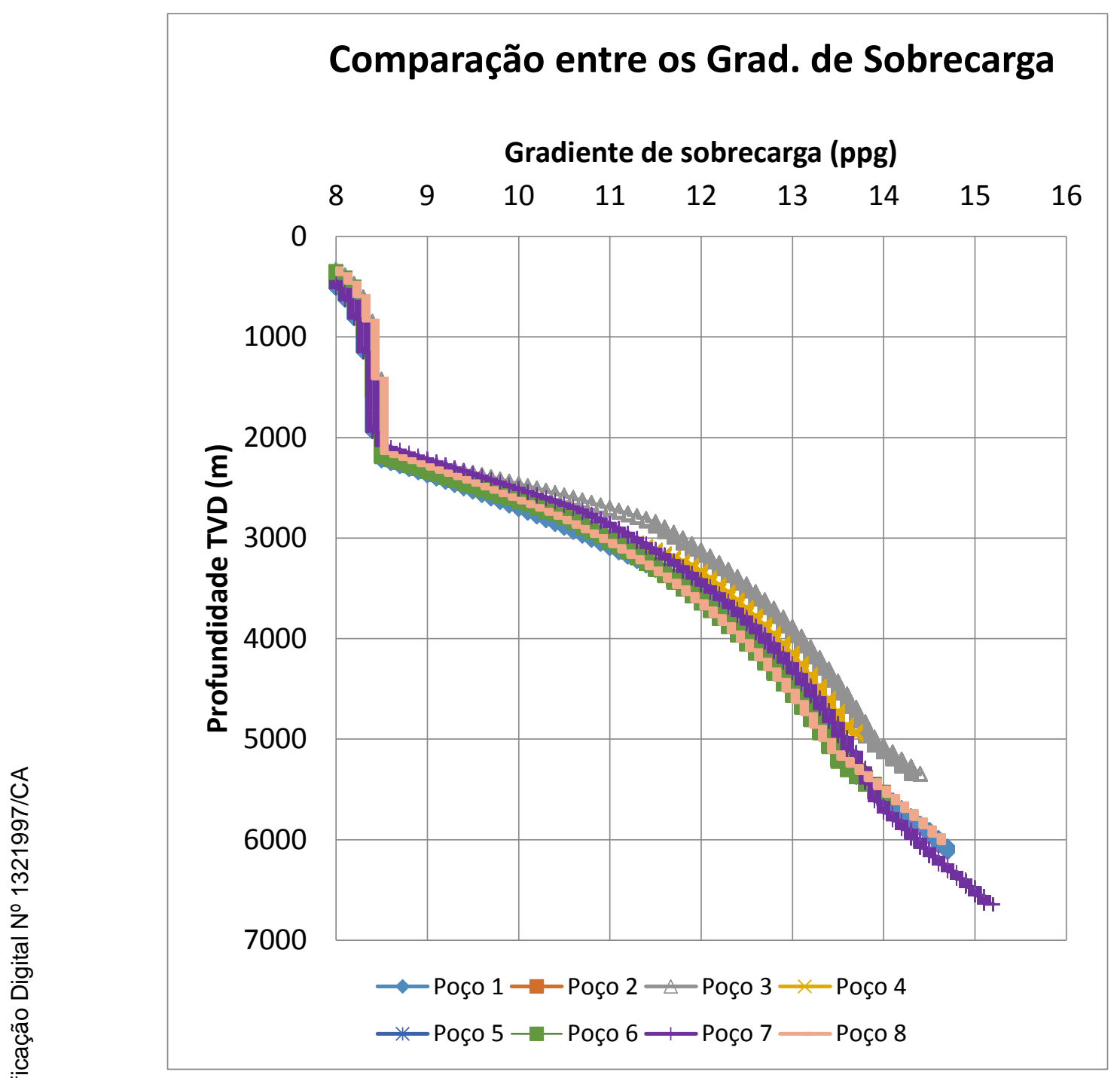

Gráfico 4.1 - Comparação das curvas do gradiente da tensão vertical

4.2

\section{Pressão de poros}

Foram realizadas 249 medidas diretas de pressão de poros nos carbonatos do pré-sal e a Tabela 4.7 indica a quantidade de medições que foram realizadas em cada poço. Como a metodologia de subcompactação não se aplica à esse tipo de reservatório, essas medições foram consideradas para a estimativa da pressão de poros. Além dessas pressões medidas, o evento de kick relatado a $5753 \mathrm{~m}$, que ocorreu no Poço 7, também foi considerado para a calibração da estimativa desse parâmetro. 
Tabela 4.7 Número de medições diretas de pressões de poros em cada poço

\begin{tabular}{|c|c|}
\hline Poço & $\begin{array}{c}\mathbf{N}^{\mathbf{0}} \text { de medições } \\
\text { de pressão de } \\
\text { poros }\end{array}$ \\
\hline \hline 1 & 10 \\
\hline 2 & 49 \\
\hline 3 & 8 \\
\hline 4 & 25 \\
\hline 5 & 74 \\
\hline 6 & 11 \\
\hline 7 & 69 \\
\hline 8 & 3 \\
\hline Total & $\mathbf{2 4 9}$ \\
\hline
\end{tabular}

Nos Gráficos 4.2 e 4.3 e na Tabela 4.8 estão apresentados os valores das pressões de poros medidas nos poços analisados.

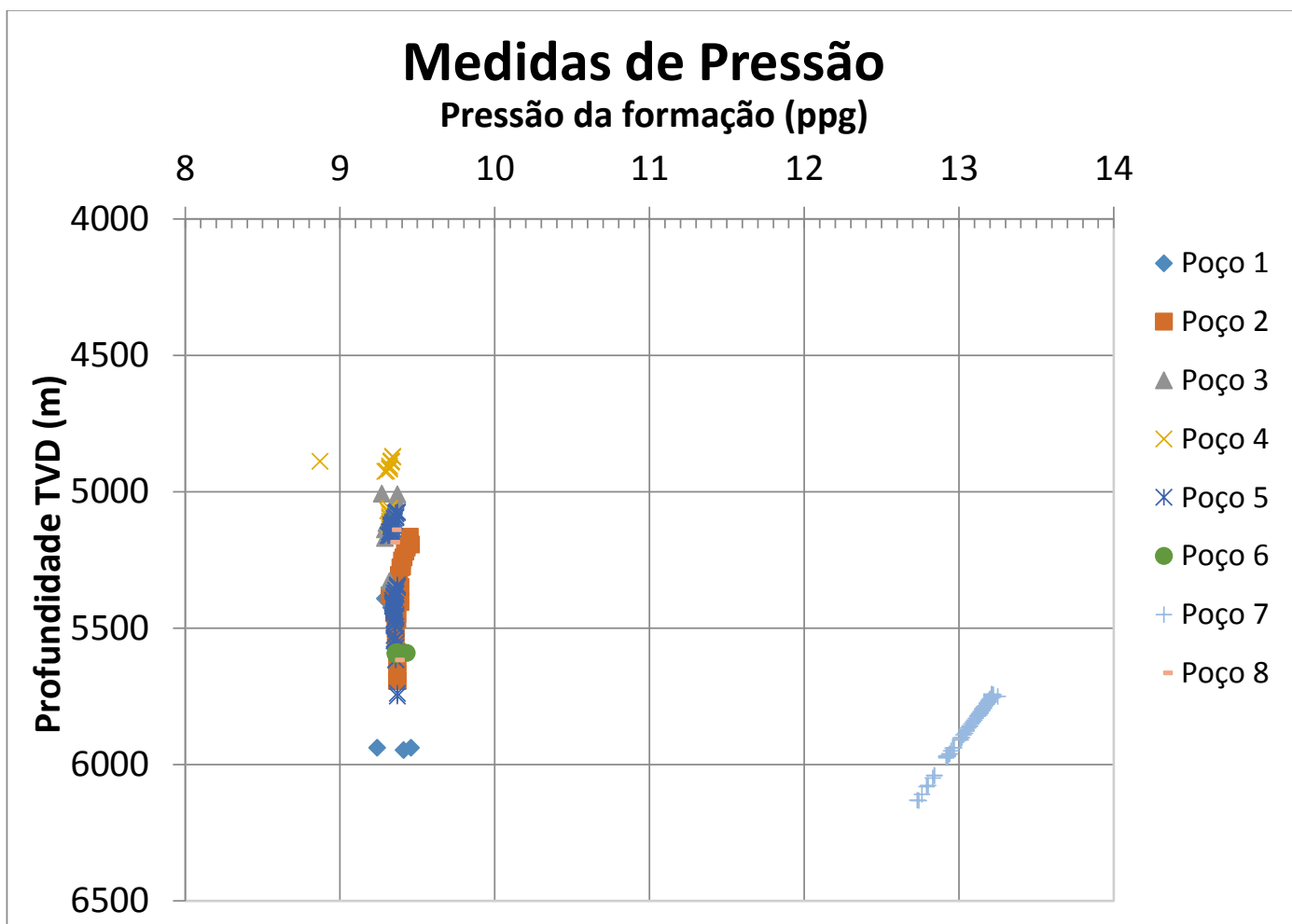

Gráfico 4.2 - Valores dos gradientes de pressões de poros medidas nos carbonatos do pré-sal

Após a análise dos Gráficos 4.2 e 4.3 foi possível observar dois cenários de pressões de poros na área de estudo: uma região com pressão de poros levemente sobrepressurizada $\left(9,0 \mathrm{ppg}<\mathrm{P}_{\mathrm{P}}<9,5 \mathrm{ppg}\right)$ e outra com pressão de poros anormalmente alta $\left(\mathrm{P}_{\mathrm{P}}>9,5 \mathrm{ppg}\right)$. 


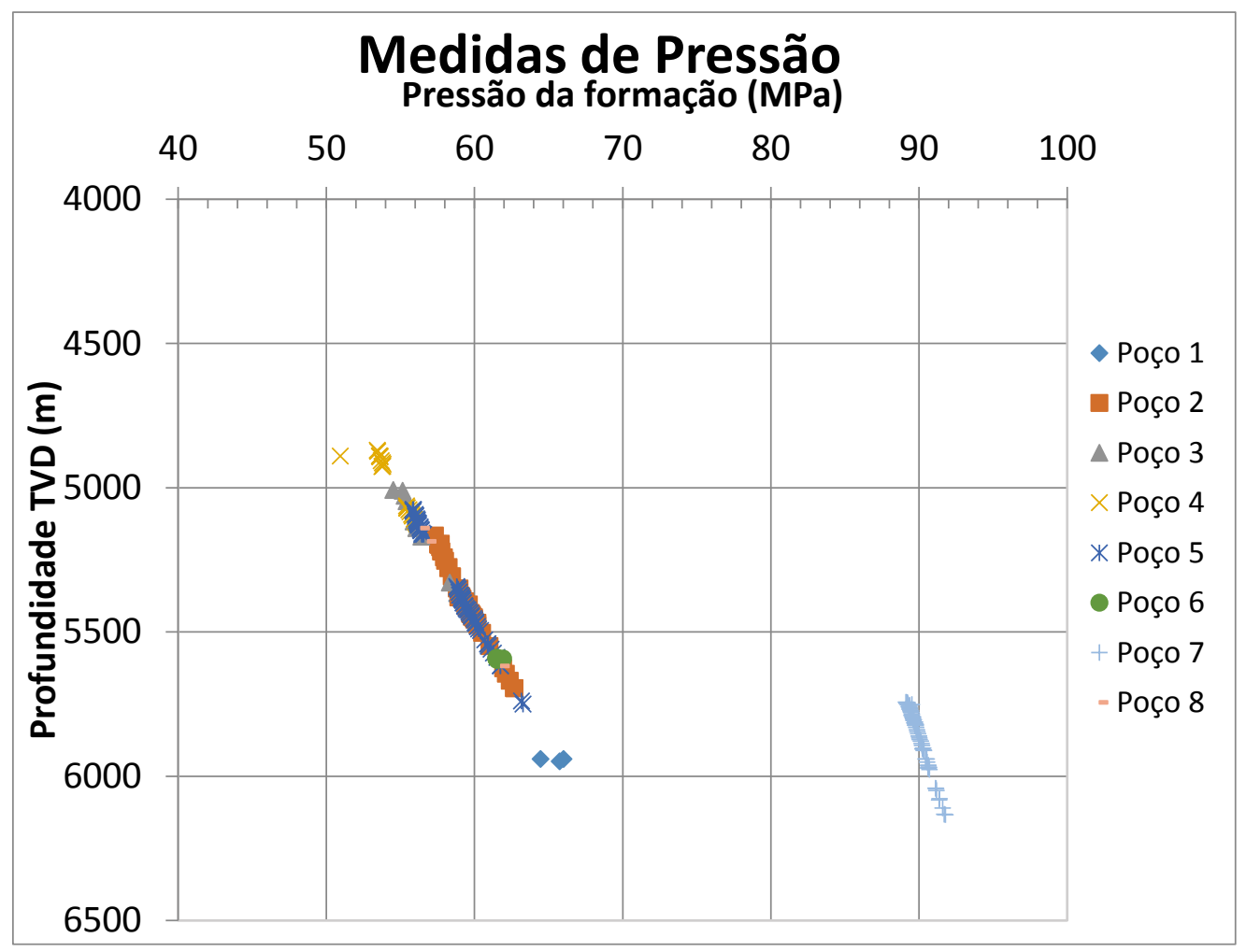

Gráfico 4.3 - Valores de pressão de poros medidas nos carbonatos do pré-sal

Além dos valores de pressões medidas nos poços, o evento do kick reafirma que o Poço 7 está localizado em uma região de pressão de poros anormalmente alta com gradientes entre 13,2 e 12,7ppg. Enquanto que no outro cenário (Poços 1, 2, 3, 4, 5, 6 e 8), observou-se valores de gradiente de pressão em torno de 9,2ppg. Vale ressaltar que para controlar o kick que ocorreu à 5753m, no Poço 7, foi utilizado um peso de fluido de 13,6ppg.

Tabela 4.8 - Valores estatísticos das pressões de poros medidas nos carbonatos do pré-sal

\begin{tabular}{|l|c|c|c|}
\hline \multicolumn{4}{|c|}{ Gradiente de Pressão de Poros (ppg) } \\
\hline \hline Carbonato & Média & $\mathrm{P}_{10}$ & $\mathrm{P}_{90}$ \\
\hline Poço 1 & 9,4 & 9,4 & 9,4 \\
\hline Poço 2 & 9,4 & 9,3 & 9,4 \\
\hline Poço 3 & 9,3 & 9,3 & 9,3 \\
\hline Poço 4 & 9,3 & 9,3 & 9,3 \\
\hline Poço 5 & 9,3 & 9,3 & 9,3 \\
\hline Poço 6 & 9,4 & 9,3 & 9,4 \\
\hline Poço 7 & 12,7 & 12,7 & 13,2 \\
\hline Poço 8 & 9,3 & 9,3 & 9,3 \\
\hline
\end{tabular}


Os valores de gás registrados nos Poços 1 e 7 estão apresentados na Tabela 4.9. Pode-se associar os valores de gás total de 417UGT ao kick reportado durante a perfuração do Poço 7. Os outros valores de gás total não sugerem indícios de anormalidades de pressão de poros nas outras profundidades.

Tabela 4.9 - Valores de gás registrados nos Poços

\begin{tabular}{|c|c|c|c|c|c|}
\hline \multicolumn{3}{|c|}{ Poço 1 } & \multicolumn{3}{|c|}{ Poço 7 } \\
\cline { 1 - 3 } Prof. TVD $(\mathrm{m})$ & \multirow{2}{*}{$\begin{array}{c}\text { Gás Total } \\
\text { (UGT) }\end{array}$} & Prof. TVD (m) & Gás Total \\
\cline { 5 - 6 } Topo & Base & Topo & Base & (UGT) \\
\hline \hline 5413 & 5421 & 5,2 & 5740 & 5742 & 417 \\
\hline 5478 & 5484 & 5,6 & 5853 & 5854 & 24,4 \\
\hline 5502 & 5507 & 7,2 & 6164 & 6164 & 20,4 \\
\hline 5792 & 5795 & 14,2 & \multicolumn{3}{|c}{} \\
\cline { 1 - 1 } 6103 & 6118 & 19,5 & &
\end{tabular}

O poço que apresentou os maiores valores de pressão de poros atravessa a maior camada de sal e também um trecho de rocha ígnea. Levando em conta as características do sistema petrolífero do pré-sal brasileiro (Figura 1.2), foram estabelecidas algumas hipóteses para justificar a alta pressão no Poço 7:

$\checkmark$ Como o reservatório carbonático localiza-se entre o sal e a rocha ígnea, isso pode ter formado uma espécie de selo, o que provocou a pressurização do reservatório.

$\checkmark$ A presença de falhas geológicas no sistema petrolífero, que estejam com um comportamento selante, poderia ter provocado uma compartimentalização do reservatório e, consequentemente, poderia causar uma pressurização do mesmo;

$\checkmark$ Pode-se supor que tenha havido uma transferência de pressão de poros anormal para o reservatório do pré-sal, em um determinado tempo geológico, através das falhas geológicas não selantes;

$\checkmark$ Supõe-se que o poço foi perfurado muito próximo ou que tenha atravessado um domo salino. Em regiões com presença desses domos salinos existe a grande possibilidade de que o regime de pressão tenha sido afetado;

$\checkmark$ Supõe-se que tenha ocorrido o efeito de flotabilidade de fluidos em uma zona anticlinal do reservatório. 


\section{3}

\section{Temperatura}

A temperatura também é um fator que pode influenciar na pressão de poros, por isso, esses dados foram avaliados. Observa-se no Gráfico 4.4 que os valores de temperatura medidas pelo perfil estão entre $60^{\circ}$ e $80^{\circ} \mathrm{C}$, que são valores abaixo do que é considerado como característico de poço de alta temperatura (temperatura de fundo maior do que $150^{\circ} \mathrm{C}$ ).

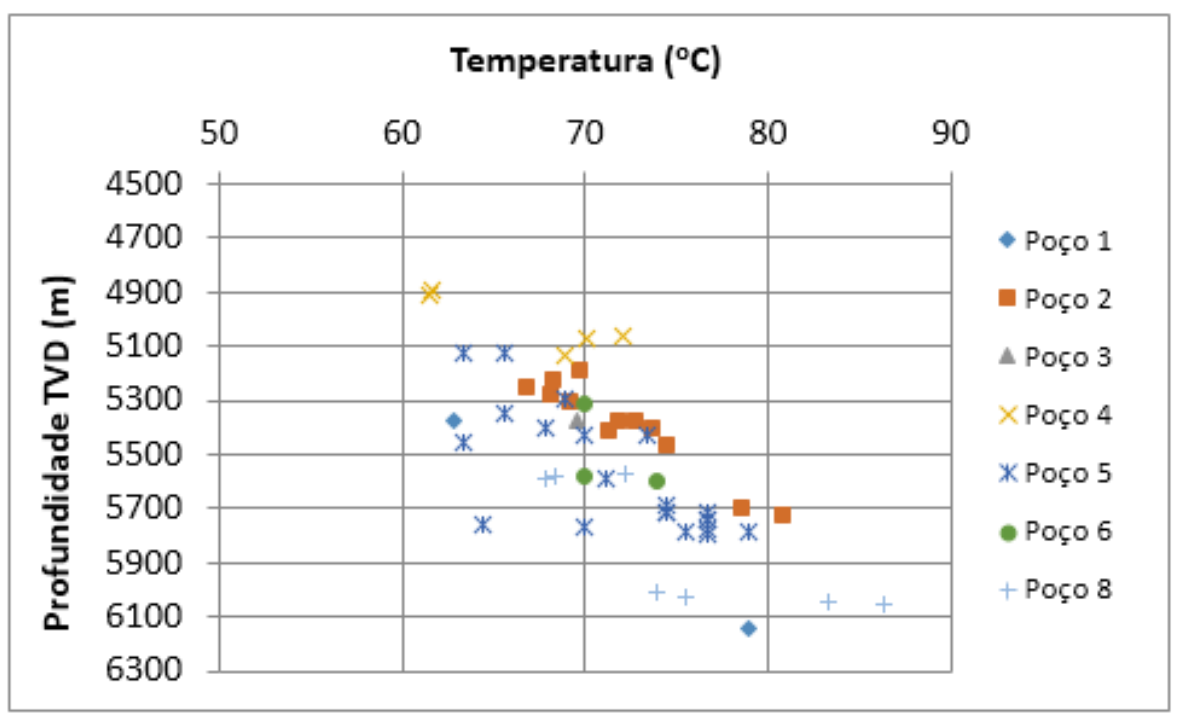

Gráfico 4.4 - Valores de temperatura medidos em perfil

Apesar da dispersão dos dados observado no Gráfico 4.5, o trecho em análise (4900 a $6200 \mathrm{~m}$ ) apresenta gradiente geotérmico médio normal de $23.5^{\circ} \mathrm{C} / \mathrm{km}$, o que indica que os poços desse estudo não são HT (High Temperature).

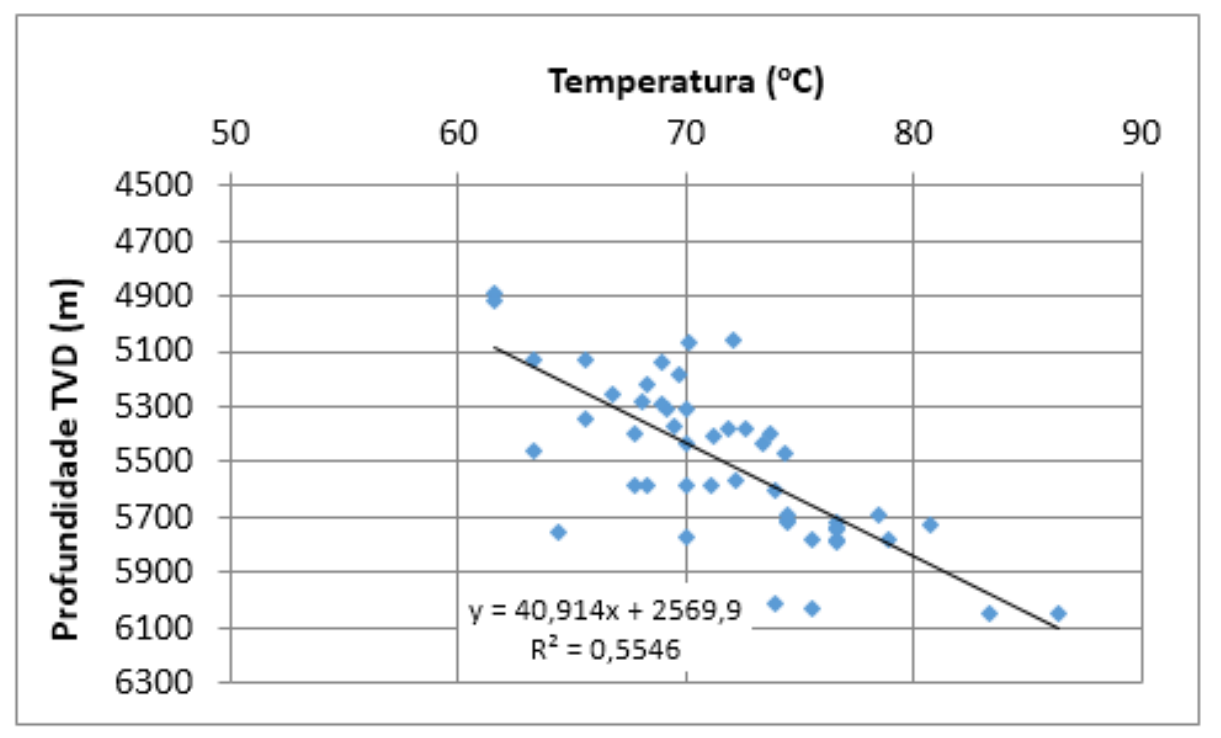

Gráfico 4.5 - Relação dos valores de temperatura medidos 
Vale ressaltar que os dados de temperatura do Poço 7 só foram medidos no sal e nas rochas igneas, por isso, não estão considerados no Grafico 4.4.

\section{4}

\section{Tensão horizontal mínima}

Os testes realizados para avaliação da formação foram o LOT e FIT. Os Gráficos 4.6 e 4.7 apresentam todos os testes realizados nos poços da região em análise.

Alguns destes testes foram realizados no sal e não foram considerados na análise. Do Gráfico 4.6, observa-se que a maioria dos resultados dos testes indica valores entre 11,8 e 14,0ppg para os carbonatos presentes entre as profundidades de 5000 e $6100 \mathrm{~m}$. Analisando os resultados na profundidade de $6000 \mathrm{~m}$, em termos de pressão (Gráfico 4.7) e levando em conta que os valores de FIT são valores representativos de um limite inferior, os valores estimados para o início da ruptura da rocha carbonática estariam entre 78 a 104MPa.

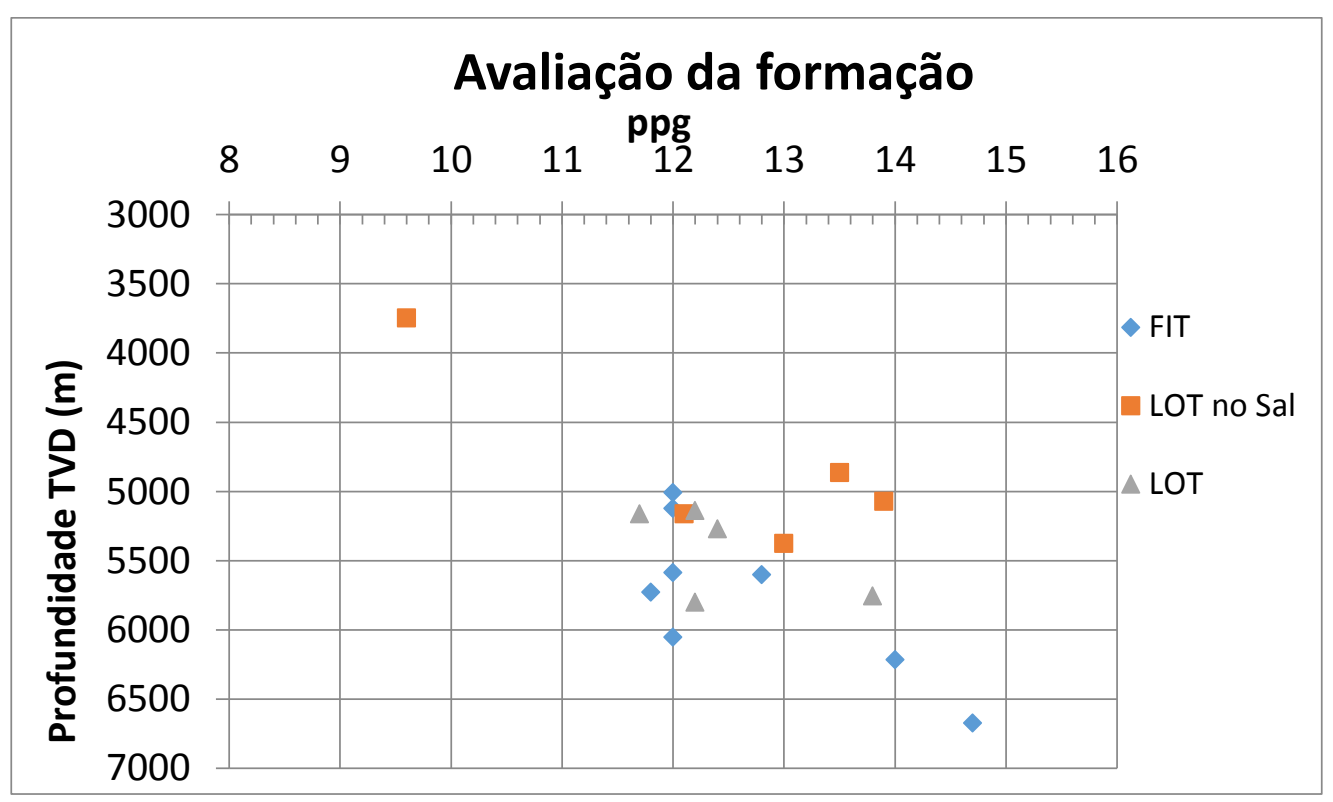

Gráfico 4.6 - Resultados da avaliação da formação de todos os testes

O coeficiente de correlação, $\mathrm{R}^{2}(0,7781)$, indica uma boa correlação entre os resultados das provas de LOT, de acordo com o Gráfico 4.8. Esse coeficiente permite considerar válida a estimativa de $\mathrm{S}_{\mathrm{hmin}}$ para a área considerando os valores de LOT realizados nos carbonatos dos poços analisados. 


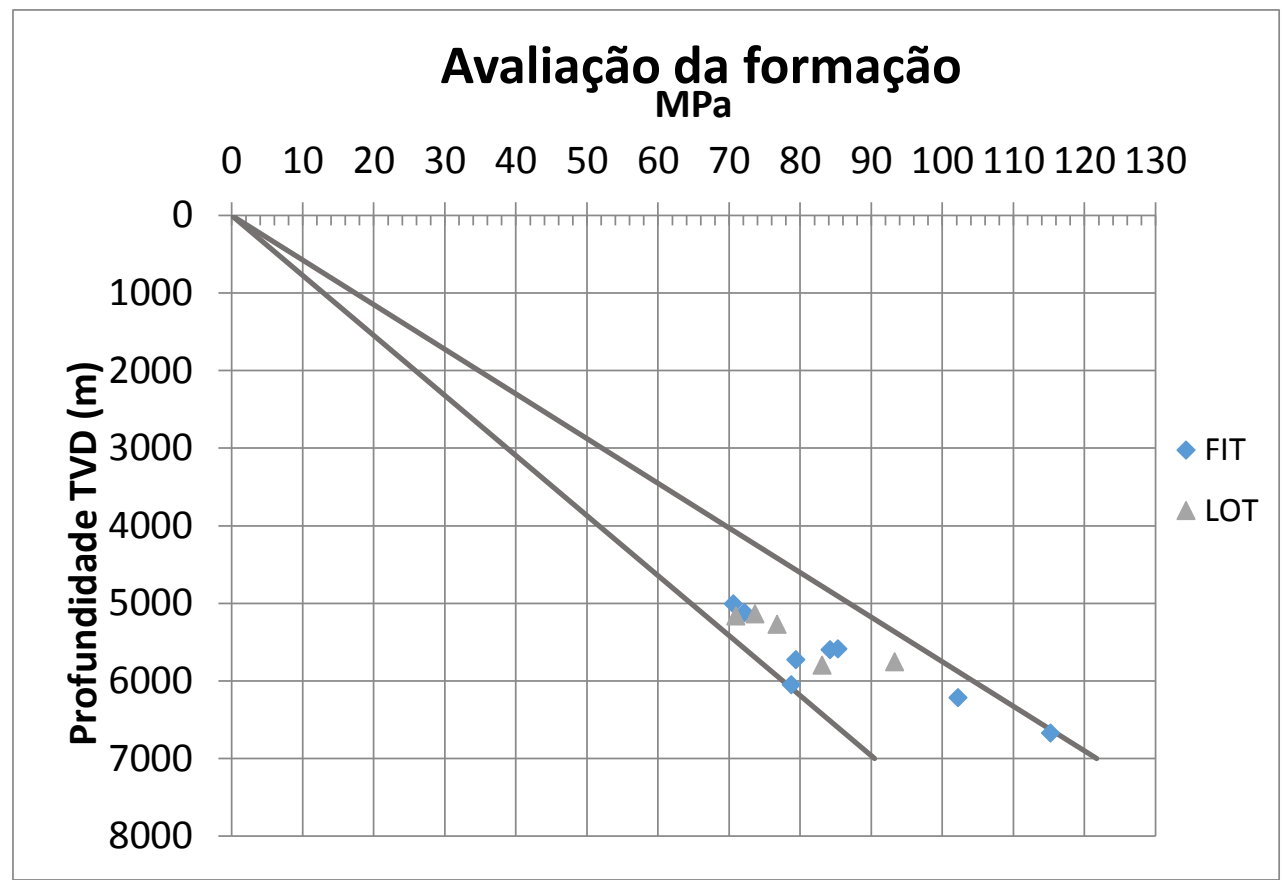

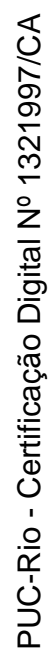

Gráfico 4.7 - Resultados da avaliação da formação em unidades de pressão

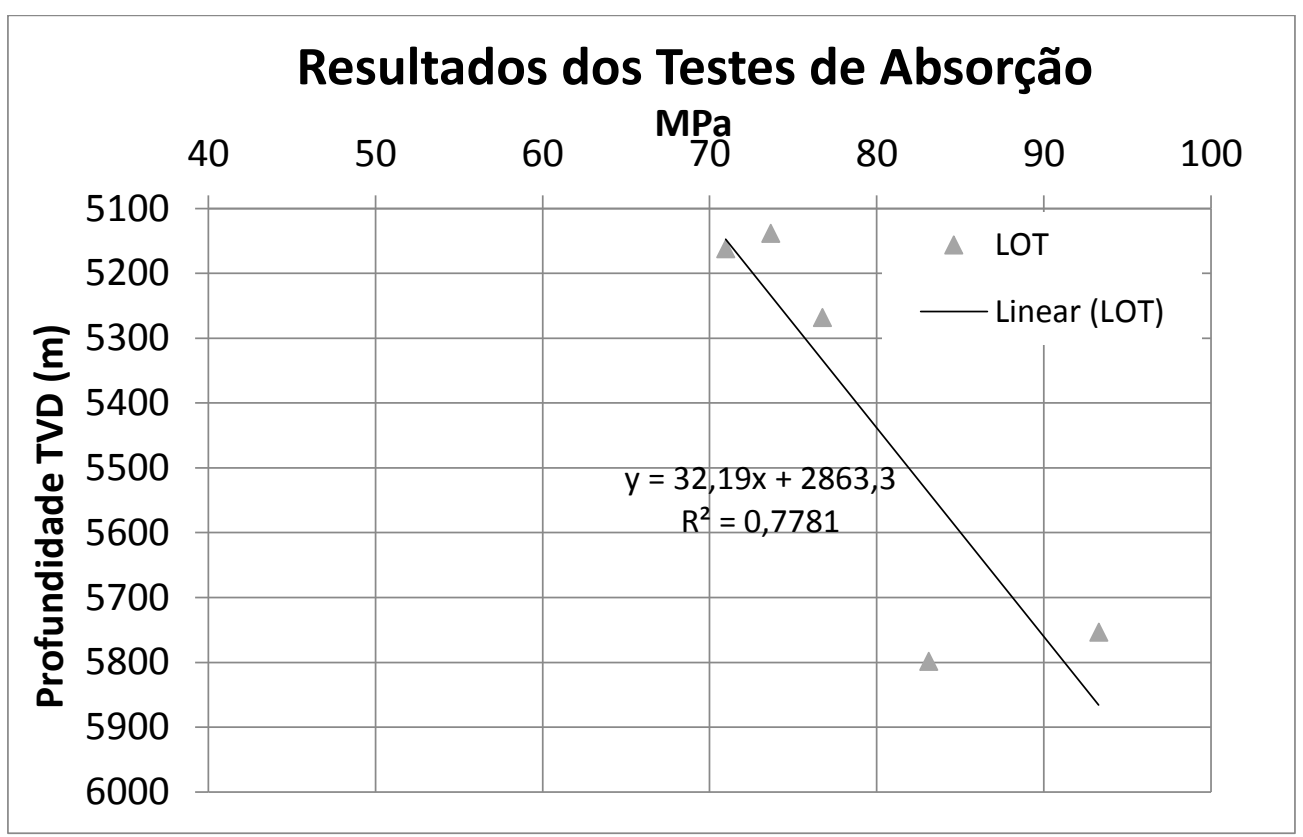

Gráfico 4.8 - Correlação dos resultados dos testes de LOT

$\mathrm{Na}$ Tabela 4.10 estão apresentados os valores da estimativa de $\mathrm{S}_{\mathrm{hmin}}$ referente aos testes de LOT e a Razão das Tensões Efetivas (Effetive Stress Ratio - ESR) mínimas calculadas para a respectiva profundidade em que o teste foi realizado. Levando em conta esses valores para a estimativa de $\mathrm{ESR}_{\min }$ para a região em 
análise, considerou-se para o modelo geomecânico um valor médio de 0,65 . Devese ressaltar que foi construído um único modelo de ESR tanto para a zona de pressões levemente pressurizada quanto para a de pressões anormais.

Tabela 4.10 - Valores estimados de $S_{\text {hmin }}$ e ESR $\min$

\begin{tabular}{|l|c|c|c|c|c|}
\hline \multicolumn{1}{|c|}{ Poço } & $\begin{array}{c}\text { Prof Sedim } \\
(\mathrm{m})\end{array}$ & TVD $(\mathrm{m})$ & $\mathrm{S}_{\text {hmin }}(\mathrm{ppg})$ & $\mathrm{S}_{\text {hmin }}(\mathrm{MPa})$ & ESR $_{\text {min }}$ \\
\hline \hline Poço 2 & 2982 & 5162 & 11,7 & 70,96 & 0,56 \\
\hline Poço 4 & 2956 & 5138 & 12,2 & 73,64 & 0,74 \\
\hline Poço 5 & 3616 & 5798 & 12,2 & 83,10 & 0,55 \\
\hline Poço 6 & 3092 & 5268 & 12,4 & 76,75 & 0,72 \\
\hline Poço 7 & 3704 & 5753 & 13,8 & 93,27 & 0,72 \\
\hline
\end{tabular}

Esse valor médio estimado para ESRmin $(0,65)$ representa bacias que são influenciadas por efeitos devido ao tectonismo (gerando compressão) ou compartimentalização, ocorrência de domos salinos e pressão de poros alta. Esses eventos podem induzir o incremento de $\mathrm{ESR}_{\min }$ (Zoback, 2008).

\section{5 \\ Propriedades mecânicas da rocha}

Os valores estatísticos dos resultados de UCS obtidos através das três correlações empíricas estão apresentados na Figura 4.7 e no Gráfico 4.9. Observase que as correlações de Militzer (1973) e CPM (Santos e Ferreira, 2010) resultaram em valores médios de resistência dos carbonatos próximos entre si, entre de 35 e 50MPa (Gráfico 4.9). Já a correlação de Golubev (1976) resultou em um valor médio maior em 51\% em relação ao valor médio obtido por Militzer (1973) (43,1 MPa) e 47\% comparando com o valor médio obtido por CPM (Santos e Ferreira, 2010) $(43,7 \mathrm{MPa})$, indicando que os carbonatos dessa região seriam muito mais resistentes. Em função dessa análise comparativa, os valores obtidos pela correlação de Golubev (1976) foram desconsiderados nessa análise, pois não seriam representativos da experiência regional de perfuração para a estimativa das pressões de colapso. 


\begin{tabular}{|l|c|c|c|c|}
\hline \multicolumn{5}{|c|}{ UCS Militzer (MPa) } \\
\hline \hline Carbonato & Média & Mediana & $\mathrm{P}_{10}$ & $\mathrm{P}_{90}$ \\
\hline Poço 1 & 43,85 & 39,48 & 31,63 & 64,57 \\
\hline Poço 2 & 46,16 & 46,22 & 34,58 & 56,60 \\
\hline Poço 3 & 42,75 & 42,61 & 35,55 & 50,19 \\
\hline Poço 4 & 52,63 & 54,62 & 37,00 & 64,86 \\
\hline Poço 5 & 43,55 & 45,45 & 31,16 & 53,29 \\
\hline Poço 6 & 37,36 & 38,23 & 25,86 & 45,54 \\
\hline Poço 7 & 39,73 & 39,85 & 31,94 & 47,51 \\
\hline Poço 8 & 38,59 & 38,73 & 35,15 & 41,77 \\
\hline
\end{tabular}

\begin{tabular}{|l|c|c|c|c|}
\hline \multicolumn{5}{|c|}{ UCS CPM (MPa) } \\
\hline \hline Carbonato & Média & Mediana & $\mathrm{P}_{10}$ & $\mathrm{P}_{90}$ \\
\hline Poço 1 & 52,21 & 31,13 & 20,21 & 122,40 \\
\hline Poço 2 & 49,80 & 46,83 & 22,25 & 78,81 \\
\hline Poço 3 & 42,65 & 40,92 & 26,20 & 61,11 \\
\hline Poço 4 & 73,86 & 74,70 & 31,02 & 114,74 \\
\hline Poço 5 & 44,78 & 45,83 & 19,30 & 68,87 \\
\hline Poço 6 & 30,53 & 29,74 & 11,34 & 48,52 \\
\hline Poço 7 & 34,62 & 32,58 & 19,18 & 52,32 \\
\hline Poço 8 & 31,88 & 31,85 & 25,84 & 38,02 \\
\hline
\end{tabular}

\begin{tabular}{|l|c|c|c|c|}
\hline \multicolumn{5}{|c|}{ UCS Golubev (MPa) } \\
\hline \hline Carbonato & Média & Mediana & $\mathrm{P}_{10}$ & $\mathrm{P}_{90}$ \\
\hline Poço 1 & 124,87 & 84,69 & 54,81 & 275,06 \\
\hline Poço 2 & 126,75 & 119,35 & 64,84 & 194,41 \\
\hline Poço 3 & 104,10 & 99,61 & 68,45 & 144,65 \\
\hline Poço 4 & 177,19 & 177,70 & 74,16 & 278,49 \\
\hline Poço 5 & 112,13 & 114,90 & 53,30 & 167,15 \\
\hline Poço 6 & 79,86 & 79,22 & 38,52 & 115,45 \\
\hline Poço 7 & 89,20 & 86,35 & 55,78 & 127,17 \\
\hline Poço 8 & 81,31 & 81,34 & 66,93 & 95,43 \\
\hline
\end{tabular}

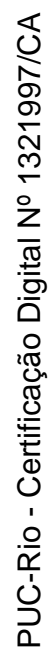

Figura 4.7 - Resultados estatísticos da estimativa da UCS das rochas carbonáticas do pré-sal

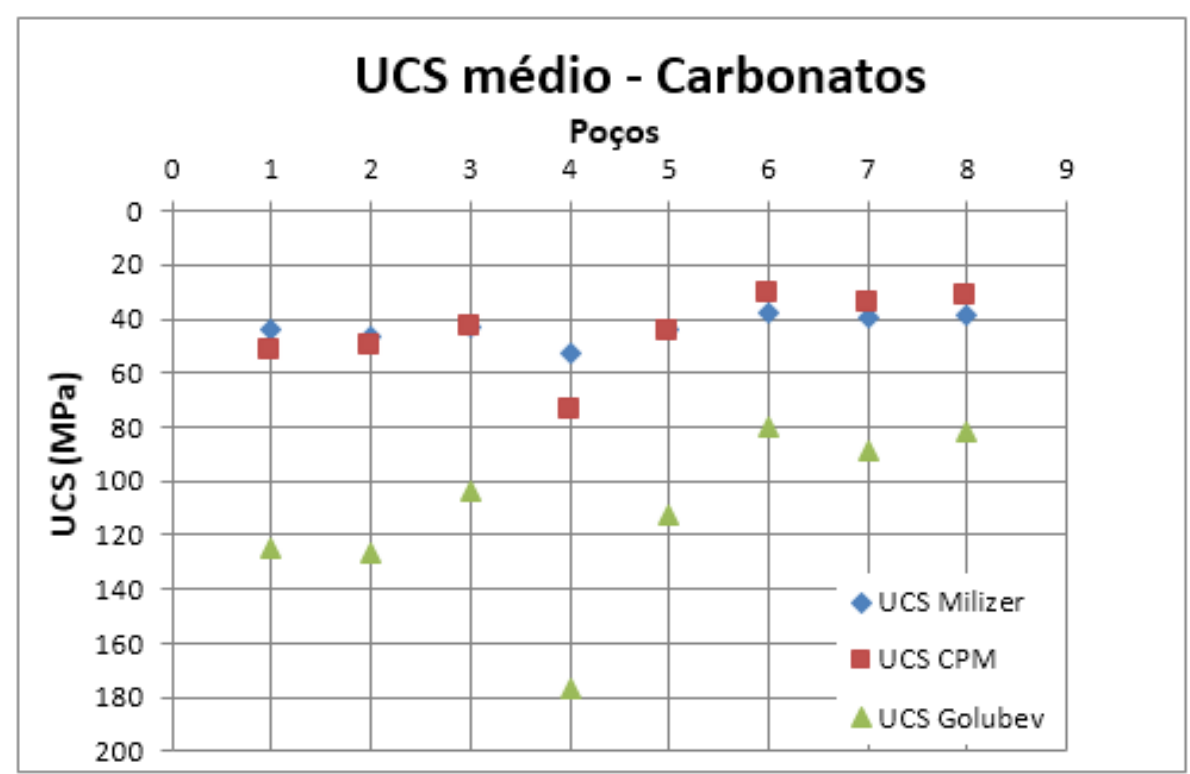

Gráfico 4.9 - Valores médios de UCS para os carbonatos do pré-sal

Os resultados dos ensaios de resistência de rocha realizados por Domingues (2011) nos corpos de prova do carbonato análogo do pré-sal (Travertino de Itaboraí), estão apresentados na Tabela 4.11. 
Tabela 4.11 - Resultados dos ensaios de compressão UCS nos corpos de prova do Travertino de Itaboraí (Fonte: Domingues, 2011)

\begin{tabular}{|c|c|}
\hline $\begin{array}{c}\text { Corpos de } \\
\text { prova }\end{array}$ & $\begin{array}{c}\text { UCS } \\
\text { (MPa) }\end{array}$ \\
\hline TRI-04 (01) & 56,39 \\
\hline TRI-04 (02) & 55,03 \\
\hline TRI-05 (01) & 39,86 \\
\hline TRI-05 (02) & 27,2 \\
\hline TRI-05 (03) & 40,69 \\
\hline TRI-05 (04) & 43,29 \\
\hline
\end{tabular}

Do estudo de Domingues (2011), os corpos de prova retirados do bloco TRI04 apresentaram maiores valores de resistência à compressão simples se comparados com os corpos de prova retirados do bloco TRI-05. A forma dos grãos e textura dos corpos de prova TRI-04 e TRI-05 são diferentes e o corpo de prova TRI-04 é mais poroso do que o TRI-05 (04), que por sua vez é o mais compacto e deveria ser mais resistente. Os baixos valores de resistência encontrados para os corpos de prova TRI-05 podem ser explicados pelo contato entre os grãos. Vale ressaltar que durante a realização do ensaio de compressão simples no corpo de prova TRI-05 (2) ocorreu um problema na leitura do strain gage, que pode ter influenciado no resultado final do ensaio.

O estudo de Deere e Miller (1966) também foi considerado como referência para a obtenção de uma melhor estimativa da resistência dos carbonatos. A classificação proposta por esses autores é baseada em duas importantes propriedades das rochas: a resistência à compressão simples (UCS) e o módulo de elasticidade (Módulo de Young - E). No Gráfico 4.10 observa-se regiões demarcadas em função do tipo de rocha e ainda uma classificação de rochas com base na resistência proposta pelos autores. Por essa proposta, os resultados de resistência obtidos para os carbonatos do pré-sal indicam resistência baixa (coluna D). 


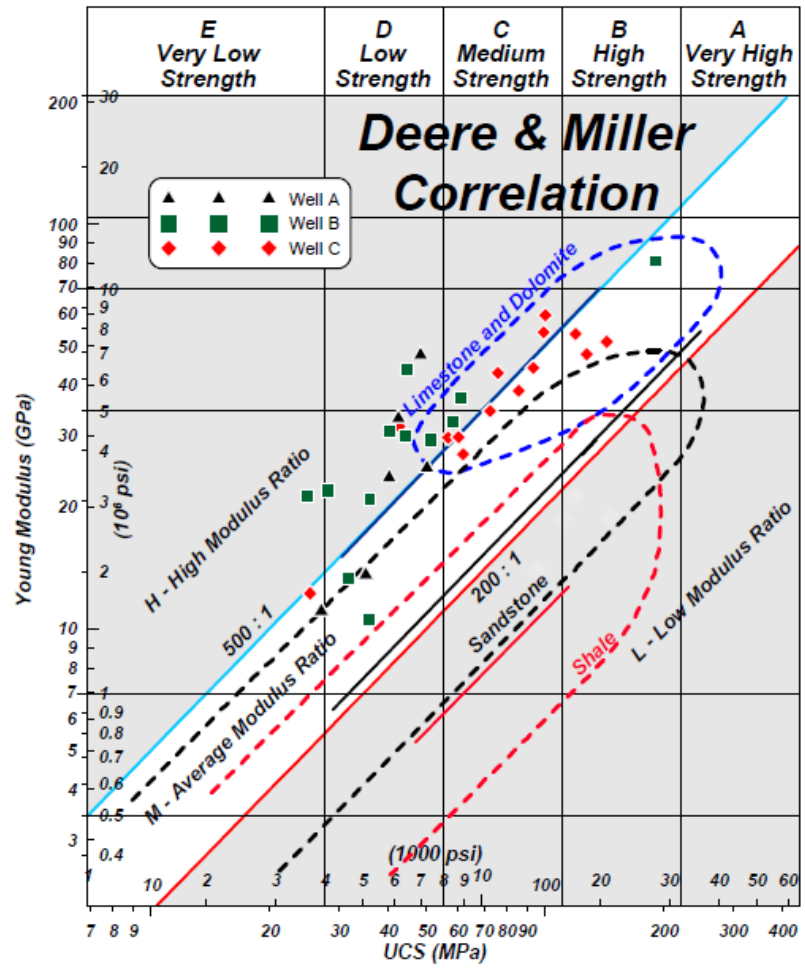

Gráfico 4.10 - Gráfico resumido da classificação de rochas intactas para os carbonatos (Deer e Miller, 1966)

Através de uma análise comparativa dos valores de UCS obtidos pela correlação de Militzer (1973) e CPM (Santos e Ferreira, 2010) com os resultados de Domingues (2011), observa-se uma similaridade nos resultados, de acordo com a Tabela 4.12.

Tabela 4.12 - Valores médios estimados de UCS obtidos para o pré-sal e para o seu análogo de acordo com o estudo de Domingues (2011).

\begin{tabular}{|c|c|c|c|}
\hline \multicolumn{2}{|c|}{ Pré-sal } & \multicolumn{2}{c|}{ Análogo } \\
\hline Correlação & UCS médio (Mpa) & Amostra & UCS médio (Mpa) \\
\hline \hline Militzer & 43,1 & TRI-04 & 55,7 \\
\hline CPM & 43,7 & TRI-05 & 41,3 \\
\hline
\end{tabular}

O valor médio de resistência obtido pelas correlações indica números bem próximos do valor de resistência médio encontrado nos ensaios da amostra TRI-05, com uma diferença de 4,2\% em relação a Militzer (1973) e 5,5\% em relação a CPM (Santos e Ferreira, 2010). Com isso, conclui-se que, do ponto de vista de resistência 
UCS, as características do pré-sal, da área em estudo, se assemelham às características das amostras TRI-05 e a analogia poderia ser considerada.

Vale ressaltar que não foram disponibilizadas amostras dos carbonatos do pré-sal para que ensaios de laboratório pudessem ser realizados para validar a escolha das correlações e, por isso, as comparações são preliminares e foram feitas entre os resultados de correlações empíricas com base nos dados de perfiis destes carbonatos e ensaios de laboratório de amostras do análogo Travertino de Itaboraí, do estudo de Domingues (2011). A correlação de Militzer (1973) e CPM (Santos e Ferreira, 2010) tem limitações em função da diferença da região onde as correlações empíricas foram realizadas e a região em questão.

Para a estimativa da resistência das rochas ígneas foi considerada a correlação de Teikoku-Vp (GMI, 2007) e os resultados estatísticos estão apresentados na Tabela 4.13. Observa-se que os valores estão entre 120 e $155 \mathrm{MPa}$, indicando uma rocha com resistência elevada.

Tabela 4.13 - Resultados estatísticos da estimativa da resistência da rocha ígnea

\begin{tabular}{|c|c|c|c|c|}
\hline \multicolumn{5}{|c|}{ UCS Teikoku-Vp $(\mathrm{MPa})$} \\
\hline \hline \multicolumn{1}{|c|}{ Ignea } & Média & Mediana & $\mathrm{P}_{10}$ & $\mathrm{P}_{90}$ \\
\hline Poço 1 & 123,4 & 112,01 & 77,95 & 189,02 \\
\hline Poço 7 & 154,15 & 155,79 & 126,81 & 181,64 \\
\hline
\end{tabular}

\subsection{1}

\section{Propriedades elásticas}

Domingues (2011) também estimou os valores de módulo de Young e de coeficiente de Poisson com amostras do Travertino de Itaboraí (Tabela 4.12). Os corpos de prova retirados do bloco TRI-04 apresentaram maiores valores de resistência à compressão e de deformação axial máxima e menores valores de módulo de Young e de coeficiente de Poisson, comparados com os corpos de prova retirados do bloco TRI-05.

Esses valores também foram comparados com os resultados obtidos para os poços analisados neste estudo. O Gráfico 4.11 indica que os valores de módulo de Young dos poços analisados variaram de 20 a $80 \mathrm{GPa}$. Observou-se uma variação entre os resultados do Módulo de Young obtidos por correlação (Equação 3.8) na 
área estudada e o estudo dos análogos de Domingues (2011). Considerando o limite inferior do resultado do Módulo de Young obtido pela correlação (20GPa) observou-se que é 30\% maior do que o resultado de menor valor obtido para a amostra TRI-04 (01) $(13,83 \mathrm{GPa})$ e o limite superior $(80 \mathrm{GPa})$ é $14 \%$ maior em relação ao resultado da amostra TRI-05 (03) (68,46 GPa) do estudo de Domingues (2011). Vale ressaltar que a ausência de ensaios estáticos do Módulo de Young limitam a aferição dos valores comparados.

Tabela 4.14 - Resultados das propriedades elásticas do carbonato Travertino de Itaboraí (Fonte:

Domingues, 2011)

\begin{tabular}{|c|c|c|c|c|}
\hline $\begin{array}{c}\text { Corpos de } \\
\text { prova }\end{array}$ & $\begin{array}{c}\text { UCS } \\
(\mathrm{MPa})\end{array}$ & $\begin{array}{c}\text { Módulo de } \\
\text { Young (E) } \\
(\mathrm{GPa})\end{array}$ & $\begin{array}{c}\text { Coeficiente de } \\
\text { Poisson }(\mathrm{v})\end{array}$ & $\begin{array}{c}\text { Deformação axial } \\
\text { máxima }\left(\varepsilon_{\mathrm{ax}}\right) \\
(\%)\end{array}$ \\
\hline TRI-04 (01) & 56,39 & 13,83 & 0,06 & 0,46 \\
\hline TRI-04 (02) & 55,03 & 15,67 & 0,16 & 0,51 \\
\hline TRI-05 (01) & 39,86 & 62,93 & 0,35 & 0,067 \\
\hline TRI-05 (02) & 27,2 & 39,83 & 0,25 & 0,074 \\
\hline TRI-05 (03) & 40,69 & 68,46 & 0,37 & 0,068 \\
\hline TRI-05 (04) & 43,29 & 42,62 & 0,19 & 0,094 \\
\hline
\end{tabular}

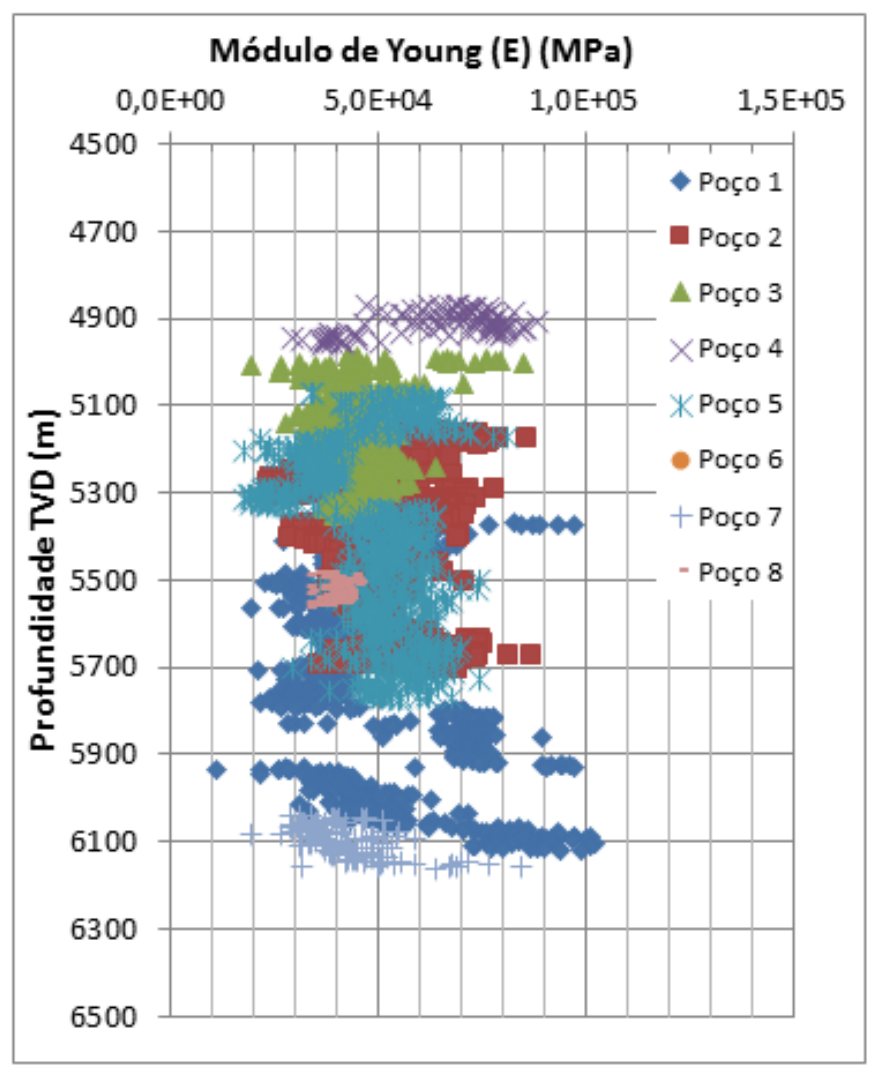

Gráfico 4.11 - Valores do módulo de Young dos poços em análise 
Avaliando o coeficiente de Poisson no Gráfico 4.12, observa-se uma variação entre 0,2 e 0,35 para os poços em análise, valores similares aos obtidos para a amostra TRI-05 do estudo de Domingues (2011).

Valores do coeficiente de atrito interno também foram estimados através de correlações e os resultados estão apresentados no Gráfico 4.13. Observa-se uma dispersão dos dados que variam entre 0,6 a 1,05.

As correlações utilizadas para a estimativa das propriedades mecânicas e elástica das rochas se baseiam nos parâmetros de velocidade acústica, porosidade e Módulo de Young, por isso, foram estabelecidas relações entre esses parâmetros que estão apresentados no Anexo 8.2.

O UCS incrementa em função do aumento da velocidade e isto se deve, em partes, pela baixa porosidade de rochas cuja velocidade é mais alta (Gráficos 8.7 a 8.9 - Anexo 8.2). Já o comportamento do UCS diminui com o aumento da porosidade, de acordo com os Gráficos 8.10 a 8.13, do Anexo 8.2. Com relação ao módulo de Young, os valores de UCS incrementam à medida que esse parâmetro aumenta (Gráficos 8.14 a 8.17 - Anexo 8.2).

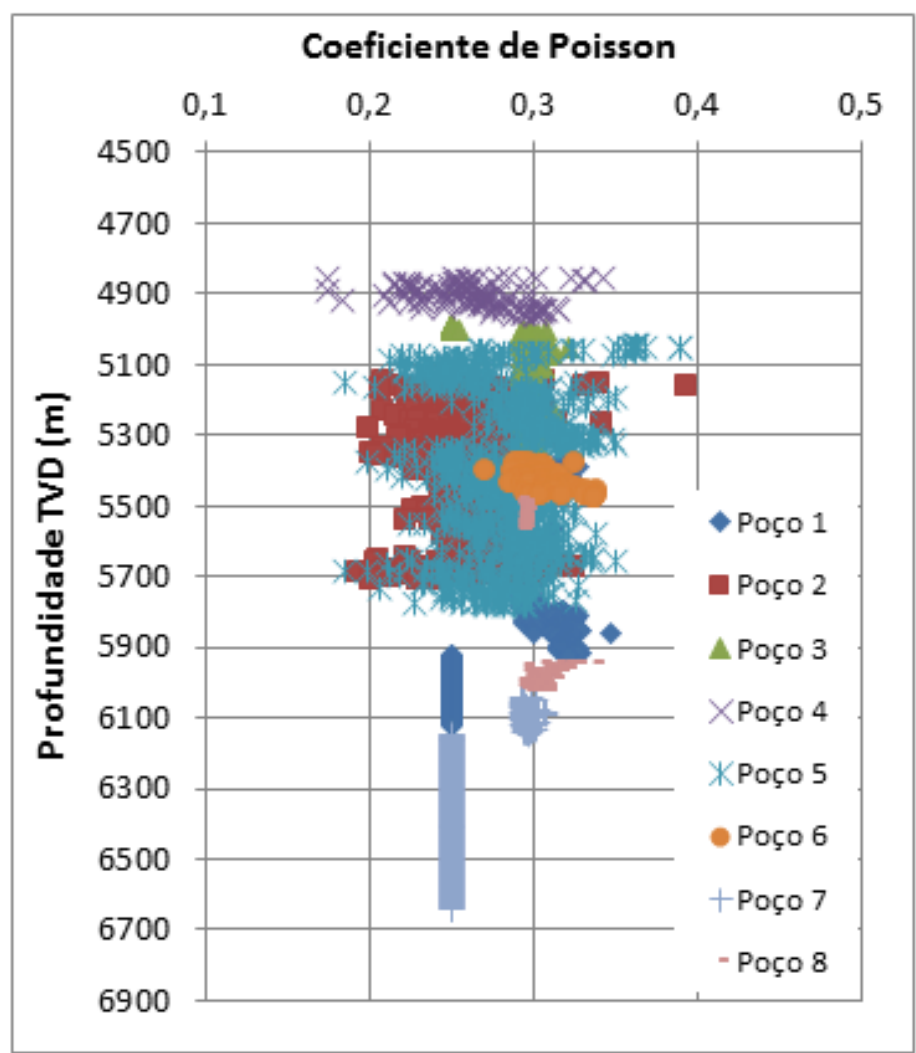

Gráfico 4.12 - Valores de Poisson para os poços em análise 


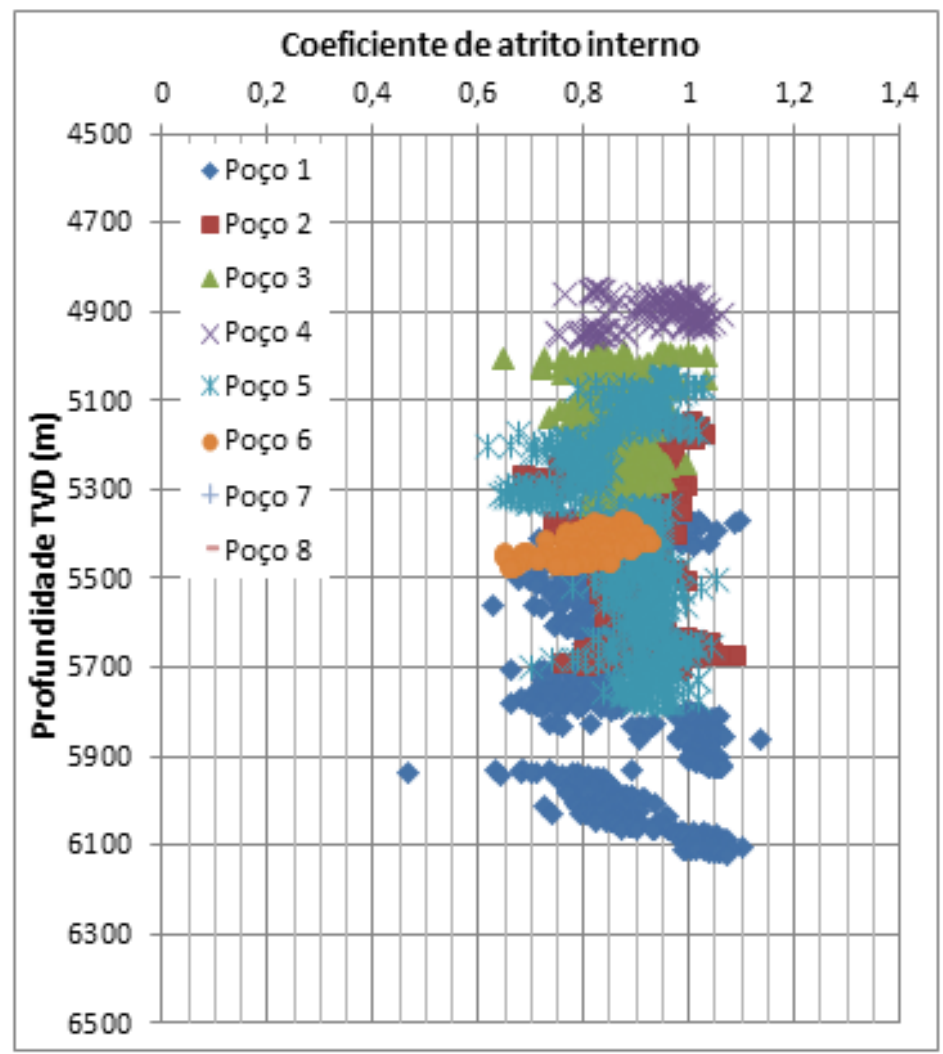

Gráfico 4.13 - Valores do coeficiente de atrito interno para os poços em análise

A relação entre as velocidades compressional $\left(V_{p}\right)$ e cisalhante $\left(V_{s}\right)$ também foi avaliada e está apresentada no Gráfico 8.18 do Anexo 8.2. Os resultados indicam que as relações de $V_{p}$ e $V_{s}$ estão em torno de 0,50 , de acordo com as equações estabelecidas para cada poço, e se incrementa com o aumento de $\mathrm{V}_{\mathrm{s}}$.

\section{6}

\section{Direção da tensão horizontal máxima}

A direção da tensão horizontal máxima $\left(\mathrm{S}_{\mathrm{Hmax}}\right)$ foi estimada com base nas tensões do banco de dados do world stress map, como mostram as Figuras $4.8 \mathrm{e}$ 4.9 .

$\mathrm{Na}$ Figura 4.8 foram indicadas duas regiões onde havia dados de direção de tensões no WSM: uma de poços de terra, a $310 \mathrm{~km}$ da área de estudo, e outra sobre a placa tectônica do Atlântico Sul a aproximadamente $3000 \mathrm{~km}$ da área de estudo. Em função da proximidade da área de estudo, considerou-se para o modelo geomecânico de estabilidade a direção de $95^{\circ}(\mathrm{E}-\mathrm{W})$ para $\mathrm{S}_{\mathrm{Hmax}}$. 


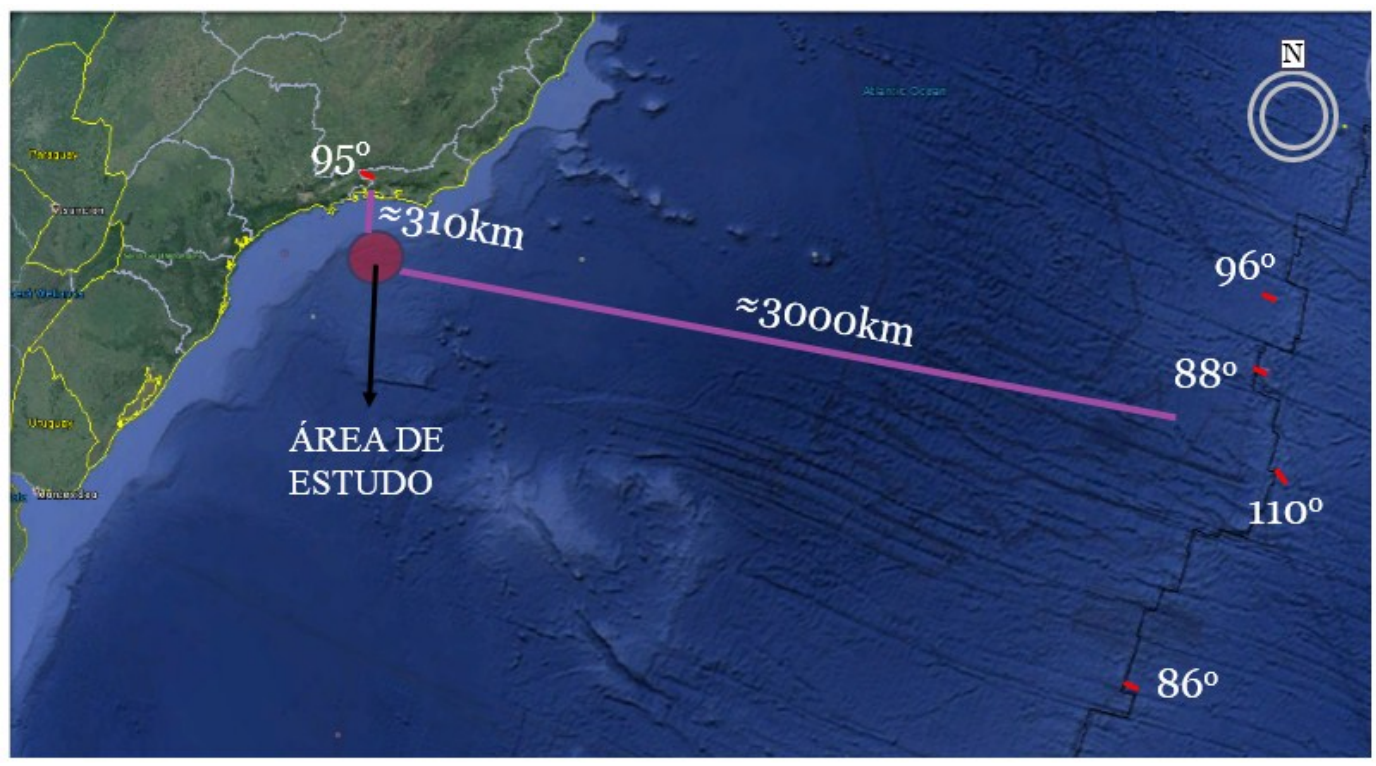

Figura 4.8 - Direção de tensões horizontais máximas encontradas próximo à área de estudo

(Imagem do Google Earth e Tensões do WSM)

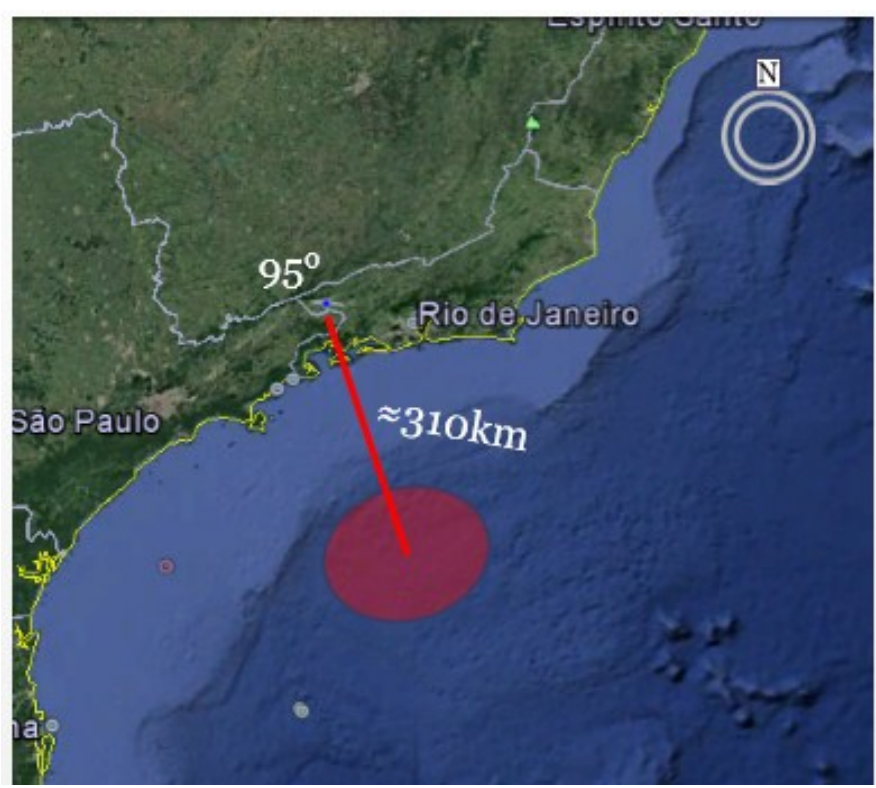

Figura 4.9 - Direção da tensão horizontal máxima considerada para área de estudo (Imagem do Google Earth e Tensões do WSM)

Vale ressaltar que essa região do pré-sal é complexa do ponto de vista da geologia (presença de compartimentalizações, em função do estágio drifte) e pela presença de domos salinos (geração de zonas de falhamentos normais e 
transcorrentes) que podem ter gerado variabilidade lateral de tensões. No entanto, para o caso desse estudo, a direção de $S_{\text {Hmax }}$ não influencia no modelo de estabilidade de poços, uma vez que todos os oito poços são verticais.

\section{7}

Magnitude da tensão horizontal máxima

Em função da ausência de dados de imagem para a calibração da magnitude da tensão horizontal máxima foi necessário simular vários cenários utilizando o polígono de tensões. Para a estimativa da magnitude de $\mathrm{S}_{H \max }$ foram criados cinco cenários, sendo três para o Poço 1 e dois para o Poço 7, onde variaram-se os seguintes parâmetros: UCS, Abertura de Breakout e coeficiente de Biot.

As Tabelas 4.15, 4.16 e 4.17 e as Figuras 4.10 e 4.11 apresentam os valores de cada parâmetro considerado nos cenários. 
Tabela 4.15 - Resultados das simulações para a estimativa da magnitude da tensão horizontal máxima para a rocha carbonática do Poço 1

\begin{tabular}{|c|c|c|c|c|c|c|c|}
\hline $\begin{array}{l}\text { Poço } 1 \\
\text { Cenário } 1\end{array}$ & & & & & & & \\
\hline Prof TVD $(\mathrm{m})$ & UCSM $>$ & (MPa) & Ab Breakout & & Valores & $S_{H \max }$ & \\
\hline Prot TVD (m) & Ucs iv & (IVIPd) & AD. Dreakout & & & & \\
\hline & Médio & 37,92 & $0^{\circ}$ & 13,67 & 14,15 & 14,76 & 15,22 \\
\hline 5400 & Mín & 33,78 & $30^{\circ}$ & 13,8 & 14,36 & 15,01 & 15,54 \\
\hline & Máx & 42,75 & $60^{\circ}$ & 14,42 & 15,33 & 14,98 & 15,76 \\
\hline & Médio & 34,80 & $0^{\circ}$ & 13,66 & 14,25 & 14,53 & 15,13 \\
\hline 5600 & Mín & 29,65 & $30^{\circ}$ & 13,8 & 14,1 & 14,81 & 15,35 \\
\hline & Máx & 39,30 & $60^{\circ}$ & 14,35 & 15,12 & 16,03 & 16,83 \\
\hline & Médio & 53,78 & $0^{\circ}$ & 14,46 & 15,81 & 15,88 & 17,20 \\
\hline 5800 & Mín & 34,47 & $30^{\circ}$ & 14,59 & 16,11 & 16,21 & 17,77 \\
\hline & Máx & 62,74 & $60^{\circ}$ & 15,34 & 17,39 & 17,56 & 19,48 \\
\hline Cenário 2 & & & & & & & \\
\hline Prof TVD $(\mathrm{m})$ & UCS & MPal & Ab Breakout & & Valores & $S_{H \max }$ & \\
\hline Prot IVD (m) & UCs & VIPa) & Ab. Breakout & & & & \\
\hline & Médio & 34,13 & $0^{\circ}$ & 13,16 & 14,42 & 14,18 & 15,49 \\
\hline 5400 & Mín & 23,44 & $30^{\circ}$ & 13,24 & 14,63 & 14,39 & 15,78 \\
\hline & Máx & 46,88 & $60^{\circ}$ & 13,64 & 15,52 & 15,19 & 17,10 \\
\hline & Médio & 26,61 & $0^{\circ}$ & 12,84 & 14,01 & 13,92 & 15,01 \\
\hline 5600 & Mín & 15,86 & $30^{\circ}$ & 12,90 & 14,10 & 13,98 & 15,32 \\
\hline & Máx & 37,23 & $60^{\circ}$ & 13,13 & 14,84 & 14,67 & 16,34 \\
\hline & Médio & 108,94 & $0^{\circ}$ & 17,50 & 18,52 & - & - \\
\hline 5800 & Mín & 98,60 & $30^{\circ}$ & 17,92 & 19,09 & - & - \\
\hline & Máx & 117,90 & $60^{\circ}$ & - & - & - & - \\
\hline
\end{tabular}

Tabela 4.16- Resultados das simulações para a estimativa da magnitude da tensão horizontal máxima para a rocha ígnea do Poço 1

Cenário 3- Ignea

\begin{tabular}{|c|c|c|c|c|c|c|c|}
\hline \multirow{2}{*}{ Prof TVD (m) } & \multicolumn{2}{|c|}{ UCS Teikoku (MPa) } & \multirow{2}{*}{ Ab. Breakout } & \multicolumn{4}{c|}{ Valores de $S_{\text {Hmax }}$} \\
\cline { 5 - 8 } & \multicolumn{3}{|c|}{} & & \multicolumn{2}{|c|}{ Biot= 1 } & \multicolumn{2}{c|}{ Biot= 0,9 } \\
\hline \hline \multirow{3}{*}{6000} & Médio & 103,42 & $0^{\circ}$ & 16,91 & 18,24 & 18,12 & 19,41 \\
\cline { 2 - 8 } & Mín & 97,91 & $30^{\circ}$ & 17,29 & 18,745 & 18,55 & 19,73 \\
\cline { 2 - 8 } & Máx & 125,48 & $60^{\circ}$ & 19,03 & 19,79 & - & - \\
\hline
\end{tabular}

Para o Poço 1 considerou-se três profundidades dentre o trecho de carbonatos $(5400,5600$ e 5800m TVD) e uma profundidade na rocha ígnea $(6000 \mathrm{~m}$ TVD) e para o Poço 2 considerou-se duas profundidades (6050 e 6090m TVD) nos carbonatos. 

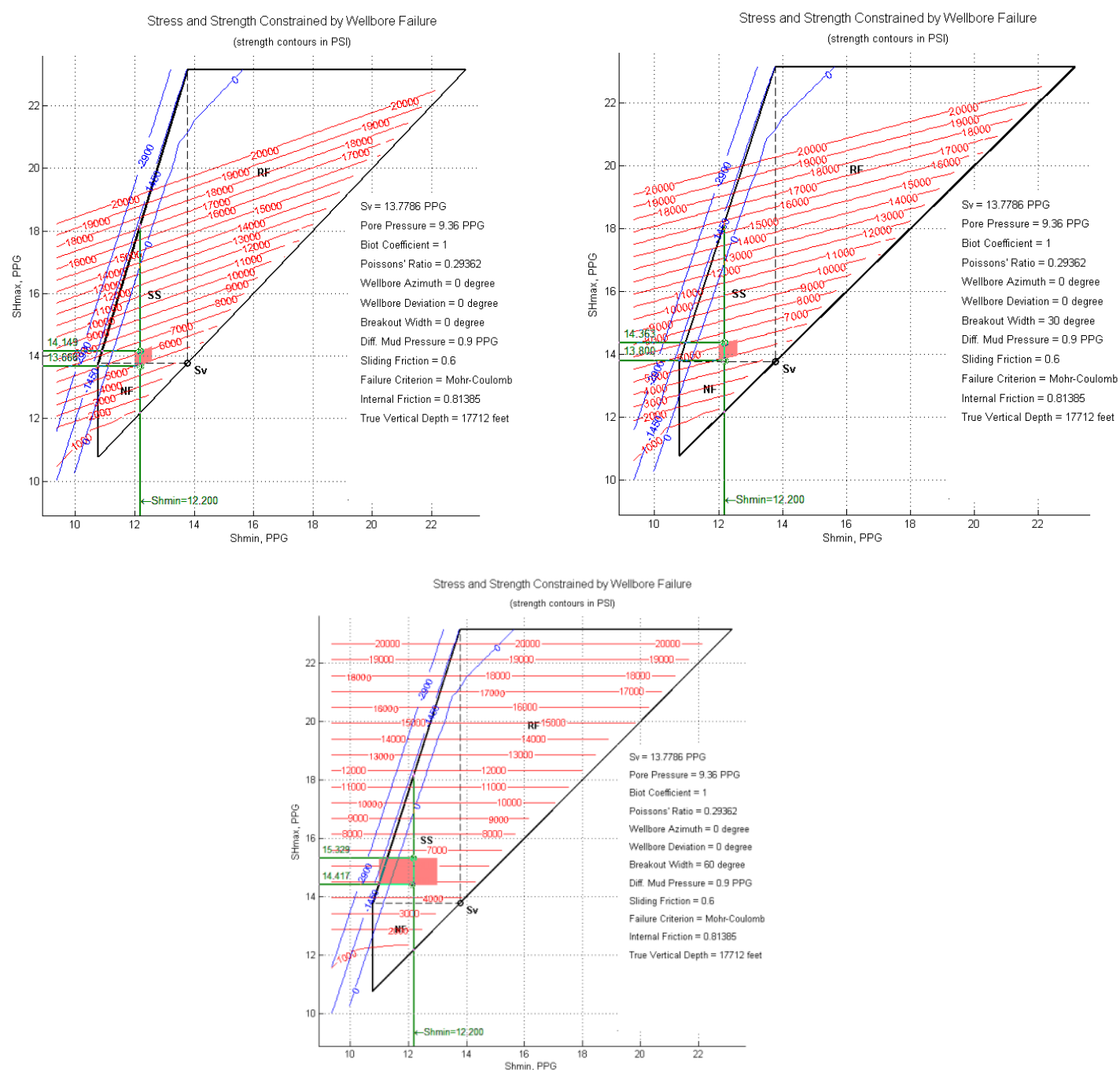

Figura 4.10 - Resultados da simulação da profundidade de 5600m TVD do Cenário 1 e com coeficiente de Biot igual a 1 (Poço 1) 
Tabela 4.17- Resultados das simulações para a estimativa da magnitude da tensão horizontal máxima para a rocha carbonática do Poço 7

\begin{tabular}{|c|c|c|c|c|c|c|c|}
\hline \multicolumn{8}{|l|}{$\begin{array}{l}\text { Poço } 7 \\
\text { Cenário } 1\end{array}$} \\
\hline \multirow{2}{*}{ Prof TVD $(\mathrm{m})$} & \multirow{2}{*}{\multicolumn{2}{|c|}{ UCS Militzer (MPa) }} & \multirow{2}{*}{ Ab. Breakout } & \multicolumn{4}{|c|}{ Valores de $S_{\mathrm{Hmax}}$} \\
\hline & & & & \multicolumn{2}{|c|}{ Biot $=1$} & \multicolumn{2}{|c|}{ Biot $=0.9$} \\
\hline \multirow{3}{*}{6050} & Médio & 38,33 & $0^{\circ}$ & 15,5 & 16,02 & - & - \\
\hline & Mín & 31,72 & $30^{\circ}$ & 15,68 & 16,05 & - & - \\
\hline & Máx & 46,88 & $60^{\circ}$ & - & - & - & - \\
\hline \multirow{3}{*}{6090} & Médio & 37,92 & $0^{\circ}$ & 16,13 & 16,26 & - & - \\
\hline & Mín & 24,82 & $30^{\circ}$ & - & - & - & - \\
\hline & Máx & 49,64 & $60^{\circ}$ & - & - & - & - \\
\hline \multicolumn{8}{|l|}{ Cenário 2} \\
\hline \multirow{2}{*}{ Prof TVD (m) } & \multirow{2}{*}{\multicolumn{2}{|c|}{ UCS CPM (MPa) }} & \multirow{2}{*}{ Ab. Breakout } & \multicolumn{4}{|c|}{ Valores de $S_{\mathrm{Hmax}}$} \\
\hline & & & & \multicolumn{2}{|c|}{ Biot $=1$} & \multicolumn{2}{|c|}{ Biot $=0.9$} \\
\hline \multirow{3}{*}{6050} & Médio & 30,68 & $0^{\circ}$ & 15,15 & 16,04 & - & - \\
\hline & Mín & 15,17 & $30^{\circ}$ & 15,32 & 16,05 & - & - \\
\hline & Máx & 57,23 & $60^{\circ}$ & 15,81 & 16,1 & - & - \\
\hline \multirow{3}{*}{6090} & Médio & 35,85 & $0^{\circ}$ & 14,94 & 16,23 & - & - \\
\hline & Mín & 17,24 & $30^{\circ}$ & 15,05 & 16,23 & - & - \\
\hline & Máx & 58,61 & $60^{\circ}$ & - & - & - & - \\
\hline
\end{tabular}

Nos Cenários 1, foi considerado a correlação de Militzer (1973) para a estimativa do UCS e os valores de $\mathrm{S}_{\mathrm{Hmax}}$ foram obtidos variando a abertura de breakout $\left(0^{\circ}, 30^{\circ}\right.$ e $\left.60^{\circ}\right)$ e o coeficiente de Biot $(0,9$ e 1,0$)$, enquanto que para o Cenário 2 considerou-se o UCS obtido pela correlação de CPM (Ferreira e Santos, 2010) e variou-se os mesmos parâmetros do Cenário 1.

A simulação no polígono de tensões leva em conta diversos dados de entrada. Além dos parâmetros que foram citados (UCS, Biot e Abertura de breakout), a simulação também é dependente do gradiente de sobrecarga (Sv), pressão de poros, azimute e desvio do poço, diferença entre o peso de fluido e pressão de poros, coeficiente de Poisson, coeficiente de deslizamento de falha geológica, critério de falhamento e o coeficiente de atrito interno. Como resultado da simulação, foram obtidos valores mínimos e máximos de $\mathrm{S}_{\mathrm{Hmax}}$ para cada profundidade analisada. 
A Tabela 4.18 apresenta um resumo dos resultados estimados para $\mathrm{S}_{\mathrm{Hmax}}$ indicando os limites inferior e superior encontrados nas simulações realizadas para o Poço 1 e Poço 7.

Além dos valores estimados para $\mathrm{S}_{\mathrm{Hmax}}$, os resultados gerados pelo polígono de tensões também indicam o tipo de falhamento da região em análise. Os resultados indicam que o tipo de campo de tensões e de falhamento está transicional entre normal a transcorrente, isto é, $\mathrm{S}_{\mathrm{Hmax}}>\mathrm{Sv}>\mathrm{S}_{\mathrm{hmin}}$.
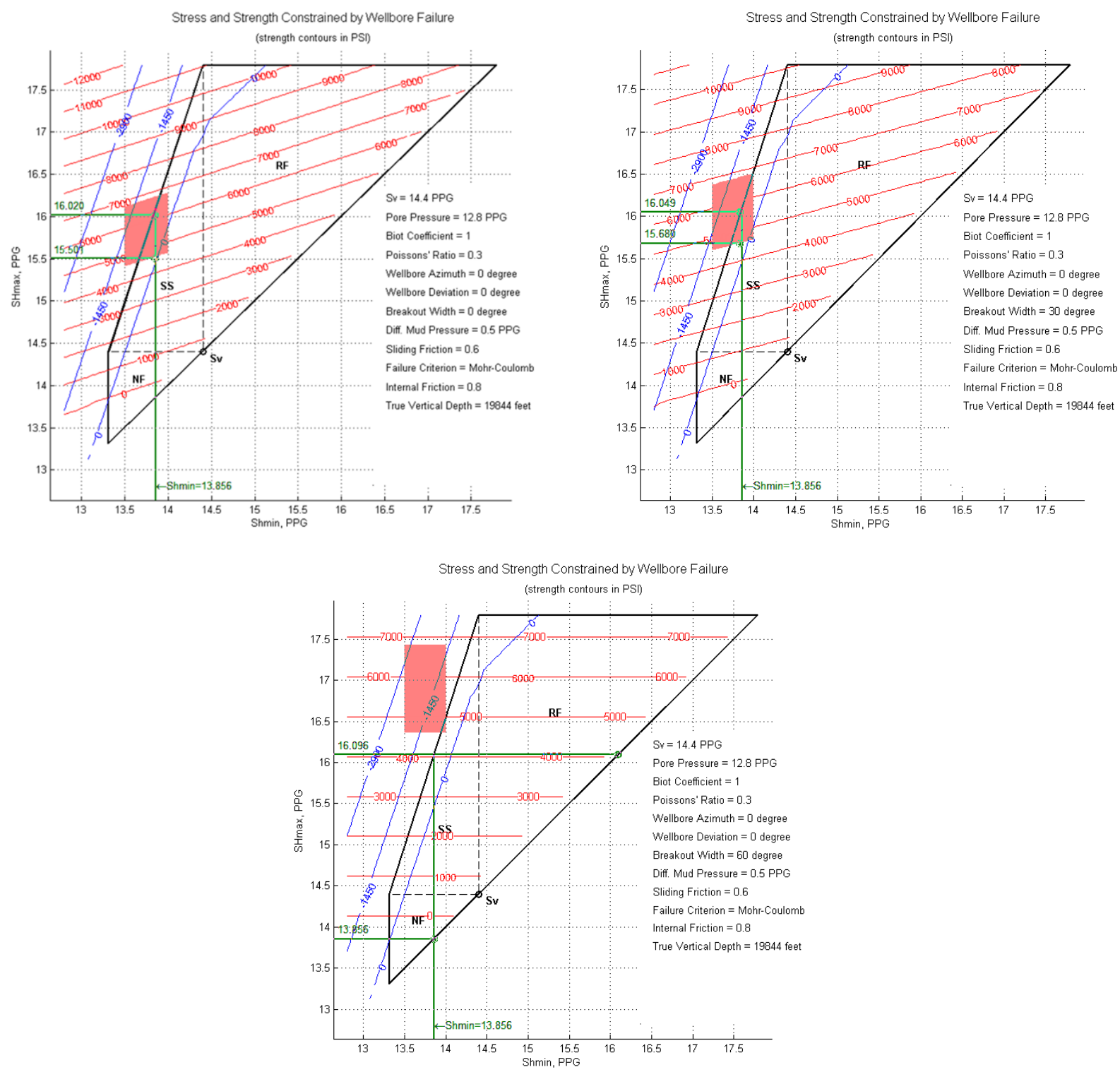

Figura 4.11 - Resultados da simulação da profundidade de 6050m TVD do Cenário 1 e com coeficiente de Biot 1 (Poço 7) 
Tabela 4.18 - Resumo dos resultados da estimativa de $\mathrm{S}_{\text {Hmax }}$

\begin{tabular}{|c|c|c|c|c|c|}
\hline \multirow{3}{*}{ Poço } & \multirow{2}{*}{$\begin{array}{c}\text { Ab. } \\
\text { Breakout }\end{array}$} & \multicolumn{2}{|c|}{ Valores de $\mathrm{S}_{\mathrm{hmax}}$ (Carbonatos) considerando correlação de Militzer } \\
\cline { 3 - 6 } & & \multicolumn{2}{|c|}{ Biot= 1 } & \multicolumn{2}{c|}{ Biot= 0,9 } \\
\cline { 3 - 6 } & & Limite inferior & Limite superior & Limite inferior & Limite superior \\
\hline \hline \multirow{3}{*}{1} & $0^{\circ}$ & 13,7 & 15,8 & 14,5 & 17,2 \\
\cline { 2 - 6 } & $30^{\circ}$ & 13,8 & 16,1 & 14,8 & 17,8 \\
\cline { 2 - 6 } & $60^{\circ}$ & 14,4 & 17,4 & 15,0 & 19,5 \\
\hline \multirow{2}{*}{7} & $0^{\circ}$ & 15,5 & 16,3 & - & - \\
\cline { 2 - 6 } & $30^{\circ}$ & 15,7 & 16,1 & - & - \\
\hline
\end{tabular}

\begin{tabular}{|c|c|c|c|c|c|}
\hline \multirow{3}{*}{ Poço } & \multirow{2}{*}{$\begin{array}{c}\text { Ab. } \\
\text { Breakout }\end{array}$} & \multicolumn{2}{|c|}{ Valores de $\mathrm{S}_{\mathrm{hmax}}$ (Carbonatos) considerando correlação de CPM } \\
\cline { 3 - 6 } & & \multicolumn{2}{|c|}{ Biot=1 } & \multicolumn{2}{c|}{ Biot= 0,9 } \\
\cline { 3 - 6 } & & Limite inferior & Limite superior & Limite inferior & Limite superior \\
\hline \hline \multirow{3}{*}{1} & $0^{\circ}$ & 12,8 & 18,5 & 13,9 & 15,5 \\
\cline { 2 - 6 } & $30^{\circ}$ & 12,9 & 19,1 & 14,0 & 15,8 \\
\cline { 2 - 6 } & $60^{\circ}$ & 13,1 & 15,5 & 14,7 & 17,1 \\
\hline \multirow{3}{*}{7} & $0^{\circ}$ & 14,9 & 16,2 & - & - \\
\cline { 2 - 6 } & $30^{\circ}$ & 15,1 & 16,2 & - & - \\
\cline { 2 - 6 } & $60^{\circ}$ & 15,8 & 16,1 & - & - \\
\hline
\end{tabular}

\section{8}

\section{Modelo Geomecânico de estabilidade de poço}

O modelo geomecânico de estabilidade de poço resultou na definição de uma janela operacional que utilizou os resultados de todos os parâmetros geomecânicos discutidos anteriormente. A janela operacional é definida pelo gradiente de colapso ou pressão de poros como limite inferior e o gradiente de $\mathrm{S}_{\mathrm{hmin}}$ como limite superior. Assim, durante a perfuração do poço, devem ser utilizados valores de densidade do fluido superiores ao gradiente de colapso ou pressão de poros e inferiores ao gradiente de $\mathrm{S}_{\mathrm{hmin}}$.

A pressão de colapso foi estimada utilizando os valores de peso de fluido, pressão de poros, UCS, $\mathrm{S}_{\mathrm{hmin}}$, $\mathrm{S}_{\mathrm{Hmax}}$ e temperatura. Devido às incertezas envolvidas no modelo geomecânico, foram criados cenários onde considerou-se diferentes condições de UCS, coeficiente de Biot, abertura de breakout e ESR para estimar o gradiente de colapso. Os resultados das simulações estão apresentados nas Tabelas 4.19 a 4.22 .

Os valores da janela operacional para o Poço 1 foram analisados em dois pontos: um no início da fase, em 5500m, e outro no ponto de maior valor de colapso, aproximadamente em 5980m. 
Tabela 4.19 - Resultados da janela operacional dos diferentes cenários para o carbonato do Poço 1

\begin{tabular}{|c|c|c|c|c|c|}
\hline \multicolumn{7}{|c|}{ Poço 1 } \\
\hline Cenários & $\begin{array}{c}\text { Correlação } \\
\text { UCS }\end{array}$ & Biot & $\begin{array}{c}\text { Abertura } \\
\text { Breakout }\end{array}$ & ESRmax & $\begin{array}{c}\text { Janela operacional } \\
\text { (P. colapso/Shmin }\end{array}$ \\
\hline \hline Cenário 1 & Militzer & 1 & 0 & 0,95 & $\begin{array}{c}10,5 / 12,3 \\
10,9 / 12,6\end{array}$ \\
\hline Cenário 2 & Militzer & 1 & 30 & 1,05 & $\begin{array}{c}10,5 / 12,3 \\
11,1 / 12,6\end{array}$ \\
\hline Cenário 3 & Militzer & 1 & 60 & 1,2 & $\begin{array}{c}10,8 / 12,3 \\
11,2 / 12,6\end{array}$ \\
\hline Cenário 4 & Militzer & 0,9 & 0 & 1,15 & $\begin{array}{c}10,6 / 12,3 \\
11,1 / 12,6\end{array}$ \\
\hline Cenário 5 & Militzer & 0,9 & 30 & 1,3 & $\begin{array}{l}10,8 / 12,3 \\
11,4 / 12,6\end{array}$ \\
\hline Cenário 6 & Militzer & 0,9 & 60 & 1,4 & $\begin{array}{l}10,6 / 12,3 \\
11,1 / 12,6\end{array}$ \\
\hline Cenário 7 & CPM & 1 & 0 & 0,95 & $\begin{array}{l}11,1 / 12,3 \\
11,3 / 12,6\end{array}$ \\
\hline Cenário 8 & CPM & 1 & 30 & 0,95 & $\begin{array}{l}11,0 / 12,3 \\
11,2 / 12,6\end{array}$ \\
\hline Cenário 9 & CPM & 0,9 & 0 & 1,1 & $\begin{array}{l}11,0 / 12,3 \\
11,2 / 12,6\end{array}$ \\
\hline Cenário 10 & CPM & 0,9 & 30 & 1,15 & $\begin{array}{l}11,0 / 12,3 \\
11,2 / 12,6\end{array}$ \\
\hline
\end{tabular}

Os valores de $\mathrm{ESR}_{\max }$, encontrados incrementam com o aumento da abertura de breakout. Da Tabela 4.19, observa-se que os valores de gradiente de colapso resultantes dos Cenários 7, 8, 9 e 10 apresentam-se ligeiramente superiores aos valores de gradiente obtidos nos Cenários 1 a 6 . Os maiores valores de gradiente de colapso ocorreram nos Cenários que apresentavam menores valores de UCS, coeficiente de Biot alto (1) e maior abertura de breakout $\left(60^{\circ}\right)$. A variação do conjunto de parâmetros em cada cenário pode ter gerado efeitos secundários nos resultados.

Esses efeitos também influenciaram os resultados do gradiente de colapso para o Poço 7, de acordo com a Tabela 4.20. 
Tabela 4.20 - Resultados da janela operacional dos diferentes cenários para o carbonato do Poço 7

\begin{tabular}{|c|c|c|c|c|c|}
\hline \multicolumn{7}{|c|}{ Poço 7 } \\
\hline Cenários & $\begin{array}{c}\text { Correlação } \\
\text { UCS }\end{array}$ & Biot & $\begin{array}{c}\text { Abertura } \\
\text { Breakout }\end{array}$ & ESRmax & $\begin{array}{c}\text { Janela operacional } \\
\text { (P. colapso/S }\end{array}$ \\
\hline \hline Cenário 1 & Militzer & 1 & 0 & 1,67 & $13,3 / 13,8$ \\
\hline Cenário 2 & Militzer & 1 & 30 & 1,8 & $13,3 / 13,8$ \\
\hline Cenário 3 & CPM & 1 & 0 & 1,35 & $13,4 / 13,8$ \\
\hline Cenário 4 & CPM & 1 & 30 & 1,45 & $13,4 / 13,8$ \\
\hline
\end{tabular}

Valores estatísticos do gradiente de colapso também foram analisados e estão apresentados nas Tabelas 4.21. e 4.22. Os resultados obtidos das simulações indicam valores médios de 10,7ppg para o Poço 1 e 13.4ppg para o Poço 7 com probabilidade de ocorrência de 90\%, segundo o método de Monte Carlo.

Tabela 4.21 - Valores estatísticos da pressão de colapso em cada cenário para o Poço 1

\begin{tabular}{|c|c|c|c|}
\hline \multicolumn{4}{|c|}{ Pressão de Colapso (ppg) - Poço 1 } \\
\hline Cenários & Média & $\mathbf{P}_{10}$ & $\mathbf{P}_{90}$ \\
\hline \hline Cenário 1 & 10,1 & 9,6 & 10,5 \\
\hline Cenário 2 & 10,2 & 9,7 & 10,7 \\
\hline Cenário 3 & 10,2 & 9,7 & 10,7 \\
\hline Cenário 4 & 9,9 & 9,3 & 10,5 \\
\hline Cenário 5 & 10,2 & 9,5 & 10,8 \\
\hline Cenário 6 & 9,9 & 9,3 & 10,5 \\
\hline Cenário 7 & 9,9 & 8,4 & 10,8 \\
\hline Cenário 8 & 9,9 & 8,4 & 10,7 \\
\hline Cenário 9 & 9,7 & 8,1 & 10,7 \\
\hline Cenário 10 & 9,8 & 9,2 & 10,4 \\
\hline
\end{tabular}

Os resultados das curvas de gradiente de colapso obtidos de cada cenário foram plotados nos Gráficos 4.14 e 4.15. Observa-se no Gráfico 4.14 que ocorre uma mudança no comportamento da curva de gradiente de colapso a partir de $5800 \mathrm{~m}$ e é onde a dispersão entre as curvas é maior nos Cenários, 3, 5 e 6, variando de 9,2 a 9,8 ppg. 
Tabela 4.22 - Valores estatísticos da pressão de colapso em cada cenário para o Poço 7

\begin{tabular}{|c|c|c|c|}
\hline \multicolumn{4}{|c|}{ Pressão de Colapso (ppg) - Poço 7 } \\
\hline Cenários & Média & $\mathbf{P}_{10}$ & $\mathbf{P}_{\mathbf{9 0}}$ \\
\hline \hline Cenário 1 & 13,1 & 12,9 & 13,3 \\
\hline Cenário 2 & 13,2 & 12,9 & 13,4 \\
\hline Cenário 3 & 13,0 & 12,5 & 13,4 \\
\hline Cenário 4 & 13,0 & 12,5 & 13,4 \\
\hline
\end{tabular}

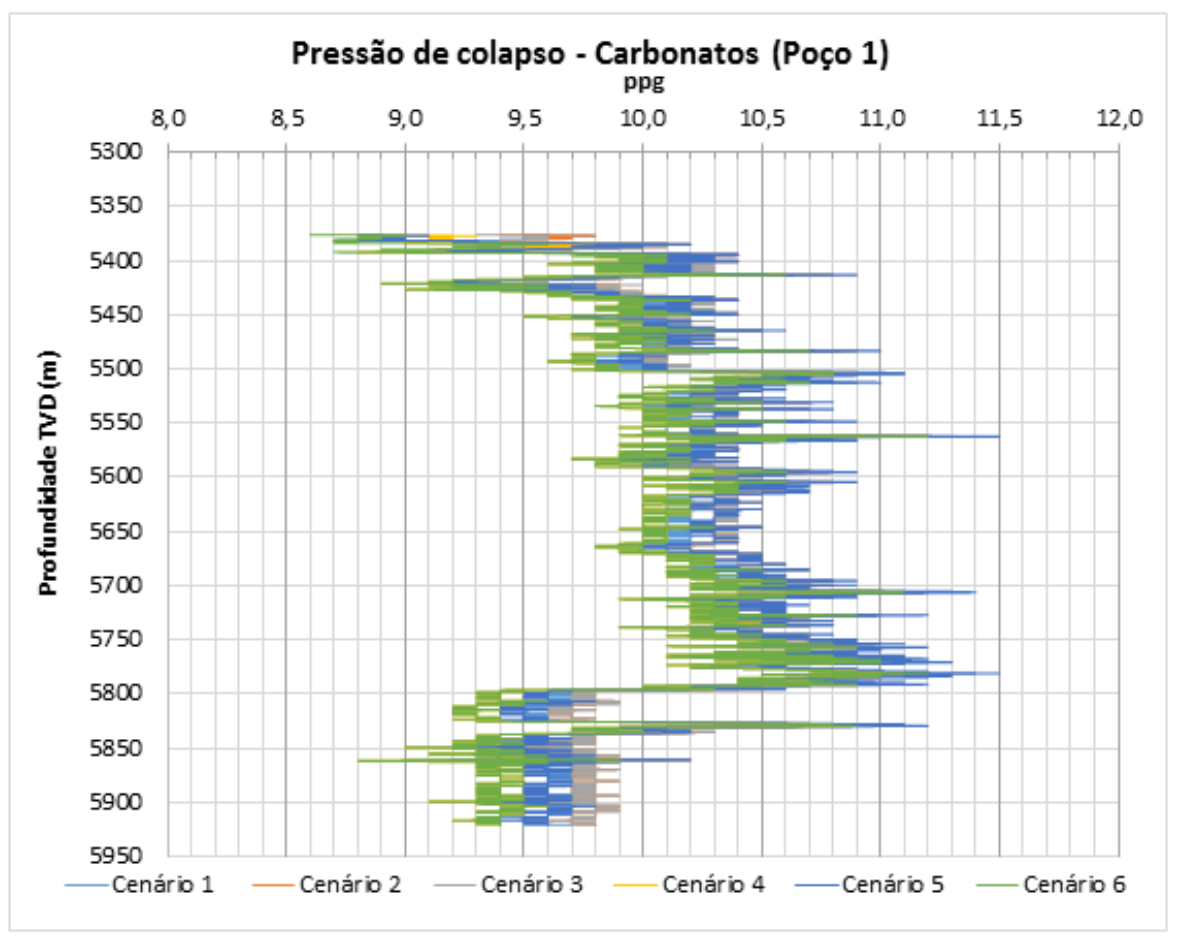

Gráfico 4.14 - Gráfico comparativo das curvas de gradiente de colapso resultante dos Cenários de $\frac{0}{\frac{1}{0}}$ 1 a 6 para o Poço 1

No Gráfico 4.15, a maior dispersão entre as curvas de gradiente de colapso pode ser observada no trecho de 5800 a $5920 \mathrm{~m}$, no qual o UCS foi estimado com a correlação de CPM. Os valores nesse trecho variaram de 8,0 a 9,4ppg. 


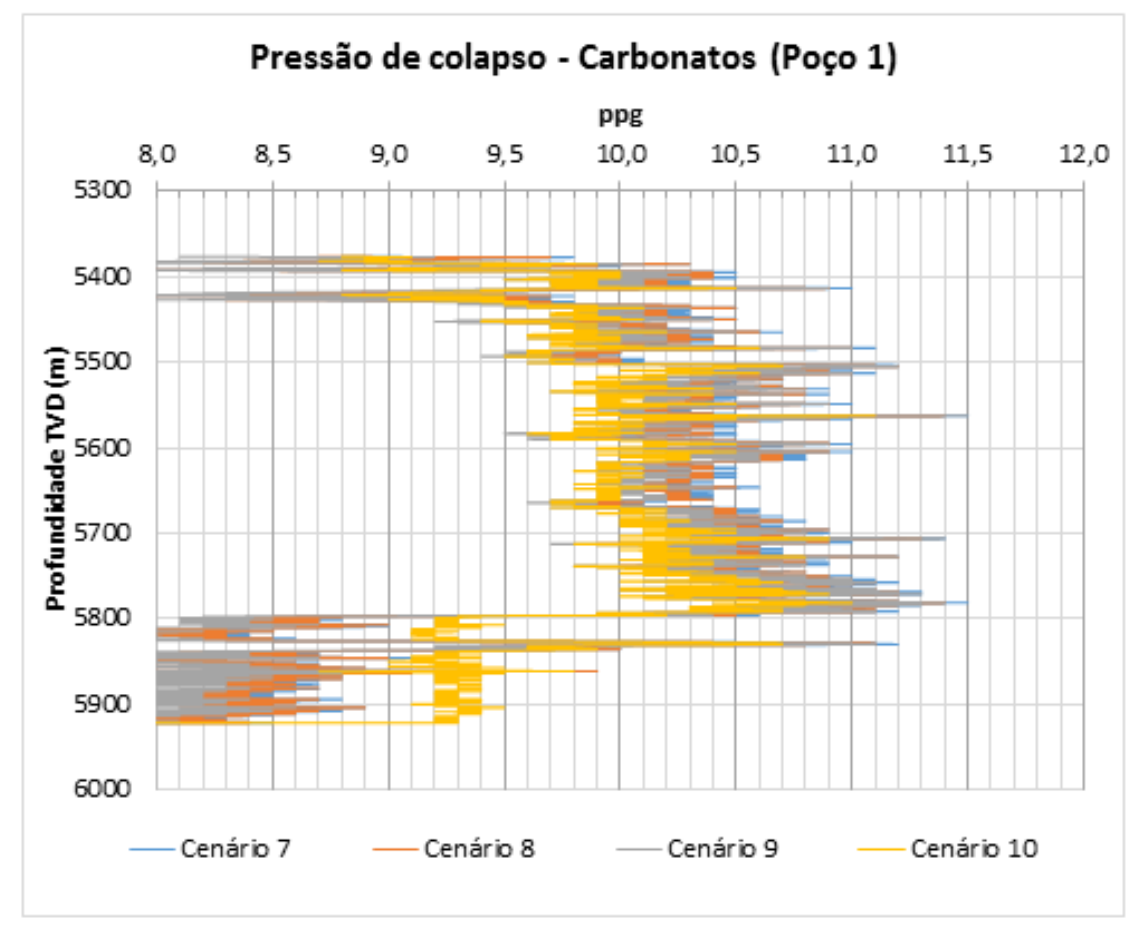

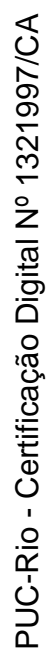

Gráfico 4.15 - Gráfico comparativo das curvas de gradiente de colapso resultante dos cenários de 7 a 10 para o Poço 1

Os Gráficos 4.16 e 4.17 apresentam as curvas de gradiente de colapso resultantes do Poço 7.

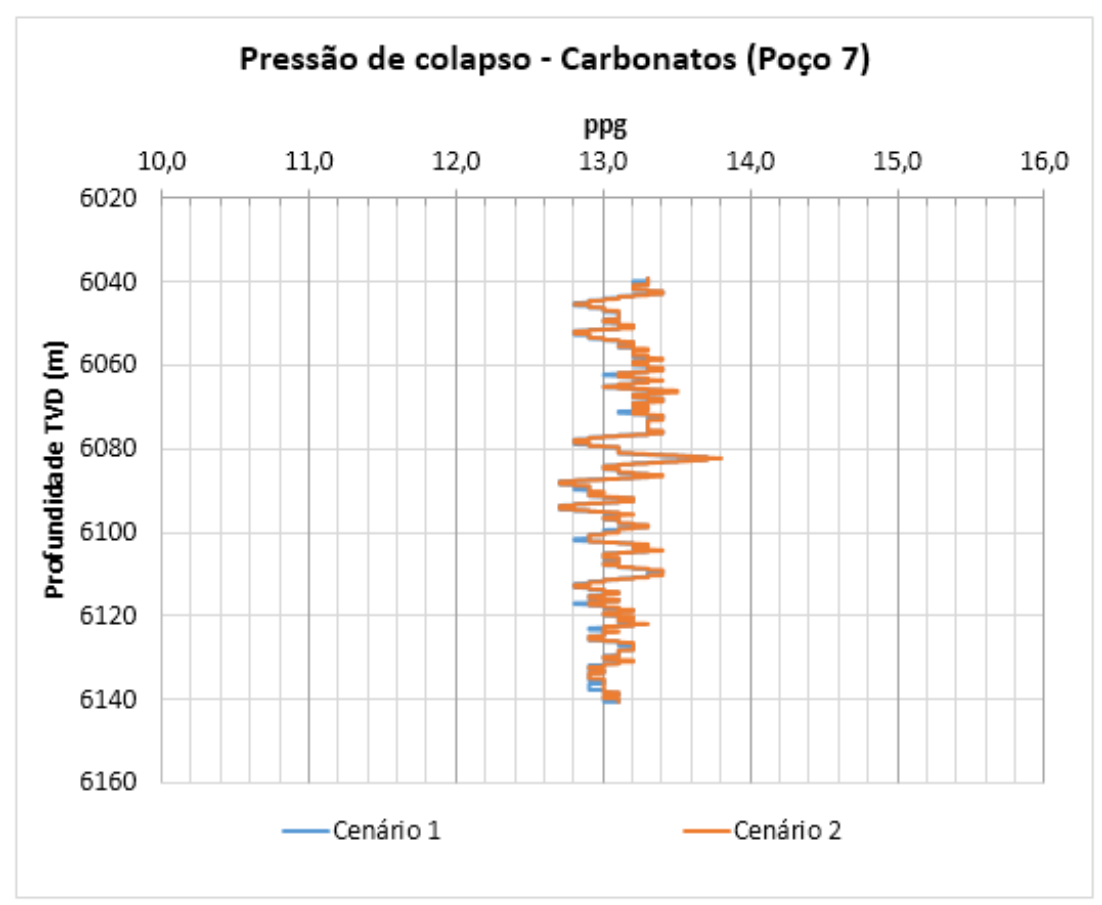

Gráfico 4.16 - Gráfico comparativo das curvas de gradiente de colapso resultante dos Cenários 1 e 2 para o Poço 7 
No Gráfico 4.16, os resultados apresentam similaridade entre os cenários variando de 13,0 a 13,3ppg e apresentaram maior dispersão nos resultados dos Cenários 3 e 4, que foi de 1,2ppg (Gráfico 4.17).

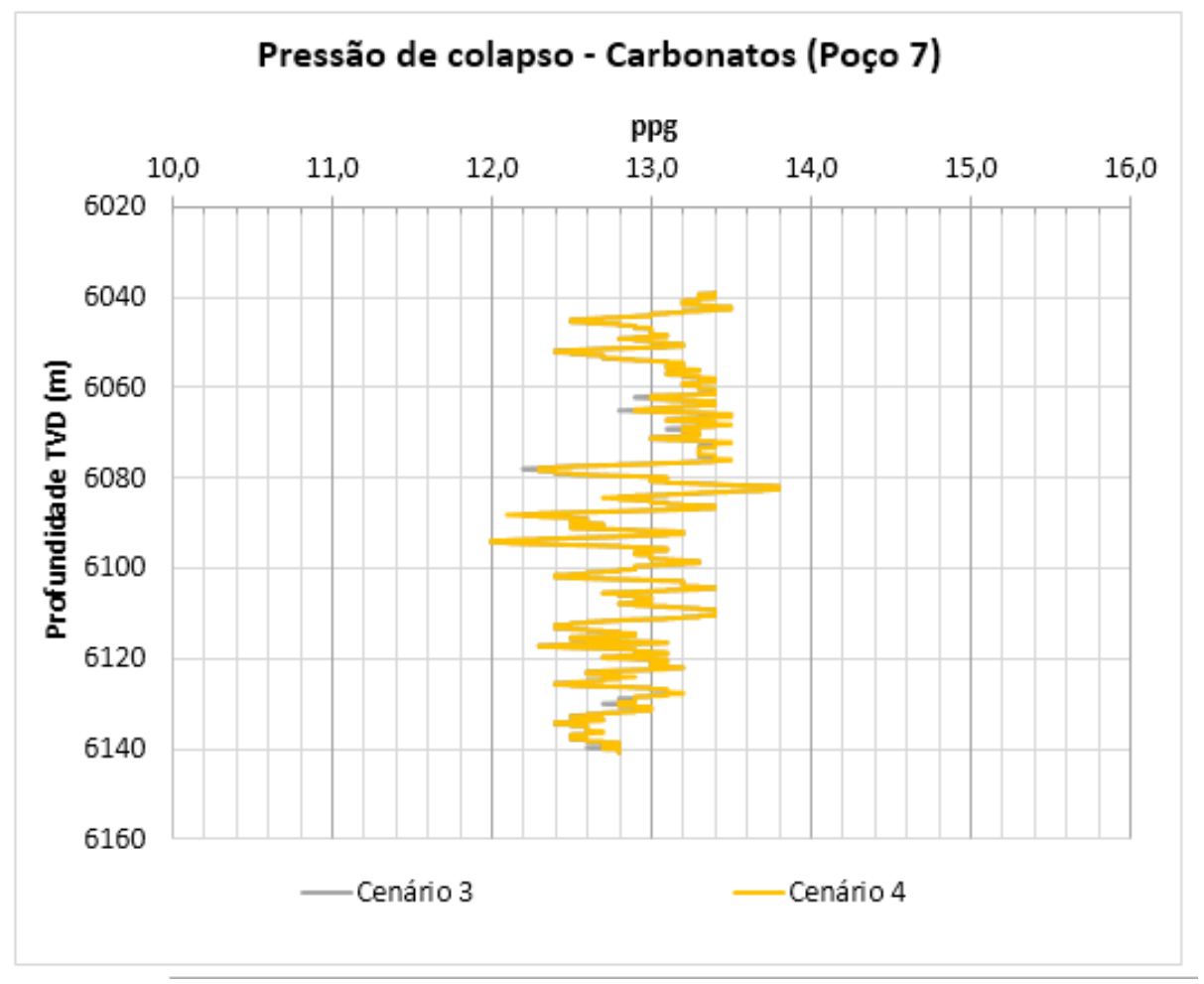

Gráfico 4.17 - Gráfico comparativo das curvas de gradiente de colapso resultante dos Cenários $3 \mathrm{e}$ 4 para o Poço 7

A seguir será apresentado o modelo geomecânico de estabilidade para o Cenário 2 dos Poços 1 e 7. A Figura 4.12 apresenta, da esquerda para direita, a profundidade em TVD, litologia, os topos das formações, $\mathrm{ESR}_{\min }$ e $\mathrm{ESR}_{\max }$ para cada tipo de litologia e o azimute de $\mathrm{S}_{\mathrm{Hmax}}\left(95^{\circ}\right)$, respectivamente em cada coluna. Para os carbonatos, considerou-se ESR min igual a 0,65 e ESR $\max$ igual a 1,05. 


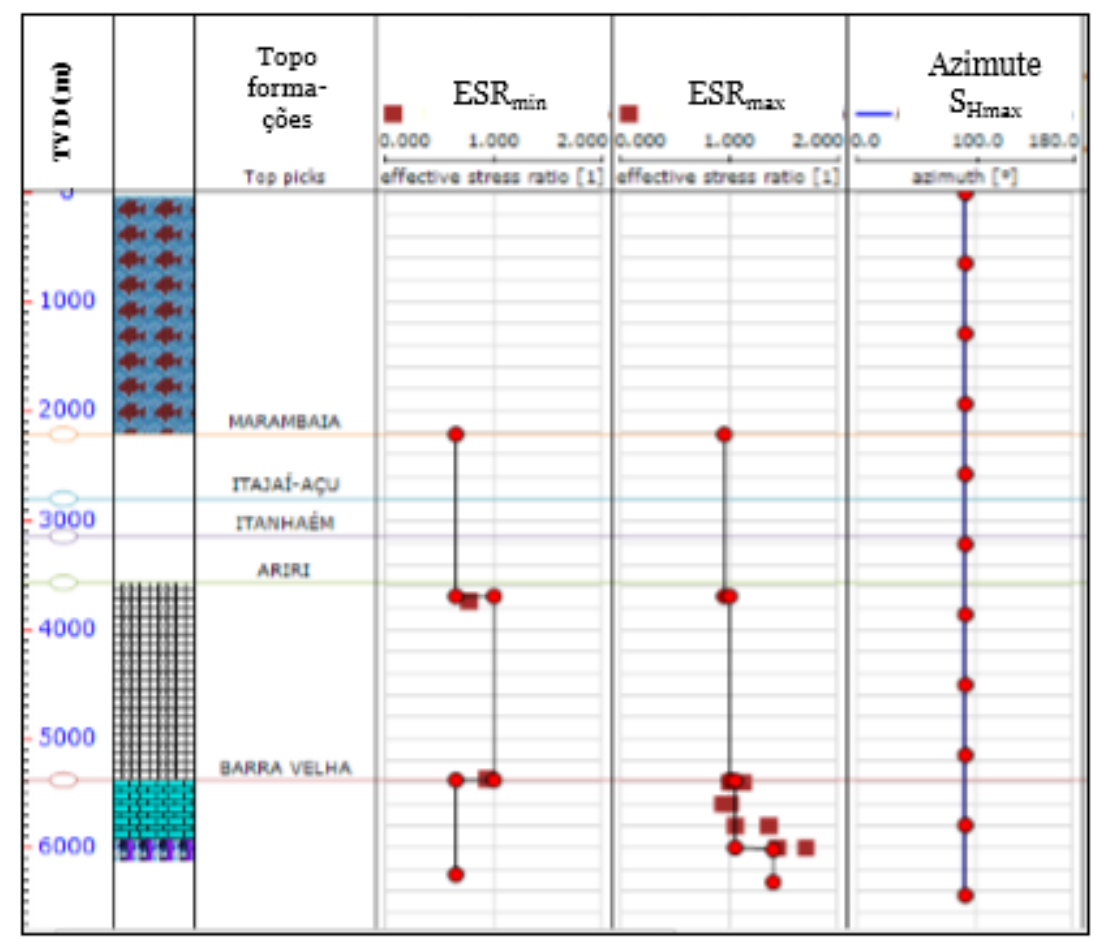

Figura 4.12 - Valores de ESR $\min , \mathrm{ESR}_{\max }$ e Direção de $\mathrm{S}_{\mathrm{Hmax}}$ (Poço 1 - Cenário 2)

Na Figura 4.13, as informações estão distribuídas nas colunas da direita para a esquerda: profundidade em TVD (m), topo de formação, curvas dos gradientes da janela operacional (onde PP é o gradiente de pressão de poros, GC é o gradiente de

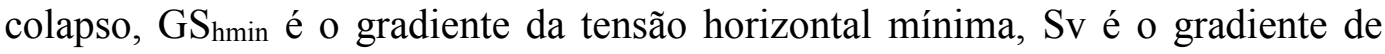
sobrecarga e o GS $S_{\text {max }}$ é o gradiente da tensão horizontal máxima), abertura de breakout, UCS e propriedades elásticas e profundidade da sapata. Na coluna 4 os círculos vermelhos são as pressões medidas durante a perfuração e que foram utilizadas para a calibração da curva de pressão de poros, enquanto os círculos azuis são os LOTs.

Avaliando a coluna 3 da Figura 4.13, observa-se que no trecho entre 5400 e $5690 \mathrm{~m}$ o gradiente de colapso apresenta valores $3 \%$ acima do peso de fluido que foi utilizado na perfuração dessa fase (10,2ppg). A partir de $5690 \mathrm{~m}$ os valores sofrem um incremento, chegando a um diferencial de 1,0ppg entre as curvas de peso de fluido e GC em 5800m (11,2ppg). 


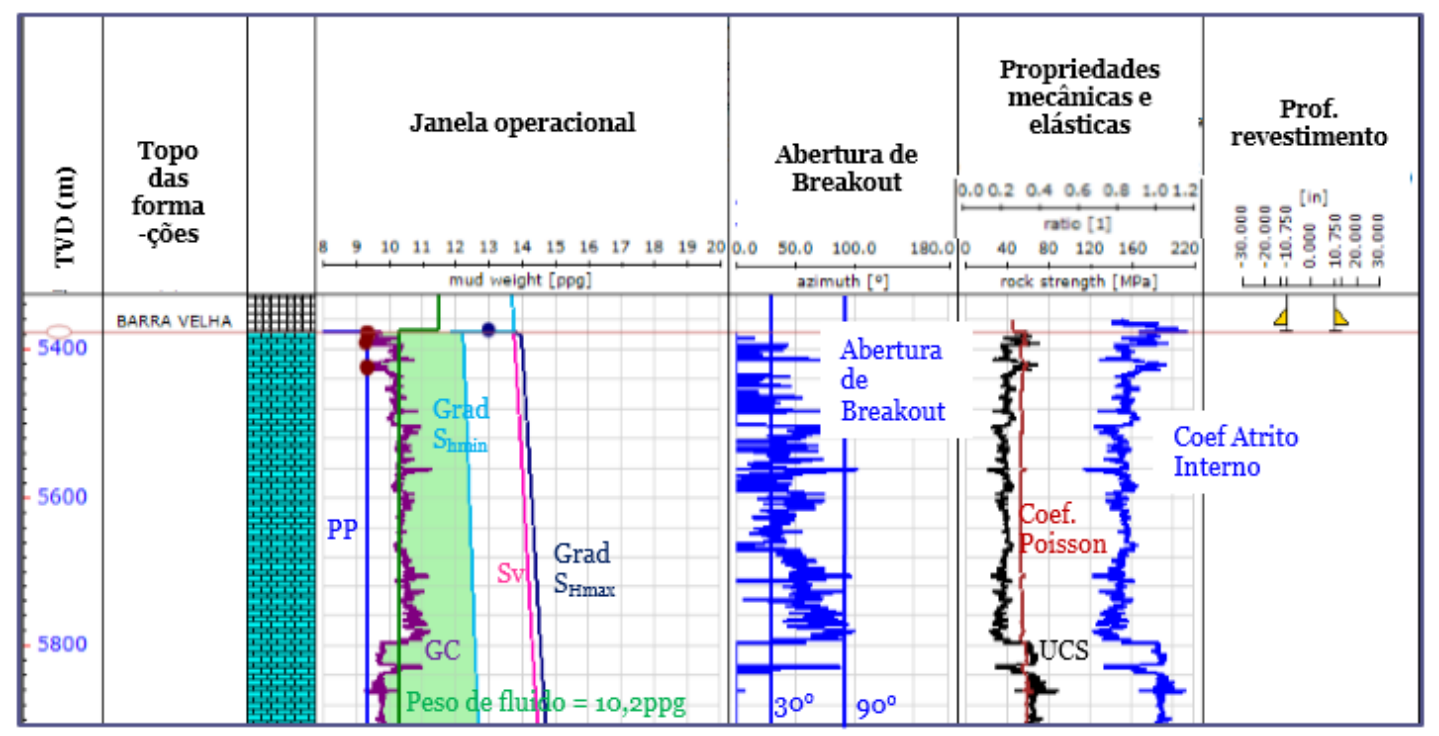

Figura 4.13 - Resultado do modelo geomecânico de estabilidade (Poço 1 - Cenário 2)

De 5800 à 5920m, o gradiente de colapso sofre uma mudança de comportamento, onde os valores diminuem para, aproximadamente, 9,5ppg. Os valores de UCS sofreram um incremento de $10 \mathrm{MPa}$ nesse mesmo trecho. $\mathrm{O}$ incremento desse parâmetro juntamente com os efeitos da variação do coeficiente de Biot, da abertura de breakout e da heterogeneidade da rocha carbonática, podem ter influenciado nessa redução do gradiente de colapso.

A coluna 6 da Figura 4.13 mostra os valores de abertura de breakout obtidos no modelo de estabilidade de poço. Assume-se que breakouts com abertura de até $90^{\circ} \mathrm{em}$ poços verticais e $30^{\circ}$ para poços horizontais seriam aceitáveis e não trariam problemas significativos durante a perfuração, já que acredita-se que o volume de cascalhos gerados seria facilmente removidos do anular. Nesse caso, as aberturas de breakout resultantes variaram entre $20^{\circ}$ e $70^{\circ}$, com um pequeno trecho, próximo a $5800 \mathrm{~m}$, que variou em torno de $90^{\circ}$. Os resultados indicaram que houve instabilidade do poço, mas que as aberturas de breakout se apresentaram dentro do intervalo de segurança assumido para os poços verticais.

Os resultados encontrados para a rocha ignea não será considerado nesse estudo, já que a ausência de relatórios diários de perfuração, dados de pressões medidas, dados de ensaios de laboratório e dados de imagem não possibilita a calibração dos resultados. 
Os resultados do modelo geomecânico de estabilidade do Poço 7 (Cenário 2) também serão apresentados. Observa-se na Figura 4.14, que os valores de $\mathrm{ESR}_{\min } \mathrm{e}$ $\mathrm{ESR}_{\max }$ considerados foram, respectivamente, iguais a 0,65 e 1,8 .

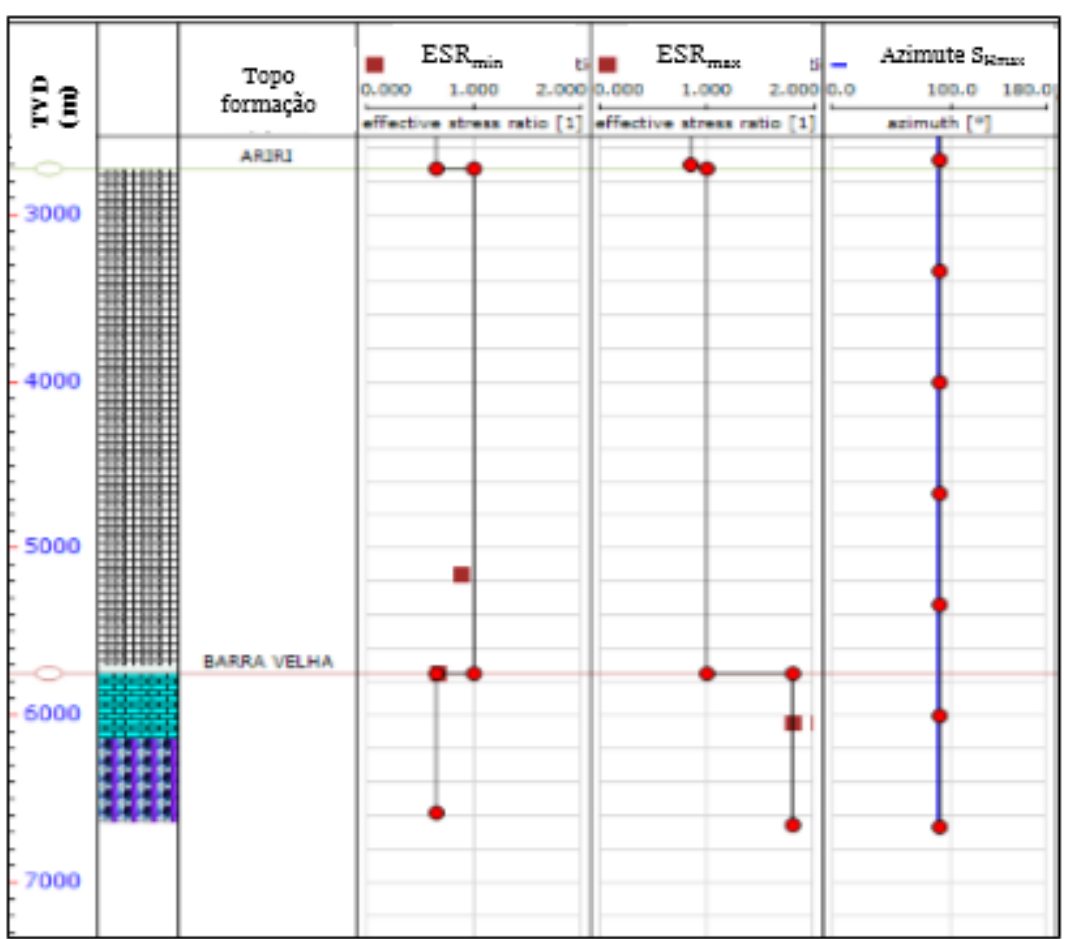

Figura 4.14 - Valores de ESR $\mathrm{min}_{\text {n, }} \mathrm{ESR}_{\max }$ e Direção de $\mathrm{S}_{\mathrm{Hmax}}($ Poço 7 - Cenário 2)

Como observou-se na análise de pressão de poros (item 4.2) o Poço 7 está localizado em uma área onde a pressão de poros é normalmente alta, com gradientes variando entre 13,1 e 12,7ppg. De acordo com a Figura 4.15, o GC resultou em valores menores que o peso de fluido utilizado na perfuração. Vale ressaltar que não há dados de perfis no trecho de 5760 a $6040 \mathrm{~m}$ e, por isso, não foi possível estimar o GC para esse trecho dos carbonatos. O comportamento da curva de gradiente de colapso não apresenta grande variação, resultando em um valor médio de $13,2 \pm 0,2$ ppg. 


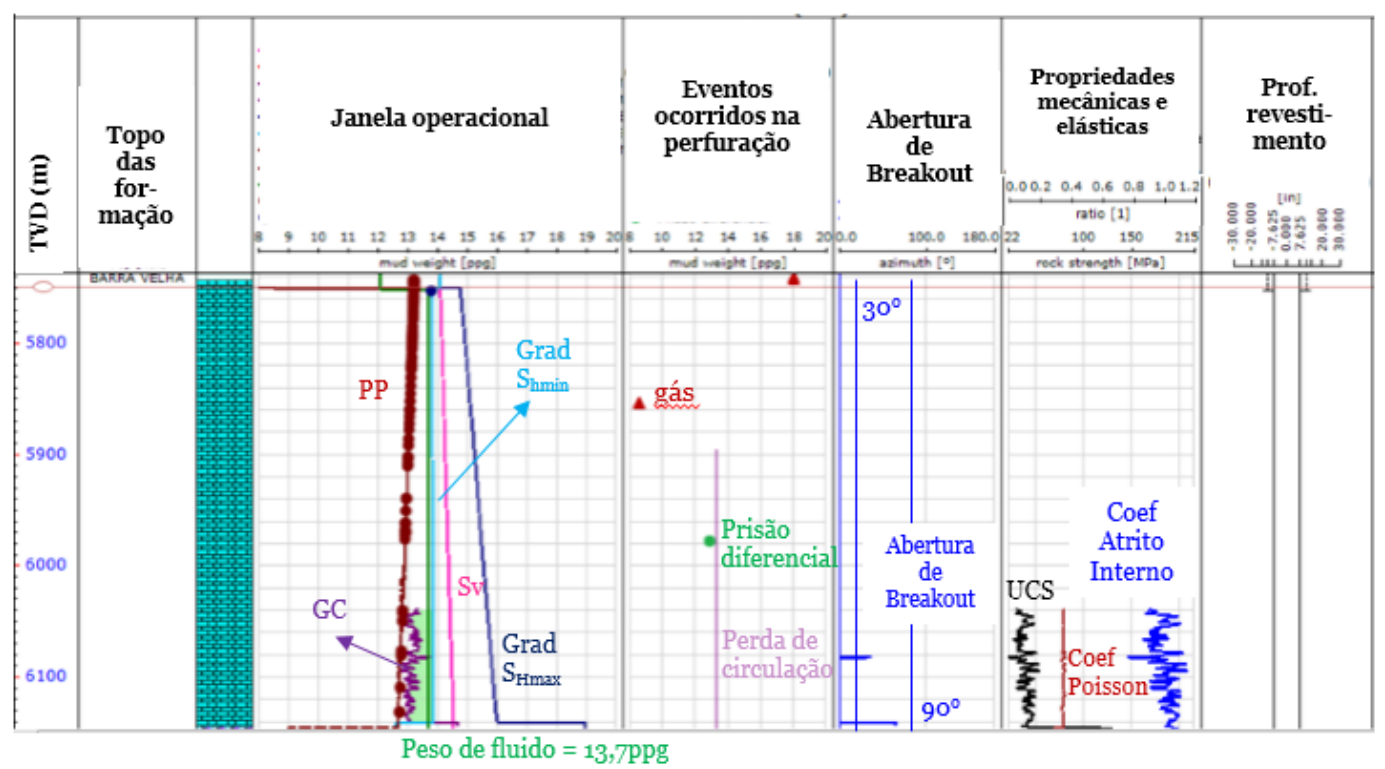

Figura 4.15 - Resultado do modelo geomecânico de estabilidade (Poço 7 - Cenário 2)

A fim de realizar uma análise de sensibilidade dos resultados obtidos, utilizou-se a técnica de Avaliação Quantitativa de Risco (Quantitative Risk Assessment - QRA). Como descrito por Ottesen et al. (1999) e Moos et al. (2003), o QRA permite que se considere como a incerteza de um dos parâmetros afetam a estabilidade do poço em termos de peso de fluido necessário para alcançar o grau de abertura de breakout máximo aceitável a fim de se garantir a estabilidade do poço.

A Figura 4.16 mostra uma janela de peso de fluido para a profundidade $5600 \mathrm{~m}$ no qual o limite inferior e superior foram quantificados em termos probabilísticos. O limite inferior é representado pelo valor mínimo de peso de fluido para se previnir o aparecimento de breakouts e o limite superior é representado pelo valor máximo para se evitar a perda de circulação. A linha horizontal em azul indica a janela de peso de fluido que garante, com $90 \%$ de probabilidade de ocorrência de sucesso na perfuração, que os problemas de breakouts e de perdas de circulação não ocorrerão. A janela operacional a 5600m no caso do Poço 1 é bem ampla, onde os valores de peso de fluido podem variar entre de 9,8 a 12,4ppg. 


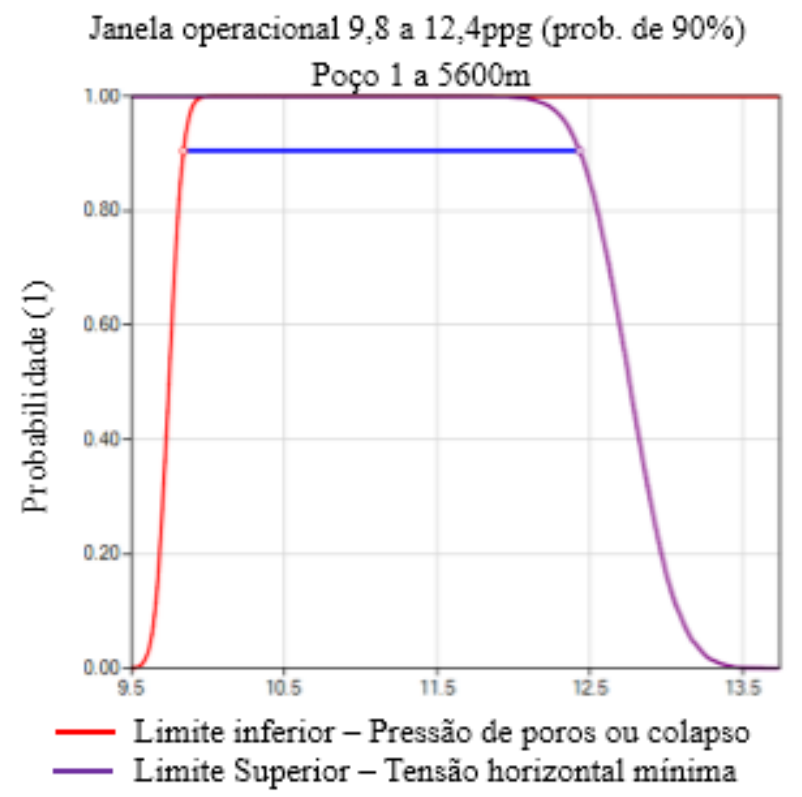

Figura 4.16 - Resultados da janela operacional em termos de probabilidade na profundidade de 5600m (Poço 1 - Cenário 2)

A janela de peso de fluido para o Poço 7 (Cenário 2) está indicada na Figura 4.17. É possível observar que no caso desse poço a janela operacional na profundidade de $6100 \mathrm{~m}$ é bem estreita, variando entre 12,9 e 13,5ppg e também considerando uma probabilidade de $90 \%$ de êxito na perfuração.

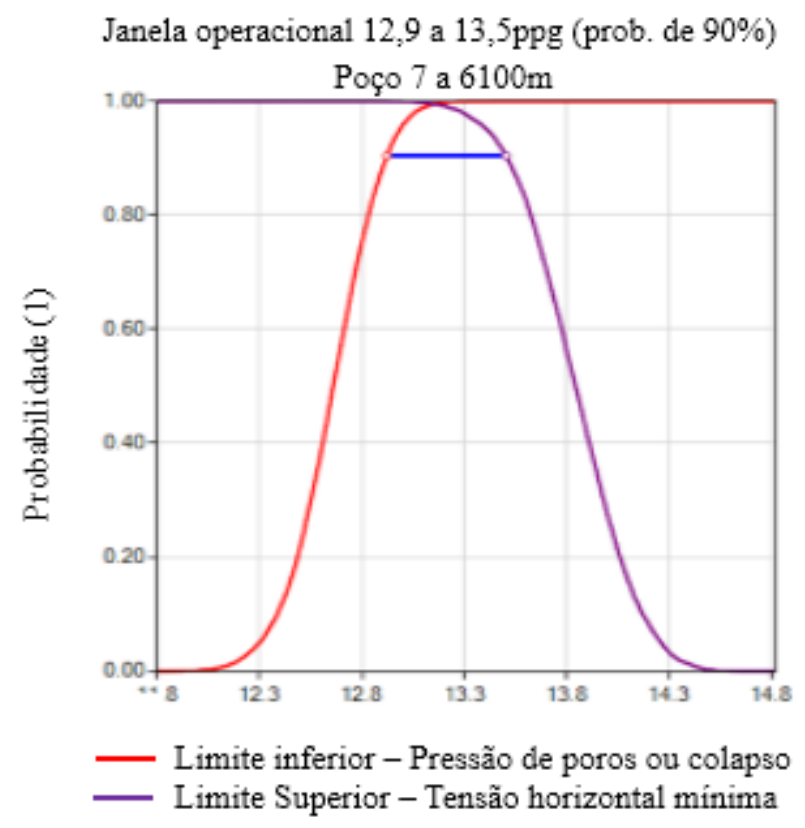

Figura 4.17 - Resultados da janela operacional em termos de probabilidade na profundidade de 6100m (Poço 7 - Cenário 2) 
A análise de sensibilidade da incerteza dos parâmetros considerados no modelo geomecânico está apresentada nas Figuras 4.18 e 4.19. Estas figuras mostram a variação do peso de fluido em relação a cada parâmetro. O resultado da análise de sensibilidade para o Poço 1 indicou que a previsão do peso de fluido é mais sensível à incerteza associada às tensões horizontais $\mathrm{S}_{\mathrm{hmin}}$ e $\mathrm{S}_{\mathrm{Hmax}}$, pelo UCS e a pressão de poros.

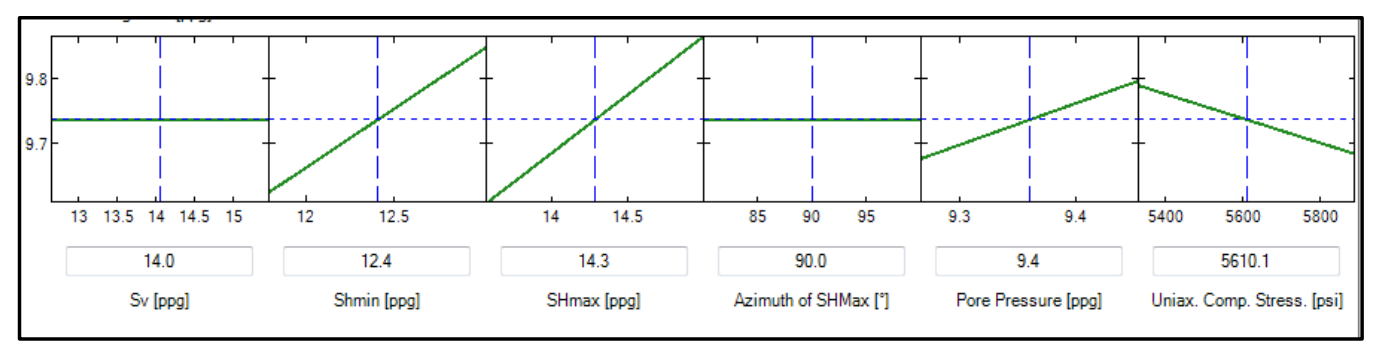

Figura 4.18 - Resultados que ilustram a sensibilidade da previsão do peso de fluido (em ppg) associado à incerteza de cada parâmetro (Poço 1 - Cenário 2)

No caso do Poço 7, o resultado da análise de sensibilidade (Figura 4.19) indicou que a previsão do peso de fluido é mais sensível a incerteza associada à pressão de poros, que é anormalmente alta na região onde esse poço foi perfurado. Isso quer dizer que as incertezas associadas ao modelo geomecânico para esse poço gira em torno do efeito da pressão de poros.

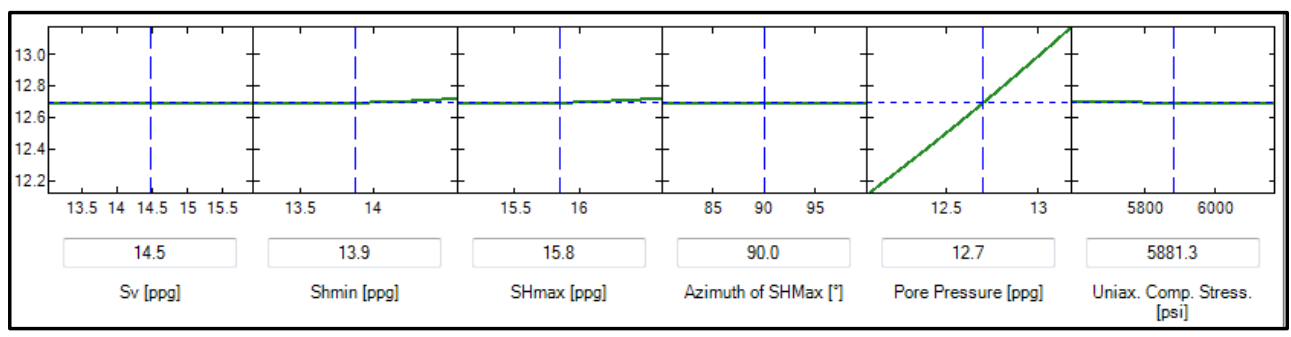

Figura 4.19 - Resultados que ilustram a sensibilidade da previsão do peso de fluido (em ppg) associado à incerteza de cada parâmetro (Poço 7 - Cenário 2)

A Tabela 4.23 mostra os resultados da análise de sensibilidade para os carbonatos em todos os cenários. Os resultados das janelas operacionais resultantes do QRA, para os cenários do Poço 1 a 5600m, indica um intervalo médio entre 9,7 e 12,4ppg e, para o Poço 7 a 6100m, indica valores entre 12,9 e 13,5ppg. Observou- 
se que, de acordo com a análise de sensibilidade, os parâmetros que tem influencia na previsão do peso de fluido no modelo geomecânico são as tensões horizontais mínimas e máximas, o UCS e a pressão de poros.

Tabela 4.23 - Análise de sensibilidade para a fase dos carbonatos para os Poços 1 e 7

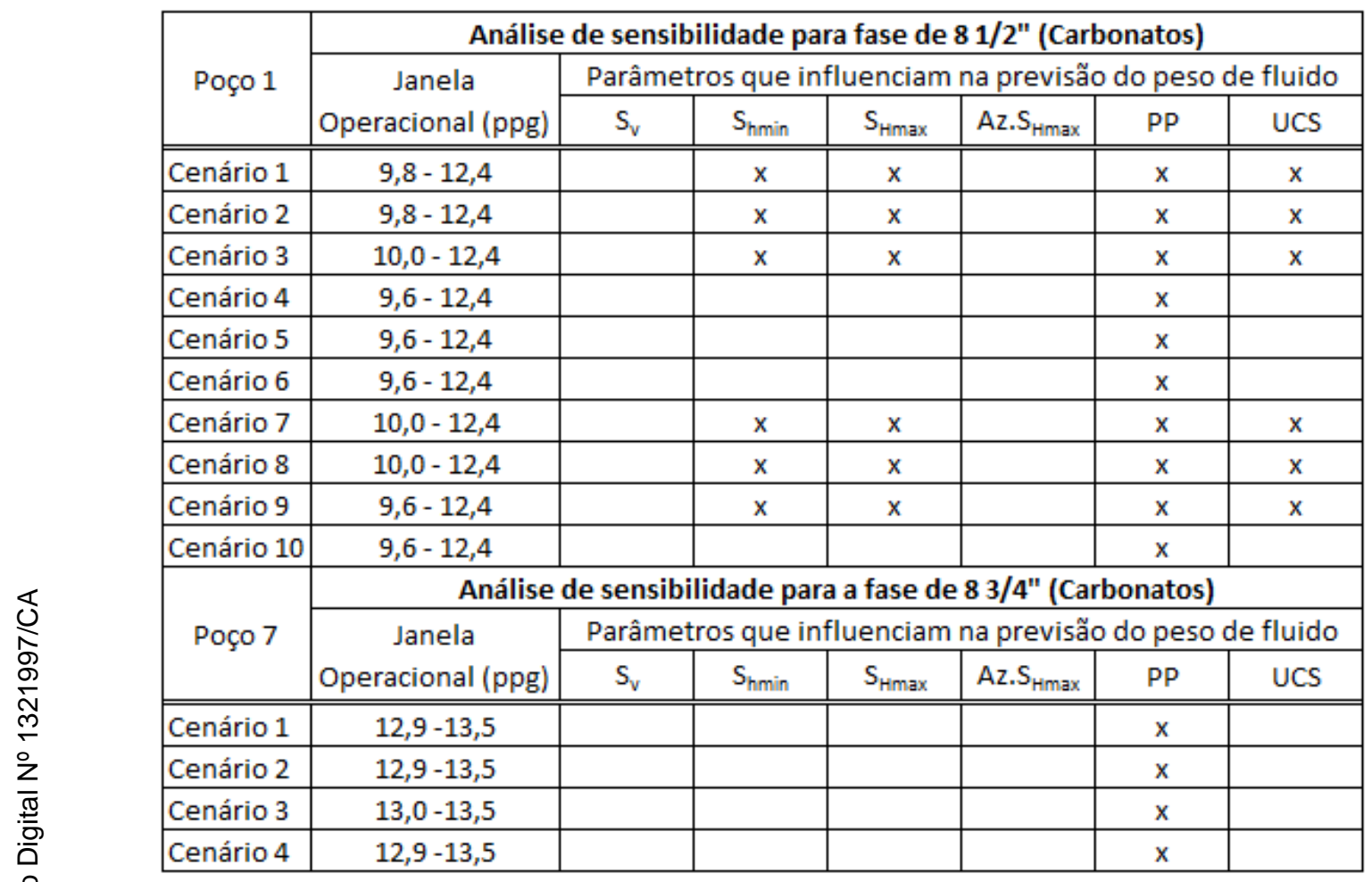

$\mathrm{Na}$ Tabela 4.24, fez-se um levantamento do peso de fluido utilizado em cada poço na fase onde localiza-se os carbonatos. Durante a perfuração dos Poços 1, 2, $3,4,6,8$ o peso de fluido utilizado foi em torno de 10,3ppg, enquanto que para os Poços 5 e 7 os valores de peso de fluido utilizados foram de, 11,5 e 13,7ppg, respectivamente. Observa-se que no Poço 5 o peso de fluido utilizado na perfuração do sal e dos carbonatos foi o mesmo (11,5ppg). Já no Poço 7 o peso de fluido utilizado na fase de $83 / 4$ " foi de $13,7 \mathrm{ppg}$. 
Tabela 4.24 - Peso de fluido utilizado na perfuração de cada poço da fase dos carbonatos

\begin{tabular}{|c|c|c|}
\hline \multirow{2}{*}{ Poço } & \multicolumn{2}{|c|}{ Dados nos Carbonatos } \\
\cline { 2 - 3 } & Fase & $\begin{array}{l}\text { Peso de fluido } \\
\text { utilizado (ppg) }\end{array}$ \\
\hline \hline 1 & $81 / 2^{\prime \prime}$ & 10,3 \\
\hline 2 & $81 / 2^{\prime \prime}$ & 10,2 \\
\hline 3 & $121 / 4^{\prime \prime}$ & 10,1 \\
\hline 4 & $81 / 2^{\prime \prime}$ & 10,1 \\
\hline 5 & $121 / 4^{\prime \prime}$ & 11,5 \\
\hline 6 & $81 / 2^{\prime \prime}$ & 10,3 \\
\hline 7 & $83 / 4^{\prime \prime}$ & 13,7 \\
\hline 8 & $121 / 4^{\prime \prime}$ & 10,3 \\
\hline
\end{tabular}




\section{Conclusões}

No presente estudo foi elaborado um modelo geomecânico de estabilidade de poço no qual foi possível estimar a janela operacional de peso de fluido do pré-sal brasileiro da área de estudo na Bacia de Santos. O modelo geomecânico levou em conta informações de oito poços e apresenta incertezas associadas à estimativa de alguns parâmetros dependentes de dados importantes que não foram disponibilizados ou que não foram adquiridos pelas Operadoras/ANP.

Os resultados da estimativa do gradiente de sobrecarga indicaram valores médios entre 13,6 e 14,3ppg na profundidade dos carbonatos (5000m até $6140 \mathrm{~m})$. Essa variação se dá devido à diferença de LDA e à possíveis intercalações de diferentes tipos de carbonatos ou outras litologias que podem estar presentes nos reservatórios do pré-sal (observado através da variação dos valores de densidade encontrados nos perfis $\left(2,4 \mathrm{a} 2,7 \mathrm{~g} / \mathrm{cm}^{3}\right)$.

A análise das pressões de poros medidas indicou a presença de dois cenários na área de estudo: um cenário de pressão de poros levemente pressurizada em torno de 9,2ppg e outro com pressão de poros anormalmente alta variando de 12,7 até 13,1ppg. Algumas hipóteses foram levantadas a fim de justificar essa diferença de pressão: pressurização do reservatório provocada pela presença do sal e da rocha ígnea, que funcionariam como um selo; presença de falhas geológicas selantes, provocando uma compartimentalização do reservatório; transferência de pressão de poros anormal para o reservatório carbonático através de falhas geológicas nãoselantes; o regime de pressão afetado pela presença de domos salinos; e/ou o efeito da flotabilidade dos fluidos.

A presença desses dois cenários de pressão de poros só reforça a necessidade de estudos geomecânicos em áreas com a presença de sal e uma avaliação mais detalhada dos fenômenos tectônicos na área estudada. $O$ conhecimento da variação de pressão de poros na extensão da área de interesse é fundamental para que, ao perfurar o poço, não haja surpresas negativas em relação a tempo perdido e em relação à segurança durante as operações. 
Os dados de testes de avaliação de formação (LOT e FIT) realizados nos carbonatos dos poços indicaram boa correlação e foram considerados para a estimativa da tensão horizontal mínima. Com as análises dos LOTs foi obtido um $E_{\text {SRin }}$ de 0,65 , constante para toda a profundidade dos carbonatos, que foi utilizado para a estimativa do gradiente de $S_{\text {hmin }}$ que variou de 12,3 a 12,8ppg, para o Poço 1 e para o Poço 7 o gradiente de $S_{\text {hmin }}$ foi de 13,8ppg no trecho de 6040 a $6140 \mathrm{~m}$, onde havia dados de perfil disponível.

Para a estimativa do UCS dos carbonatos foram consideradas três correlações de resistência de rocha, sendo que duas delas (Militzer e CPM) resultaram em valores médios próximos entre si, em torno de $43 \mathrm{MPa}$, enquanto que a correlação de Golubev resultou em valores, aproximadamente 50\% maiores do que os resultados de resistência das outras correlações e foram desconsiderados no estudo. Além dessa análise, os valores de UCS também foram comparados com resultados de ensaios de laboratório do análogo do pré-sal, Travertino de Itaboraí, e os resultados das correlações empíricas de Militzer e CPM indicaram valores de UCS similares, em torno de 5\% menores do que os resultados do análogo. Conclui-se que os resultados empíricos de UCS obtidos pelas correlações se assemelham com os resultados do Travertino de Itaboraí e do ponto de vista de resistência de rocha poderiam sem considerados similares. As análises das propriedades das rochas desse estudo são preliminares e os resultados têm um grau de incerteza associado, devido à ausência de dados de ensaios de laboratório de UCS e de outras propriedades mecânicas das rochas dos carbonatos do pré-sal e às limitações das correlações empíricas.

A estimativa da direção e magnitude da tensão horizontal máxima foram as que apresentaram um maior grau de incerteza associada em função da ausência de dados de imagem, que permitiriam uma avaliação da abertura de breakouts e da direção de $\mathrm{S}_{\mathrm{Hmax}}$. Desse modo, para a estimativa da direção de $\mathrm{S}_{\mathrm{Hmax}}$ foi obtida através da análise das tensões encontradas no World Stress Map e a direção considerada foi de $95^{\circ} \mathrm{NE}$.

Devido à ausência das informações para a calibração da estimativa da magnitude de $\mathrm{S}_{\mathrm{Hmax}}$ foi necessário realizar simulações variando os parâmetros de UCS, Biot e abertura de breakout no polígono de tensões. A partir dos resultados, conclui-se que os mesmos são menores com o aumento do valor do coeficiente de Biot e a diminuição do ângulo de abertura de breakout. Isso foi observado 
independente da correlação de UCS que foi utilizada. Os resultados de $\mathrm{S}_{\mathrm{Hmax}}$ encontrados foram utilizados para a estimativa de $\mathrm{ESR}_{\max }$ que variou entre 0,95 e 1,8 em função dos cenários avaliados. Esses valores indicam que a área em questão apresenta falhamento transicional entre normal $\left(\mathrm{S}_{\mathrm{v}}>\mathrm{S}_{\mathrm{hmin}}>\mathrm{S}_{\mathrm{Hmax}}\right)$ e transcorrente $\left(\mathrm{S}_{\mathrm{H} \max }>\mathrm{S}_{\mathrm{v}}>\mathrm{S}_{\mathrm{hmin}}\right)$.

A estimativa do gradiente de colapso foi obtida a partir dos resultados estimados dos parâmetros de $\mathrm{S}_{\mathrm{v}}, \mathrm{PP}, \mathrm{UCS}, \mathrm{S}_{\mathrm{hmin}}, \mathrm{S}_{\mathrm{Hmax}}$ e foi a última curva estimada para a definição da janela operacional. Foram criados cenários para os Poços 1 e 7,

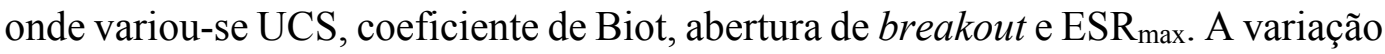
do conjunto de parâmetros em cada cenário pode ter gerado efeitos secundários nos resultados e os maiores valores de gradiente de colapso ocorreram quando a variação das condições indicava menores valores de UCS, um coeficiente de Biot alto (1) e uma maior abertura de breakout $\left(60^{\circ}\right)$.

No Poço 1, a curva do gradiente de colapso sofreu uma mudança de comportamento a partir de $5800 \mathrm{~m}$, reduzindo os valores de gradiente de colapso de 11,2ppg para 9,5ppg, aproximadamente. Os valores de UCS sofreram um incremento de 10MPa nesse mesmo trecho e esse incremento, juntamente com os efeitos da variação de Biot, da abertura de breakout e da heterogeneidade da rocha carbonática podem ter influenciado nessa redução do gradiente de colapso.

No trecho de 5400 e 5690m, ainda do Poço 1, os resultados do gradiente de colapso se apresentaram acima do peso de fluido indicando que poderia ter ocorrido instabilidade do poço, porém, como a abertura de breakout resultante do modelo geomecânico indica valores de até $90^{\circ}$, acredita-se que nessas condições os cascalhos gerados no desmoronamento do poço seriam removidos sem grandes problemas com um programa de hidráulica eficiente. A hipótese de instabiliadde do poço só poderia ser confirmada a partir de relatos de eventos geomecânicos ocorridos durante a perfuração.

Os resultados da curva de gradiente de colapso para o Poço 7 não apresentaram grande variação, resultando em um valor médio de 13,2 $\pm 0,2 \mathrm{ppg}$.

A análise de sensibilidade realizada com os parâmetros envolvidos na elaboração do modelo geomecânico indicou que a previsão do peso de fluido é mais sensível à incerteza associada às tensões horizontais mínimas e máximas, pelo UCS e, principalmente, pela pressão de poros. 
A Análise Quantitativa de Risco também indicou uma janela operacional para o trecho dos carbonatos. Estima-se que para a região com PP levemente pressurizada a janela operacional dos carbonatos a 5600m tenha como limite inferior valores entre 9,6 e 10,0ppg e como limite superior 12,4ppg. Já na região com PP anormalmente pressurizada a janela operacional para a fase dos carbonatos a $6100 \mathrm{~m}$ é de 12,9 a $13,5 \mathrm{ppg}$.

Realizou-se uma análise quantitativa entre os limites inferior e superior das janelas operacionais obtidas no modelo geomecânico e o peso de fluido utilizado na perfuração do trecho dos carbonatos, observa-se que na região com PP levemente pressurizada o valor de peso de fluido seria suficiente para combater o surgimento de breakout ou suficiente para agir como um agente eficiente na limpeza do poço e ao mesmo tempo é um valor que não provocaria eventos de perdas de circulação. A mesma avaliação foi realizada na área com PP alta e observou-se uma janela mais estreita, onde, possivelmente, se perfurou em uma condição nearbalance, ou seja, onde o peso de fluido e a PP possuíam valores muito próximos entre si. Acreditase nessa condição pelo fato relatado de que o kick ocorrido no Poço 7 foi controlado com o valor de peso de fluido de 13,6ppg.

Vale ressaltar que, para se confirmar ou não a instabilidade dos poços relatados anteriormente, há a necessidade de se avaliar os eventos geomecânicos observados durante a perfuração dos mesmos, a fim de que o modelo geomecânico de estabilidade de poço pudesse ser calibrado. 


\section{6 \\ Recomendações}

As análises e considerações apresentadas no estudo em questão indicaram a necessidade e importância da coleta de dados durante ou logo após a perfuração dos poços, principalmente no caso de uma área estratégica e exploratória. O modelo geomecânico é uma ferramenta que exige uma quantidade e variabilidade significativa de dados para que a incerteza seja reduzida, por isso, recomenda-se obter dados de perfis em toda a extensão dos poços, realizar testes de mini-fracs nas rochas carbonáticas quando possível, realizar ensaios de resistência de rocha em laboratório (uniaxiais e triaxiais), registrar dados de imagem através de perfis elétricos e/ou caliper de 4 ou 6 braços para avaliar washouts e direção das tensões, monitorar dados de poços como ECD, peso de fluido de entrada (mud in) e de saída (mud out), etc.

O estudo geomecânico 3D pode ser uma solução eficiente para minimizar os problemas causados pela complexidade da área do pré-sal, já que proporciona um conhecimento visual e quantitativo da variação lateral e vertical do gradiente de pressão de poros, resistência das rochas e campo de tensões. Vale ressaltar a dificuldade em se adquirir os dados necessários para o mapeamento geológico da região.

A presença da rocha ígnea observada após o trecho dos carbonatos pode ser elemento de um estudo geomecânico mais detalhado, a fim de se avaliar a influência dessa rocha nas características mecânicas do reservatório carbonático.

Visando realizar análises mais detalhadas e assim confirmar os resultados preliminares obtidos nesse estudo, recomenda-se à ANP (BDEP) aumentar o pacote de dados disponíveis, como as imagens dos poços, relatórios detalhados de perfuração e ensaios de laboratório, dados estes que poderiam contribuir ainda mais com as análises do modelo geomecânico proposto. 
7

\section{Referências bibliográficas}

AADNOY B. S. E CHENEVERT, Stability of highly inclined boreholes, SPE Driling Eng., 2 (4): 34-374. 1987.

ALCURE, M. F., Uma avaliação de modelo para a determinação do gradiente de fratura em problemas de estabilidade de poços e sua influência na janela operacional. Rio de Janeiro. 2013. Dissertação de mestrado (Engenharia civil). Pontifícia Universidade Católica do Rio de Janeiro.

ALVES, J. L.D., COELHO, L. C., Estabilidade de poços em rochas carbonáticas. 4o PDPETRO, Campinas, SP. 2.2.234.pg 7. 2007.

ATASHBARI, V., TINGAY, M. R., Pore pressure prediction in carbonate reservoirs. SPE -150835.2012.

AZEVEDO, M. S., Análise geomecânica aplicada à análise de estabilidade de poços. Rio de Janeiro, 2011. Monografia (Engenharia de petróleo). Escola Poliécnica, Universidade Federal do Rio de Janeiro.

BELLOTI, P., GIACCA, D., Pressure evaluation improves drilling. The oil and gas journal, p.76-85, Set, 1978.

BOWERS, G., Pore pressure estimation from velocity data accounting for overpressure mechanisms besides undecompaction. SPE Paper 27488. 1995.

BRACE WF. Dependence of fracture strength of rocks on grain size. Proc. 4th Symposium Rock Mechanics. Univ. Park Penn. 1961.99-103. 
BRADFORD, I.D.R., FULLER, J., THOMPSON, P.J., WALSGROVE, T.R., 1998. Benefits of assessing the solids production risk in a North Sea reservoir using elastoplastic modeling, SPE/ISRM Eurock, Trondheim, Norway, pp. 261269.

BYERLEE, J. D., 1978. Friction of rock: Pure and applied geophysics, v. 116, p. 615-626.

CARMICHAEL, R.S., 1982. Handbook of Physical Properties of Rocks, Volume II. CRC Pres, Boca Raton.

CHANG, C., ZOBACK, M.D., KHAKSASR, A., 2006. Empirical relations between rock strength and physical properties in sedimentary rocks, J. Pet. Sec and Eng., 51, 223-237.

CHANG, H. K. et al., Sistemas petrolíferos e modelos de acumulação de hidrocarbonetos na Bacia de Santos. Revista Brasileira de Geociências, Curitiba. V. 38 n.2, p. 29-46, jun. 2008. Contém suplemento: Geologia e exploração de petróleo.

CHANG, H. K.; KOWSMANM, R. O.; FIGUEIREDO, A. M. F. Novos Conceitos sobre o Desenvolvimento das Bacias Marginais do Leste Brasileiro, em G. P. Raja Gabaglia \& E. J. Milani (eds.). Origem e Evolução de Bacias Sedimentares. Rio de Janeiro, Petrobras, 1990, pp. 269-89.

CHIEZA, Carolina. P., Diagnósticos de problemas operacionais durante a perfuração de poços de petróleo. Rio de Janeiro. 2011. Dissertação de mestrado. (Engenharia Mecânica). Pontifícia Universidade Católica do Rio de Janeiro.

DEERE, D. U.; MILLER, R. P. Engineering classification and index properties for intact rock (AFWL-TR-65-116). Air Force Weapons Lab., Kirtland Air Force Base, New Mexico, 1966. 
DIAS, J. L. Estratigrafia e sedimentação do evaporitos neo-aptianos na Margem Leste Brasileira. In: Mohriak, w. Szatmari, P., Anjos, S. M. C. Sal: Geologia e tectônica, exemplos nas bacias brasileiras. São Paulo: Beca, 2008, p. 220-229.

DOMINGUES, D. L. P., Caracterização geológica e geomecânica de travertinos. Rio de Janeiro. 2011. Dissertação de mestrado (Engenharia civil). Pontifícia Universidade Católica do Rio de Janeiro.

DOROBEK, S. et al., Carbonate Rock-forming Processes in the Pre-salt 'Sag' Successions of Campos Basin, Offshore Brazil: Evidence for Seasonal, Dominantly Abiotic Carbonate Precipitation, Substrate Controls, and Broader Geologic Implications, in AAPG Hedberg Conference Microbial Carbonate Reservoir Characterization. Houston, AAPG (AAPG Search and Discovery Article \#90153(C2012), 2012.

EATON, B. A., The equation for geopressure prediction from well logs. SPE paper 5544. 1975.

ESTRELlA, G. O. Pré-sal: conhecimento, estratégia e oportunidades. In: FÓRUM NACIONAL/INAE, 20. Edição Extraordinária, 3 dez. 2008, Rio de Janeiro.

FAHY. M. P. e GUCCIONE, M. J., 1979. Estimating strength of sandstone using petrographic thin-section data. Bulletin of the Association of Engineering Geologist, 16: 467-485.

FERTL, W. H. Abnormal formation pressures. Elsevie Scientific Publishing Co., New York, pp. 210, 1976.

FJAER, E. et al. Petroleum related rock mechanics. Amsterdam; Elsevier Science B. V., 1992.

FJAER, E., Holt, R. M., Horsrud, P., Raaen, A. M., Risnes, R., Petroleum Related Rock Mechanics, $2^{\text {nd }}$ Edition, Elsevier, 2008. 
FREDRICH, J. T., et al., 2003. Stress perturbations adjacent to salt bodies in the deepwater Gulf of Mexico. SPE 8454.SPE Annual Technical Conference and Exhibition, Denver, CO, Society of Petroleum Engineers.

FREITAS, J. T. R. Ciclos deposicionais evaporíticos da Bacia de Santos: uma análise cicloestratigráfica a partir de dados de 2 poços e de traços de sísmica. Dissertação de mestrado. Universidade Federal do Rio Grande do Sul, Porto Alegre. 2006. 169 p.

GAMBOA, L. A. P., ET AL., Evaporitos estratificados no Atlântico Sul: interpretação sísmica e controle tectono- estratigráfico na Bacia de Santos. In: MORIAK, W.; Szarmari, P.; ANJOS, S. M. C. Sal: geologia e tectônica: exemplos nas bacias brasileiras. São Paulo: Beca Ed., 2008. P. 340-359.

GARDNER, G. H. F., Gardner, L.W., Gregory, A.R., Formation velocity and density: the diagnostic basis for stratigraphic traps. Geophysics, vol 39. n.6, 770 -780, December, 1974.

GOLUBEV, A. A., RABINOVICH, G. Y., Resultaty primencia appartury akusticeskogo karotasa dlja predeleina proconstych svoistv gornych porod na mestorosdeniaach tverdych isjopaemych, Prikl. Geofiz. Moskva 73, 109-116. 1976. (Citado por Zoback, 2010).

GONÇALVES, J. C. Análise Geomecânica na Estabilidade de Poços Horizontais. Lisboa, 2015. Dissertação de mestrado (Engenharia de Petróleo), Técnico Lisboa (IST).

HAIMSON, B. C.; FAIRHURST C. Initiation and extension of hydraulic fractures in rock, Soc. Petroleum Engineer. J.7, 310-318. 1967.

HAIMSON, B.C., The hydrofracturing stress measurement technique method and recent field results. Int. Journal of rock mech. and min. sci., 15(4). Pp. 167178. 1978. 
HOWARTH, D.F., ROWLANDS, J.C., 1986. Development of an index to quantify rock texture for qualitative assessment of intact rock properties, Geotech. Testing J. 9: 4, 169-179.

HUBBERT, M. K., WILLIS, D. G. Mechanics of hydraulic fracturing. Trans. Soc. Petroleum Eng. AIME. Vol 210. 1957.

HUGMAN, R.H.H, FRIEDMAN, M. Effects of Textural and Composition on Mechanical Behavior of Experimentally deformed Carbonate Rocks. Am. Soc. Pet. Geol. Bull. 1979: 63. 9. 1478-1489.

JAEGER, J. C.; COOK, N. G. W., 1979. Fundamentals of rock mechanics. London, Chapman and Hall, 593p.

JIZBA, D., 1991. Mechanical and acoustical properties of sandstones and shales, $\mathrm{PhD}$ thesis, Standford University.

KWASNIEWSKI, M., 1989. Laws of brittle failure and of B-D transition in sandstones, In: Maury, V., Fourmaintraux, D. (Eds.), Rock at Great Depth. A.A. Balkema, Brookfield, VT, pp. 45-58.

LAMA, R.D., VUTUKURI, V.S., 1978. Handbook on Mechanical Properties of Rocks, vol.II. Trans Tech Publications, Clausthal, Germany.

LIMA, G. A. C.; VIDAL, A. C., SUSLICK, S.B., Análise de impactos da metodologia de estimativa da porosidade em reservas de petróleo por meio de simulação de Monte Carlo. Ver. Esc. Minas vol. 59 no.2. Ouro Preto. Abr/Jun 2006.

MAGOON, L. B.; BEAUMONT, E. A. Petroleum Systems, in E. A. Beaumont \& N. H. Forster (eds.). Exploring for Oil and Gas Traps, Treatise of Petroleum Geology, Handbook of Petroleum Geology. Tulsa, American Association of Petroleum Geologists, 1999, pp. 3.1-3.34. 
MELLO, U. T.; KARNER, G. D.; ANDERSON, R. A. Role of salt in restraining the maturation of subsalt source rock. Marine and Petroleum Geology, v. 12, n. 7, p. 697-716, 1995.

MILITZER, H., STOLL, R., Einige Beirageder geophysics zur primadatenerfassung im Bergbau, Neue Berbautechnik. Lipzig 3, 21-25.1973. (Citado por Zoback, 2010).

MOHRIAK, W., 2008. Tectônica de sal das bacias do Espírito Santo e de Mucuri. In: Mohriak, W., Szatmari, P \& Anjos, S. M. C., Sal: Geologia e Tectônica. Editora Beca, São Paulo, 284-299.

MOREIRA, J. L. P. et al. Bacia de Santos. Boletim de Geociências da Petrobras, Rio de Janeiro, v. 15, n. 2, p. 531-549, maio/nov. 2007.

MORILLOS, M. Os impactos do pré-sal na economia brasileira. Florianópolis, 2013. Monografia. (Ciências Econômicas), Universidade Federal de Santa Catarina,

NASCIMENTO, R. C. A. M., et al, O fenômeno de prisão diferencial: uma revisão da literatura. Revista Eletrônica de materiais e processos. V.5.2. ISSN 1809-8797. 76-87. 2010.

NUR, A., BYERLEE, J.D., An exact effective stress law for elastic deformation of rock with fluids. Stanford University, California. Journal of Geophysical Research, Volume 76, Issue 26, pp. 6414-6419.1971.

OTTESEN, S., ZHENG, R. H. et al., 1999. Wellbore Stability Assessment using quantitative risk analysis, SPE/IADC 52864. SPE/IADC Drilling Conference, Amsterdam, The Netherlands, Society of Petroleum Engineers. 
PAPATERRA, G. E. Z. Pré-sal: Conceituação Geológica sobre uma Nova Fronteira Exploratória no Brasil. Rio de Janeiro, 2010.Dissertação de mestrado. Instituto de Geociências, Universidade Federal do Rio de Janeiro.

PEREIRA, B. C. M. Proposta de uma metodologia para estimativa de geopressões. Rio de Janeiro, 2007. Dissertação de mestrado (Engenharia civil). Universidade Federal do Rio de Janeiro.

PEREIRA, M. J. \& FEIJÓ, F. J. Bacia de Santos, Boletim de Geociências da Petrobras, Rio de Janeiro, v. 8, n. 1, p. 219-234, 1994.

PETROBRAS. $<\underline{\text { http: }: / \text { www.petrobras.com.br/pt/nossas-atividades/areas-de- }}$ atuacao/exploracao-e-producao-de-petroleo-e-gas/pre-sal/> acesso em: $20 \mathrm{de}$ outubro de 2016.

PONTE, F. C., ASMUS, H. E., Geological framework of the Brazilian Continental Margin. International Journal of Earth Sciences, Berlin, v.67, n. 1, p. 201-235, Fev. 1978.

RICCOMINI, Cláudio, SANT'ANNA, Lucy Gomes, TASSINARI, Colombo Celso Gaeta. Pré-sal: Geologia e Exploração. Revista USP, n.95. p. 33-42. Set/Out/Nov 2012.

ROCHA, L.A.S., AZEVEDO, C. T., Projetos de poços de petróleo-Geopressões e Assentamento de Colunas de Revestimentos. $1^{\text {a }}$ Edição, Editora Interciência, Rio de Janeiro. 2007. 511p.

SANTOS, E.S.R., FERREIRA, F.H. Mechanical Behavior of Brazilian Off-shore Carbonate Reservoir. $44^{\text {th }}$ U.S. Rock Mechanics Symposium and $5^{\text {th }}$ U.S. Canada Rock Mechanics Symposium, Salt Lake City, UT, USA. ARMA 10-199. 2010.

SILVA, D. R. et al., Depositional Ages of Paleozoic and Mesozoic Pre-rift Supersequences of the Recôncavo Basin in Northeastern Brazil: a Rb-Sr 
Radiometric Study, in Journal of South American Earth Sciences, 37, 2012, pp. $13-24$.

SILVEIRA, B. T., Estimativa de pressão de poros em 3 Dimensões. Rio de Janeiro. 2009. Dissertação de mestrado (Engenharia civil). Pontifícia Universidade Católica do Rio de Janeiro.

SIMON, K., Gaurina-Medimuree, N., Pasic, B., Drilling fluids differential sticking tendency, Rudarsko-geolosko-naftni zbonik, UDC 622.244.42, Vol.17, pas 31-35, Zagreb 2005.

TEIKOKU-Vp, 2007. Technical Reference and User's Manual. GMI WellCheck ${ }^{\mathrm{TM}}$ Version 3.2.

TERZAGHI, K. Theoretical Soil Mechanics. Editora John Wiley, Universidade de Michigan. p. 510. 1943.

TOKLE, K., HORSRUD, P., BRATLI, R.K., 1986. Predicting uniaxial compressive strength from log parameters, SPE ATCE, New Orleans, Lousiana, USA.

VASQUEZ, G. F. et al., Experimental determination of the effective pressure coefficients for Brazilian limestones and sandstones. Revista brasileira de geofísica. N.27:43-53. 2009.

WELLING \& Co. (2009); Global Industry Survey http://www.welling.com/

WINTER, R. W., et al., Bacia de Campos. Boletim de geociências da Petrobras, Rio de Jnaeiro, v. 15, n. 2, p. 501-509, maio/nov. 2007.

WONG, T.F., DAVID, C., ZHU, W., 1997. The transition from brittle faulting to cataclastic flow in porous sandstones: mechanical deformation, J. Geophys. Res. 102, 3009-3025. 
ZAINE, M. F., ROVERI, M.G., A importância do pré-sal na economia brasileira e suas oportunidades - $10^{\circ}$ Amostra Acadêmica UNIMEP - Simpósio de Ensino de Graduação, São Paulo, 2012.

ZOBACK M.D.; POLLARD, D. D., 1978. Hydraulic fracture propagation and the interpretation of pressure-time records for in-situ determination. $19^{\text {th }} \mathrm{U} . \mathrm{S}$ Symposium on rock mechanics, Mac Kay School of mines, University of Nevada Reno, Nevada.

ZOBACK, M. D. E HEALY, J. H., 1984. Friction, faulting and "in-situ" stresses. Annales Geophysics, 2, 689-698.

ZOBACK, M. D. E TOWNEND, J. 2001 Implications of hydrostatic pore pressure and high crustal strength for the deformation of intraplate lithosphere. Tectonophysics, 336, 19.30.

ZOBACK, M. Reservoir Geomechanics. Cambridge University Press, 464 pages. 2007, 2010. 
8

Anexos

8.1

Anexo 1: Dados gerais recebidos de cada poço

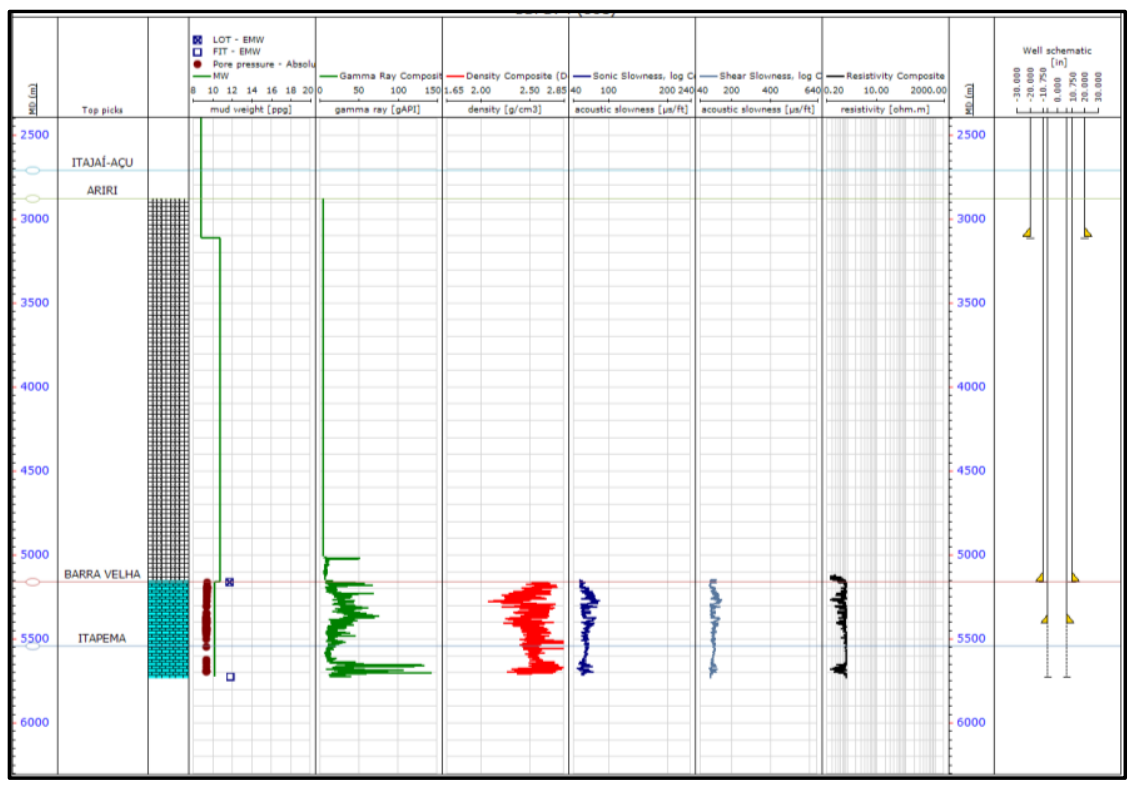

Figura 8.1 - Dados gerais do poço 2

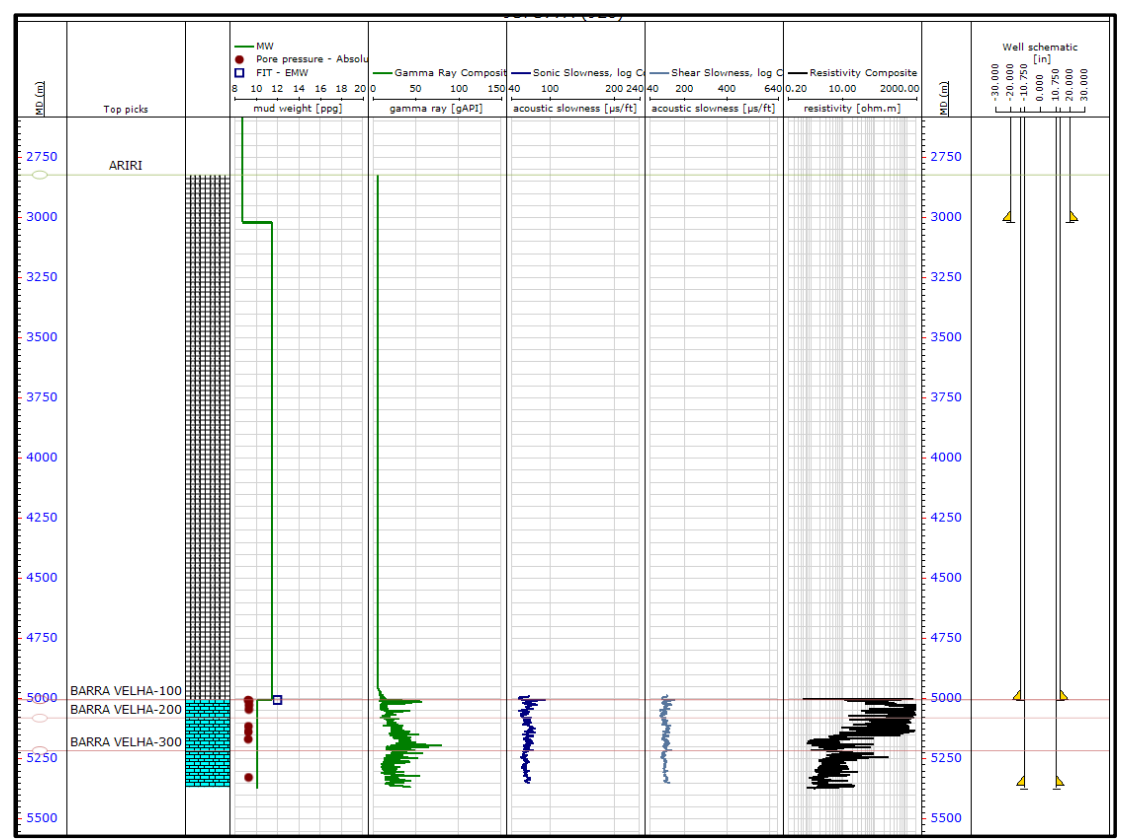

Figura 8.2 - Dados gerais do poço 3 


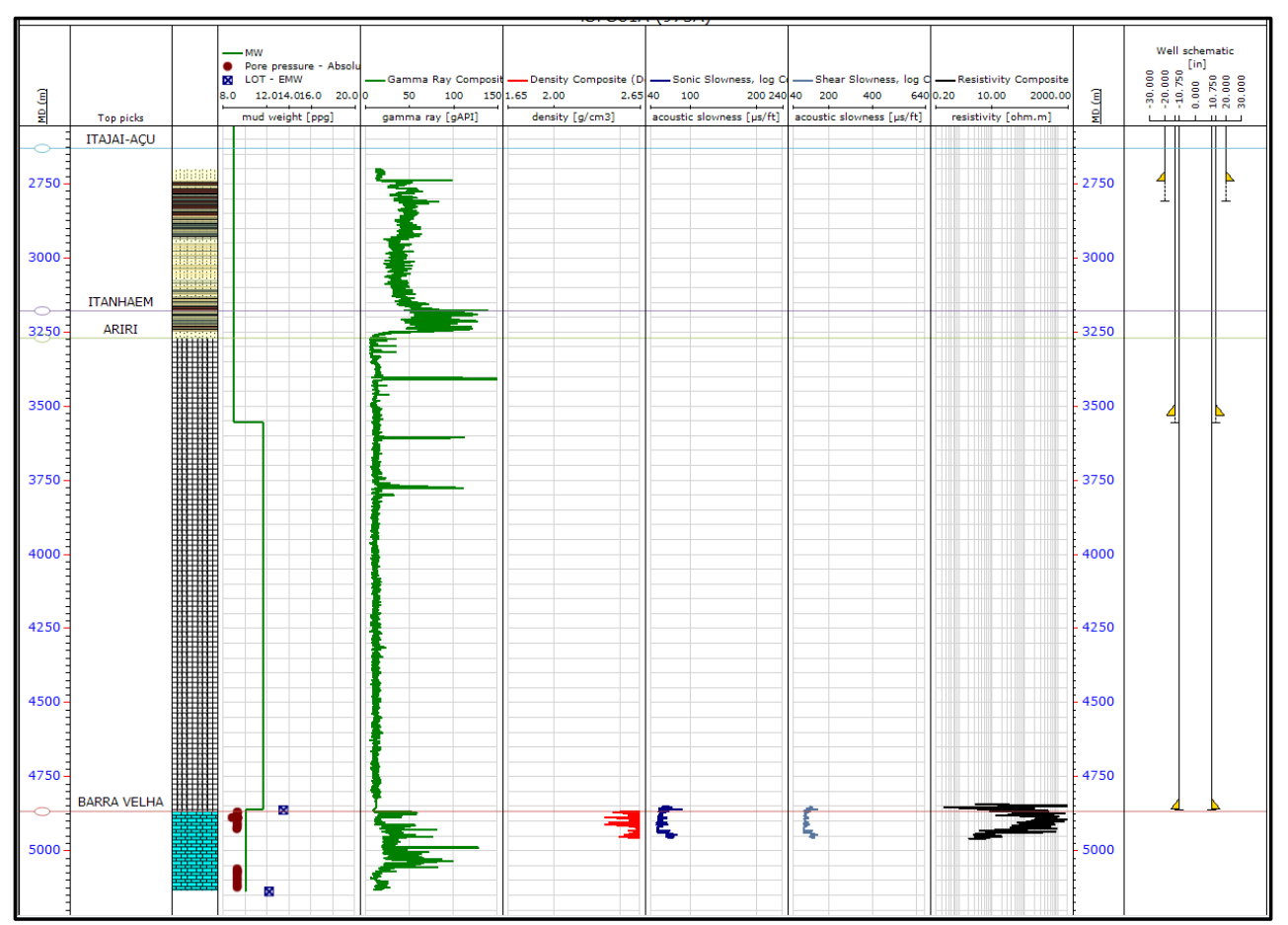

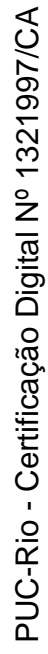

Figura 8.3 - Dados gerais do poço 4

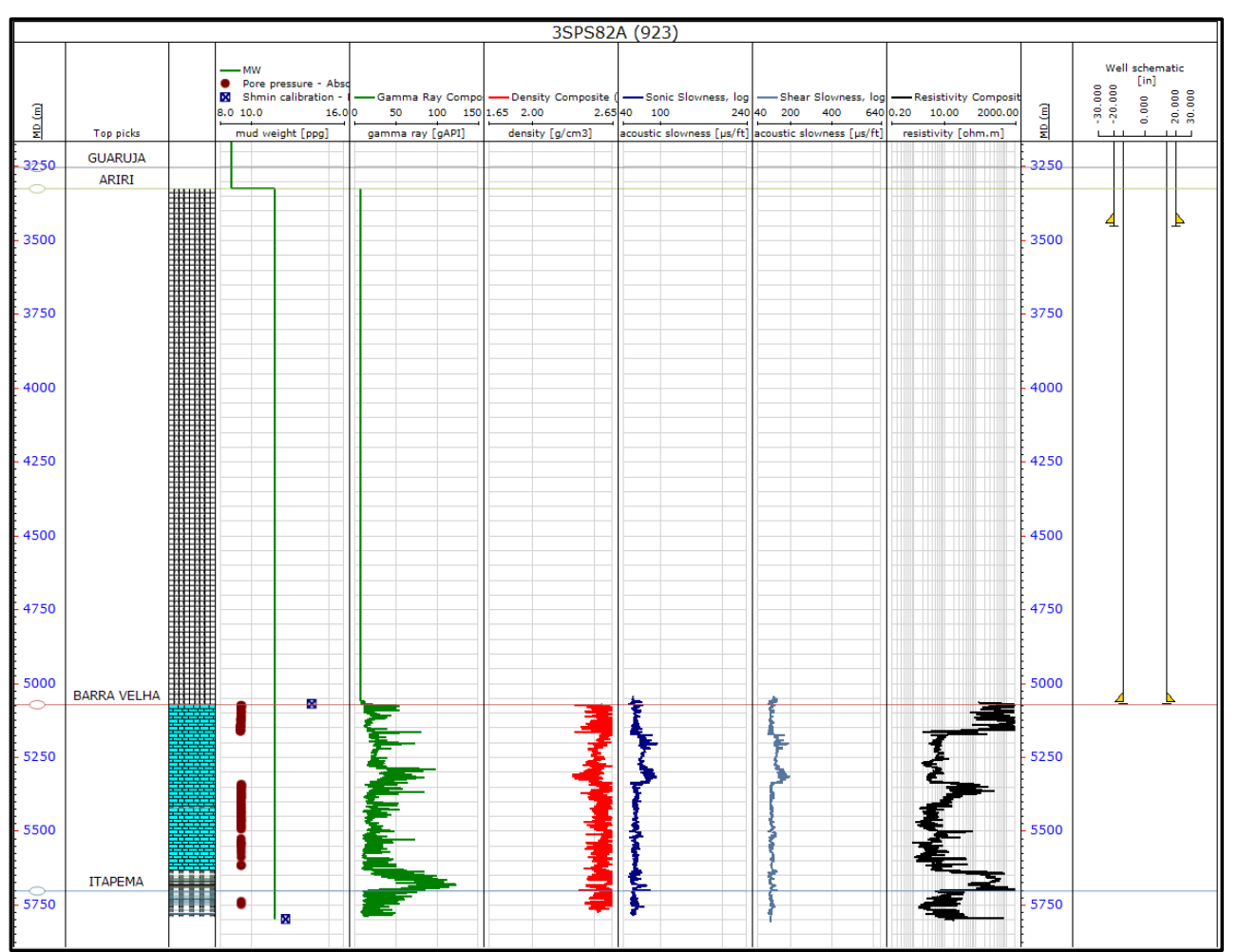

Figura 8.4 - Dados gerais do poço 5 


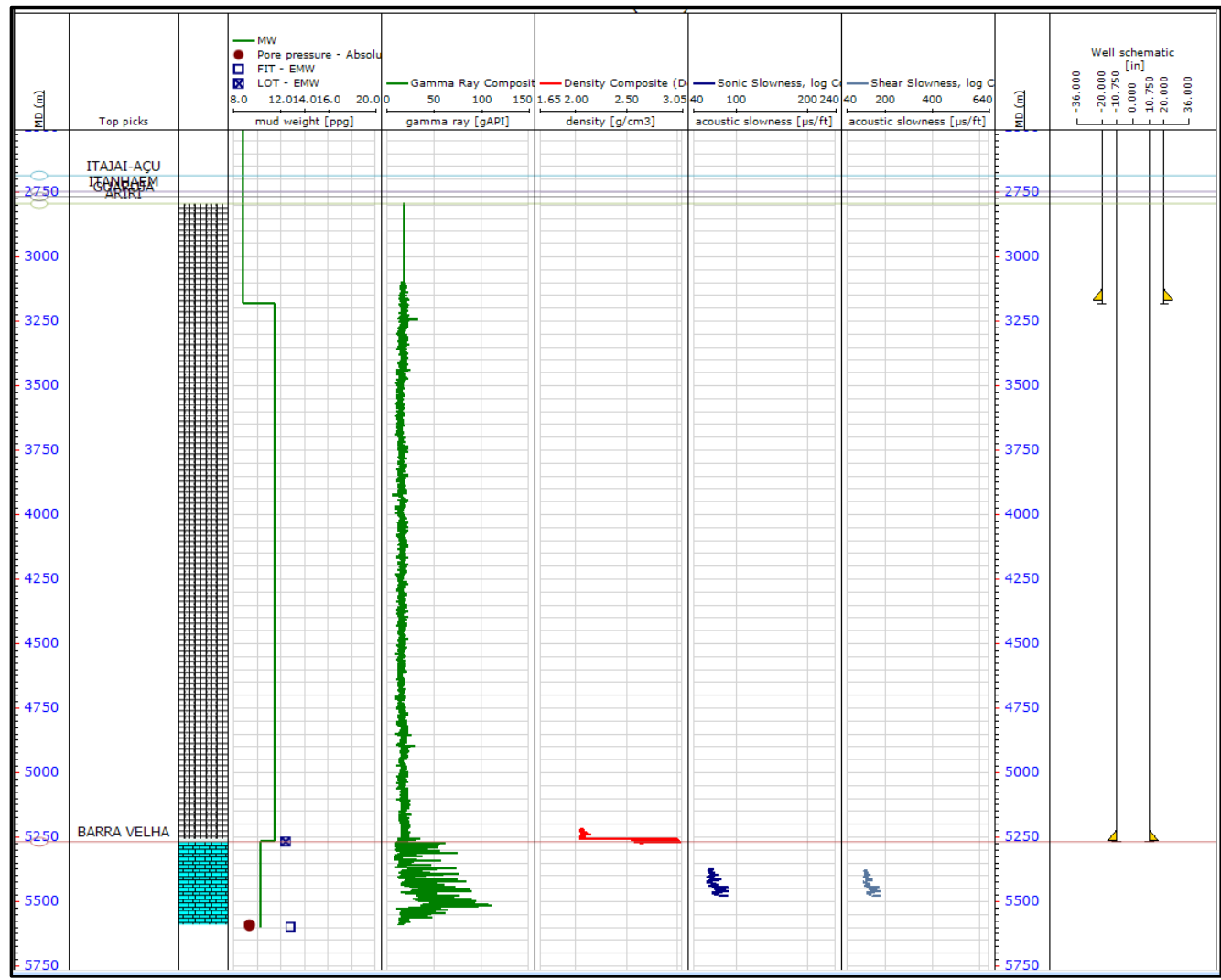

Figura 8.5 - Dados gerais do poço 6

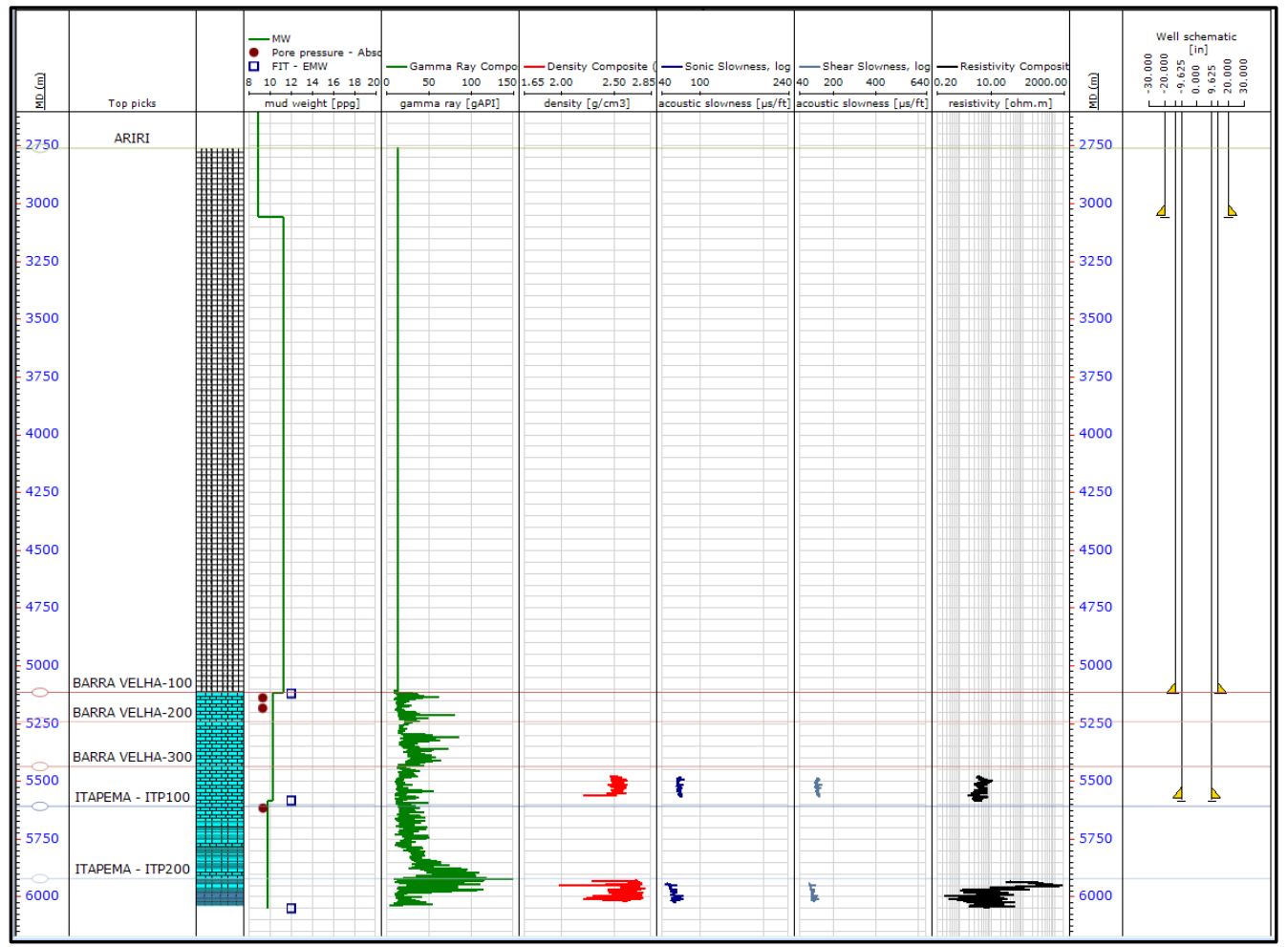

Figura 8.6 - Dados gerais do poço 8 
8.2

Anexo 2: Relação de UCS x velocidade, UCS x Porosidade e UCS x E

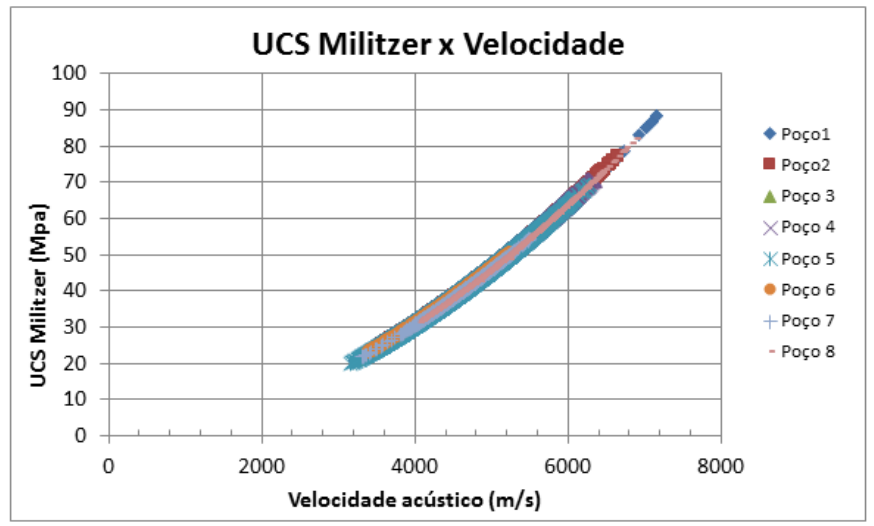

\begin{tabular}{|c|c|c|}
\hline & UCS Militzer x Velocidade & $\mathrm{R}^{2}$ \\
\hline Poço 1 & $y=-2 E-11 \times 3+2 E-06 \times 2+0,0018 x-1,2935$ & 1.000 \\
\hline Poço 2 & $y=-2 E-11 \times 3+2 E-06 \times 2+0,0015 x-0,9189$ & 1.000 \\
\hline Poço 3 & $y=-2 E-11 \times 3+2 E-06 \times 2+0,0016 x-1,0896$ & 1.000 \\
\hline Poço 4 & $y=-1 E-11 \times 3+2 E-06 \times 2+0,002 x-1,7321$ & 1.000 \\
\hline Poço 5 & $y=-2 E-11 \times 3+2 E-06 \times 2+0,0017 x-1,2606$ & 1.000 \\
\hline Poço 6 & $y=-2 E-11 \times 3+2 E-06 \times 2+0,0016 x-1,0171$ & 1.000 \\
\hline Poço 7 & $y=-2 E-11 \times 3+2 E-06 \times 2+0,0016 x-1,0263$ & 1.000 \\
\hline Poço 8 & $y=-2 E-11 \times 3+2 E-06 \times 2+0,0014 x-0,6631$ & 1.000 \\
\hline
\end{tabular}

Figura 8.7 - Relação de UCS Militzer x Velocidade acústica

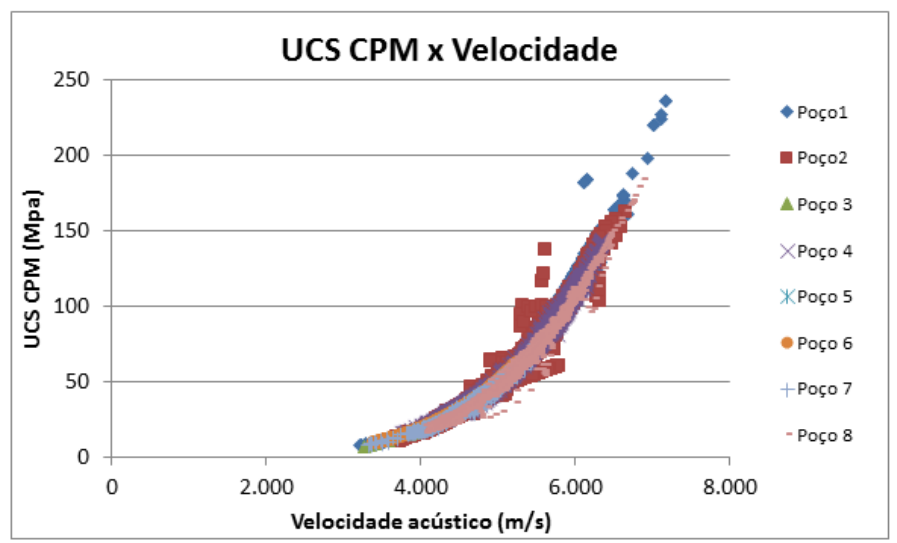

\begin{tabular}{|c|c|c|}
\hline & UCS CPM $\times$ Velocidade & $R^{2}$ \\
\hline \hline Poço 1 & $y=1 E-09 \times 3-1 E-06 \times 2-0,0325 x+88,621$ & 0.9938 \\
\hline Poço 2 & $y=2 E-09 \times 3-9 E-06 \times 2+0,0145 x+3,1615$ & 0.9785 \\
\hline Poço 3 & $y=2 E-09 \times 3-2 E-05 \times 2+0,0463 x-51,249$ & 1.000 \\
\hline PoçO 4 & $y=4 E-09 \times 3-4 E-05 \times 2+0,1642 x-226,59$ & 0.9935 \\
\hline Poço 5 & $y=4 E-09 \times 3-4 E-05 \times 2+0,1411 x-186,35$ & 0.9933 \\
\hline PoçO 6 & $y=2 E-09 \times 3-2 E-05 \times 2+0,0562 x-64,607$ & 0.9999 \\
\hline Poço 7 & $y=1 E-09 \times 3-3 E-06 \times 2-0,0092 x+33,214$ & 0.9807 \\
\hline Poço 8 & $y=2 E-09 \times 3-8 E-06 \times 2+0,0077 x+17,089$ & 0.9893 \\
\hline
\end{tabular}

Figura 8.8 - Relação de UCS CPM x Velocidade acústica
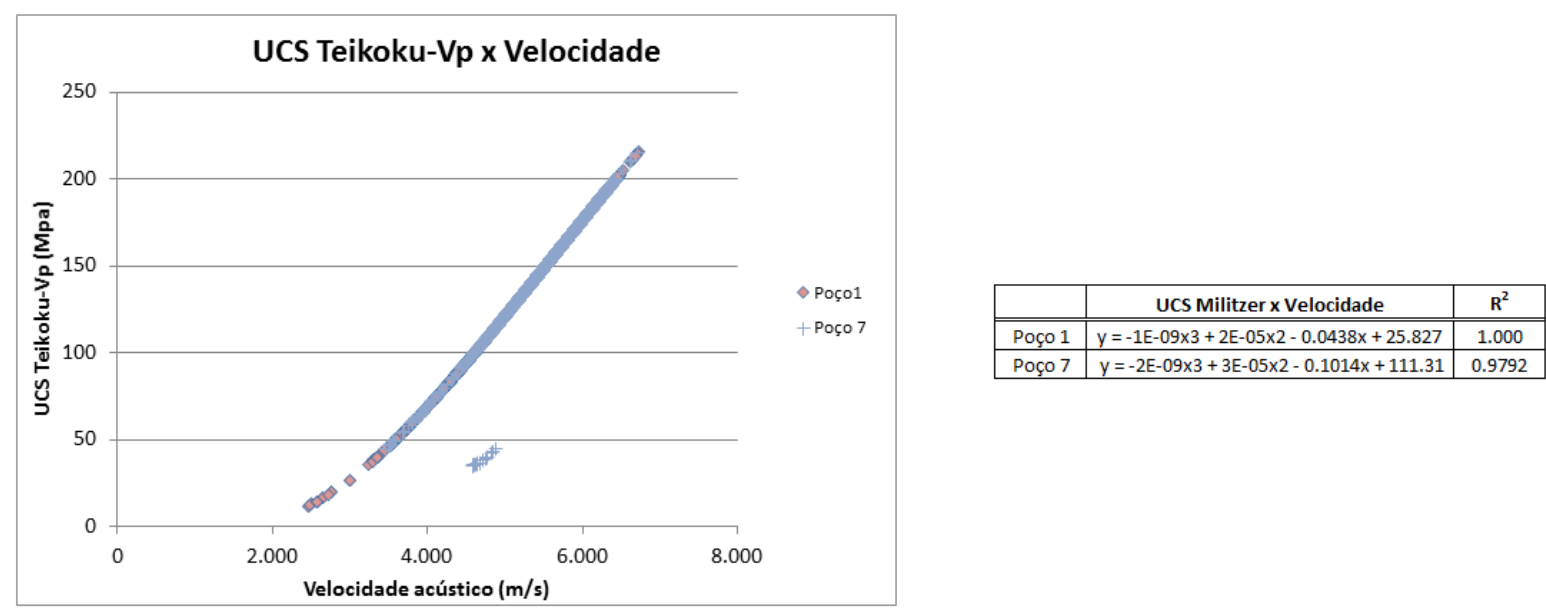

Figura 8.9 - Relação de UCS Teikoku-VP (Rocha ígnea) x Velocidade acústica 


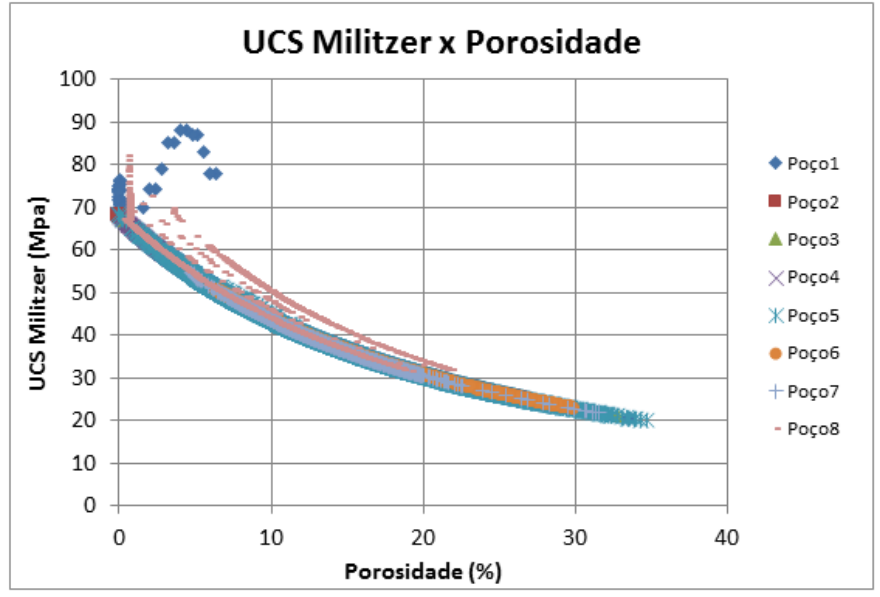

Figura 8.10 - Relação de UCS Militzer x Porosidade

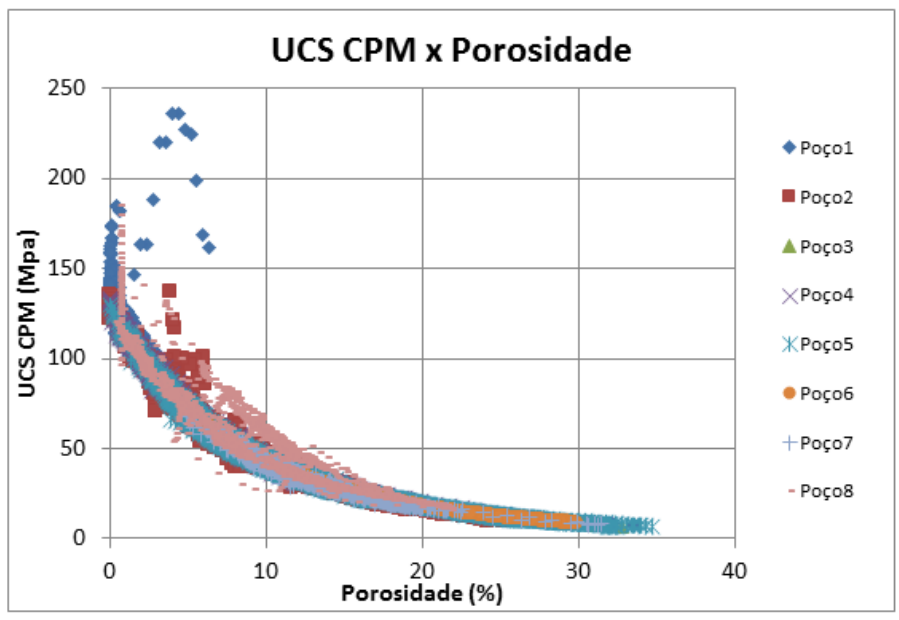

Figura 8.11- Relação de UCS CPM x Porosidade

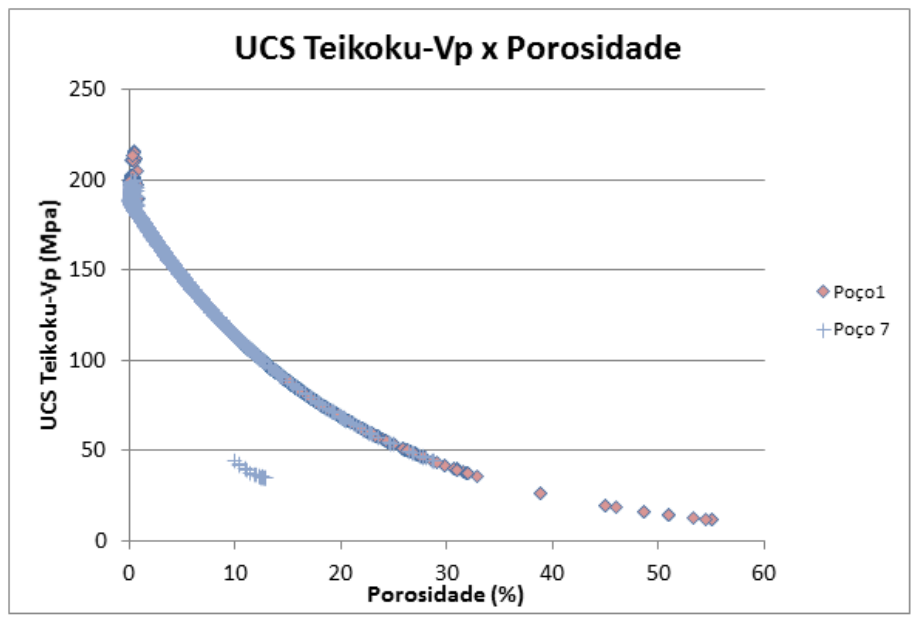

Figura 8.12 - Relação de UCS Teikoku-VP x Porosidade

\begin{tabular}{|c|l|c|}
\hline & \multicolumn{1}{|c|}{ UCS Militzer $x$ Porosidade } & $\mathbf{R}^{2}$ \\
\hline \hline Poço 1 & $y=-0,0011 \times 3+0,0887 \times 2-3,2432 x+68,42$ & 0.988 \\
\hline Poço 2 & $y=-0,0012 \times 3+0,0922 \times 2-3,2169 x+67,825$ & 0.9999 \\
\hline Poço 3 & $y=-0,001 \times 3+0,083 \times 2-3,1127 x+67,477$ & 0.9999 \\
\hline Poço 4 & $y=-0,0024 \times 3+0,1198 \times 2-3,409 x+68,2$ & 0.9999 \\
\hline Poço 5 & $y=-0,0009 \times 3+0,0795 \times 2-3,0738 x+67,381$ & 0.9997 \\
\hline Poço 6 & $y=-0,0007 \times 3+0,0707 \times 2-2,912 x+66,495$ & 1.000 \\
\hline Poço 7 & $y=-0,0008 \times 3+0,0749 \times 2-2,9882 x+66,909$ & 0.9999 \\
\hline Poço 8 & $y=0,0037 \times 3-0,0724 \times 2-1,7581 x+67,073$ & 0.9236 \\
\hline
\end{tabular}

\begin{tabular}{|c|c|c|}
\hline & UCS CPM $\times$ Porosidade & $\mathbf{R}^{\mathbf{2}}$ \\
\hline \hline Poço 1 & $y=-0,0104 \times 3+0,6609 \times 2-14,992 x+138,43$ & 0.9709 \\
\hline Poço 2 & $y=-0,0103 \times 3+0,6143 \times 2-13,667 x+126,71$ & 0.9873 \\
\hline Poço 3 & $y=-0,0066 \times 3+0,4579 \times 2-11,575 x+119,99$ & 0.9988 \\
\hline Poço 4 & $y=-0,0156 \times 3+0,7789 \times 2-14,724 x+127,96$ & 0.9927 \\
\hline Poço 5 & $y=-0,0074 \times 3+0,4974 \times 2-12,039 x+119,73$ & 0.9904 \\
\hline Poço 6 & $y=-0,0045 \times 3+0,3478 \times 2-9,8766 x+112,14$ & 0.9996 \\
\hline Poço 7 & $y=-0,0047 \times 3+0,3629 \times 2-10,067 x+111,43$ & 0.9807 \\
\hline Poço 8 & $y=-0,0022 \times 3+0,3037 \times 2-10,499 x+124,38$ & 0.9081 \\
\hline
\end{tabular}

\begin{tabular}{|c|c|c|}
\hline & UCS CPM $\times$ Porosidade & $\mathbf{R}^{2}$ \\
\hline \hline Poço 1 & $y=-0,0018 \times 3+0,2171 \times 2-9,7693 x+191,66$ & 0.9943 \\
\hline Poço 7 & $y=-0,0017 \times 3+0,2078 \times 2-9,6096 x+189,16$ & 0.9755 \\
\hline
\end{tabular}




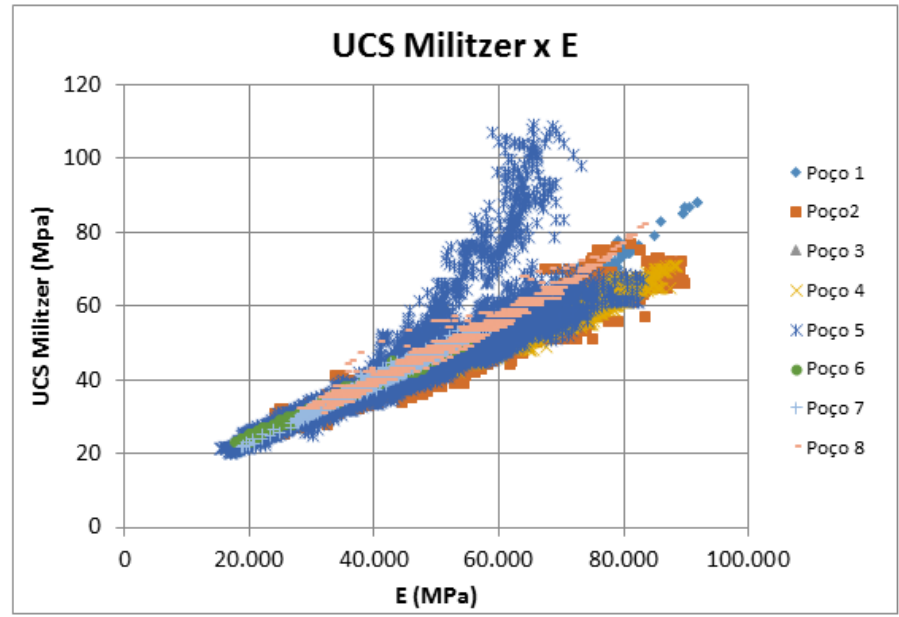

Figura 8.13 - Relação de UCS Militzer x E

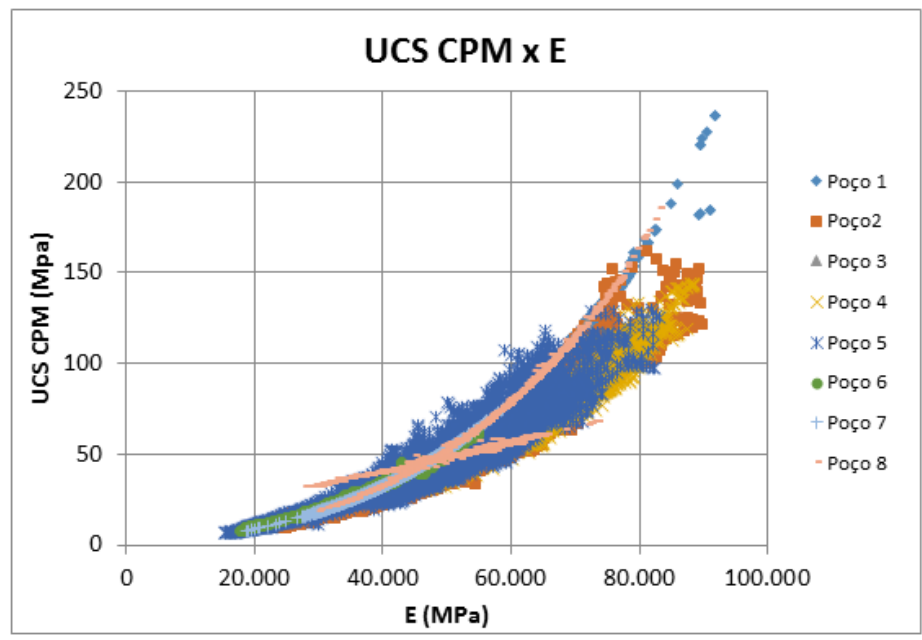

Figura 8.14 - Relação de UCS CPM x E

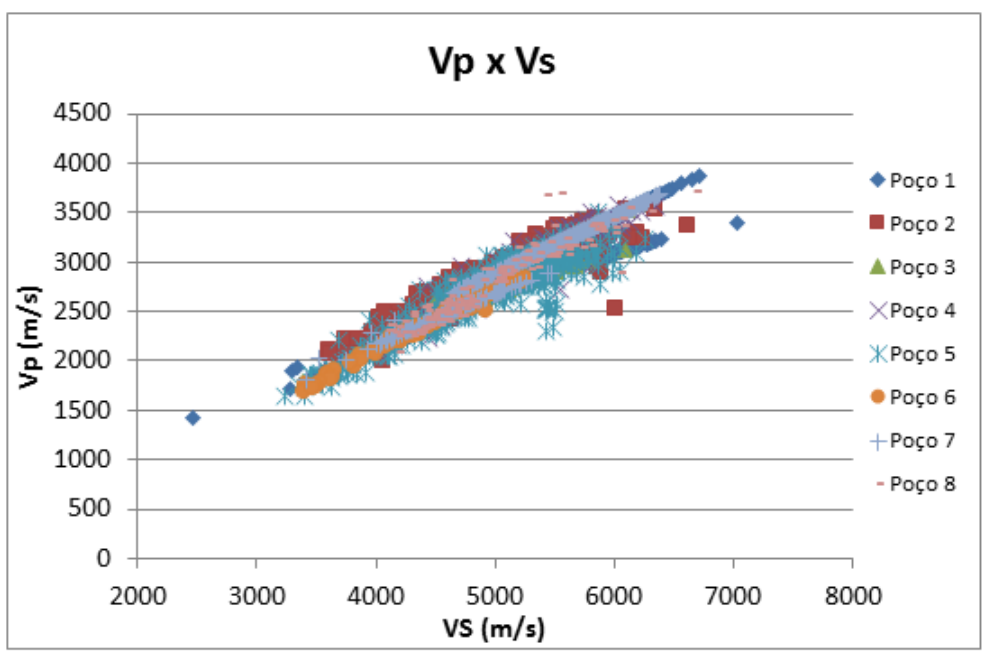

Figura 8.15 - Relação de Vp x Vs

\begin{tabular}{|c|c|c|}
\hline & Equação Vp x Vs & $R^{2}$ \\
\hline \hline Poço1 & $y=0.5162 x+142.17$ & 0.919 \\
\hline Poço 2 & $y=0.5523 x+67.701$ & 0.8788 \\
\hline Poço 3 & $y=0.5375 x+7.2395$ & 0.9475 \\
\hline Poço 4 & $y=0.6402 x-393.3$ & 0.9106 \\
\hline Poço 5 & $y=0.5638 x-71.737$ & 0.8384 \\
\hline Poço 6 & $y=0.6124 x-367.24$ & 0.9885 \\
\hline Poço 7 & $y=0.66 x-480.6$ & 0.9782 \\
\hline Poço 8 & $y=0.6329 x-374.66$ & 0.8906 \\
\hline
\end{tabular}

\begin{tabular}{|c|l|c|}
\hline & \multicolumn{1}{|c|}{ UCS Militzer $\times \mathrm{E}$} & $\mathbf{R}^{\mathbf{2}}$ \\
\hline \hline Poço 1 & $\mathrm{y}=5 \mathrm{E}-14 \times 3-7 \mathrm{E}-09 \times 2+0,0012 \mathrm{x}+0,4602$ & 0.9957 \\
\hline Poço 2 & $\mathrm{y}=9 \mathrm{E}-14 \times 3-2 \mathrm{E}-08 \times 2+0,0015 \mathrm{x}-2,949$ & 0.9473 \\
\hline Poço 3 & $\mathrm{y}=3 \mathrm{E}-14 \times 3-3 \mathrm{E}-09 \times 2+0,0009 \mathrm{x}+6,2911$ & 1.000 \\
\hline Poço 4 & $\mathrm{y}=1 \mathrm{E}-13 \times 3-2 \mathrm{E}-08 \times 2+0,0015 \mathrm{x}-2,3387$ & 0.9679 \\
\hline Poço 5 & $\mathrm{y}=-6 \mathrm{E}-14 \times 3+8 \mathrm{E}-09 \times 2+0,0004 \mathrm{x}+12,933$ & 0.7558 \\
\hline Poço 6 & $\mathrm{y}=-5 \mathrm{E}-14 \times 3+4 \mathrm{E}-09 \times 2+0,0007 \mathrm{x}+9,6371$ & 0.9923 \\
\hline Poço 7 & $\mathrm{y}=1 \mathrm{E}-13 \times 3-1 \mathrm{E}-08 \times 2+0,0014 \mathrm{x}-0,3285$ & 0.9816 \\
\hline Poço 8 & $\mathrm{y}=-3 \mathrm{E}-15 \times 3+3 \mathrm{E}-09 \times 2+0,0006 \mathrm{x}+11,441$ & 0.9853 \\
\hline
\end{tabular}

\begin{tabular}{|c|l|c|}
\hline & UCS CPM x E & $\mathbf{R}^{2}$ \\
\hline \hline Poço 1 & $y=2 E-13 \times 3+2 E-09 \times 2+0,0005 x-3,9879$ & 0.9993 \\
\hline Poço 2 & $y=3 E-13 \times 3-3 E-08 \times 2+0,0021 x-32,016$ & 0.9475 \\
\hline Poço 3 & $y=2 E-13 \times 3-7 E-10 \times 2+0,0006 x-4,6949$ & 1.000 \\
\hline Poço 4 & $y=4 E-13 \times 3-5 E-08 \times 2+0,0029 x-35,331$ & 0.9578 \\
\hline Poço 5 & $y=3 E-14 \times 3+1 E-08 \times 2+0,0002 x+0,0445$ & 0.8989 \\
\hline Poço 6 & $y=5 E-15 \times 3+2 E-08 \times 2+0,0001 x+0,1353$ & 0.9937 \\
\hline Poço 7 & $y=2 E-13 \times 3+6 E-09 \times 2+0,0003 x-1,6073$ & 0.9999 \\
\hline Poço 8 & $y=3 E-13 \times 3+7 E-09 \times 2-0,0009 x+39,211$ & 0.9441 \\
\hline
\end{tabular}

\begin{tabular}{|l|l|l|}
\hline Poço 8 & $y=0.6329 x-374.66$ & 0.8906 \\
\hline
\end{tabular} 